


\title{
LISTENING TO \\ THE SILENT PATIENT
}

UGANDA'S JOURNEY TOWARDS INSTITUTIONALIZING

INCLUSIVE PLANT HEALTH SERVICES

CABI WORKING PAPER 7

June 2015

\author{
Editors \\ Remco Mur \\ Frances Williams \\ Solveig Danielsen \\ Geneviève Audet-Bélanger \\ Joseph Mulema
}

please visit www.plantwise.org for more information 


\author{
CABI \\ Canary Bird \\ 673 Limuru Road, Muthaiga \\ PO Box 633-00621 \\ Nairobi, Kenya \\ $\mathrm{T}:+254(0) 202271000 / 20$ \\ E: africa@cabi.org \\ www.cabi.org \\ KIT Sustainable Economic Development \\ PO Box 95001, 1090 HA Amsterdam, the Netherlands \\ www.kit.nl/sed
}

Film production and editing: Julia Dennis (CABI) and Lauren Brown (CABI)

Design and layout: Sarah Hilliar (CABI) and John Gittins

Technical Editing: Rebecca J Murphy

Publishing and distribution: $\mathrm{CABI}$

(c) $2015 \mathrm{CAB}$

This study and the preparation of the working paper was financially supported by the Plantwise Programme. However, it does not necessarily represent the views of those organizations and is the sole work of its authors.

The copyright holder of this work is $\mathrm{CAB}$ International (trading as $\mathrm{CABI}$ ). It is made available under a Creative Commons Attribution-Non-commercial Licence (CC BY-NC). For further details please refer to http://creativecommons.org/license/.

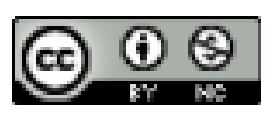

This working paper was internally peer-reviewed. It may be cited as:

Mur, R., Williams, F., Danielsen, S., Audet-Bélanger, G. and Mulema, J. (eds) (2015) Listening to the Silent Patient. Uganda's Journey towards Institutionalizing Inclusive Plant Health Services. CABI Working Paper 7, 224 pp.

ORCID numbers: Remco Mur 0000-0003-0518-3152; Frances Williams 0000-0002-6772-0753; Solveig Danielsen 0000-

0002-0464-8395; Geneviève Audet-Bélanger 0000-0003-3111-2622; Joseph Mulema 0000-0002-8738-1306.

http://dx.doi.org/10.1079/CABIPLANT-37-55 


\section{Contents}

Contents

Acronyms

Summary

Foreword

Acknowledgements

Part I The evolution of plant clinics in Uganda 13

1. An introduction to the working paper $\quad \mathbf{1 5}$

Plantwise: an attempt to strengthen plant health systems worldwide $\quad 19$

Agriculture in Uganda $\quad 22$

Agricultural advisory services in Uganda: a major challenge 24

Methodological process 26

Structure of the working paper $\quad 30$

2. Looking at plant clinics: making sense of practice 35

About institutions and plant health systems 36

Gender $\quad 42$

3. Plant clinics in Uganda $\quad \mathbf{4 9}$

History at a glance $\quad 50$

Where are we now? $\quad 56$

$\begin{array}{ll}\text { Plant clinic operations } & 57\end{array}$

$\begin{array}{ll}\text { Plant doctors } & 59\end{array}$

Plant clinic users $\quad 62$

The Plantwise Online Management System 68

$\begin{array}{ll}\text { Plant doctor conferences } & 69\end{array}$

It's an emergency! Plant health rallies and other approaches for rapid delivery of plant health messages $\quad 70$

4. Plant clinic adaptations $\quad \mathbf{7 5}$

$\begin{array}{ll}\text { An overview of some of the plant clinic adaptations } & 77\end{array}$

How local adaptation improves service delivery 84

5. Gender responsiveness in plant clinic delivery $\quad \mathbf{8 7}$

Attending the plant clinic. Or not? 88

Encouraging women's involvement 96

Is the advice suitable? $\quad 99$

What happens to the advice? 103

Gender-responsive delivery from implementing organizations 106

Reflections and implications for plant clinic service provision 107

$\begin{array}{ll}\text { 6. Institutionalization } & 109\end{array}$

Policy support 111

$\begin{array}{ll}\text { Financing } & 113\end{array}$

$\begin{array}{ll}\text { Building a plant clinic workforce } & 116\end{array}$

$\begin{array}{lr}\text { Stakeholder engagement and networking } & 119\end{array}$

Local ownership and accountability 120

Basic procedures $\quad 122$

$\begin{array}{ll}\text { Project identity } & 128\end{array}$

$\begin{array}{ll}\text { What is required to create a coherent plant health system? } & 129\end{array}$ 
7. Conclusions 135

$\begin{array}{ll}\text { Local adaptation } & 137\end{array}$

$\begin{array}{ll}\text { The need for a systems approach } & 138\end{array}$

$\begin{array}{ll}\text { A new focus: building adaptive capacity } & 140\end{array}$

$\begin{array}{ll}\text { Gender } & 142\end{array}$

Institutionalizing plant clinics: creating an enabling environment 143

$\begin{array}{ll}\text { Final remarks } & 145\end{array}$

Part II Case studies $\quad 149$

A. Nakifuma clinic $\quad 151$

Nakifuma plant clinic at a glance 152

Farming in Nakifuma $\quad 153$

Back to the beginning: 2005

Clinic operations $\quad 156$

B. Bwera plant clinic $\quad 163$

$\begin{array}{ll}\text { Bwera plant clinic at a glance } & 164\end{array}$

$\begin{array}{ll}\text { Farming in Bwera } & 165\end{array}$

How it started and was sustained $\quad 166$

$\begin{array}{ll}\text { How it works } & 168\end{array}$

$\begin{array}{ll}\text { C. Kayunga mobile clinic } & \mathbf{1 7 7}\end{array}$

$\begin{array}{ll}\text { Kayunga district mobile plant clinic at a glance } & 178\end{array}$

$\begin{array}{ll}\text { Farming systems } & 179\end{array}$

How were services provided prior to plant clinics? 181

How did it start? 181

Plant clinic operations 183

A plant clinic day: from mobilization to the end 185

$\begin{array}{ll}\text { Adaptations: what is special? } & 188\end{array}$

$\begin{array}{ll}\text { Sustaining the plant clinics } & 189\end{array}$

D. Kabarwa plant clinic $\quad 191$

Kabarwa plant clinic at a glance 192

Farming system 193

$\begin{array}{ll}\text { The urge to provide quality services } & 194\end{array}$

This is how it works 196

E. Mairirwe plant clinic $\quad 201$

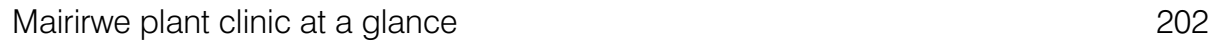

Farming in Bugambe sub-county 203

From local initiative to routine operations $\quad 204$

How does it work? 206

Annex 1. List of movies $\quad 213$

$\begin{array}{ll}\text { Annex 2. Contributors } & 217\end{array}$

$\begin{array}{ll}\text { Contributors } & 217\end{array}$

Editing team $\quad 220$

Annex 3. The organizations 222 


\section{Acronyms}

\begin{tabular}{|c|c|}
\hline AASP & Agricultural advisory service provider \\
\hline AFAAS & African Forum for Agricultural Advisory Services \\
\hline ATAAS & Agricultural Technology and Agribusiness Advisory Services \\
\hline BIC & Bwera Information Centre \\
\hline CAADP & Comprehensive Africa Agriculture Development Programme \\
\hline CBF & Community-based facilitator \\
\hline CBO & Community-based organization \\
\hline CIF & Community information facilitator \\
\hline CPF & Community process facilitator \\
\hline CSO & Civil society organization \\
\hline DSIP & Development Strategy and Investment Plan \\
\hline FAO & Food and Agriculture Organization of the United Nations \\
\hline FOWODE & Forum for Women in Democracy, Uganda \\
\hline GDP & Gross domestic product \\
\hline HORTEXA & Horticultural Exporters Association of Uganda \\
\hline ICT & Information and Communications Technology \\
\hline KIT & Royal Tropical Institute, the Netherlands \\
\hline MAAIF & Ministry of Agriculture, Animal Industry and Fisheries \\
\hline M\&E & Monitoring and Evaluation \\
\hline MUZARDI & Mukono Zonal Agricultural Research and Development Institute \\
\hline NAADS & National Agricultural Advisory Services \\
\hline NARO & National Agricultural Research Organisation \\
\hline NGO & Non-governmental organization \\
\hline OECD & Organisation for Economic Co-Operation and Development \\
\hline POMS & Plantwise Online Management System \\
\hline PKPi & Pest Knowledge Partnership initiative \\
\hline QR code & Quick response code \\
\hline RIC-NET & Rwenzori Information Centres Network \\
\hline RWECO & Rwenzori Consortium for Civil Competence \\
\hline SATNET & Sustainable Agricultural Trainers Network \\
\hline SG2000 & Sasakawa Global 2000 \\
\hline SMS & Short message service \\
\hline SNV & Netherlands Development Organisation \\
\hline SOCADIDO & Soroti Catholic Diocese Integrated Development Organisation \\
\hline ToT & Training of trainers \\
\hline UBOS & Uganda Bureau of Statistics \\
\hline UNADA & Uganda National Agro-Input Dealers Association \\
\hline UNFFE & Uganda National Farmers Federation \\
\hline URL & Uniform resource locator \\
\hline USD & United States dollar ( 1 USD = 2500 Uganda shillings, UGX) \\
\hline
\end{tabular}




\section{Summary}

Every year, farmers in sub-Saharan Africa suffer from unacceptable levels of crop loss as a result of plant health problems, threatening their food security, income and livelihoods. This working paper shares lessons from Plantwise, an initiative to improve smallholder farmers' access to plant health services in Uganda so that they can improve their yields, increase their incomes and improve their food security and livelihoods. The working paper presents lessons from almost ten years of experiences in implementing plant clinics in Uganda. It includes case studies that describe, and put into perspective, the experiences of five plant clinics.

Plantwise (which started in 2011) is aiming to make high quality, relevant information available to farmers, extension systems and governments, contributing to strengthening plant health systems by working with local extension services, non-governmental organizations and other key actors in plant health to provide smallholder farmers with access to advisory services from plant clinics. The idea behind plant clinics comes from human health clinics: people visit health clinics for preventive and curative care. Likewise, farmers could go to plant clinics with their crop samples. In this working paper we zoom in on three important practice areas related to plant clinics.

- Plant clinic operations and local plant clinic adaptations that emerged to improve performance, reach, quality, effectiveness and impact.

- Inclusion in plant clinic services, addressing the needs of diverse farmers in Uganda and, more specifically, gender issues.

- Embedding and institutionalization of plant clinics in policies, procedures and practices of the organizations and institutions of which they are part.

Plantwise has achieved a lot in Uganda in three years. The plant clinic expansion has happened very quickly. The number of plant doctors trained is impressive. A total of 145 plant clinics are now established in four regions of Uganda. There are plant clinics in 71 of the 112 districts in these regions, operating at different levels as they become established. The plant clinics are either run by the district local government or nongovernmental organizations, or run by both in order to share the responsibilities of coordinating and making resources and staff available as plant doctors. 
The case studies show that, in Uganda, there is no such thing as 'the plant clinic'. Many unplanned plant clinic adaptations have emerged; changes made to the plant clinic model to make it fit the local context, to remain or become more relevant, performing, inclusive and sustainable. Some of the local adaptations are district-wide or particular to the local implementing organization, and concern multiple plant clinics, others are plant clinic-specific. Currently, adaptations mainly contribute to increased reach and proximity, but they could potentially contribute to inclusion, quality, relevance and exposure. Interestingly, the adaptations described in the case studies were not part of the Plantwise interventions at all, even though its ultimate purpose is "to develop sustainable and adaptive plant health systems, securing accessible, relevant, inclusive and demand-driven quality plant health services in Uganda”. Local adaptation requires adaptive capacity in the plant health system and its actors. A more explicit focus on building this capacity on sub-national and local levels is deemed necessary in the near future.

Although Plantwise does have its Gender Strategy, gender is not explicitly addressed by the plant clinic interventions in any of the regions. Many of the plant clinic adaptations are believed to bring services closer to farmers, but they do not explicitly focus on the suitability and relevance of the advice for different groups of farmers. Gender-disaggregated data are collected on clinic attendance to start to address gender issues. In most districts, more men than women visit the clinics. The plant health service needs of women and other marginalized groups and the constraints they face in accessing plant health services are related to their specific roles and responsibilities, (intra-household) power relations and culture, among others. It is time to address explicitly these issues with rigour and broad experimentation. There is a need for experimentation with inclusive approaches to integrate gender in design, decision making, service provision, monitoring and evaluation, and accountability mechanisms. An explicit focus on strengthening the adaptive capacity of the plant health system at sub-national level can facilitate more attention to gender issues and the inclusion of women in the plant health system. Sound representation of women and other marginalized groups in multi-stakeholder mechanisms to adapt, learn and address system challenges is key.

This working paper also looks at the institutionalization of plant clinics, i.e. how they became part of the prevailing norms and values related to plant health services, consequent policies, and procedures and practices of the organizations involved at different levels, from community to sub-national and national. The inclusion of plant clinics in government policy was a key condition for the expansion of plant 
clinics in Uganda. The Ministry of Agriculture, Animal Industry and Fisheries' (MAAIF) Department of Crop Protection has allocated staff and some funds for backstopping and clinic materials and to manage plant clinic data. Some districts have started to include plant clinics in their annual budgets and work plans. Makerere University is pro-actively seeking to take over full responsibility of plant doctor training. Yet, there is still a long way to go before plant clinics are fully embedded in the Ugandan service landscape. The uncertainty about the future of agriculture extension in Uganda makes it hard for the districts to consolidate the clinics. In addition, Plantwise's top-down planning and intervention mode limits the meaningful engagement of sub-national and local stakeholders. The Plantwise branding and pre-established procedures signal that plant clinics are part of a CABI project, limiting ownership and buy-in at the different levels. Also, the dependency on Plantwise funds for key activities is a risk to ownership and sustainability. Hence, there is a need for focus on consolidating and strengthening the capacity and ownership at district and farmer community levels. Whether the districts take up the plant clinics and embed them in the existing work dynamics with their own budget line depends on the attitudes of the individual district leaders.

An important pillar of the Plantwise intervention is the data management system. However, the established system is not working as effectively as it could. There are several bottlenecks in the data management chains which make the data inaccessible for decision making and monitoring, at both district and central level. Simple and effective procedures are needed, and attention should be paid to the quality of the service, effective communication and feedback mechanisms.

The establishment of procedures for coordination, reporting, data management and monitoring has so far focused on the central level. It has turned out to be a challenging task because of the speed of plant clinic expansion, the lack of clear initial procedures, insufficient funding and capacity, and weak communication and coordination mechanisms between MAAIF and the decentralized districts. Uganda's parallel extension systems with different extension approaches and uneven budgeting for the National Agricultural Advisory Services (NAADS) versus district local government add to the difficulties. The emphasis must be redirected, with more effort put into helping strengthen the districts' capacity to deliver the best possible service under the given conditions, and building adaptive capacity at district level. This requires support from central level. There is a need to clearly define roles and responsibilities at central and district levels. This is particularly important in a Ugandan setting where the districts have a high degree of autonomy in policy implementation and decision 
making and where MAAIF is constrained by its limited resources. The central level should facilitate, not impose or control, and constantly look for creative ways to make best use of its scare human and financial resources.

A number of challenges must be addressed in order to make plant clinics and the related changes in the plant health system more effective, responsive and sustainable. Systems change requires capacity at different levels. Plantwise has contributed greatly to enhancing personal capacity by training plant doctors. However, to take its objective of strengthening plant health systems in Uganda seriously, it is also necessary that organizational and institutional strengthening are at the spearhead of its interventions. Systems change rooted in local realities requires reflexivity from the stakeholders involved, and a consciousness of their own practices, position and influence on the context they operate in and also an understanding of how the context influences them. Taking a step back, and reflecting, contextualizing, learning from experiences and adapting, is critical for development practitioners, managers and decision and policy makers. However, time and resources are often too scarce to allow such reflective processes to happen. But eventually the reflective process will pay off: if lacunas, challenges and threats are identified quickly and addressed by the stakeholders of the plant health system, and if assumptions are regularly tested, change in the plant health system can be achieved and become sustainable. 


\section{Foreword}

This working paper is based on a timely study carried out in 2014, the International Year of Family Farming, an effort by the United Nations to highlight the potential family farmers have to eradicate hunger, preserve natural resources and promote sustainable development.

Every year, farmers in sub-Saharan Africa suffer from unacceptable levels of crop loss as a result of plant health problems, threatening their food security, income and livelihoods. Crop diseases continue to emerge and at the same time there is a persistent threat of known problems. Pests and diseases can flare up unpredictably, yet there often is no mechanism for responding quickly. And indeed, plants cannot speak for themselves. They are silent patients. Farmers routinely have to make vital decisions in response to unpredictable conditions and unknown risks. One way to help farmers achieve this is by providing them with the information and knowledge that they need through a well-functioning extension system. In many countries the extension system is weak, understaffed and underfunded. The systems often do not deliver the advice needed by farmers.

CABI's Plantwise programme is one approach to strengthening the delivery of plant health advice to farmers, working with government- and NGO-run extension systems to bring advice to the farmers in response to the problems that they are facing at any particular moment. The Plantwise programme has now been running for over three years. It is time to learn from experiences, to identify successes and remaining challenges and to address those challenges.

This working paper is the end result of a series of workshops and studies that have been taking place in Uganda over the past year to examine the Plantwise approach in that country. As will be seen in the introductory chapter, Uganda is an interesting place in which to carry out such work as it has a decade-long history of CABI involvement and has led, with a number of Latin American countries, the piloting of many activities. This long history has led to a wealth of experience, thoughts and ideas about what is working and what is not. These opinions, voiced not only by those running the programme, but also by plant doctors, local government staff, local partners and farmers, form the basis of this working paper. Their experiences and ideas have led the authors to the conclusions they have reached, based not on theoretical findings, but on the realities on the ground. 
The authors have identified many positive adaptations occurring in Uganda that can be supported and encouraged to strengthen the delivery of plant health advice to farmers. There are also a number of areas where more work is needed if the plant health system is to be truly strengthened. Many of these lessons are applicable not just to Uganda, or indeed to the African continent, but can be applied to any country in which Plantwise is operating. In that sense, this working paper, while focusing on Uganda, is of interest to those working to support and strengthen extension services worldwide. We hope that the lessons learnt and described in this working paper will help to improve the way that the Plantwise approach, and extension services in general so as to truly respond to the farmers' needs.

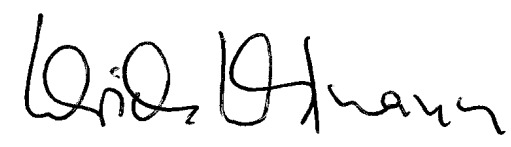

\section{Dr Ulrich Kuhlmann}

Programme Executive, Plantwise CABI 


\section{Acknowledgements}

CABI and KIT Sustainable Economic Development have developed this working paper based on the lessons learnt by Plantwise partners and implementers in Uganda. This working paper is an accumulation of their experiences, thoughts and reflections, brought together through a writeshop held in Uganda in June 2014. The authors would like to thank all the participants of the writeshop, including those mentioned as authors as well as those who contributed insightful anecdotes and stories. In particular we thank:

- Participants in the Monitoring and Evaluation Stakeholder Workshop held in August 2013 in Kampala

- Participants in the Study Design Workshop held in September 2013 in Kampala

- Those who participated in data collection across Uganda

- Mirjam Schoonhoven, who guided the data collection

- Wouter Klein, who analysed the data

- Julia Dennis for her movie recording

- Lauren Brown for her movie editing

- Sarah Hilliar for the design and John Gittings for the layout

- Dannie Romney for her review of the text

This working paper was made possible through funding from Plantwise, allowing us to critically review the state of progress of Plantwise in Uganda. 


\section{PART I}

The evolution

of plant olfinios

in Uganda 

1

\section{An introduction to} the working paper

By Remco Mur, Frances Williams, Geneviève Audet-Bélanger and Solveig Danielsen

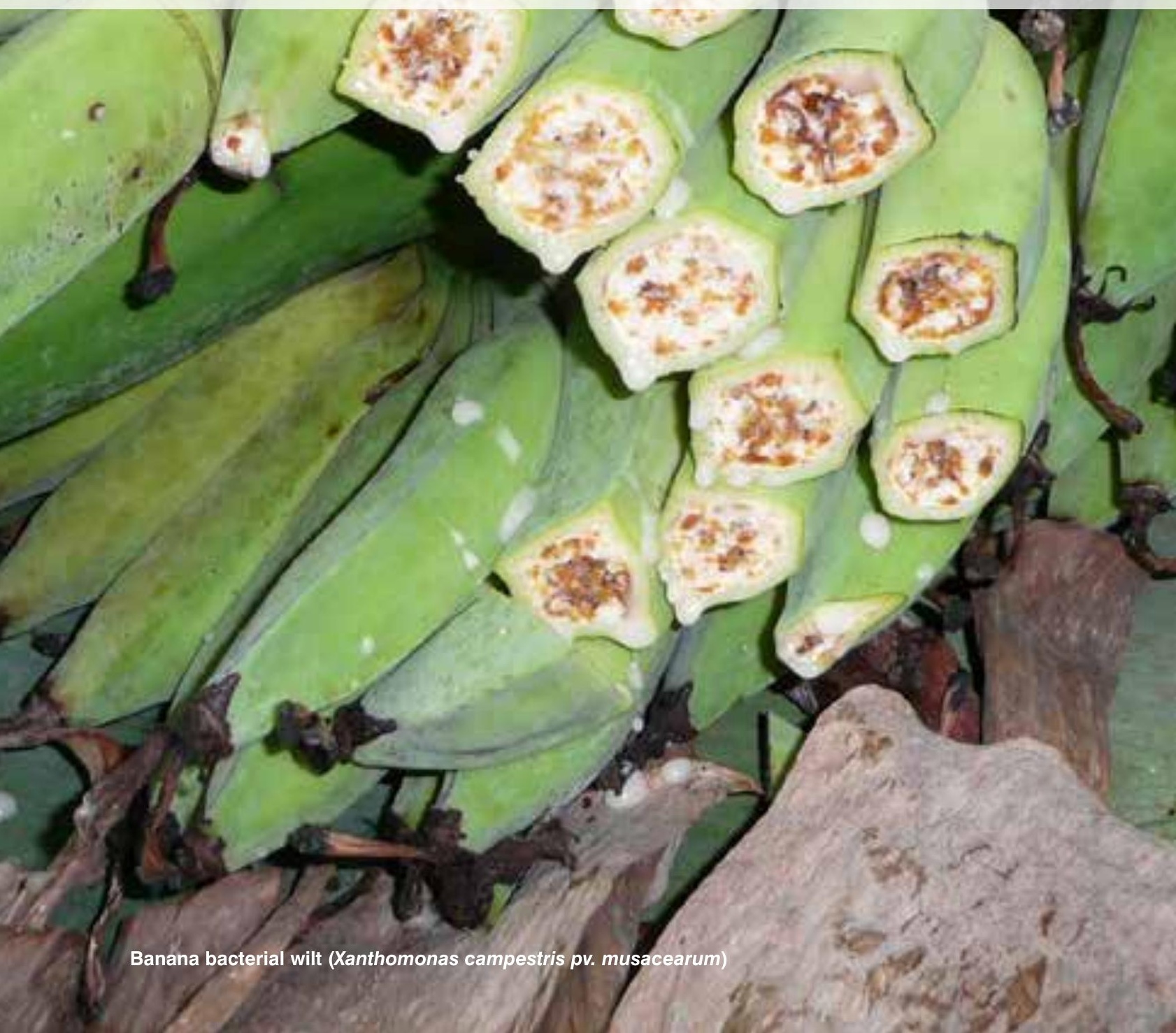



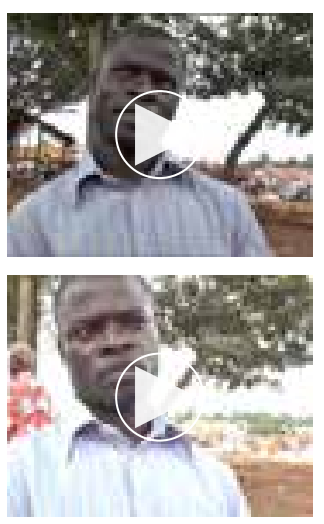

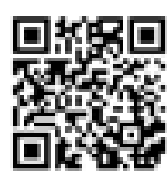

Video

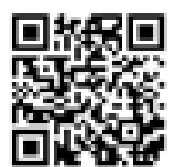

Video 2
"My name is Mayambala Frederick. I'm 30 years old. I'm a farmer, for about ten years. I grow coffee, banana and also maize. I have come to the clinic to get expert advice for problems with my bananas and coffee. It's not my first time, I always come. There are two ways I hear about the clinic, I go to sell my produce at market and find the tent, but also I over hear among the farmers in the village that the market has experts in plant diseases."

"I am interested in value addition. In the next five years I want to expand my farm and add value, for example not selling maize directly, but drying it and storing and milling and then selling it as maize flour, not grain. So I want to add value by processing. Learning is a continuous experience, so every time new problems arise, I have to come to the plant clinic and be advised. Farming is one of the enterprises that gives money that is tax free, and I want young farmers to know what an enterprise this is."

Mayambala Frederick - farmer, Nakifuma sub-county

The above quote from Mayambala Frederick, a farmer in Nakifuma sub-county in Mukono district in Uganda, illustrates the need for farmers to access information through plant health advisory services, allowing them to learn and improve their practices, making farming a viable business.

This working paper is about the silent patient: pest affected crops do not speak for themselves, unlike human beings. First and foremost, the health of a crop depends on farmers, men and women, who grow the crop for their food security and income and who, on a daily basis, monitor their fields to assure a healthy crop. The identification, diagnosis and treatment of affected crops require special knowledge and skills. Often, smallholder farmers do have the capacity to do this themselves. But in some cases they depend on external expertise. In this working paper we share lessons from Plantwise, an initiative in Uganda to improve smallholder farmers' access to plant health services through plant clinics so that they can improve their yields, increase their incomes, improve their food security and livelihoods, and become more resilient.

The aim of this working paper is to learn from experiences in implementing plant clinics in Uganda. It describes the experiences of five plant clinics and puts these experiences into perspective. Almost ten years' experience has led to a number of 
important lessons that can help to improve the performance of plant clinics in the widest sense. This working paper contributes to the understanding of how interventions can influence rural advisory services. It is first and foremost written for practitioners, managers and decision makers involved in rural advisory services in Uganda. More broadly, it informs the Plantwise strategy and approaches. Our clear intention is that experiences and learning from Uganda will be shared in other sub-Saharan African countries and beyond.

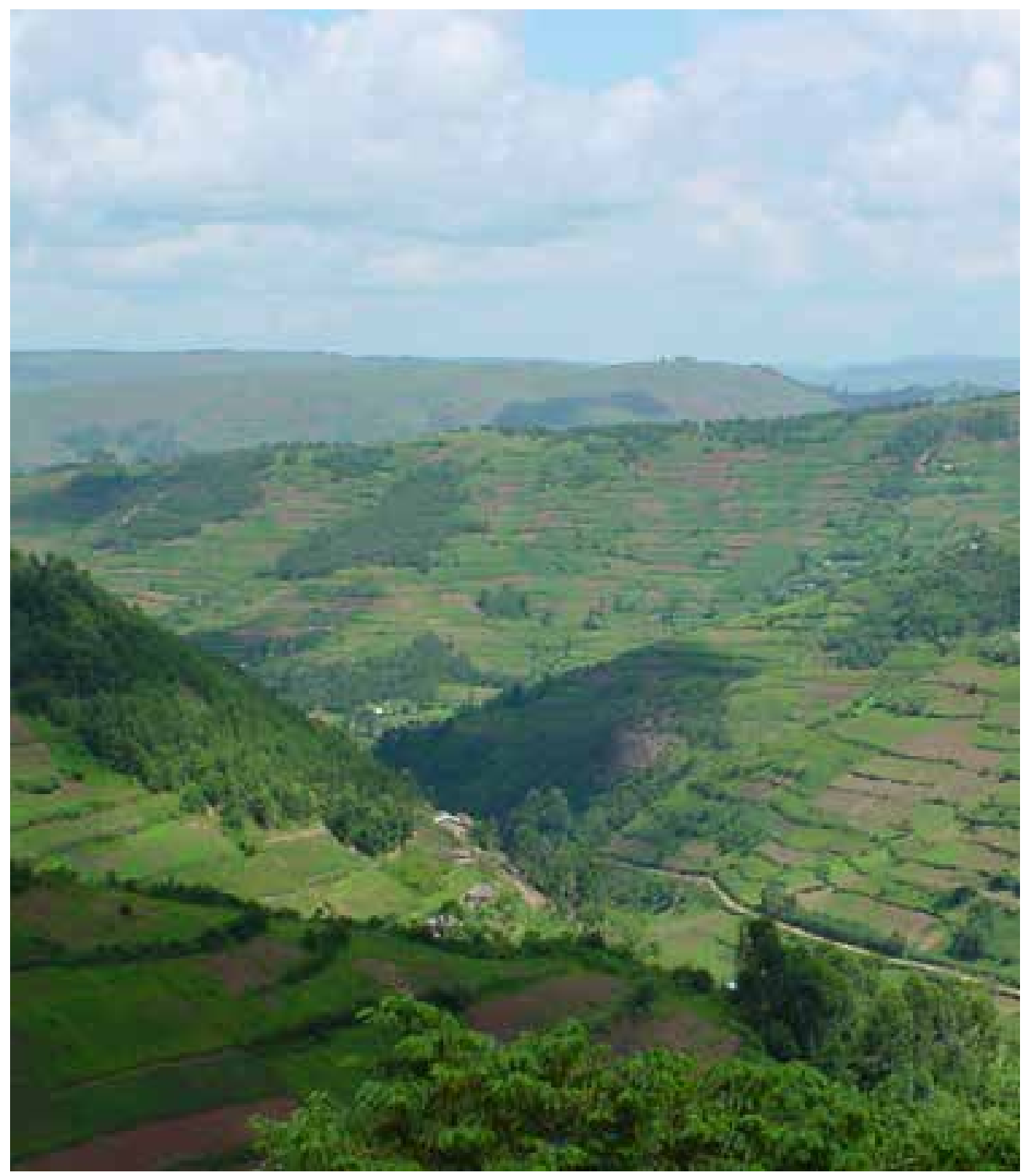

Smallholder potato fields in Kabale District in Western Uganda 
Nearly one billion people around the world go hungry every day. Over half are smallholder farmers and their families, who rely on their crops for food and income. These farmers lose an estimated $30-40 \%$ of their produce to plant health problems (Oerke, 2006) and even higher losses regularly occur in key crops. At the same time, production costs increase as farmers spend more time weeding and are forced to use additional pesticides which may also damage the environment. The staple food crops that provide Africa's food security face constant threats from pests including corn borer, wheat rust (Ug99), banana xanthomonas wilt and cassava virus diseases. Underlying crop management problems that influence the prevalence of pests and diseases, such as soil health management, are often not recognized as key problems.

In order to address the acute and chronic problems that they face, farmers need knowledge to make informed decisions so that they can make the best use of limited resources. In today's world, we may believe that information is more widely available than ever before, yet access to advice is limited and the majority of farmers have never seen an extension worker. There is a poor and irregular flow of information about the threats that farmers face. New diseases continue to emerge, though it is perhaps the persistent threat of already known problems that poses the biggest threat to farmers. Pests and diseases can flare up unpredictably, yet there is no mechanism for responding quickly or providing the technical support necessary to confirm causes and suggest effective, accessible and pragmatic solutions. Farmers routinely have to make vital decisions in response to unpredictable conditions and unknown risks - and without the right information at the right time, this is truly a stab in the dark. The poorer the farmer, the greater the impact of making the wrong decision or failing to get advice on time.

Most developing countries provide extension services to farmers but these services generally have limited capacity with few extension providers serving many farmers over large areas. Extension services frequently work apart from other organizations delivering plant health services. Little information flows along the poor lines of communication between research and extension and research results often do not make it beyond the laboratory and into the farmers' hands. There are also poor links between extension and diagnostic laboratories that identify pests, and to input suppliers, making farmers' access to appropriate, safe and effective management solutions difficult. Different approaches are needed that make the most of limited resources, particularly human capacity, by bringing these elements together.

Providing improved advisory services that are 'relevant, regular and reliable' requires innovative solutions that recognize the entrenched weaknesses in agricultural support 
systems: using traditional methods of communication there are not enough extension workers to reach all farmers, and plant health expertise is limited and difficult to access. There are also positives to build on, though regrettably they are often ignored: extension workers have a good knowledge of farmers and local conditions, researchers want to work more closely with extension, while agro-input suppliers want to respond to customers' needs and to be trusted. Plantwise (ongoing since 2011) is building on these attributes, aiming to make high quality, relevant information available to farmers, extension systems and governments.

\section{Plantwise: an attempt to strengthen plant health systems worldwide}

Plantwise aims to contribute to strengthening plant health systems by working with local extension services, nongovernmental organizations (NGOs) and other key actors in plant health to provide smallholder farmers with access to advisory services from plant clinics. Plantwise, which is a programme led by CABI, is now being implemented in 31 countries worldwide (www.plantwise.org). Plant clinics are at the core of the initiative. They are regarded as

\section{The idea behind plant clinics}

The idea behind plant clinics is based on human health clinics: people visit health clinics for preventive and curative care. Likewise, farmers could go to plant clinics with their crop sample. The first clinics started in Bolivia as 'Posta para plantas', a name borrowed from 'Posta de Salud' a human health clinic (Boa, 2009).

\section{Box 1} for establishing smallholder access to extension services on demand, tailored to the farmer's individual needs. Plantwise works with existing extension providers and other stakeholders to improve collaboration between them.

By supporting the establishment of plant clinics, Plantwise aims to contribute to the strengthening of national plant health systems. The plant clinics are used as an entry point to strengthen linkages between key stakeholders in a plant health system. This system aims to link the farmer to an integrated support network, consisting of input suppliers (e.g. pesticide manufacturers), diagnostic laboratories, researchers, national plant protection organizations and policy makers. The system should function to prevent and manage pest problems, reduce crop losses and promote plant health. Plant 


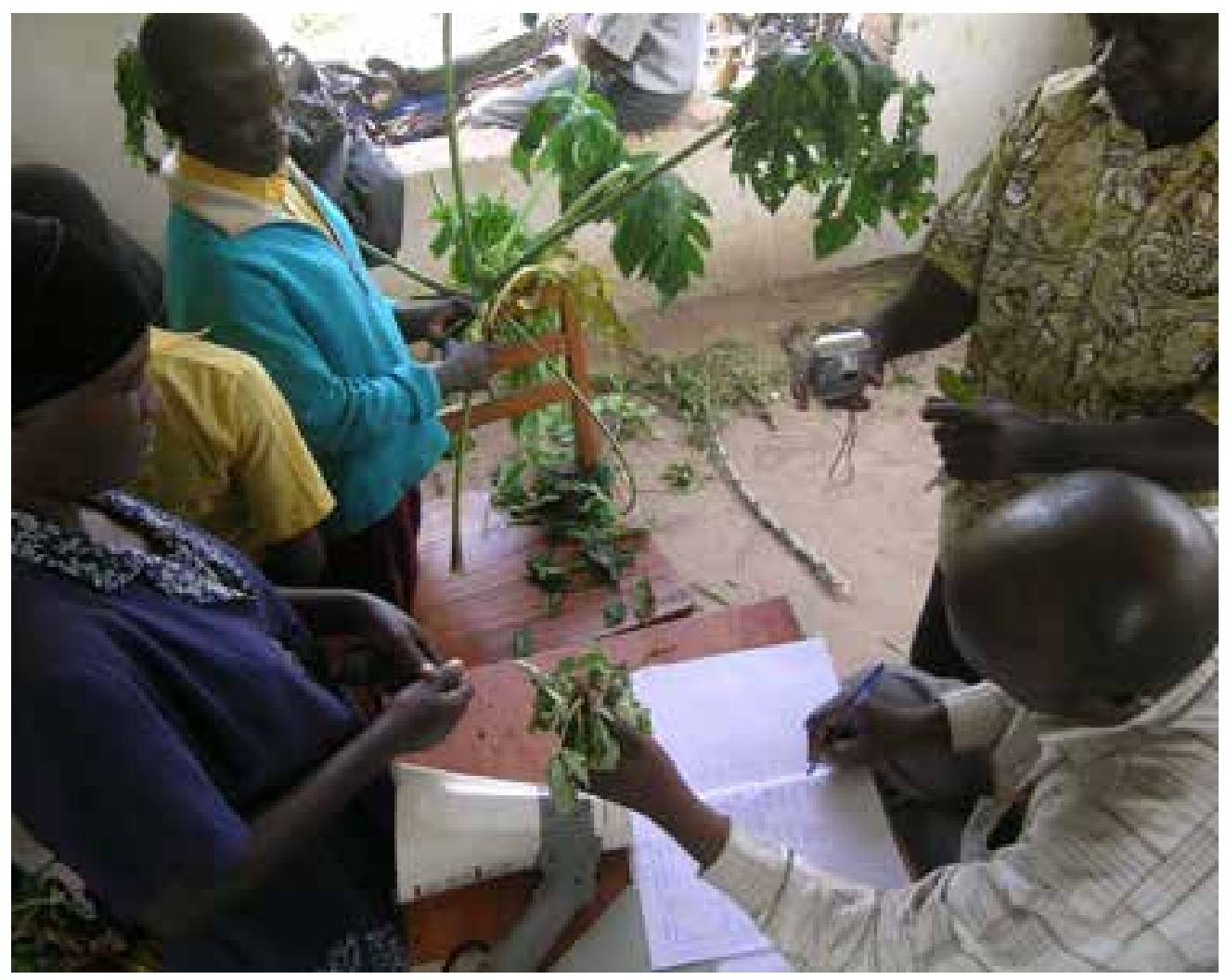

The plant doctor diagnoses a farmers' problem

health system components already exist in all countries but often operate in disparate ways. Plantwise acts as a catalyst to stimulate the interaction and integration of these parts into a stronger and more effective system; however, the exact nature of the plant health systems will vary from country to country and from district to district. Plant clinics are reinforced by the Plantwise Knowledge Bank, a global gateway to practical plant health information from diverse expert sources, with online and offline resources for advisory services. The Knowledge Bank also serves as a platform for plant clinic data management and use, where permitted, as well as information exchange within countries and as part of a global vigilance system to help identify invasive species and other emerging threats to plant health. Overall, it serves as a free, open-access source of locally relevant, comprehensive knowledge about plant health problems affecting any crop grown.

The Plantwise theory of change (Fig. 1) refers to the following linkages to be strengthened: 
Link farmers to extension through plant clinics: Extension staff trained as plant doctors run regular plant clinics in public places where farmers congregate so that they are easily accessible to any farmer who can bring any crop problem to the clinic.

\section{Link different extension providers through clinics and the Knowledge Bank:} Plant doctors and plant clinic implementing organizations meet regularly to share information on plant health problems; information that can later be used in extension activities at local, district or national levels.

Link extension staff to technical expertise: Plant clinics are linked to networks of diagnostic laboratories to provide advice on unknown problems. Researchers can quickly learn about any new and emerging diseases and share their knowledge and expertise, which is subsequently shared with plant doctors and then farmers. The Knowledge Bank supports extension workers with information about pests and plant health problems and records those encountered by farmers in their region.

Link extension and input suppliers: Plant clinics aim to work with trusted agroinput dealers to ensure that the products recommended by plant doctors are locally available and to promote codes of practice to help ensure ethical trading.

Link extension and regulatory bodies: New pests that cannot be identified at plant clinics or many farmers with samples of the same pest, signifying an outbreak, are reported to national bodies such as ministries of agriculture and the national plant protection organizations, regulating bodies that register and regulate the use of chemicals, and environmental management authorities. This improves national pest lists as well as enabling early alerts to be issued and rapid response measures. The Plantwise Knowledge Bank provides a mechanism to capture data and enable those working in the national plant health and regulatory bodies to analyse the data as part of any pest risk analysis. The Knowledge Bank will allow countries to manage data in ways that will help them spot local problems before they flare up and become acute problems at the national level.

Key outcomes from this approach will be a functioning plant health system that enables farmers to access timely and locally relevant information through both plant clinics and other information sources. The functioning plant health system will also ensure that emerging pests are detected rapidly and appropriate measures are put in place to counteract the spread of the pest. Clinics are expected to facilitate more effective use of scarce resources. Organizations operating within the plant health system will be more accountable to farmers, and work together to respond to farmers' needs. 


\section{How a Plant Health System works and what it achieves}

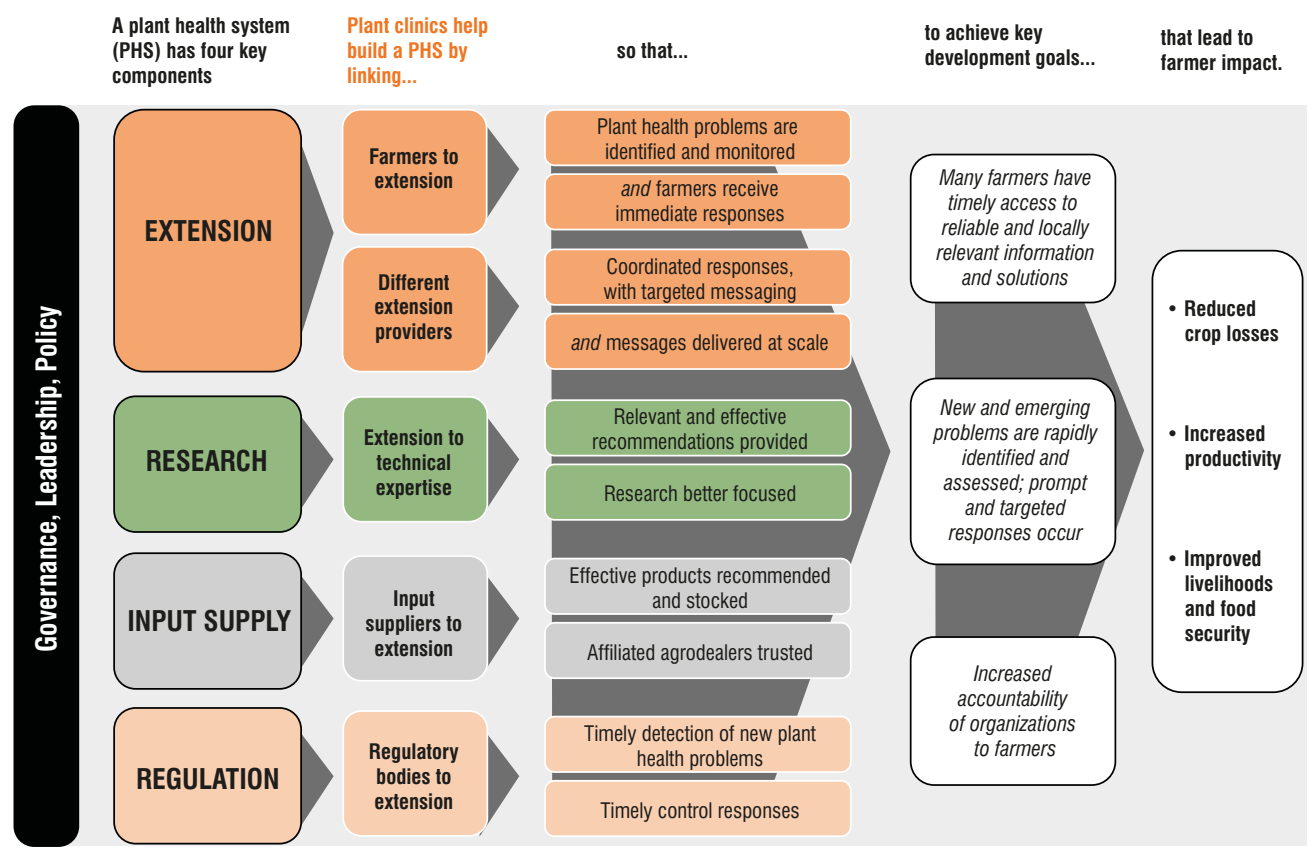

Fig. 1. Plantwise theory of change (Plantwise Strategic Plan 2012-2016)

That is the theory. But what is happening in practice? To answer this question, we focus on the experiences of five plant clinics in Uganda. In Uganda, the first plant clinic opened in 2005 under the Global Plant Clinic initiative. Plantwise started in 2011, building on the Global Plant Clinic experiences, in collaboration with the Ministry of Agriculture, Animal Industries and Fisheries (MAAIF).

\section{Agriculture in Uganda}

Uganda is a land-locked country covering 142,000 km2, of which 70\% (World Bank, 2011) is agricultural land, with a variety of landscapes and altitudes ranging from 1000 to $5000 \mathrm{~m}$ above sea level. It has huge potential to produce a range of crops such as cassava, citrus, coffee, maize, plantain, sugarcane, sweet potato and tea, but also for livestock raising and fisheries throughout the year. Agriculture contributes $25 \%$ of the country's GDP (World Bank, 2011). Agricultural produce makes up 46\% of all exports and provides a large proportion of the raw materials for national industries. The country's population is approximately 37.5 million, with $84 \%$ of the population living in rural areas. It is estimated that about 3.96 million of Uganda's households rely 
on agriculture with an average land size of 1.1 ha per household (UBOS, 2010). Total employment in agriculture is $72 \%$ (World Bank, 2005), accounting for about $76 \%$ of women's employment (World Bank, 2005) and 61\% of men's employment (World Bank, 2003). Agriculture accounts for 95\% of all children's employment between seven and 14 years of age (World Bank, 2012).

The agricultural sector is quite vibrant and offers many opportunities. The main food crops are bananas, beans, cassava, maize and sweet potato (Table 1), which are cultivated by most households. Citrus, oil seed, coffee, potato, and tea are grown as commercial crops. Farmers face a wide range of pests and diseases in different crops including banana bacterial wilt, cassava mosaic virus and cassava brown streak virus, leaf miner and fruit fly in citrus, striga in maize, rice and sorghum, fusarium wilt in tomato, coffee wilt in coffee, rosette virus in groundnut, black rot in cabbage and stalk borer in sorghum.

Farmers use few inputs, with an average of $1.7 \mathrm{~kg}$ of fertilizer applied per hectare annually (World Bank, 2010), while 92\% use local seeds (UBOS, 2010). Access to regular extension services remains limited with about $19 \%$ of farmers seeing an extension worker. (UBOS, 2010). The main sources of agriculture-related information for farmers are the radio and farmer-to-farmer exchange.

\section{Main agricultural crops in Uganda}

\begin{tabular}{llll}
\hline Rank & Commodity & Production (USD1000) & Production (MT) \\
1 & Plantain & $1,424,560$ & $9,200,000$ \\
2 & Cassava & 514,434 & $4,924,560$ \\
3 & Maize & 343,687 & $2,734,000$ \\
4 & Sweet potato & 200,149 & $2,650,000$ \\
5 & Sugar cane & 82,093 & $2,500,000$ \\
6 & Cow's Milk & 376,814 & $1,207,500$ \\
7 & Vegetables & 169,597 & 900,000 \\
8 & Potato & 119,902 & 800,000 \\
9 & Banana & 160,530 & 570,000 \\
10 & Beans, dry & 223,960 & 425,400 \\
(Source: FAO stats 2012) & &
\end{tabular}

\section{Table 1}




\section{Agricultural advisory services in Uganda: a major challenge}

Major transformation towards economic growth and poverty reduction began in the late 1980s with the adoption of the Vision 2025 Strategy. The Poverty Eradication Action Plan outlined the necessary policy actions for social transformation. Low agricultural productivity was identified as one of the major constraints to development. As a response, a comprehensive Plan for Modernisation of Agriculture was adopted in 2001. The Plan aimed to address the factors undermining agricultural productivity, including poor crop and livestock husbandry, poor natural resource management, minimal use of improved inputs, limited access to technical advice, inadequate access to credit, poor transport and communications and marketing infrastructures, and insecure land tenure and user rights (Heemskerk et al., 2008). Reforms to the national extension system by establishing the National Agricultural Advisory Services (NAADS, www. naads.or.ug) became the main driving force behind the implementation of the Plan for Modernisation of Agriculture.

Since 2010, the Development Strategy and Investment Plan (DSIP) 2010/112014/15 has constituted the national policy for agricultural development in Uganda and represents Uganda's commitment to the Comprehensive Africa Agriculture Development Programme (CAADP). The Agricultural Technology and Agribusiness Advisory Services (ATAAS) project, implemented by MAAIF through NAADS and the National Agricultural Research Organisation (NARO), constitutes the largest component of the DSIP. In 2010, plant clinics were officially recognized by MAAIF with their inclusion in the DSIP (Danielsen et al., 2014). The district local governments are in charge of planning and budgeting for agriculture-related activities. The largest part of the district budgets comes from the central government as grants, which are partly financed by external development aid.

Despite the grand plans, the implementation of agricultural policies in Uganda faces considerable challenges at field level (Batekega et al., 2013; Rwamigisa et al., 2013) and there are no signs that the situation will improve in the foreseeable future. In principle, MAAIF has the mandate and authority to oversee policy implementation and provide guidance to sector institutions, but in reality its capacity to do so is minimal, as its capacity for policy implementation has been severely weakened since the decentralization reform of 1997 and subsequent extension reforms. After the abolishment of the Extension Directorate in 1998, MAAIF no longer had a direct role in extension. District local governments took over responsibility for pest and disease control and extension, including implementation of NAADS from 2001 onwards. 
It is widely recognized that the decentralization took place too fast and that areas such as pest and disease control were left in a vacuum without the necessary capacity, procedures and lines of command in place. The scope for collective action to manage pests and disease was severely restricted (Rwamigisa et al., 2013).

In the DSIP document and action plan for the 'non-ATAAS' components', MAAIF outlines the actions needed to strengthen its capacity to carry out its leadership role (MAAIF, 2010, 2012). Nonetheless, the funds and staff to implement the DSIP are not in place (MAAIF, 2012). Instead a 'piecemeal' approach is used, whereby the various components are funded and implemented as individual projects with limited overall coordination between

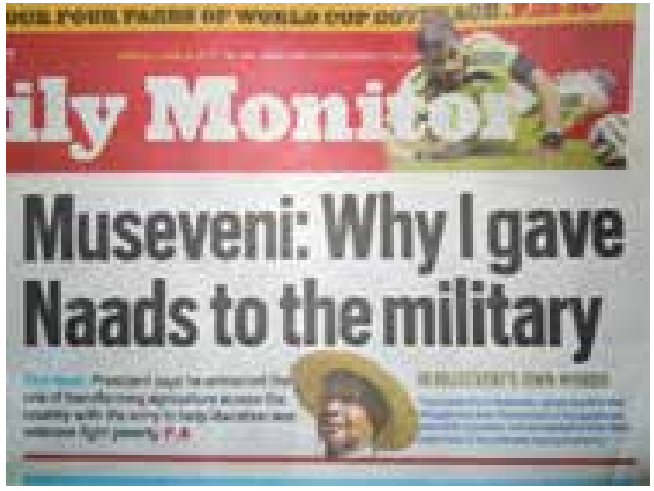

Fig. 2. The future of NAADS has been uncertain for a long time (Daily Monitor, June 16, 2014) both government agencies and donors.

The uncertainty surrounding extension policies in Uganda have added to the difficulties (Kjær and Joughin, 2012). After years of disputes it is still unclear which direction NAADS is going in. In late 2013 the government announced a major new extension reform: a proposal to "bring back extension to MAAIF" was presented to Parliament. The proposal implies the re-establishment of MAAIF's Department of Extension and a complete restructuring of NAADS, which includes bringing district level NAADS staff into the district local government system, with reporting obligations to MAAIF under a 'single-spine extension system'. In early 2014, the President publicly expressed his discontent with NAADS and announced that" all District NAADS Coordinators

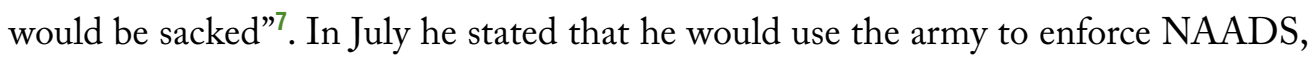
particularly liberation war veterans, to "help them fight [their own] poverty"s (Fig. 2).

\footnotetext{
6. http://www.monitor.co.ug/News/National/Museveni--Why-I-entrusted--Naads-programme-witharmy/-/688334/2349720/-/wn6sg7z/-/index.html

7. www.monitor.co.ug/News/National/Government-to-sack-all-Naads-district-coordinators/-/688334/2161478//12ik55az/-/index.html
}

8. www.monitor.co.ug/News/National/Museveni--Why-I-entrusted--Naads-programme-witharmy/-/688334/2349720/-/wn6sg7z/-/index.html 
These changing political signals have created a lot of concern and uncertainty about the future among district staff. District officials say that changes have been abrupt and unplanned, making it difficult for them to plan and consolidate their work. Farmers lose trust in government services owing to the lack of stability.

The plant clinics have entered the scene in times of considerable uncertainty about policy and institutional direction.

\section{Methodological process}

The process of writing this working paper started in August 2013 with a Plantwise Monitoring and Evaluation Stakeholder Workshop in Kampala. The workshop, facilitated by CABI, was the first step in planning an evaluation study of plant clinics in Uganda and followed requests from those involved in running plant clinics wanting to understand whether the clinics are having an impact on farmers' lives in Uganda. The objectives of the workshop were to obtain information from stakeholders working with Plantwise on progress and change towards outcomes and impacts in Uganda and to contribute to the identification of key questions to be addressed by the evaluation study. The key questions that emerged included:

- How do different approaches to advisory services complement each other?

- How do differences in the way plant clinics are run influence clinic usage and performance?

- Do farmers use the advice provided by plant doctors?

- Are plant clinics meeting the needs of stakeholders?

- Are mobile clinics more effective in reaching people?

- Prescription forms - what are the trade-offs?

- Are plant clinics an effective way to stimulate change in the plant health system? 


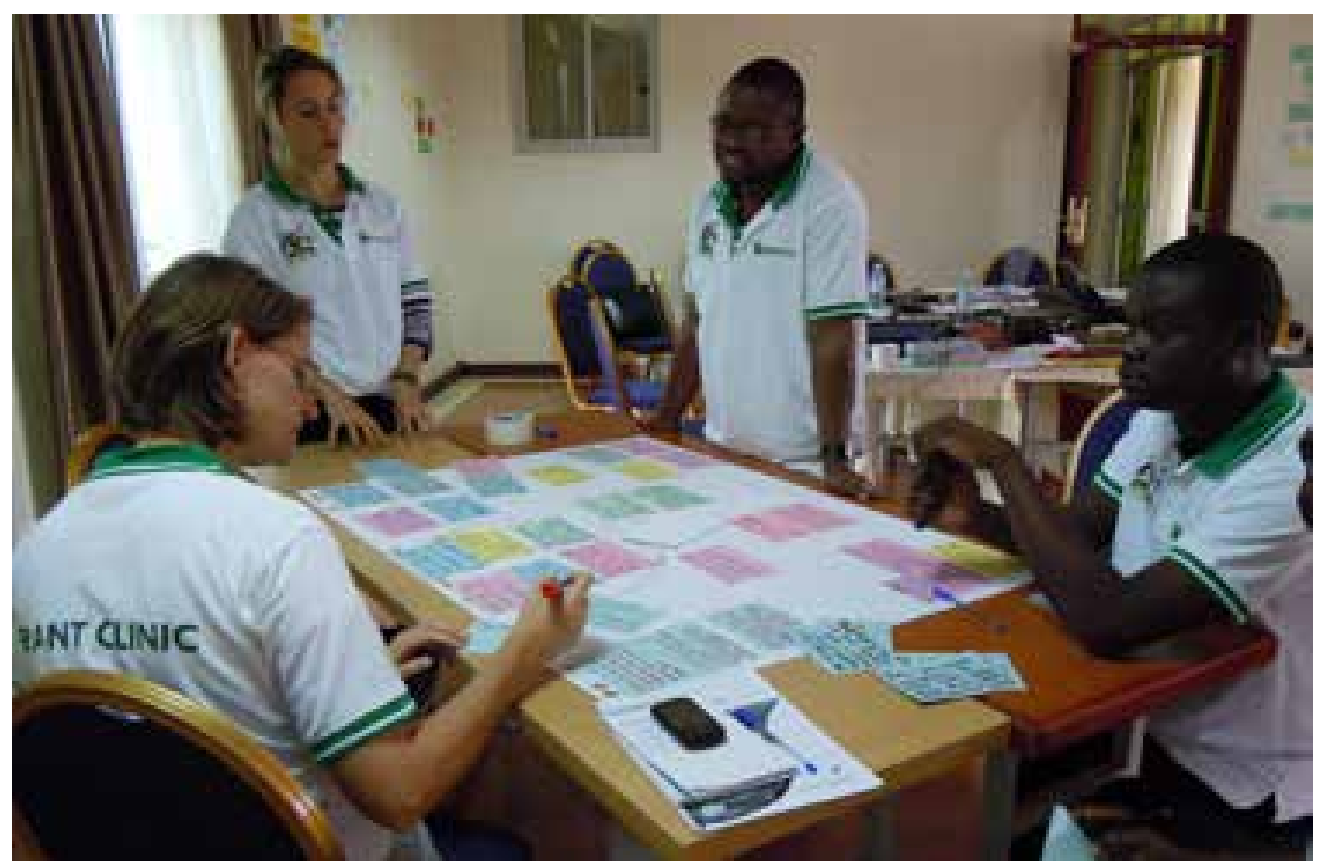

Based on the outcomes of the workshop and the identified issues, a second Study Design Workshop was organized in September 2013. The major aim of this workshop was to develop a framework and methodology to answer the questions resulting from the Monitoring and Evaluation (M\&E) workshop. During the Study Design Workshop, which was facilitated by experts from KIT Sustainable Economic Development, participants developed a methodology and tools for data collection. In the months after the workshop, participants collected data in eight districts in three regions (Western, Central and Eastern) through surveys, focus group discussions and interviews (Fig. 3). In total 348 plant clinic users and 328 non-users were surveyed. In the majority of districts, sampling was random, based on plant clinic records, but owing to incomplete records, in some districts respondents were selected directly by the plant doctors. The intention was to select 20 farmers per clinic, of which ten were to be female, but this was not possible at some clinics. Each time a clinic user was approached for interview, a non-user was also recruited by asking a non-clinic user in the vicinity for an interview (Table 2). Forty-eight focus group discussions with plant clinic users (men and women) and non-users were held. In most cases, men and women were separated into different groups although some groups were mixed. A focus group with plant doctors was also conducted in each district. The Plantwise coordinator for Uganda facilitated the discussions, with the support of MAAIF, NAADS and NGO staff, to gather perspectives on relations between actors in the plant health system. 


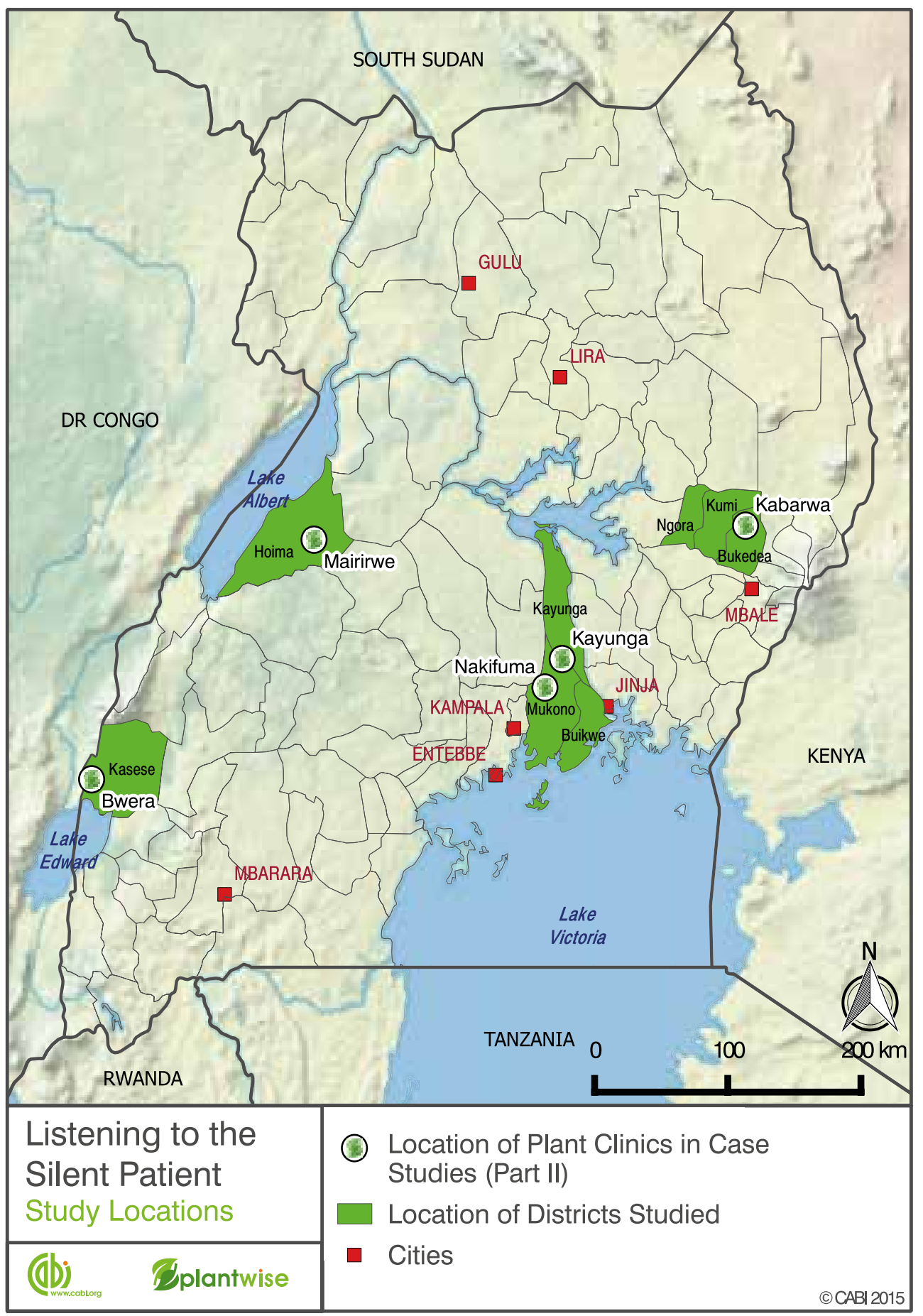

Fig. 3. Study area 
Survey sample size: plant clinic users

Users

Gender of respondent
Non-users

Gender of respondent

\begin{tabular}{lllllll}
\hline Region & Male & Female & Total & Male & Female & Total \\
\hline Central & 90 & 59 & 149 & 59 & 63 & 122 \\
Eastern & 79 & 15 & 94 & 74 & 35 & 109 \\
Western & 53 & 52 & 105 & 43 & 54 & 97 \\
Total & 222 & 126 & 348 & 176 & 152 & 328
\end{tabular}

\section{Table 2}

Interviews with ten key informants from district local authorities and the private sector were conducted to gather in-depth knowledge of their involvement with plant clinics. Parallel to this study, scientists from Makerere University's Department of Extension and Innovation Studies conducted research on two specific aspects of plant clinics: gender and the institutionalization of plant clinics. Together, these studies form the basis of this working paper. During a writeshop (writing workshop) held in Kampala in June 2014, information from the different studies was brought together, including studies completed by Solveig Danielsen while at the University of Copenhagen and a study by Andrew Tock (2014). Additional statistics from MAAIF from Central and Western regions and the Uganda Bureau of Statistics (UBOS) were used. Several Plantwise documents, plant clinic records (see Chapter 3) and the Plantwise Online Management System (POMS) provided supplementary information. The information was complemented with stories and quotes from different stakeholders involved in plant clinics and plant clinic operations. During the writeshop, key lessons and conclusions were formulated by the participants, including MAAIF and NAADS staff, NGO staff, plant doctors, CABI staff and the facilitators from KIT Sustainable Economic Development.

There are clear limitations to the data gathered during the study. For example, it was not possible to select a random sample of clinic clients for the survey at all clinics owing to the absence of complete clinic records, and the sample size was limited because of budgetary constraints. In addition, there were uneven numbers of men and women farmers and uneven numbers of informants per region. The plant clinic records also have a number of shortcomings. Data were only available for Central and Western regions, and were incomplete with some of the information on the forms not 
yet entered on the electronic system. For Eastern region, no plant clinic records were available at all. This presented not only a limitation for this study, but is hampering Plantwise efforts to set up a systematic plant health monitoring system. Hence, it was impossible to discover the total number of queries answered by the plant clinics. Nevertheless, this working paper provides interesting insights into the practices of plant clinics in Uganda.

\section{Structure of the working paper}

The working paper consists of two parts. The first part focuses on the process through which plant clinics evolved in Uganda. First we present the conceptual framework that helped us analyse the plant clinic experiences. Then we look at the evolution and current situation of plant clinics in Uganda by applying a number of concepts: plant clinic adaptations, gender and institutionalization.

The second part of the working paper consists of plant clinic case studies from Western, Eastern and Central regions. They contain stories and tales specific to the clinics and provide concrete examples of the themes used for the analysis in Part I.

\section{Part I: The evolution of plant clinics in Uganda}

Following this introductory chapter, Chapter 2 presents the framework that helped us to look at plant clinics and make sense of practice. We introduce the major guiding concepts that we have used to structure our findings. The chapter provides the lens through which we look at plant clinic experiences in Uganda. It helps us to make sense of all the available information on how plant clinics in Uganda developed over the years, guiding our analysis of and reflections on Plantwise experiences.

Chapter 3, Plant clinics in Uganda starts by explaining the background of Plantwise and plant clinics in Uganda. It briefly presents the history of plant clinics in the country, emphasizing the most important and decisive events that made plant clinics what they are today. It then describes the current situation, and lastly focuses on the operations of clinics and users' behaviour.

Chapter 4, Plant clinic adaptations describes the various adaptations local stakeholders have used to make the clinics more responsive to the needs of their clients. The reason and the means by which the adaptations were introduced are discussed, as well as the potential impact these adaptations may have. 
Chapter 5, Gender responsiveness in plant clinic delivery focuses on gender and plant clinics. Issues dealt with include the differences in accessing plant clinics between men and women in the three regions, and the inclusion of women and their specific needs. We also look at the ways strategies and adaptations employed by the different clinics influence access, use and relevance for men and women. Finally we reflect on the associated constraints and opportunities.

Chapter 6, Institutionalization focuses on institutional aspects of plant health services, and plant clinics in particular: how do they fit and how are they embedded in the existing formal plant health system at different levels, including policy, management and operational levels? We look at the different ways plant clinics have contributed to changes in the wider plant health system, strengthening critical linkages between existing organizations and stakeholders.

Chapter 7 presents a number of key conclusions. We return to the concepts introduced in Chapter 2 and provide answers to the guiding questions. We summarize the lessons learnt, based on the case studies and the analytical chapters. We reflect on what went well and elaborate on ideas on how current challenges could be addressed.

\section{Part II: Case studies}

In Part II of the working paper, we focus on five individual plant clinics. We provide descriptions of plant clinics in the Western, Central and Eastern regions of Uganda. These plant clinics were purposely chosen. We wanted to be able to compare the NGO operated and government operated plant clinics. We were also curious about the experiences of mobile versus fixed clinics. And we wanted a geographical spread: clinics from the Western, Central and Eastern regions. In this section, the stories of the plant clinics are told. Who are the different actors and how do they interact with each other? What are the different institutional adaptations in the plant health system that are reaching out to farmers and how are they embedded in the local plant health system? What are the differences between government and NGO operated plant clinics? And are there regional differences? The plant clinics described are:

\section{District (region)}

1. Nakifuma (Central) Fixed

2. Bwera (Western) Fixed

3. Kayunga (Central) Mobile

\section{Operation model Operating organization}

Mukono district local government

RIC-NET

Kayunga district local government and Self Help Africa 


\section{Kabarwa (Eastern) Fixed Bukedea district local government \\ 5. Mairirwe (Western) Fixed Hoima district local government}

Personal experiences of the people involved in plant clinics in Uganda, including farmers, plant doctors, plant nurses, change agents and policy makers are an important part of the case studies. Each of them has his or her own story about how they became involved in plant clinics, what their role is, how the clinics work for them, the benefits and the challenges. Throughout the working paper we have used pictures and quotes, and fascinating stories from those people. We also used short films to illustrate these stories. There are links to YouTube along with QR codes. You can scan the QR code with the $\mathrm{QR}$ reader or $\mathrm{QR}$ scanner application on your smartphone and watch the movie. Or you can type the URL address in your internet search engine and enjoy seeing and hearing the real-life experiences from people in the field, in their own environment and in their own words.

\section{References}

Batekega, L., Kiiza, J. and Kasirye, I. (2013) Institutional Constraints to Agriculture Development in Uganda. Research Series no. 100. Economic Policy Research Centre, Kampala.

Boa, E. (2009) How the Global Plant Clinic began. Outlooks on Pest Management 20(6), $112-116$.

CABI. 2012. Plantwise Strategic Plan. CABI, Wallingford, UK.

Danielsen, S., Matsiko, F. and Kjær, A.M. (2014) Implementing plant clinics in the maelstrom of policy reform in Uganda. Food Security 6(6), 807-818

FAO (2012) Country Statistics Uganda. www.countrystat.org/home.aspx?c=UGA (accessed 19 June 2014).

Heemskerk W., Nederlof, S. and Wennink, B. (2008) Outsourcing Agricultural Advisory Services. Enhancing Rural Innovation in Sub-Sabaran Africa. Bulletins of the Royal Tropical Institute 380. KIT Publishers, Amsterdam, the Netherlands.

Kjær, A.M. and Joughin, J. (2012) The reversal of agricultural reform in Uganda. Ownership and Values. Policy and Society 31(4), 319-330.

MAAIF (2010) Development Strategy and Investment Plan 2010/11-2015/16. Ministry of Agriculture Animal Industry and Fisheries, Entebbe, Uganda.

MAAIF (2012) Proposed Plan to Operationalise the non-ATAAS Component of the Agricultural Sector Development Strategy and Investment Plan. Ministry of Agriculture Animal Industry and Fisheries, Entebbe, Uganda. 
Oerke E.C. (2006) Crop losses to pests. Journal of Agricultural Science 144, 31-43

Rwamigisa, P., Birner, R., Mangheni, M. and Semana, A. (2013) How to promote reforms in the agricultural sector? A case study of Uganda's National Agricultural Advisory Services (NAADS). Paper presented at the International Conference on the Political Economy of Agricultural Policy in Africa, Pretoria, 18-20 March 2013.

Tock, A. (2014) Monitoring plant clinic performance. Internship report. BBSRC-sponsored Professional Internship Placement with CABI. University of Warwick Crop Centre, UK.

UBOS (2010) Uganda Census of Agriculture 2008/2009. Volume 1, Summary Report. Uganda Bureau of Statistics in collaboration with the Ministry of Agriculture, Animal, Industry and Fisheries, Kampala.

World Bank (2003, 2005, 2010, 2011, 2012) Statistics. http://data.worldbank.org/country/ uganda. (accessed 19 June 2014). 

2

Looking at plant clinics: making sense of practice

By Remco Mur, Frances Williams and Solveig Danielsen 
This working paper is about plant clinics. We used a number of concepts that helped us to focus, reflect and analyse certain important aspects of the plant clinic experiences in Uganda. They are the lens through which we looked at the plant clinics. This was a deliberate choice the authors of the working paper made together: we simply cannot tell the full story in 200 pages. Based on the concepts described in this chapter, we formulated a number of guiding questions, which we aim to answer in this working paper.

We look at plant clinics from an agricultural innovation systems perspective. Plant clinics are an effort to improve the plant health system, a particular part of the wider agricultural innovation system (Danielsen et al., 2013; Romney et al., 2013). Using the agricultural innovation systems perspective allows us to focus on the institutional aspects of the plant clinics.

Plant clinics aim to address the needs of farmers in Uganda, but farmers in Uganda are highly diverse. Who is accessing and benefitting from plant clinics and how exactly plant clinics are implemented, managed and adapted locally depend on many factors. As the cases in this working paper show, agro-ecological and socio-economic disparities are enormous. There are inequalities in access to and control of assets, information, organizations and markets in the agricultural sector. This includes access to and control of advisory services. We specifically look at the disparities between men and women, using a gender lens while looking at plant health services and plant clinics.

\section{About institutions and plant health systems}

Smallholder producers in sub-Saharan Africa operate in an increasingly complex, uncertain and rapidly changing environment. Factors like climate change, uncertain and changing political, social and economic conditions, and rapid land-use shifts all have an impact on their day-to-day lives, leaving many of them vulnerable to droughts and floods, pests and diseases, and other shocks and stresses. Within this context, farmers face the challenge of securing their livelihoods, and remaining competitive by increasing their productivity in a sustainable way and taking advantage of emerging market opportunities. Farmers often lack the know-how and the capacity to deal with risks associated with adapting to those challenges and seizing the opportunities available. There is a need for advice and information. Advisory services and, as discussed in this working paper, plant health advisory services can contribute to building the resilience of farmers, allowing them to better cope with threats such as crop pests and diseases. 
It is useful to focus on the plant health system to understand how farmers, plant clinics and other actors operate and interact with each other and, more importantly, the constraints and opportunities of these interactions. Röling (1992) defines a system as "the relationships and linkages among elements within an arbitrary boundary". Which elements are important depend on the theme or focus of the issue in question. The plant health system concerns the actors, individuals and organizations that are involved, directly or indirectly, in developing, sharing and adapting plant health knowledge, information and technologies and getting them out to and applied by farmers. The boundaries of the plant health system are arbitrary and contextual. Fig. 4 illustrates the plant health system in Uganda as defined by participants of the Monitoring and Evaluation Stakeholder Workshop held in Kampala in August 2013. But as we will see in this working paper, the system in each of the different districts looks different, with each having its own challenges.

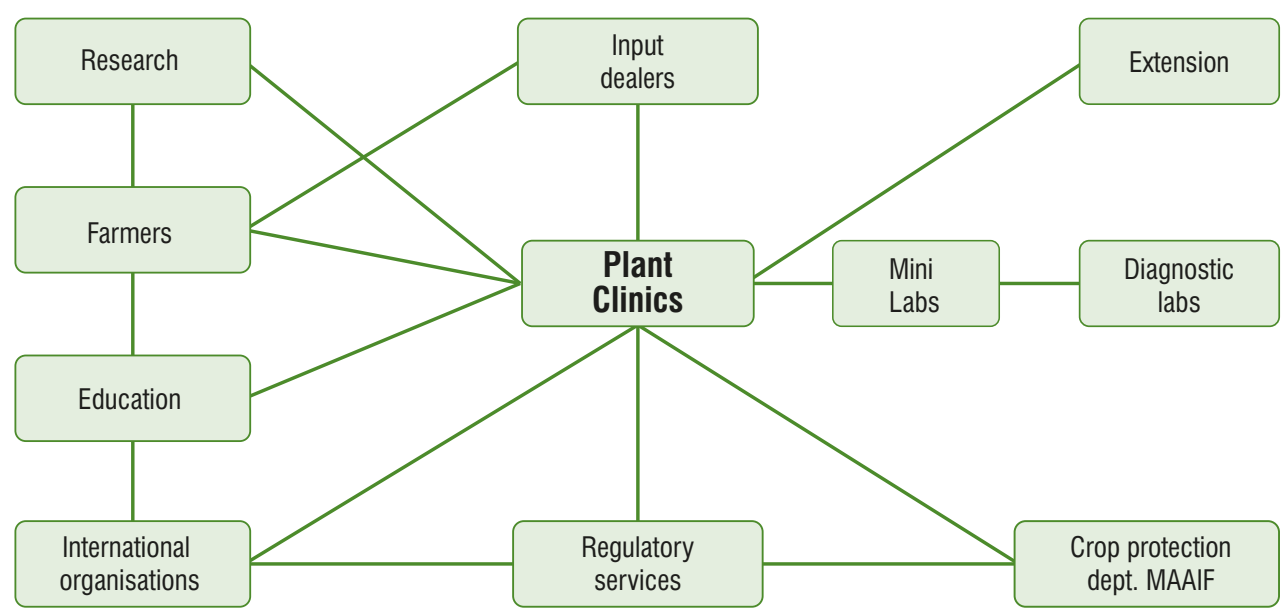

Fig. 4. Visualization of the plant health system in Uganda in 2013 (by participants of the Plantwise Monitoring and Evaluation Stakeholder Workshop, Kampala, August 2013)

\section{GUIDING QUESTION}

\section{Who are the actors in the plant health systems in different localities in} Uganda and how do they interact? 
A system and its actors need to develop the capacity to continuously innovate, as changes keep on happening. The capacity to innovate will increase the resilience of the system and its actors (Pyburn, in Sanyang et al., 2014). This applies for the plant health system. When talking about innovation, we mean the process of bringing knowledge (of all types) into use to achieve desired social or economic outcomes. Agricultural innovation is context-specific, actor-oriented and farmer-centric (Meridian Institute, 2013). Hence, there is no blueprint for it.

Often technology plays an important role in innovation. However there are also organizational and institutional aspects to innovation. An institution, formal or informal, is any collectively accepted system of rules (procedures, practices, norms) aimed to pursue a particular endeavour (Searle, 2005). In fact, one could refer to plant clinics as an institutional change that influences innovation: they represent new ways and arrangements for different actors to develop, share and put into practice technical information related to plant health more effectively and efficiently. What is new is not the technological information itself, but the new arrangements between different actors and mechanisms to get the technological information out to and applied by farmers. Innovation requires experimentation, learning and reflexivity. Van Mierlo and Reeger (2010) refer to reflexivity as "the ability to affect and interact with the environment within which a system operates".

The agricultural innovation systems perspective allows us to focus on the institutional aspects of plant clinics and the plant health system. The Food and Agriculture Organization of the United Nations (FAO) refers to an agricultural innovation system as "a network of individuals, organizations and enterprises focused on bringing new products, processes and forms of organization into social and economic use, together with the institutions and policies that affect their behaviour and performance" (Rajalahti, 2012). The innovation system not only includes the formal suppliers of knowledge and information, but also acknowledges the roles, knowledge and interactions of other actors, including farmers and the private sector. Agricultural innovation systems are most often defined in relation to a particular domain of human activity, for example, a specific commodity, value chain or business cluster, or in a specific agricultural or ecological system (Daane, 2009). In our case, it is the plant health system (Danielsen et al., 2013). In practice, agricultural innovation systems are not always self-organizing. Often there is a need for external intervention. Plant clinics are an external intervention. They are something new in themselves, but also require experimentation and adaptation, leading to 'plant clinic adaptations' at the local level. 


\section{2 guiding Question}

What are the different plant clinic adaptations that are reaching out to more and to different types of farmers in the selected Plantwise localities?

Plant clinics aim to stimulate sustainable changes in the wider plant health system, strengthening critical linkages between existing organizations and stakeholders (Plantwise Strategic Plan 2012-2016). Systems change requires capacity at different levels. Potter and Brough (2004), building on experiences from the health sector, differentiate four levels of capacity needs for systems change: performance capacity, personal capacity, organizational capacity and institutional capacity.

Performance capacity tools, money, equipment and consumables (tents, kits, factsheets, allowances)

Personal capacity of plant doctors, plant nurses, government staff, policy makers: knowledge, skills, competencies, self-confidence (e.g. knowledge on pests and solutions to pests, diagnostic skills)

Organizational capacity of the local implementing organizations: human resources, welldefined roles and responsibilities, reporting and monitoring systems, clear lines of supervision, reporting accountability and feedback, possibilities for learning, effective incentives, facility and support capacity (e.g. the data management system, number of plant doctors, plant doctor job descriptions, availability of subject matter specialist)

Institutional capacity of the plant health system: relations and flows of information, communication between stakeholders, links with different interest groups and with external actors, decision making mechanisms, accountability authority and responsibility to make decisions (for example information flows from MAAIF to district local government and vice versa, functioning of the data management system, downward accountability, participation in decision making, trust, policy frameworks, financing mechanisms) 
They emphasize the interrelatedness between the different levels. This also applies for the plant health system. Change happens in an iterative and sometimes unintended manner To achieve system change, Plantwise aims to build the capacities of individuals and organizations, and to ensure the sustainability of their interventions, for example by putting into place new procedures to deliver services and manage information. Local ownership is crucial to achieve lasting effects of capacity building, as articulated by Datta et al. (2012, p.3): "If change processes are not owned and led by those whose capacity is being developed, they are unlikely to happen (or if they do, to be sustainable)". The nature of projects implies a time limited intervention designed to create change. This raises several questions for organizations in trying to sustain change. Such questions include but are not limited to: is there ownership of the new practices at different levels? Are they relevant? Do the leaders buy in? Is the policy environment supportive? Are there sufficient human resources, skills and funds to continue the new practice? How well does it fit with the core institutional mandate, structure, capacity and work dynamics? Are the practices accepted by the clients/ end-users? In other words: have plant clinics been institutionalized? Or, as we will further explain below, is there sufficient institutional capacity? Institutional capacity refers to the enabling environment with appropriate policy and legal frameworks, including community participation (of women in particular), human resources development and strengthening of governance systems (Hilderbrand and Grindle, 1994). Plant clinic institutionalization is the process leading to mainstreaming plant clinics and associated processes into the prevailing policies, procedures and practices of the organizations involved, at different levels, from community to sub-national and national (Table 3, Fig. 5).

When new procedures or practices are institutionalized they become part of the core functions of the organizations in the system, while they also define the way in which organizations and individuals are interacting. Institutional capacity building is a long-term, continuing process, in which the involvement of relevant stakeholders of the plant health system is crucial (e.g. MAAIF, district local government, NGOs and plant doctors, farmer representatives including women, NARO and universities).

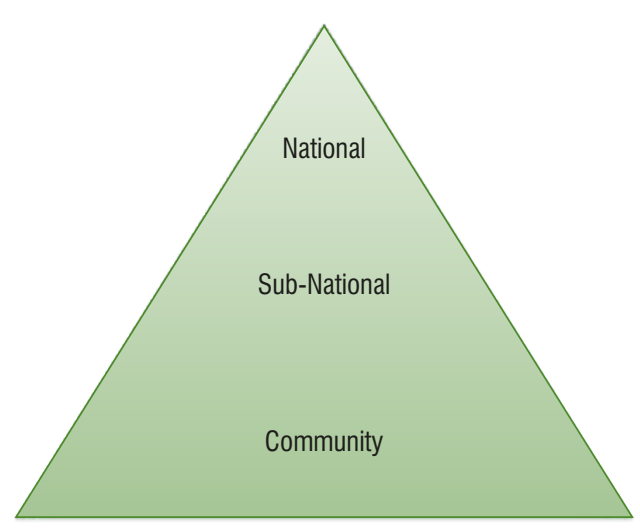

Fig. 5. Levels of institutionalization of plant clinics 
Although Plantwise has invested resources in strengthening certain aspects of organizational and institutional capacities of the plant health system, most efforts were put into personal capacity building of plant doctors.

\section{Plant clinic institutionalization at three levels}

\begin{tabular}{|c|c|c|}
\hline Level & Function & Determinants of institutionalization \\
\hline National & $\begin{array}{l}\text { Policy making } \\
\text { Stewardship }\end{array}$ & $\begin{array}{l}\text { Political support and commitment } \\
\text { Leadership and adaptive capacity } \\
\text { Effective policy implementation }\end{array}$ \\
\hline District & $\begin{array}{l}\text { Plant clinic service } \\
\text { delivery }\end{array}$ & $\begin{array}{l}\text { Ownership } \\
\text { Leadership and adaptive capacity } \\
\text { Institutional fit and resources }\end{array}$ \\
\hline $\begin{array}{l}\text { Farming } \\
\text { community }\end{array}$ & Plant clinic use & $\begin{array}{l}\text { Ownership } \\
\text { Sustained demand for service } \\
\text { Trust }\end{array}$ \\
\hline
\end{tabular}

\section{Table 3}

These issues need to be understood and addressed collectively by decision makers and implementers to guide the institutionalization process.

\section{GUIDING QUESTIONS}

How are plant clinics embedded in the existing formal plant health system at different levels, including national (policy), district (management) and local (operational) levels? What are the enabling and constraining factors at the different levels that affect the institutionalization of plant clinics?

How have plant clinics contributed to changes in the wider plant health system, such as strengthening critical linkages between existing organizations and stakeholders? 
We already referred to the importance for the system and its actors to adapt to changes in the policy, socio-economic as well as agro-ecological, context. Learning and reflexivity are key to adaptation and innovation. A reflexive practitioner adapts to changes in the context and responds consciously. There is an ongoing iterative 'conversation' between the agent and the context. An organization's learning system is made up of structures that channel inquiry, and the culture of the organization further facilitates or hinders inquiry (Argyris and Schön, 1996, p.28). As part of the M\&E system, the POMS, which is an integral part of the Plantwise Knowledge Bank, aims to support national stakeholders to collect and consolidate data from plant clinics, and analyse and feed the information back to the districts and to other stakeholders at different levels, allowing them to reflect and adjust their practices where required.

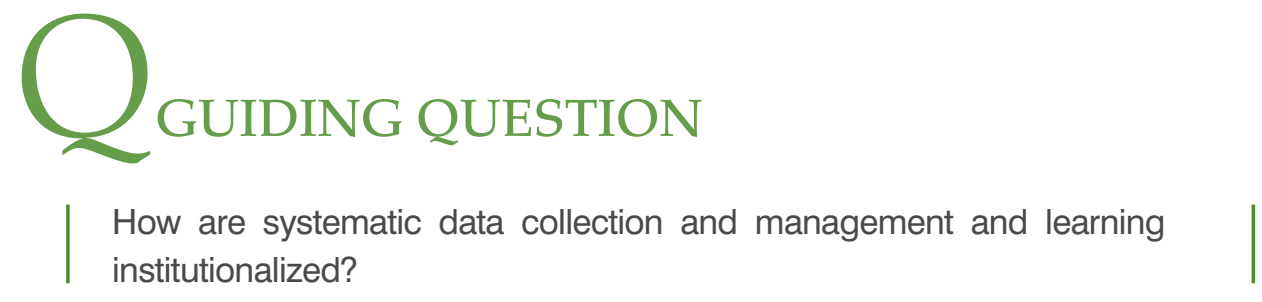

\section{Gender}

FAO argues that closing the gender gap in access to productive resources could increase agricultural output in the developing world as a whole by $2.5-4 \%$ and reduce the number of undernourished people by $12-17 \%$, with higher gains in countries where the gender gap is wider and where women are heavily involved in agriculture $(\mathrm{FAO}, 2011)$. Such a reduction in gender inequality in agriculture would also have important benefits for poverty reduction and gender equality overall (Meinzen-Dick et al., 2011).

A gender perspective helps us to understand how women and men are socially related as well as positioned differently in society. It takes into account other social identities (such as age, ethnicity or class) in understanding women's and men's relative needs, interest and opportunities. In this working paper, however, we limit ourselves to social differences related to being a woman or a man and the implications these have for accessing and controlling plant health services as well as the benefits derived from them. 


\section{Some key definitions}

Gender equality: The equal enjoyment by women and men of socially valued goods, opportunities, resources and rewards. The aim is not that women and men become the same, but that their opportunities and life chances become and remain equal (FAO, 2011).

Gender equity: Fairness in treatment for women and men, according to their respective needs. It may include equal treatment or treatment that is different but considered equivalent in terms of rights, benefits, obligations and opportunities (Meinzen-Dick et al., 2011).

Gender mainstreaming: Mainstreaming a gender perspective is the process of assessing the implications for women and men of any planned action, including legislation, policies or programmes in any area and at all levels. It is a strategy for making the concerns and experiences of women as well as men an integral part of the design, implementation, monitoring and evaluation of policies and programmes in all political, economic, and societal spheres, so that women and men benefit equally, and inequality is not perpetuated. The ultimate goal of mainstreaming is to achieve gender equality (OECD, 1999).

Gender awareness: The conscious knowledge that people and communities are not homogenous.

(CABI, 2012)

Box 2

Women play a pivotal role in agriculture in Uganda and are the main source of family labour. Women's roles in agriculture largely focus on the traditional activities of food production and food security, whereby they are responsible for all farming activities from land preparation for food crops through to pre- and post-harvest activities such as drying and threshing grain. They sell a small amount of what they grow to cater for household needs. They also take care of the children, prepare food, fetch water and firewood and undertake a variety of other household tasks. Women are usually very time-constrained and restricted in their mobility. Generally women have limited decision making power and low land ownership (FOWODE, 2012). Women have gradually become more involved in cash crop production, but normally do not control the earnings from this production (FOWODE, 2012). 
In most situations, men will be involved in the production of cash crops and responsible for the bulk marketing. They undertake most of the farming activities, although women are often involved in activities such as weeding, harvesting and post-harvest handling. Within the household men are the main decision makers with control over resources, including money and productive resources such as land, labour, livestock, credit and technologies than women, as well as to services such as extension and education.

The expected end result of gender equity in advisory services is that both women and men can contribute, give feedback, and benefit from and generate new knowledge. Plant clinics as the advice delivery mechanism used by Plantwise should be equally accessible to both female and male farmers, and provide advice that is adapted to the realities of those attending the clinics. As gender is context-specific it is unlikely that a standard model for operating plant clinics is able to address gender issues worldwide, or even within one country. At local level, there is a need to understand the gender issues and to adapt the model to differing conditions in order to ensure women and men are equally able to access plant clinics and to ensure that the advice is as applicable and appropriate as possible. The Plantwise Gender Strategy (CABI, 2012) encourages those implementing plant clinics to consider a few key concepts:

Access depends on various aspects. First of all farmers need to be aware of the existence and services offered by the clinic. Second, they need to be able to access the clinic (distance, time required, costs of transport); is the time of the day and week appropriate for both men and women? Third, are farmers (men, women) willing to visit because it is relevant and meets their priorities? Fourth, are they willing to invest in plant health and related services and in pesticides? And finally, are they allowed to attend or are there any socio-cultural barriers or gender-based expectations that prevent women from accessing plant clinics? (adapted from Leeuwis, 2004).

Appropriateness of delivery methods for different user groups is important. The information needs to be delivered or packaged according to the constraints and opportunities of different groups of people wishing to access the information.

Suitable and applicable advice means consideration has been given to socioeconomic and cultural characteristics, roles and responsibilities, power relations, access to resources including land, money, farm inputs, etc., and existing labour requirements of the intended recipients. 
Gender awareness and capacity is found within implementing organizations and individuals. It can be reinforced by training (e.g. plant doctor training). It can also mean that both men and women, younger and older, can be plant doctors.

It is important for Plantwise to be equipped and able to face the different realities efficiently as roles, constraints, opportunities, ethnicity and livelihood strategies vary widely from one region to another, within and across countries where it operates. As opposed to merely including a 'gender aspect' in its programme, mainstreaming would ensure the reflexivity of the design, i.e. for the policies, actions and the implementation required for the programme and its stakeholders to operate within a (gender-) specific context.

\section{Gender and access to information}

There are strong gender disparities in access to agricultural information in Uganda, with male farmers consistently reporting better access than women, and also higher rates of adoption of technologies than women. There are many contributing factors. Women, especially rural women, have high illiteracy rates which reduce their access to written materials. In addition many extension messages, not just written materials, but also radio and TV programmes, are only produced in Luganda and English, further reducing women's access if they are only able to speak local languages. A lack of consultation with rural women concerning their priorities for agricultural advice has meant that little gender-specific information is developed to address these needs. Women's traditionally home-based roles mean that they have little opportunity to move beyond their local area and, together with their heavy time commitments, this restricts their exposure to information and access to knowledge through training and events. It also restricts their ability to exchange ideas and views on techniques and adaptations to the knowledge that they and their friends have gathered. There is little direct access to extension workers for many rural women. Extension workers have a tendency to work with heads of households, generally men, under the assumption that the information they provide will be passed on to the rest of the family, even when this is not the case. They also tend to work with farmers who have access to land and other farming resources, and who have the ability to adopt new technologies. This is generally male farmers. The low number of female extension workers (only $15 \%$ [AFAAS, 2011]), who tend to work more with female farmers than male extension workers do, compounds this situation. 
Such constraining factors do not only apply to women; many are also inherently applicable to youth. While they may be more educated, fluent in English or Luganda and more exposed to new technologies such as mobile phone services and the internet, they also face challenges in accessing land and financial and material resources. As young farmers, they may lack the knowledge and networks necessary to access the required information. Within their culture, they might be subject to the authority of the elders, with little or restricted influence or decision making power.

\section{GUIDING QUESTIONS}

What are the differences in men and women accessing plant clinics in the three regions and how can the differences be explained?

How do plant clinics address the context-specific characteristics and needs of men and women in providing plant health advice?

What are the regional differences in providing gendered plant health services?

What are the strategies and adaptations employed by the different clinics to include women and address their needs?

Do plant clinic operators have sufficient organizational gender capacity, and what can be done to strengthen this?

\section{References}

[African Forum for Agricultural Advisory Services] AFAAS (2011) A review of case studies on targeting women advisory service providers in capacity strengthening programmes: final report. AFAAS, Kampala, and the Forum for Agricultural Research in Africa (FARA), Accra.

Argyris C. and Schön, D. (1996) Organisational Learning II: Theory, Method and Practice. Addison- Wesley, Reading, Massachusetts.

CABI (2012) Plantwise Gender Strategy. CABI, Wallingford, UK.

Daane, J. (2009) Building capacity for agricultural research and innovation. Section 3 of chapter 8, Food security and sustainable agriculture: making science work for innovation. In: Molenaar, H., Box, L. and Engelhard, R. (eds) Knowledge on the Move. International Development Publications, Leiden, the Netherlands. 
Danielsen, S., Centeno, J., Lopez, J., Lezama, L., Varela, G., Castillo, P., Narvaez, C., Zeledon, I., Pavon, F. and Boa, E. (2013) Innovation in plant health services in Nicaragua: from grassroots experiment to a systems approach. Journal of International Development 25(7), 968-986.

Datta, A., Shaxson, L. and Pelleni, A. (2012) Capacity, Complexity and Consulting: Lessons from Managing Capacity Development Projects. Working Paper 344. Overseas Development Institute, London.

FAO (2011) State of Food and Agriculture 2010-11. Women in Agriculture: Closing the Gender Gap for Development. Food and Agriculture Organization of the United Nations, Rome.

[Forum for Women in Democracy] FOWODE (2012) Gender Policy Brieffor Uganda's Agriculture Sector. FOWODE, Kampala.

Hilderbrand, M.E. and Grindle, M.S. (1994) Building Sustainable Capacity. Challenges for the Public Sector. Harvard Institute for International Development, Cambridge, Massachusetts.

Leeuwis, C. (2004) Communication for Rural Innovation: Rethinking Agricultural Extension. Blackwell Science, Oxford, UK.

Meinzen-Dick, R., Quisumbing, A., Behrman, J., Biermayr-Jenzano, P., Wilde, V., Noordeloos, M., Ragasa, C. and Beintema, N. (2011) Engendering Agricultural Research, Development and Extension. IFPRI Discussion Paper 176. International Food Policy Research Institute, Washington, DC.

Meridian Institute (2013) Innovation platforms and smallholder farmer: gaps and opportunities. A report on interviews with global thought leaders and practitioners for the Bill and Melinda Gates Foundation, Seattle.

OECD (1999) DAC Guidelines on Gender Equality and Women's Emporverment in Development Cooperation. Organisation for Economic Co-operation and Development, Paris.

Potter, C. and Brough, R. (2004) Systemic capacity building: a hierarchy of needs. Health Policy and Planning 19(5), 336-345.

Rajalahti, R. (2012) Sourcebook overview and user guide. In: Agricultural Innovation Systems: an Investment Sourcebook. World Bank, Washington, DC, pp. 1-13.

Röling, N. (1992) The emergence of knowledge systems thinking: a changing perception of relationships among innovation, knowledge process and configuration. Knowledge and Policy 5(1), 42-64.

Romney, D., Day, R., Faheem, M., Finegold, C., LaMontagne-Godwin, J. and Negussie, E. (2013) Plantwise: putting innovation systems principles into practice. Agriculture for Development 18, 27-31. 
Sanyang, S., Pyburn, R., Mur, R. and Audet-Bélanger, G. (eds) (2014) Against the Grain and to the Roots: Maize and Cassava Innovation Platforms in West and Central Africa.

LM Publishers, Arnhem, the Netherlands.

Searle, J.R. (2005) What is an institution? Journal of Institutional Economics 1(1), 1-22.

van Mierlo, B. and Regeer, B. (2010) Reflexive Monitoring in Action: a Guide for Monitoring System Innovation Projects. Communication and Innovation Studies, Wageningen UR, Wageningen and Athena Institute, Amsterdam, the Netherlands. 
3

\section{Plant clinics in Uganda}

By Geneviève Audet-Bélanger and Joseph Mulema

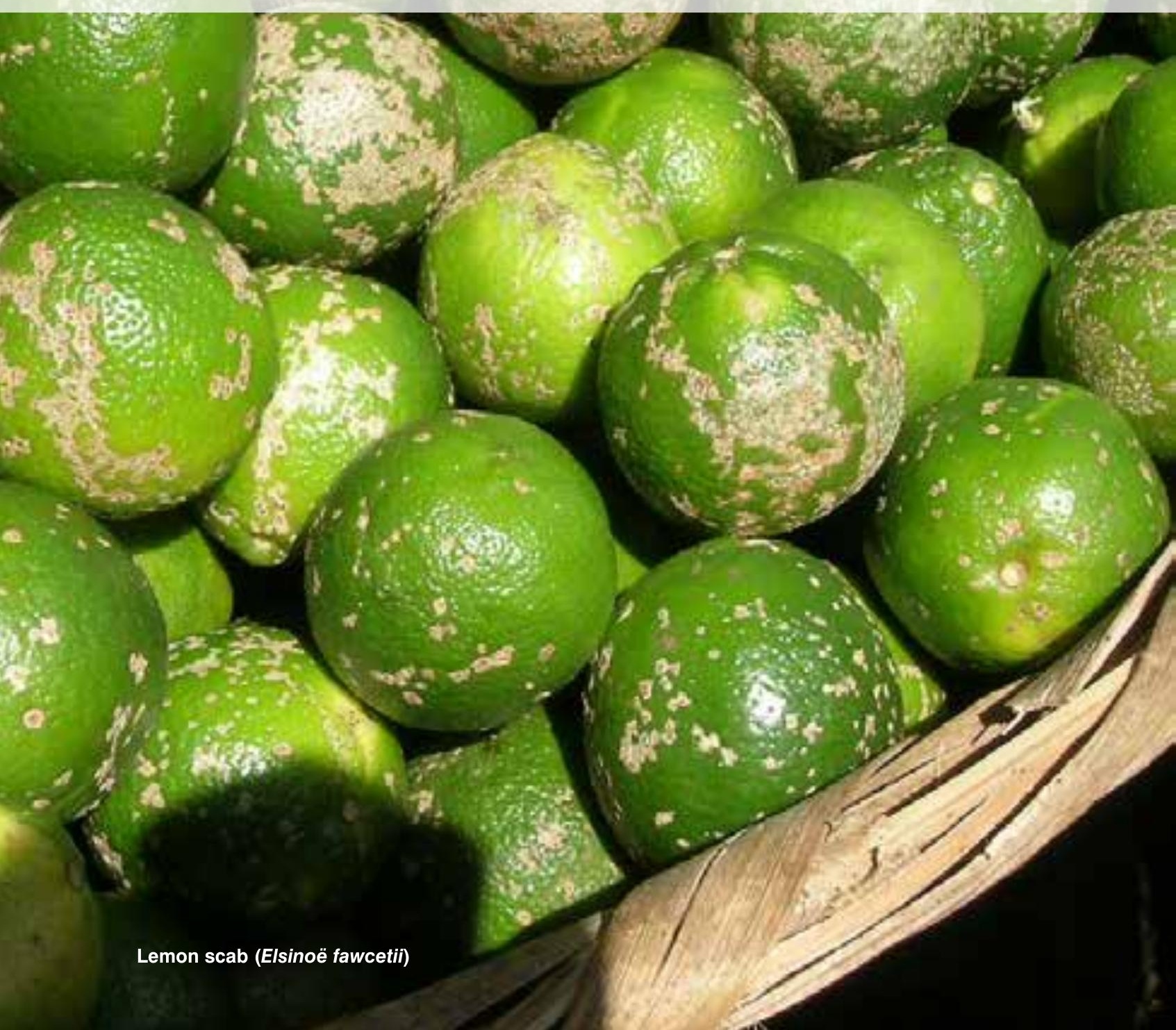




\section{History at a glance}

In July 2005, representatives of MAAIF, NARO, three district local governments, the Uganda National Farmers Federation (UNFFE), CABI's Global Plant Clinic, and three NGOs - Soroti Catholic Diocese Integrated Development Organisation (SOCADIDO), the Horticultural Exporters Association of Uganda (HORTEXA later replaced by Caritas) and Sasakawa Global 2000 (SG2000) - found themselves united in Kampala. This turned out to be the first planning meeting held in Uganda on the subject of plant clinics.

\section{The Global Plant Clinic}

The Global Plant Clinic (GPC) (2002-2010) was managed by CABI in alliance with the Food and Environment Research Agency (Fera) and plant clinic operators around the world. The GPC provided and coordinated plant health services in Africa, Asia and Latin America. It had an expert diagnostic service for all plants and types of problems and regularly published new disease records. The GPC trained plant doctors and scientists, established plant health clinics and strengthened plant health systems. It linked extension, research and farmers and worked with all sectors to improve regular and reliable access to technical support and advice. The aim was to create durable plant health services for those who need them most. Plantwise was established to considerably expand the clinics programme and provide a knowledge bank to support those clinics and the countries at a local, regional and national level.

(www.plantwise.org)

Box 3

The same year, the plant clinics in Uganda were borne out of the 'Pest Knowledge Partnership initiative' or PKPi, a collaboration between the Global Plant Clinic and MAAIF's Department of Crop Protection. Although plant clinics were something new to Uganda, it was a model that had been developed since 2003 in Bolivia, Bangladesh and Nicaragua. The Global Plant Clinic thought the plant clinic model would also suit Uganda as the extension services struggled to deliver efficient plant health advisory services to farmers within the current model. 'Mobile plant clinics' was the name used, meaning that the clinics were moved out of the office and set up in a public place; in practice these clinics always operated from the same location. 
Initially NGOs operated the plant clinics (i.e. coordination, budget allocations) with district local government extension staff functioning as plant doctors. Mukono, Iganga and Soroti districts were selected as the hosts of the first plant clinics as these three districts have different agricultural systems and differ culturally; the idea was to test the plant clinics in different settings. The clinics were meant to run twice a month in the markets of Nkokonjeru (Mukono district then but now Buikwe district), Kawete (Iganga district) and Katine (Soroti district). MAAIF was to have the role of coordination and supervision of the plant clinics.

\section{Milestones}

To ensure understanding and ownership by actors at different levels, MAAIF organized sensitization workshops throughout 2005 and 2006. The workshops targeted specifically the chief administrative officers, district agricultural officers and district production and marketing officers as they are responsible for district development plans and budgets. Other targeted stakeholders included NGO administrators, lead farmers and local communities. The aim of the workshops was to sensitize key stakeholders in the districts and to assess the needs and potential for plant clinics in Uganda.

Roles, guidelines and procedures to run the clinics were established in a workshop in 2006. By the end of 2006, there were four clinics running on a fortnightly basis. It took time for the first clinics to become operational as there was confusion about tasks, responsibilities, release of funds and organizational aspects of the plant clinics. Multiple aspects of clinic management needed to be sorted out. Clinics operated in a rather irregular fashion between 2006 and 2008. The Global Plant Clinic provided plant doctor training, technical backstopping and occasional follow-up visits to monitor progress. The Global Plant Clinic also provided a small grant to MAAIF to cover the operational costs of the clinics and travel and subsistence allowances for the MAAIF staff. This changed after some time and instead the Global Plant Clinic transferred the money directly to the NGOs operating the plant clinics. Within Uganda, the clinics were seen as a Global Plant Clinic project and were not yet institutionalized. The focus was on the four clinics running in the three districts and assigning roles and responsibilities. In this early phase, there were attempts to transfer responsibilities and coordination to the district local governments and to NGOs. Without the funds and the backstopping of the Global Plant Clinic, few activities were undertaken by the partners. Ultimately there was little collaboration with the NARO laboratories for diagnosis and limited feedback on the operations in the field. The loose arrangements between stakeholders were to blame for the lack of uptake among actors. 
The institutional landscape of Uganda did not leave space for actors to reflect or room for joint adaptation. The 'project mentality' around plant clinics in Uganda undermined ownership and the involvement of new partners; this was a severe limitation to the institutionalization of the plant clinics in Uganda. When the funds ran out in 2009, the activities of the plant clinics were interrupted (Danielsen and Mutebi, 2010). Activities resumed slowly in mid-2010 when funds started to flow again.
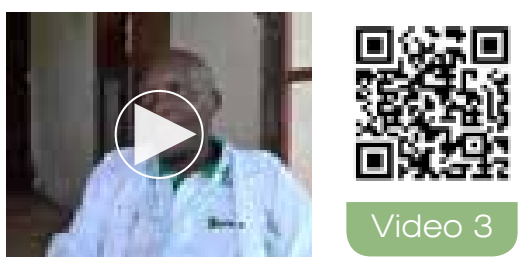

Video 3

"Since the ministry is also embracing the idea of plant clinics, I think it will go a long way to serve extension. I don't think it is going to cease tomorrow, it is going to continue. As I mentioned earlier, facilitation is decreasing every day, I don't think we are going back to the old system because it is generally expensive compared to the plant clinic system."

\section{Asaba Joseph Mercy}

plant doctor, Hoima
By 2010, the plant clinic pilot had attracted attention within MAAIF, which subsequently decided to include the plant clinics in the new five-year DSIP to strengthen disease control and surveillance. Even before the inclusion of plant clinics in the DSIP, however, there was appreciation and acceptance of the plant clinic model in Uganda. The model was also explicitly recognized at central administration level: since 2010 plant clinics have been eligible for funding under the Production and Marketing Grant.

Eventually, the inclusion of the plant clinics in the national pest and disease control programme demonstrated the government's acceptance of the plant clinics as an innovative way to deliver plant health services to small-scale farmers.
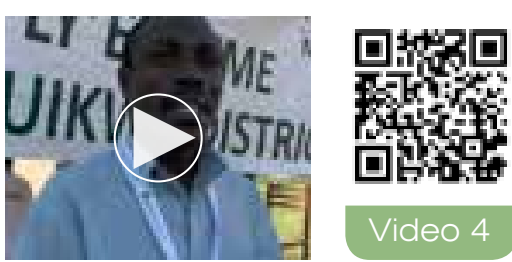

"These plant clinics, one of the areas that help us in is surveillance of pests and diseases. The plant doctors and extension workers are quite thin on the ground, we just can't be everywhere where we are needed. But with these plant clinics, definitely when a farmer sees something not familiar to him, he'll bring it to the plant clinics. And that could be an opportunity for us to see whether this is a new disease which has come up, or it's an old disease that has resurfaced. And we can only do that through these plant clinics."

\section{Luswata Kanakulya}

district agricultural officer, Buikwe 
This, combined with the lessons drawn from the Global Plant Clinic phase (2005-2010) and the launch of Plantwise, marked the start of new partnerships and events paving the way for greater national ownership of the plant clinics. Actions were taken to improve data management and exchanges between stakeholders, but much remains to be improved to ensure a continuous and responsive flow of information between institutions.

Renewed funding opportunities through Plantwise and the endorsement of plant clinics in the national strategy provided strong incentives for MAAIF and CABI to initiate discussions with Self Help Africa, NAADS and NARO about engaging with plant clinics. At subsequent sensitization and strategy meetings organized by MAAIF, the University of Copenhagen
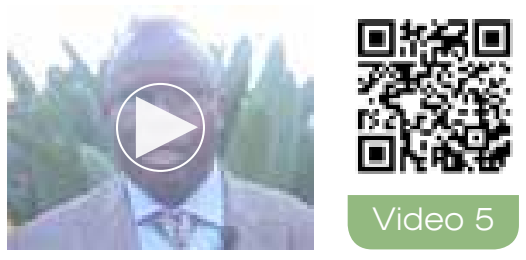

"Eric Boa visited our office and interested us in plant clinics, the cause of plant clinics. After we saw there was very big potential from plant clinics, Self Help Africa took it as a single project, as a project on its own which is funded independently by our donors Irish Aid. Self Help Africa got the information from $C A B I$, we took that information and wrote a proposal and it was funded by Irish Aid for us to implement plant clinics in Uganda."

\section{Misaki Okotel}

Self Help Africa and CABI in Mukono in March 2010, key players such as MAAIF, Makerere University and NGOs renewed their commitment to establishing plant clinics.

As a result of a CABI- and MAAIF-led plant doctor course including a training of trainers $(\mathrm{ToT})$ in 2010, additional plant doctors were trained in a number of new districts. Suddenly, 13 districts were running plant clinics and a number of other districts expressed interest in the model. Plantwise officially started in 2011, building on the Global Plant Clinic's experiences (Fig. 6). A stakeholder workshop was held in May 2011 by MAAIF, the University of Copenhagen and CABI to discuss the role of plant clinics in the decentralized extension services and pest and disease control programmes (Danielsen et al., 2012). Since 2012, we have witnessed an explosive expansion of the number of plant clinics and the number of districts covered in Uganda (Fig. 7). The strategy in 2012 was to build more ownership of the initiative among key stakeholders in the country. Awareness was very central to this strategy. Meetings bringing together district technical staff such as the chief administrative officers, district production and 
marketing officers, district agricultural officers and political leaders such as district councillors and secretaries for production were conducted in the Central, Eastern and Western regions and most recently in the Northern region to seek buy-in. Many of the people involved were unclear about plant clinics after reading about them in the DSIP. Some people thought the intention was to build permanent structures. However, these meetings increased understanding. Plantwise was showcased at agricultural shows especially the annual Source of the Nile Agricultural Show, which is attended by many people especially from the farming community. There was a demand from farmers in some districts leading to these districts asking for plant clinics to be established. A coordination team was set up with a National Steering Committee Chairman (Commissioner Crop Protection, MAAIF) who championed the initiative at any given opportunity. CABI staff spent a considerable time in the country to promote and support the initiative.

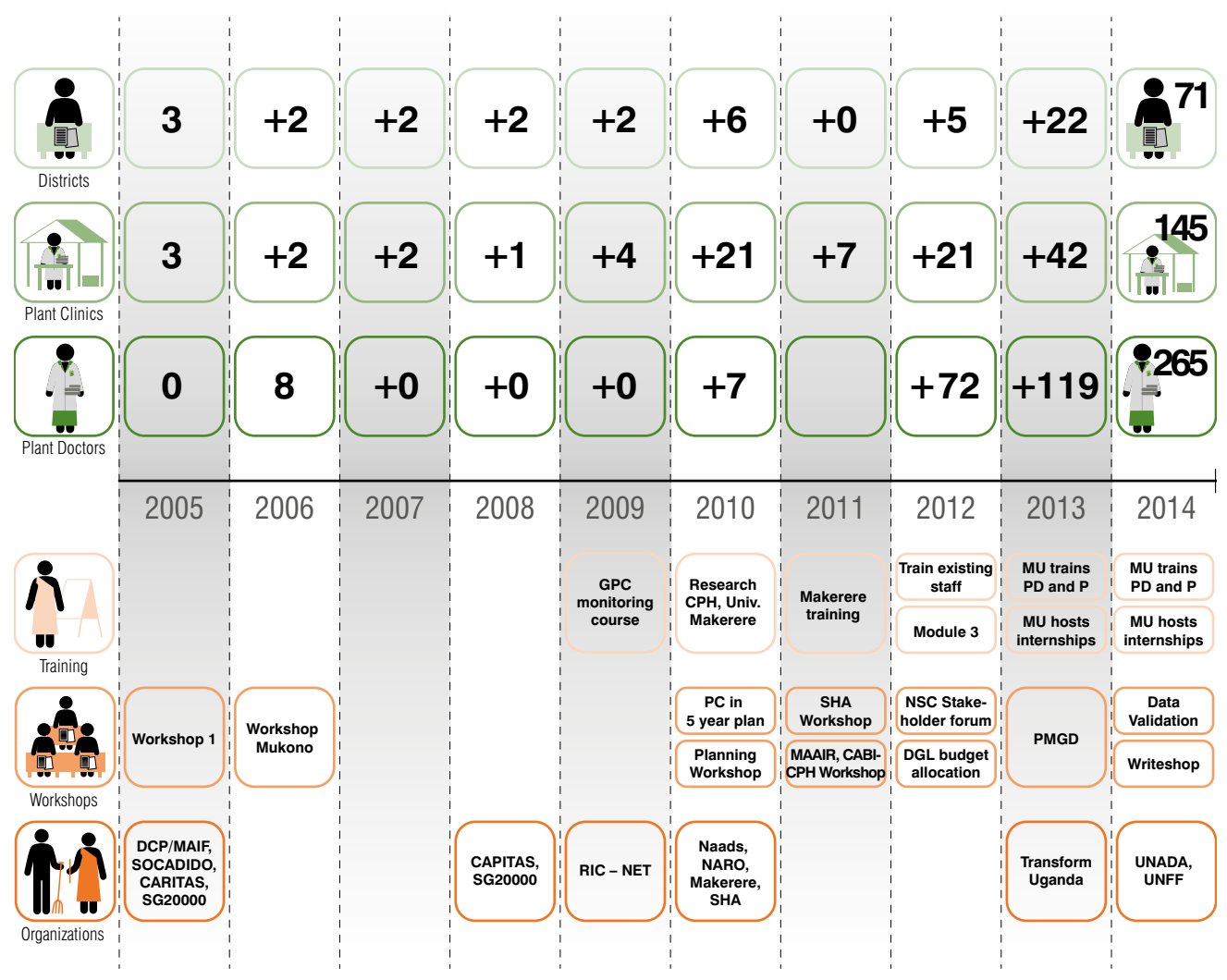

Fig. 6. Timeline of plant clinic history in Uganda 


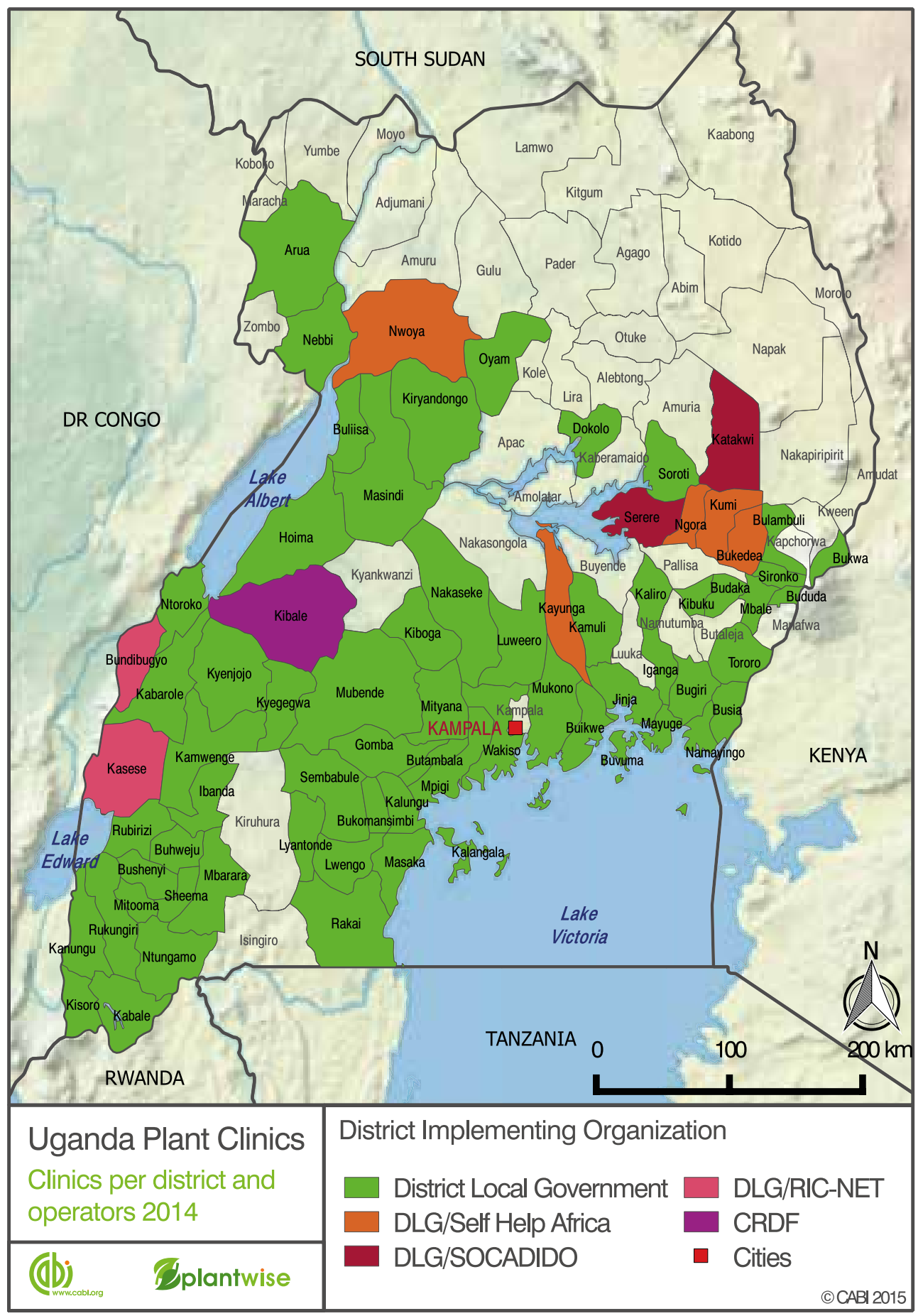

Fig. 7. Clinics per district and operators 2014 


\section{Where are we now?}

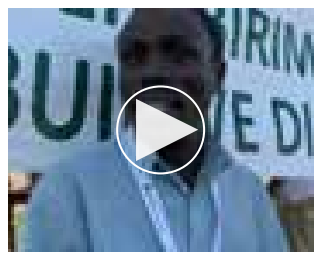

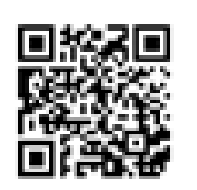

Video 6

"We now are able to reach more farmers, and to interact with farmers more than we used to. And the farmers are now quite responsive because when they get a problem on their farms, they know where to go, where to find us. In case a plant doctor is not able to operate on a particular day because of sickness, or some other commitments, I either come in and do it myself or get some other plant doctor who is not busy on that day, and he goes and operates there. So we try to make sure that the plant clinics operate on a routine basis."

\section{Luswata Kanakulya}

district agricultural officer, Buikwe

\section{Plant clinics}

Plant clinics are now established in four regions of Uganda: Western with 50 clinics, Eastern with 45 clinics, Central with 42 clinics and Northern with eight clinics (Table 4). The data management system is not yet able to provide information on how many of these 145 plant clinics are operational. Overall, there are plant clinics in 71 districts out of the total 112 districts in Uganda. The

\begin{tabular}{lll}
\multicolumn{3}{l}{ Plant clinics per district } \\
\hline Region & No. districts & No. clinics \\
\hline Central & 19 & 42 \\
Eastern & 21 & 45 \\
Northern & 6 & 8 \\
Western & 25 & 50 \\
Total & 71 & 145
\end{tabular}

\section{Table 4} plant clinics are run either by the district local government, or by NGOs, or by both in order to share the responsibilities of coordinating and making resources and staff available as plant doctors. Costs are estimated at approximately USD 37 per fixed clinic session with just one plant doctor in attendance (Table 5).

Costs are usually covered by the local implementing organization. 
Costs of running fixed and mobile clinics (USD)

Fixed clinic with... Mobile clinic with...

\begin{tabular}{lcccc} 
Cost item & $\begin{array}{c}\text { 1 plant } \\
\text { doctor }\end{array}$ & $\begin{array}{c}\text { 2 plant } \\
\text { doctors }\end{array}$ & $\begin{array}{c}2 \text { plant } \\
\text { doctors }\end{array}$ & $\begin{array}{c}3 \text { plant } \\
\text { doctors }\end{array}$ \\
\hline Allowances: Plant doctor & 4.80 & 9.60 & 9.60 & 14.40 \\
Nurses (2) & 8.00 & 8.00 & 0.00 & 0.00 \\
Announcement & 8.00 & 8.00 & 8.00 & 8.00 \\
Mobilization & 8.00 & 8.00 & 8.00 & 8.00 \\
Fuel & 8.00 & 8.00 & 16.00 & 24.00 \\
\hline Total & 36.80 & 41.60 & 41.60 & 54.40
\end{tabular}

\section{Table 5}

\section{Plant clinic operations}

The way plant clinics are operated differs from district to district and from clinic to clinic. In Part II of this working paper, the operations of five clinics are described in detail. Here, we limit ourselves to describing some of the aspects of the operations, including the operating organizations, and the users of the clinics.

\section{Number of plant clinics per plant clinic operator}

\begin{tabular}{lcccccc} 
Cost item & Central & Eastern & Northern & Western & Total & $\%$ \\
\hline $\begin{array}{l}\text { District local } \\
\text { government }\end{array}$ & 33 & 29 & 6 & 41 & 109 & $75.2 \%$ \\
$\begin{array}{l}\text { District local } \\
\text { government/ }\end{array}$ & 9 & 13 & 2 & & 24 & $16.6 \%$ \\
$\begin{array}{l}\text { Self Help Africa } \\
\text { SOCADIDO }\end{array}$ & & 3 & & & 3 & $2.1 \%$ \\
RIC-NET & & & & 8 & 8 & $5.5 \%$ \\
RIC-NET and district & & & & 1 & 1 & $0.7 \%$ \\
local government & 42 & 45 & 8 & 50 & 145 & $100 \%$ \\
\hline Total & & & & & & \\
\hline
\end{tabular}

Table 6 


\section{District local government as plant clinic implementing organization}

District local governments run the lion's share of the plant clinics $-75 \%$ of all clinics (Table 6). They are mandated to deliver agricultural services through NAADS and pest and disease control measures. District local governments bear the responsibility of translating national policies into local agricultural development plans, and drafting budgets and annual action plans based on local needs of farmers and farmer cooperatives. Plant health is an important component of agricultural services and plant clinics can be a promising way to expand the services offered at district level.

The start-up and operational costs of plant clinics are expected to be borne by district local governments, either through local revenues or through funding schemes from central government, including the Production and Marketing Grant. Unfortunately there are no data on how many plant clinics are actually exclusively funded by government funds. Awareness and buy-in from local government and politicians are essential to ensure the inclusion of plant clinics in district development plans and budgets. A number of key actors play a role in funding, coordinating and implementing plant clinics in the district. Box 4 provides an overview of the key actors within district local governments.

\section{Key actors within district local government and their roles related to plant clinic operations}

District production and marketing officer: Supports budget allocations and work plans, controls all budget allocation in the production department (agriculture, forestry, fisheries, veterinary and entomology)

District agricultural officer: Coordinates plant clinic activities and supervises plant doctors; develops work plans and budgets

District NAADS coordinator: supervises plant doctors (agricultural advisory service providers [AASPs] and sub-county NAADS coordinators)

Chief administrative officer: Chief accounting officer in local government and supports budget implementations for technical staff

Secretary for production: Supports budget allocations during sector committees, standing committees and council meetings, monitors and supervises plant clinic activities, lobbies for resources and mobilizes communities to attend plant clinic activities. 


\section{Non-governmental organization operated clinics}

In other cases NGOs have taken the full responsibility of running plant clinics under their extension-oriented programmes using their own resources. For instance, SOCADIDO, Self Help Africa and the Rwenzori Information Centres Network (RIC-NET) are running plant clinics in various districts of the country. Overall the NGOs run about $8 \%$ of the plant clinics. The mandates of SOCADIDO and Self Help Africa are food security and service provision strengthening in agriculture. Plant clinics are seen as an innovative tool to complement their activities. The NGOs main responsibilities are to coordinate the activities, release the funds for the operation of the clinics, mobilize farmers and identify plant doctors and plant nurses. They also mobilize funds from donors to operate plant clinics within their mandates. They make use of their established network of farmers, farmer groups and stakeholders in the communities to establish trust and mobilize farmers. They also combine the plant clinics activities with complementary activities run under different projects.

\section{Government and non-governmental organization jointly operated plant clinics}

In most cases, the NGO operated plant clinics are run by plant doctors from local government. The first clinics initiated in 2005 were operated under this model. In the mixed approach to management, the NGO coordinates the implementation and the funds and raises awareness through publicity activities, while plant doctors from local government or NAADS provide the technical capacity not always readily available among NGO staff. Twenty-five out of the 145 (just over 17\%) plant clinics now run under the mixed model. In the past, however, clinics that operated under a mixed model experienced setbacks with limited ownership by operators or with clinic coordinators changing positions, leaving the clinics without clear procedures to continue their operations (Danielsen and Mutebi, 2010).

\section{Plant doctors}

Plant doctors are selected and trained staff from either local government extension, NAADS or NGOs. In district local government clinics, two staff members are usually proposed for the training. They receive formal training as plant doctors from Plantwise. Agricultural extension topics are usually not new to the doctors-to-be; most are extension workers or NAADS service providers. Plantwise provides training via a number of different modules: 
- Module I: Field diagnosis and running plant clinics

- Module II: Plant healthcare

- Data management

- Production of extension materials

- Monitoring plant clinic performance training

Modules I and II are both essential training for plant doctors. Data management training is designed for data managers, supervisors and all plant doctors. Training on production of extension materials is concerned with writing factsheets and pest management decision guides. The course targets subject matter specialists such as research officers and university lecturers, although experienced extension staff including plant doctors who are good at technical writing are also included. Monitoring plant clinic performance training is given to clinic supervisors such as district agricultural officers, $M \& E$ officers of NGOs running plant clinic activities, and university staff teaching in departments of extension. It also includes some plant doctors.

The trainers are either CABI staff or trained technical experts from the MAAIF Department of Crop Protection, Makerere University and NARO.

Currently most of the plant doctor training is carried out by local extension staff trained in the first ToT, working alongside one CABI staff member (the country coordinator). Selected participants of a training course are invited to be trainers in subsequent training sessions. This is perceived as a way to build and improve local capacity and ensure the sustainability and institutionalization of plant doctor training. Plantwise has also been working with Makerere University since 2013 to ensure that it eventually handles training of plant doctors. Plantwise is by far the largest funder of training while Self Help Africa has contributed $14.4 \%$ to training efforts. Almost $24 \%$ of the plant doctors trained so far have been women
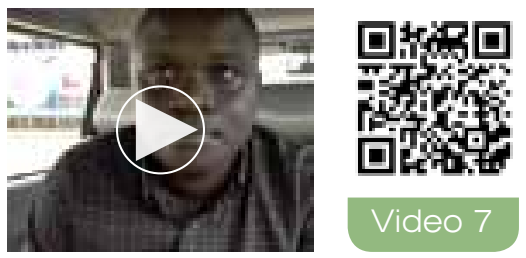

"The biggest challenge and the most sought advice from extension workers is on plant health. The biggest benefit has been on capacity building and training of plant doctors. This is very specialized training that we are given in plant health care under the Plantwise initiative."

\section{Oruka David}

NAADS, Kampala (Table 7). 
The number and percentage of plant doctors trained per funder

Women

Men

Total

\begin{tabular}{lllllll}
$\begin{array}{l}\text { Plant doctors } \\
\text { trained per funder }\end{array}$ & Number & $\begin{array}{c}\% \text { of } \\
\text { total }\end{array}$ & Number & $\begin{array}{c}\% \text { of } \\
\text { total }\end{array}$ & Number & $\begin{array}{c}\% \text { of } \\
\text { total }\end{array}$ \\
\hline Global Plant Clinic & 1 & $0.4 \%$ & 14 & $5.4 \%$ & 15 & $5.8 \%$ \\
NAADS & 1 & $0.4 \%$ & 12 & $4.7 \%$ & 13 & $5.1 \%$ \\
Plantwise & 50 & $19.5 \%$ & 142 & $55.3 \%$ & 192 & $74.7 \%$ \\
Self Help Africa & 9 & $3.5 \%$ & 28 & $10.9 \%$ & 37 & $14.4 \%$ \\
\hline Total & 61 & $23.7 \%$ & 196 & $76.3 \%$ & 257 & $100.0 \%$
\end{tabular}

\section{Table 7}

Although the plant doctor training is thorough and teaches a systematic process of 'diagnosis by elimination', plant doctors are sometimes left perplexed, with little idea about the problem in front of them. When the plant doctor does not know what is affecting the crop, it is possible to send the sample to the NARO, Makerere University and MAAIF laboratories for further examination.

Plant doctors are equipped with a plant clinic kit which comprises a branded tent, tables, chairs, two branded t-shirts and cap, lens, dustbin, Swiss army knife, ten prescription and record books, two logbooks and factsheets (Fig. 8). The kits are mainly provided by Plantwise or MAAIF through the Department of Crop Protection. However, some NGOs such as Self Help Africa and district local governments also purchase these kits as a part of their expansion programmes. The factsheets give information on specific crops, pests and diseases, and
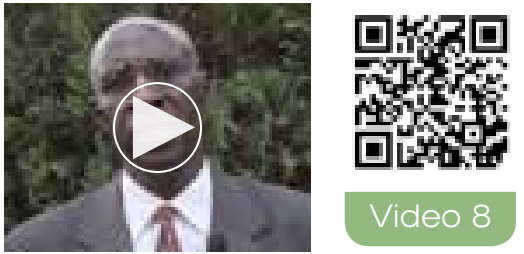

"We have a referral system where the samples are sent to the laboratory and quickly the laboratory does the diagnoses, produces the results and we give the feedback to the farmer. So it is really an extension tool that helps to back up the staff in local governments and belps to support the farmer in control of pests and diseases."

\section{Komayombi Bulegeya}

commissioner crop protection, MAAIF 
plant doctors are provided with the ones covering the major problems affecting crops in the areas in which these plant clinics will be operating. The factsheets are either generated through the training on extension materials or are downloaded from the Plantwise Knowledge Bank.

\section{Plant clinic users}

Plant clinic attendance is not regulated by membership, crop, residence, age or gender; plant clinics are open to anyone who wishes to attend. So who are the farmers that attend the plant clinics? And why are others not attending? There could be various reasons including cultural roles, operating time and distances to the plant clinics.

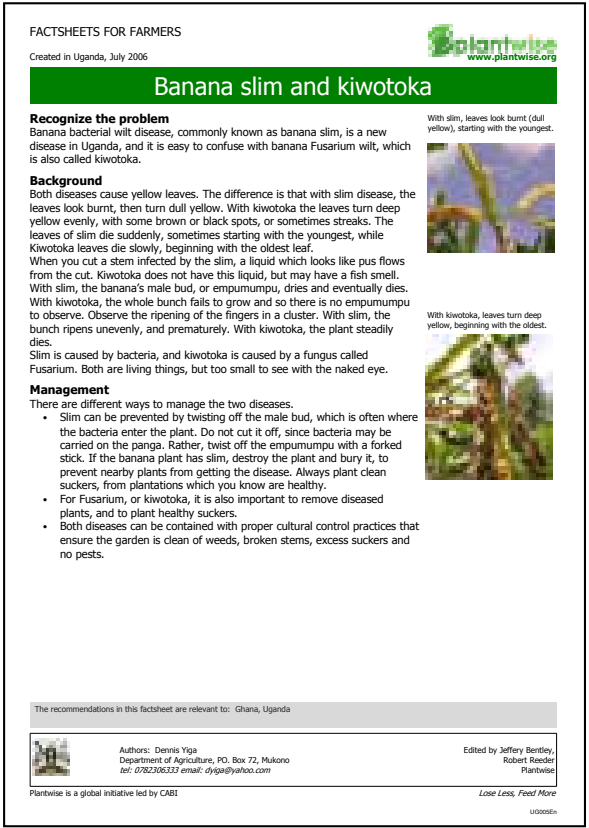

Fig. 8. Factsheet for farmers

Nearly half of the clinic users are between 36 and 50 years old, while $22.5 \%$ are young farmers (under 35 years), and over a quarter are above 50 years old. In Western Uganda clinic users are relatively young with $30 \%$ of young farmers and less than $20 \%$ older than 50 years (Table 8).

Plant clinic clients' age groups

\begin{tabular}{lllll}
\hline Age groups & Central & Eastern & Western & Total \\
\hline $\begin{array}{l}35 \text { years old } \\
\text { and below }\end{array}$ & $17.0 \%$ & $23.4 \%$ & $29.3 \%$ & $22.5 \%$ \\
$\begin{array}{l}36-50 \text { years old } \\
51-65 \text { years old }\end{array}$ & $24.8 \%$ & $39.4 \%$ & $51.5 \%$ & $48.2 \%$ \\
$\begin{array}{l}66 \text { years old } \\
\text { and over }\end{array}$ & $7.1 \%$ & $30.9 \%$ & $16.2 \%$ & $23.7 \%$ \\
\end{tabular}

\section{Table 8}


While anyone from any village can attend plant clinics, distance is often a decisive factor when deciding whether or not to visit a clinic. The survey conducted in 2013 showed that the distance between the plant clinics and their users is the smallest in Central and Western regions: 49\% and 44\% of the clinic users, respectively, live within $1 \mathrm{~km}$ of the plant clinic. In Eastern region, $80 \%$ of clinic users have to travel more than $1 \mathrm{~km}$ to get advice and $24 \%$ more than $5 \mathrm{~km}$. In Western region, only $8 \%$ of the users reported having to travel more than $5 \mathrm{~km}$ to reach the plant clinic (Fig. 9). In Central region, the number travelling this distance is $17 \%$. Most of the plant clinics target farmers at sub-county level. The size of a sub-county varies but, based on the figures above, we can conclude that in Eastern Uganda farmers are willing to travel much further than farmers in Western or Central Uganda. The reasons behind this remain unknown: is it because populations in Eastern Uganda are less dense and so people already travel further to reach markets since they are more dispersed? Or because there are far fewer options close by to access plant health information? Or perhaps there are more clinics in Central and Western Uganda meaning that farmers do not need to travel so far.

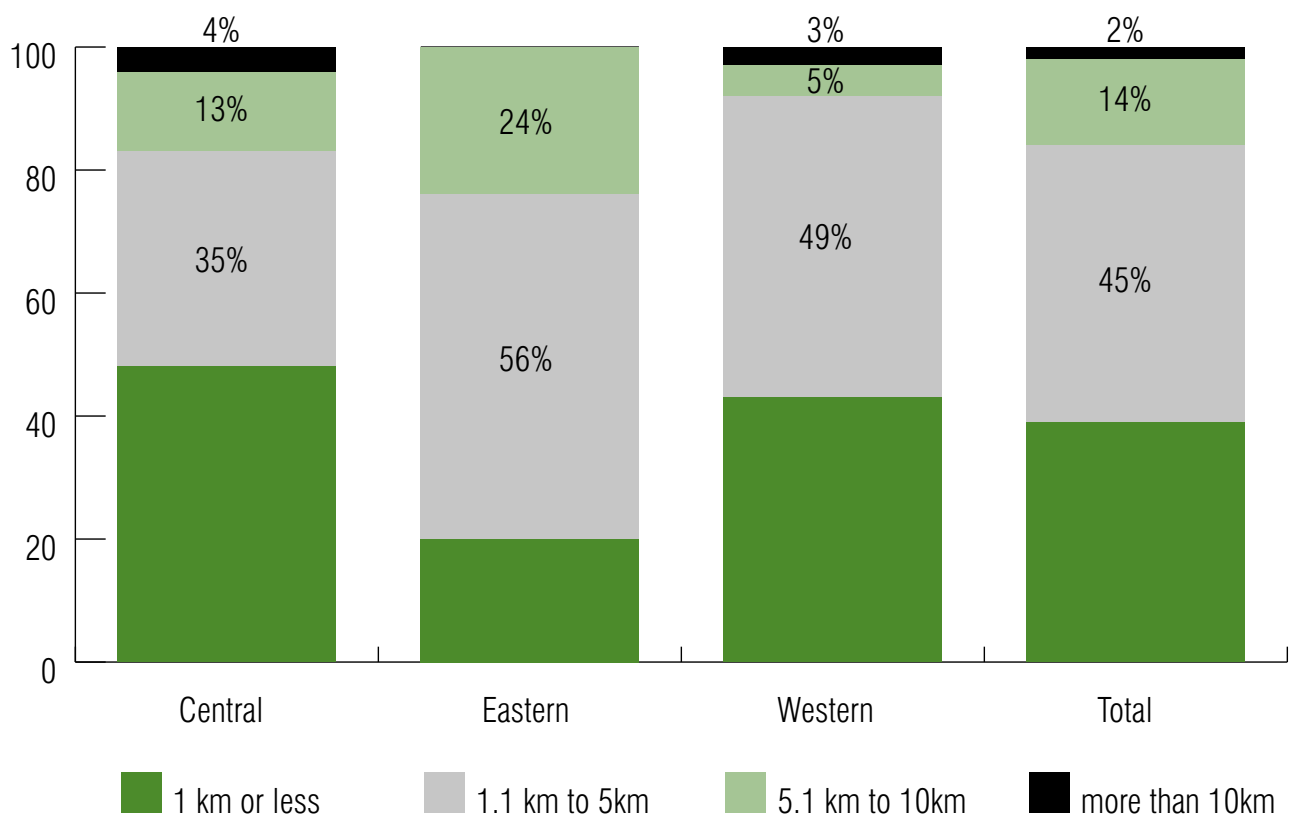

Fig. 9. Distance farmers travel to plant clinics 


\section{Plant health information sources}

Smallholder farmers in Uganda access plant health information from various formal and informal sources. For many smallholder farmers, informal sources such as family, friends and neighbours and lead farmers are very important: they are easily accessible and available in the communities. Others rely on private actors such as the agro-

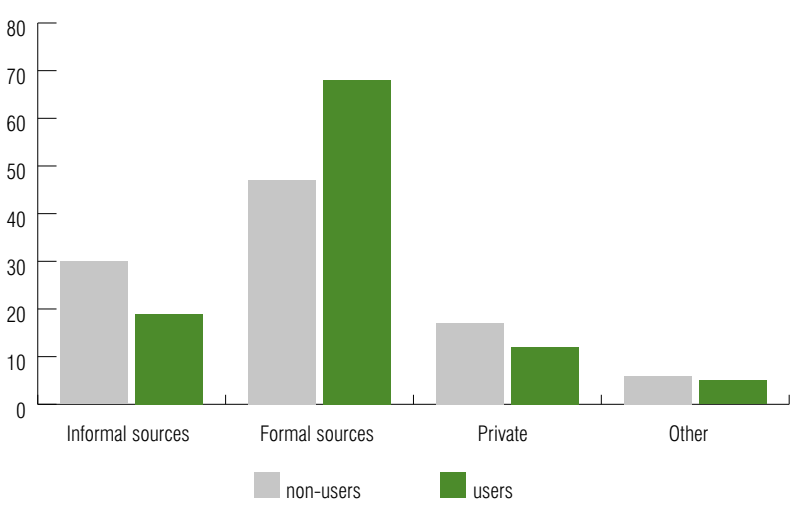

Fig. 10. Sources of plant health information accessed by clinic users and non-users input dealers. Some farmers are better connected to formal sources such as government extension services and NGO programmes. Farmers use different strategies to access the information they require at different times and for different needs and purposes. The 2013 survey conducted among users and non-users of plant clinics showed that while government extension is the first source of information for nearly a quarter of the famers, along with other formal sources such as field days, non-users also rely heavily on informal sources of information (family, friends, neighbours, lead farmers) as well as on agro-input dealers. Both groups seem to have similar access to lead farmers and local leaders as a source of information (Fig. 10). Overall, plant clinic users mostly rely on formal sources (government and non-governmental extension, community-based facilitators [CBFs]) for information on plant health. This suggests that there are some fundamental differences between users and non-users: people that use formal sources are more likely to access plant clinics. During the M\&E workshop held in August 2013, participants concluded that women, the poor and farmers that were not market-oriented are more likely to rely on informal sources. This suggests that these categories are less likely to access plant clinics.

Overall, more than $50 \%$ of the non-users interviewed did not know about the plant clinics (Fig. 11). This might be due to poor publicity but also because they rely more on informal sources of information on plant health. Many plant clinic users are wellconnected to NGOs and government extension agents; i.e. the plant doctors and operators of the clinics. A fifth of the users across the three regions had been informed about the plant clinics directly by the plant doctor. 
Additionally, there are some misconceptions among nonusers about who can attend plant clinics: a common perception is that plant clinics are there for members of NAADS groups only when it is a governmentrun clinic, or for members of NGO-established groups when an $\mathrm{NGO}$ is operating the plant clinic.

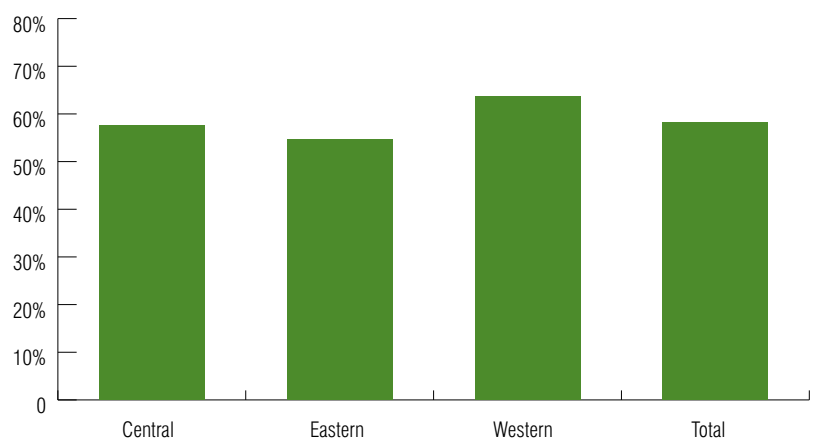

Fig. 11. Percentage of non-users that know about the plant clinic

The most widely used communication tool to inform farmers about plant clinics in Western region is the radio. In comparison, radio is rarely used in Central, where it is considered less effective; instead, the plant doctors, local leaders and lead farmers are the most significant agents to provide information about plant clinics.

Megaphone announcements are also considered a good means of communication in Eastern and Central Uganda, as are churches/mosques as people meet and exchange news and information. Announcements for clinic sessions can be made in churches/ mosques and sometimes someone may use a megaphone and move around the subcounty, parish or village announcing an upcoming plant clinic session. During a plant clinic session at markets, sub-county headquarters or community centres, plant doctors use a megaphone to remind market goers or community members of the ongoing session.

\section{Why do farmers visit the plant clinics?}

Rarely do farmers just accidently stumble upon a plant clinic and benefit from its services. In nearly all cases (94\%) they had the intention and made the conscious decision to visit the clinic.

Farmers seek advice about both cash crops and food crops at the clinics (Table 9 for the top crops brought to the clinics in Central and Eastern Uganda). 
Main crops for which farmers seek advice (Central and Eastern Uganda)

\begin{tabular}{llll}
\hline Age groups & Central & Eastern & Western \\
\hline Orange & $2 \%$ & $41 \%$ & $17 \%$ \\
Cassava & $22 \%$ & $6 \%$ & $17 \%$ \\
Banana & $19 \%$ & & $13 \%$ \\
Maize & $15 \%$ & $7 \%$ & $12 \%$ \\
Coffee & $15 \%$ & & $10 \%$ \\
Groundnut & $5 \%$ & $10 \%$ & $7 \%$ \\
Tomato & $6 \%$ & $9 \%$ & $7 \%$ \\
Bean & $8 \%$ & $3 \%$ & $7 \%$ \\
Cowpea & & $7 \%$ & $3 \%$ \\
Rice & & $5 \%$ & $3 \%$ \\
Sweet potato & $3 \%$ & $2 \%$ & $2 \%$ \\
Sorghum & & $6 \%$ & $2 \%$ \\
(Source: MAAIF plant clinics database. Statistics for 2014) & \\
Table 9 & &
\end{tabular}

Farmers bring samples of affected crops to the clinics (Fig. 12). Just as in human health clinics - seeing the patient allows for a more accurate diagnosis. The plant doctor, equipped with his/her dissection kit and factsheets, can diagnose and advise farmers accordingly. The plant doctor might refer the farmer to another service provider or may recommend a treatment.

Financial and labour constraints are part of the reason why farmers do not follow the plant doctor's advice.

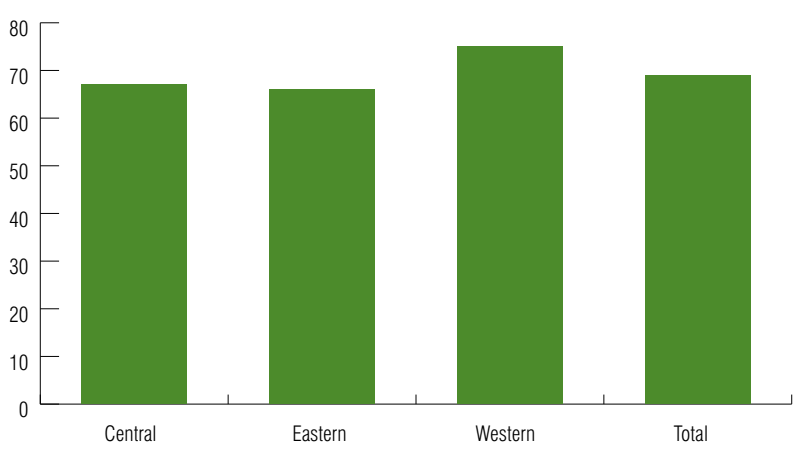

Fig. 12. Farmers who bring a sample to a plant clinic 
In other cases, a lack of information on where to buy the required products is an issue. Nevertheless, when the advice is followed fully, farmers have reported largely positive outcomes, which have helped them solve the problem for which advice was sought in the first place. Sometimes the plant doctor perceives that it might be necessary to follow up in person by phone with the farmer. They can offer this option when they think it would be useful; but in reality this practice is very limited owing to the lack of time and resources.
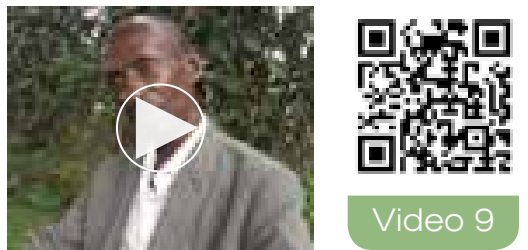

Video 9

"Farming is getting better, but we have the challenge of buying pesticides, herbicides and seed varieties. The doctors are advising us, but we find it hard to get the money to do what they advise us to do."

\section{Kyamanywa Livingstone}

farmer, Hoima

Farmers reported sharing information with various people in their locality (Fig. 13). It is rare for a farmer not share the advice received with anyone. A third of the farmers reported that they shared information with their neighbours. In all likelihood their neighbours cultivate the same crop. A lower rate of advice sharing between wives and husbands can be related to the fact that, in most households, women are responsible for certain crops and the men another set of crops.

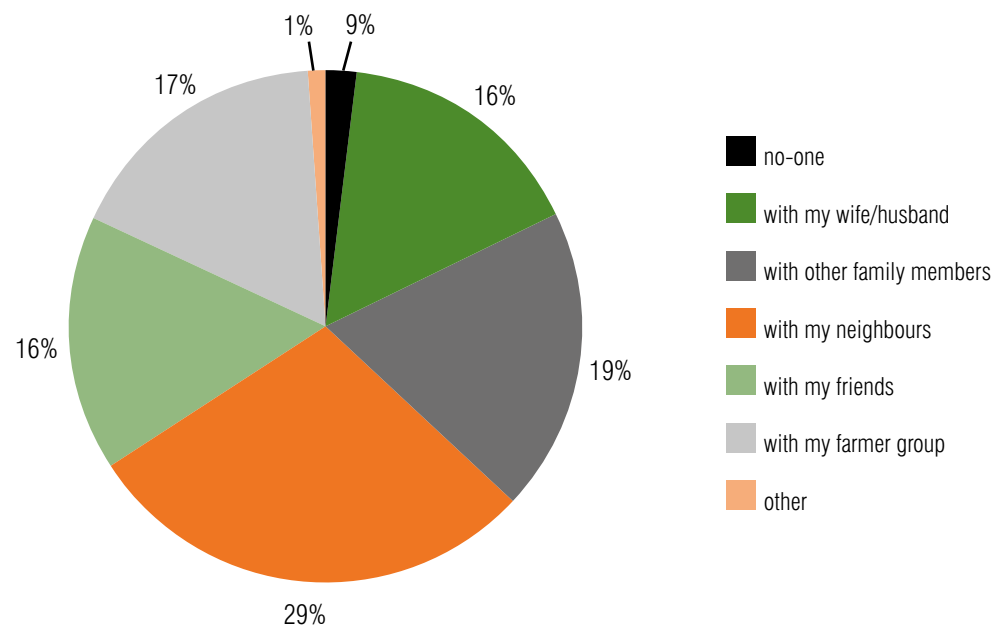

Fig. 13. How farmers share the advice received at the plant clinic $(n=596)$ 


\section{The Plantwise Online Management System}

Prescription forms are the dedicated instrument for plant doctors to write down advice for clients. The idea is that, for each attending farmer, the plant doctor fills in a prescription form (Fig. 14). The prescription form captures the details of the farmer, the crop brought to the clinic, the diagnosis and the proposed solution. Farmers are given a copy of the form.

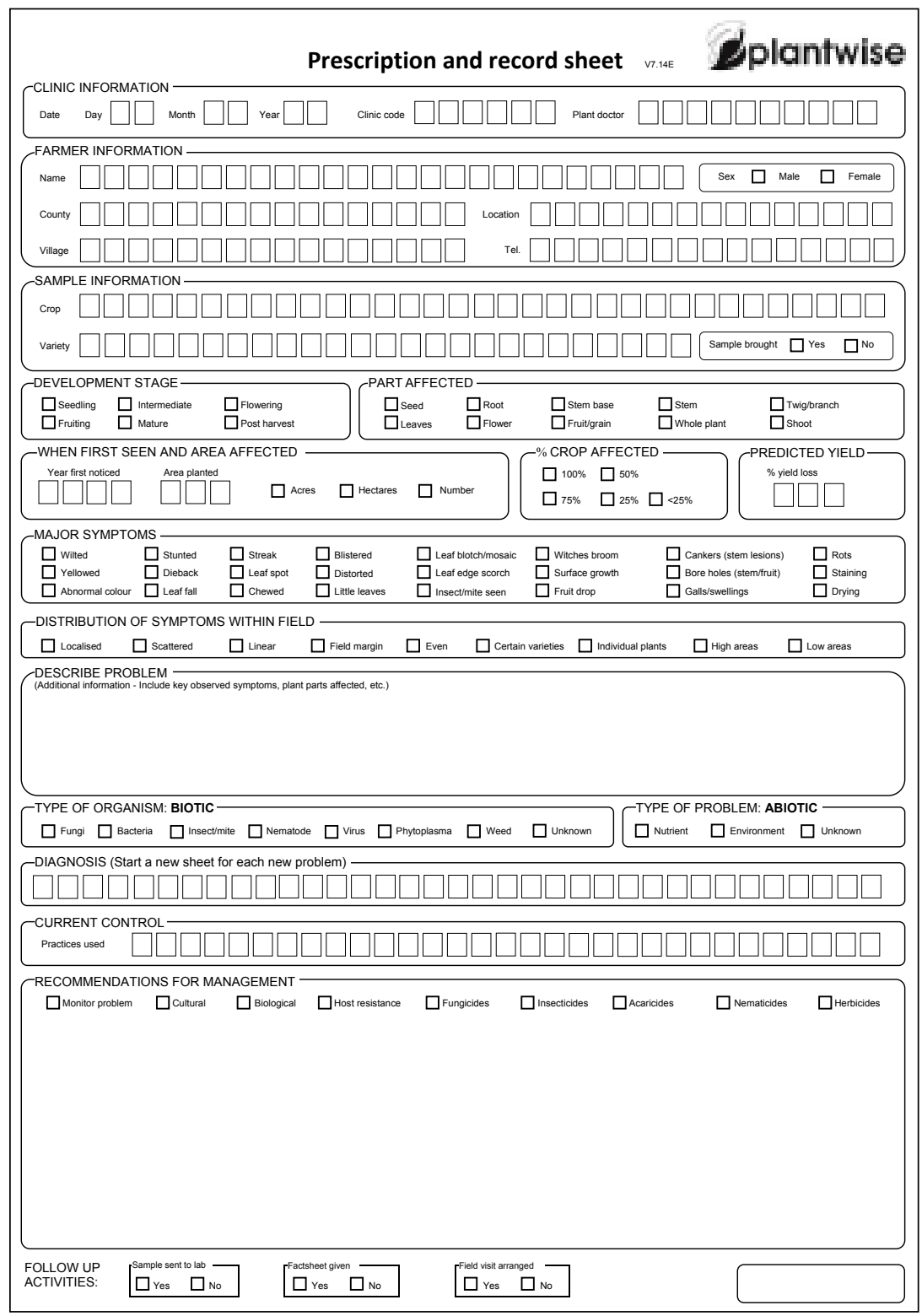

Fig. 14. The plant clinic prescription form 
A second copy is kept by the implementing organization and a third copy is send to MAAIF. MAAIF is expected to feed the data into the POMS, which is part of Plantwise's global Knowledge Bank. The data are also fed into Uganda's national pest and disease monitoring system. Data from NGOs are delivered directly in electronic form to the MAAIF data manager. A technical team comprising pathologists, extension advisors and plant doctor trainers from NARO, Makerere University and MAAIF carries out the validation of the data. There appear to be a number of constraints in using these forms. In Chapter 6 we will discuss these limitations.

\section{Plant doctor conferences}

'Plant doctor conferences' or 'cluster meetings' are part of the monitoring system for plant clinics. They help improve plant clinic operations through eliciting feedback from plant doctors, thus ensuring quality advice to the farmers. They are a crucial feature, allowing plant doctors to come together and reflect on and discuss their practices. This can stimulate improvement and adaptation of operations to the local context. The meetings are organized by MAAIF and CABI and so far have been funded by Plantwise.

Cluster meetings are organized with the following key objectives:

- To obtain information from stakeholders on the status of plant clinic operations.

- To elicit suggestions from plant doctors on how plant clinic operations can be improved.

- To gather information about the location of plant clinics and the respective plant doctors who run them.

- To capture success stories resulting from the advice given to farmers through plant clinics.

During the meetings the plant doctors from various districts make presentations on the status of plant clinics in their respective districts, the challenges, suggestions for improvement and success stories resulting from advice given to farmers. So plant doctors can share their experiences, the districts represented at a meeting are usually clustered on the basis of geographic location. So far a total of three cluster meetings have been held, in Eastern, Western and Central regions. 
Sulayiman Mulindwa attended the last plant doctor cluster meeting in Kabarole district (Western region) in November 2013.

"We were about 40 plant doctors invited by MAAIF to attend the meeting to share experiences as plant doctors. We realise that we share similar issues. For example, transport of the plant doctor and equipment is difficult and costly in comparison to the allowance provided. And as the plant clinic is sometimes far from the farmers' fields, logistics and costs to offer in-field follow-up are not covered by the allowances. The plant clinic location at sub-county level and infrequent operations make it more difficult for women to attend plant clinics. It would be better to have clinics at parish level, but this means more costs and more logistics.

\begin{abstract}
"There were also some learning points we automatically put in practice when we were back in the district, for example, bringing some chemicals to the clinic to showcase to the farmers the appropriate products, and provide information on dosage, use, protective measures and expiry date. By doing so, farmers avoid buying counterfeit products and we build our relations with agro-input dealers. Some of our nurses are also dealers and can provide very useful information to the clients. Another important learning was that we do not have to wait for farmers to bring samples of infected crops. Ourselves, we can bring some infected samples from neighbouring fields to facilitate the identification and diagnosis of plant diseases, especially in cases where farmers do not bring samples."
\end{abstract}

Sulayiman Mulindwa - plant doctor, Hoima district

\title{
It's an emergency! Plant health rallies and other approaches for rapid delivery of plant health messages
}

Plant doctors are faced with a large number of cases of the same pest or disease. Sometimes the high prevalence of an issue may raise an alarm and the plant doctor decides that it is necessary to take action and alert a large number of producers before the affected crop(s) suffer irreversible damage. Plant health rallies are a good way to spread the extension messages to a wider audience than just those who attend plant clinics. Rallies are also an attempt to enable extension workers to convey important plant health information to the farmers in the shortest time possible, but their effectiveness remains to be measured. 


\section{Once the alarm is set off:}

First, a preparatory meeting to pave the way for the rally is conducted with key stakeholders, i.e. district agricultural officers, officials from the MAAIF Department of Crop Protection, NAADS, NARO, NGOs, selected district local governments and CABI.

Second, the team confirms the problems to be addressed during the rally and completes plans for it, i.e. routes, dates and teams, and generates materials.

Third, the technical team conducts other preparatory meetings to identify and locate materials required for the rally, such as megaphones, photo sheets, factsheets (full and mini factsheets).

Fourth, the rally is announced and farmers are mobilized.

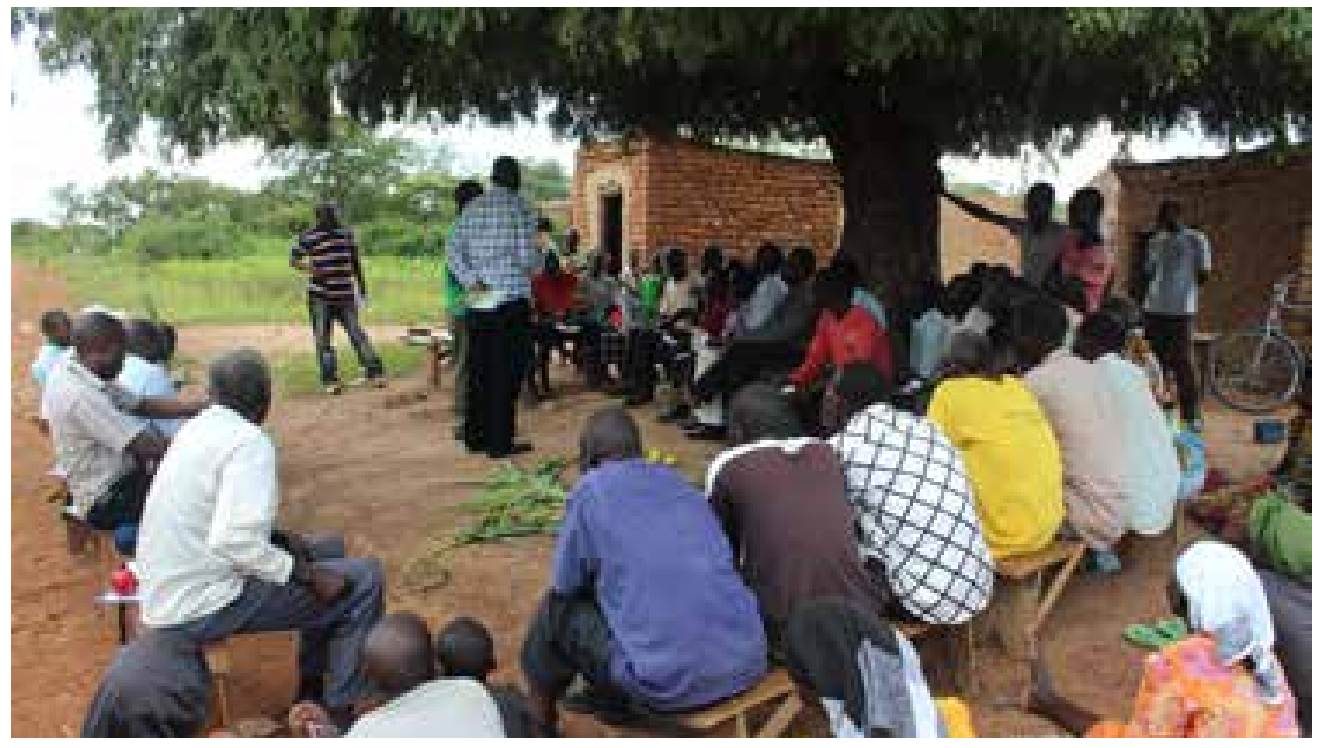

As of June 2014, a total of 16 plant health rallies had been conducted in five districts in Eastern Uganda (Bulambuli, Bukedea, Kumi, Serere and Soroti) with CABI funding. A team of technical staff from CABI, NAADS, MAAIF and NARO was joined by local extension officers and district agricultural officers in their respective districts. The rallies have addressed major crop pest and disease problems including banana bacterial wilt, groundnut rosette disease, citrus fruit and leaf spot, and cassava brown streak disease. 
The rallies were held in various locations, from sub-county headquarters to village centres, trading centres and markets. Two radio talk shows were hosted on Open Gate FM (Mbale) and Etop Radio (Soroti) on the day of plant health rallies to introduce the topics that were to be addressed and sensitize a wider audience. After the plant health rallies, feedback from the audience was collected using a predesigned short questionnaire. An estimated total of 1026 people attended the rallies across the five districts and a total of 109 feedback questionnaires were collected.

"Asuret sub-county is located in the southern part of Soroti district. It's one of the three areas where plant health rallies were conducted in Soroti district. The major crops in the sub-county include oranges, groundnuts, cassava, sorghum and millet. Asuret sub-county does not have a plant clinic. The nearest plant clinic is located in Arapai cattle market, about $7 \mathrm{~km}$ away. The plant health rallies were held on the roadside at the trading centre near the sub-county headquarters on the 30th May 2014.

"Led by Mr Amuriat John Michael, the extension worker of Asuret and plant doctor, the team addressed various plant health concerns from farmers during the rally. These included citrus fruit fly, citrus fruit and leaf spot, groundnut rosette, cassava brown streak disease. The total number of farmers that attended the rally was 66 farmers (44 male and 22 female).

"Farmers said they were mobilized on short notice hence few farmers got the information about the rally. Since the rally was at the roadside, it nevertheless managed to address concerns of farmers from other subcounties who were on their way to town or other places. Some farmers thought it was a political rally and therefore expected some money. Others asked for the establishment of a plant clinic in the sub-county to address their problems since the clinic in Arapai is very far from them."

Benius Tukahirwa - Agricultural Inspector, Plant Quarantine 
Although rallies are a promising approach, the system is currently not sufficiently responsive to emerging threats. Rallies take time to organize and are currently still heavily dependent on CABI funding. In Kabarwa, although pressing issues had been identified at the plant clinic, the rally was postponed for several months. When outbreaks occur, it is crucial that information is delivered in a timely manner. This is not yet the case. In addition, attendance remains low. More action is necessary to mobilize and raise awareness about pests and diseases among farmers.

\section{References}

Danielsen, S. and Mutebi E. (2010) The Introduction of Mobile Plant Clinics to Uganda: First Results and Lessons Learned 2005-2010. Working Paper 1. Centre for Health Research and Development (DBL), University of Copenhagen, Copenhagen.

Danielsen, S., Masiko, F., Mutebi, E. and Karubanga, G. (2012) Second Generation Plant Health Clinics in Uganda: Measuring Clinic Performance from a Plant Health System Perspective 2010-2011. Working Paper 2. Centre for Health Research and Development (DBL), University of Copenhagen, Copenhagen. 

4

\section{Plant clinic adaptations}

By Geneviève Audet-Bélanger, Remco Mur and Joseph Mulema 
The ways in which plant clinics operate, are managed and integrated into the wider plant health system, and become part of policies, procedures and routine practices depend on many factors, including the agro-ecological, policy, institutional and socioeconomic environment. These factors differ from county to county, district to district and plant clinic to plant clinic. The process of establishing performing and effective plant clinic services requires local adaptation, e.g. looking for creative ways to make the best of scarce resources to reach as many people as possible and create synergies with other activities. New ways of operating plant clinics have been tried in the attempt to reach more farmers, reduce the plant doctor workload and improve the quality of the services to clients.

Several examples of local adaptation are described in Part II of this working paper, including using plant nurses and change agents to enhance the reach of plant clinics and compensate for staff scarcity, partnering with farmers' associations to deliver a daily plant clinic service, and using a mobile scheme to cover a larger area. Another adaptation (in Hoima) is delivering advice to groups rather than individuals to minimize waiting time when the turnout is high. A new idea from Hoima, which remains to be implemented, is to establish animal clinics in connection with the plant clinics and use the NAADS livestock agricultural advisory service providers (AASPs) as service providers. In addition, communication, mass media and ICT are playing an increasingly important role in disseminating information. Knowledge and experience sharing among plant doctors and other stakeholders is essential for plant clinics to evolve and adapt to their clients' needs.

\section{"I look also at using the experience of the plant health clinics to bring. up mobile livestock clinics. Actually we are thinking about conducting parallel sessions as this one is plant health clinic, our livestock officers could around the same place conduct a livestock clinic. Farmers also have had challenges of getting these services. That would address the one health approach."}

\section{Charles Kajura - District Production and Marketing Officer, Hoima}

In some districts, clinic sessions are held on field days alongside the NAADS activities to enhance visibility and create awareness among the policy and decision makers. There are also examples of plant nurses from Buikwe mobilizing the community for plant clinic activities through community functions such as funeral rites, wedding ceremonies, church meetings and other informal community gatherings. Some communities in Buikwe use home-grown ways of creating awareness about community 
events, including plant clinics. For example, in Goli village, Najja sub-county, a mobilization drum, locally called 'Sagala Agalamidde', is kept by the chairman and used to alert the community about new initiatives. In this chapter, we discuss some of the adaptations.

\section{An overview of some of the plant clinic adaptations}

\section{See the nurse first...}

Plant clinic operations are often the responsibility of a single plant doctor. But what if five farmers suddenly show up within 15 minutes, all equally eager to receive attention? The plant doctor wants to satisfy the needs of all. Because the plant doctor cannot attend to everyone all at once, some clinics have started to work with plant nurses - as in human health clinics.
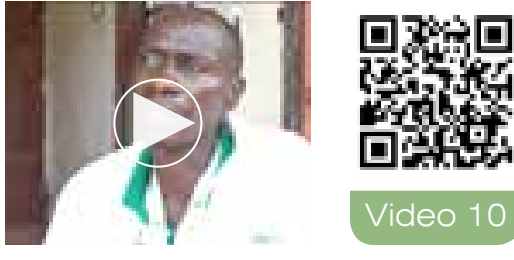

"Always when the farmers come with problems, there is a diagnosis. We have to get the foundation, the history of the problem of the farmers, find where they've got the plant, the surrounding crops, the spread of the disease, what have they been doing to control the disease, is it also on the neighbouring farms, then we see the basis. Then after we diagnose the problem, then we advise the farmers."

Sulayiman Mulindwa - plant doctor, Hoima district
Plant nurses serve as an interface between the farmers and the plant doctors and are usually able to answer simple queries from farmers. Additionally, they register the farmers' attendance, prepare the samples brought for diagnosis, and participate in the mobilization activities of the clinic. The nurses do not necessarily receive specific training on plant health or plant clinic operation. They receive on-the-job training by attending plant clinic sessions. Nurses are usually CBFs, NAADS service providers or lead farmers. They may receive a small allowance for food and transport. 


\section{Change agents - a service from within}

In other districts, change agents serve as the interface between farmers and the plant clinics. The change agents are volunteers - mostly lead farmers who are well-respected in the community. As they acquire knowledge by attending the plant clinic, they are sometimes called upon to advise in simple cases. In the villages, they disseminate the information they have acquired at the clinic to other farmers. And farmers sometimes go directly to the change agents before travelling to the plant clinic. They are a trusted source of information at village level and are able to refer farmers to the right service if they are not able to help the farmer further. (Film114) As volunteers, the change agents are not paid for their contribution to the plant clinics and mobilization duties. Acquiring knowledge, exposure and visibility are the main incentives to participate in these activities.
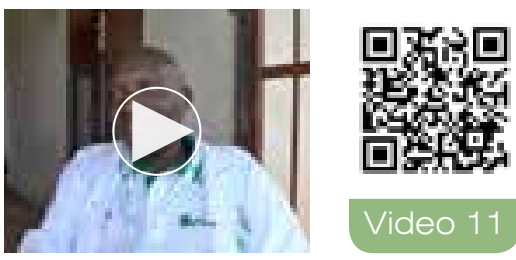

"Since we are not on the ground all the time, we have to get people that are in touch with those farmers all the time, sort of technical backstopping. We try to train them, so that they can go and assist us when we are not available. The problems are always there. Farmers can't wait for us to be available and bring their problems to us. With the change agents being resident in the area, they can always contact them. Then where they can't manage to address their problem, then they try to reach us and we give them feedback."

\section{Asaba Joseph Mercy}

plant doctor, Hoima
A careful selection of change agents is necessary to ensure maximum inclusion and reach to farmers. Criteria for selection of change agents include having a good network and being well-connected - not only to the elite but also to women and to more vulnerable groups. Change agents can be part of or connected to a farmer group, but this also represents a risk of exclusion of non-members. Hence, change agents need to be well-respected and trusted by the different groups in the community to provide inclusive services in the community where they operate. 


\section{Services on the road... mobile plant clinics}

With the hosts and the locations of clinics changing, strategies to reach farmers also change. In broad terms there are two plant clinic delivery models: fixed and mobile. The fixed clinics run according to a set schedule, a regular interval, and have a set location and time. They operate mostly at markets or trading centres from 9.00 or $10.00 \mathrm{am}$ to 1.00 or $2.00 \mathrm{pm}$, so that farmers are less likely to be in the field.

Fixed clinics are sometimes announced with a road sign to indicate their location. The big advantage of the fixed clinics is their regularity. But the regularity of the clinics can be compromised when plant doctors have to juggle other priorities.

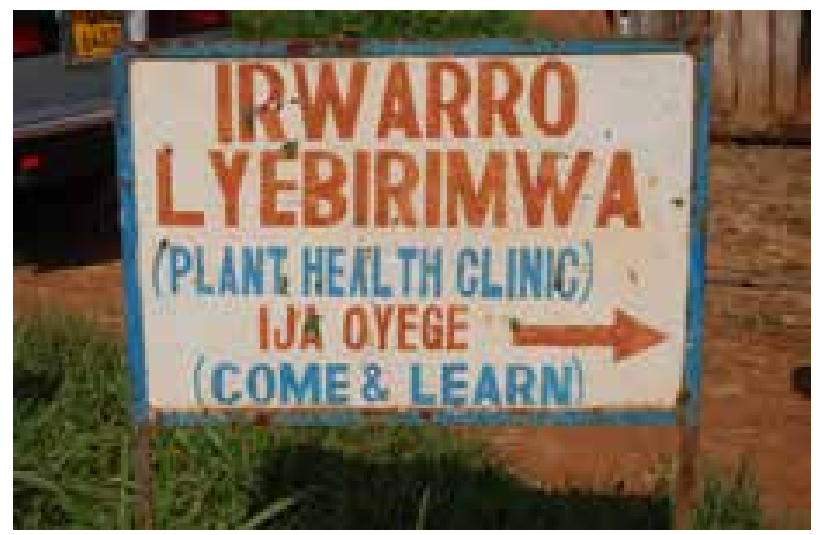

Sign board of a fixed clinic

Infrequency and lack of punctuality in clinic services affect the farmers' confidence in clinics. If farmers travel to a plant clinic and find it closed when it should have been operating it reduces their trust and the clinic's credibility. Farmers will be less likely to try and visit the clinic again.

\begin{tabular}{lrr}
\multicolumn{3}{l}{$\begin{array}{l}\text { Main agricultural crops in Ugan Mobile } \\
\text { and fixed plant clinics per region. }\end{array}$} \\
\hline Region & Fixed & Mobile \\
Central & 32 & 10 \\
Eastern & 44 & 1 \\
Northern & 8 & 0 \\
Western & 42 & 8 \\
Total & 126 & 19
\end{tabular}


Mobile plant clinics - as the name says - do not operate in fixed locations, but travel to various locations in a district where there are no fixed clinics. They operate less frequently in any one area but cover a wider territory and have the potential to reach more farmers (Table 10). The lower location-specific frequency may make it more difficult for plant clinics to respond to farmers' needs as required: a pest does not wait until the next clinic session to damage the crop. On the other hand, more farmers in the different locations may be able to access timely advice. That is the trade-off: outreach versus frequency.

Self Help Africa was the initiator of mobile clinics. Initially starting with fixed clinics in Kayunga district (Central Uganda), it realized it was not reaching its "beneficiary farmers', i.e. those farmers, men and women, individually or as a group, that participate in other Self Help Africa projects. Located in markets, clinics were too far away for producers to make a visit specifically to submit a sample. After consultation with local leaders, the idea of the mobile plant clinic was born.

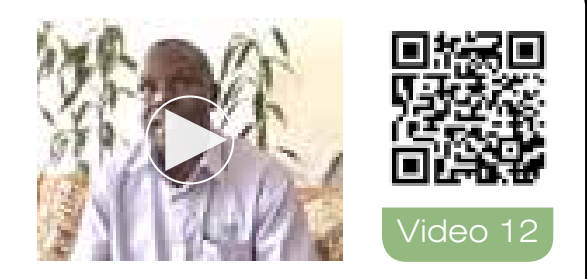

"Kayunga district is unique because when we tried to fix the clinic the attendance was not very good. So when we went on a mobile basis where we pitch a camp where farmers need a service, so we keep on rotating."

Misaki Okotel - Self Help Africa
"For instance a farmer group that has a certain plant health issue that all their farmers are facing, may contact SelfHelp Africa and request that a plant clinic be held for them. The plant clinic will hold a general meeting on the identified problem, providing advice on management techniques, and different technologies if appropriate. After this general briefing the plant doctors will then hold a regular clinic session to which the farmers will bring their plant samples for diagnosis as usual. This combination of mass extension and clinic operations has the advantage of reaching larger numbers of farmers, but does move away from the standard idea of a plant clinic as it is not held at the same place on a regular basis." (CABI, 2014, p.9)

Mobile plant clinics have the potential to be more inclusive as they are closer to the farmers. Women in particular face time (and other) constraints that prohibit them from travelling to a market place far from their village. By having mobile clinics 
operating closer to their village, women are expected to have easier access to them. However, mobile clinics can also be exclusive. For example, the Self Help Africa clinics are still perceived as being for 'beneficiary farmers exclusively' and not for the wider community. Clear communication and engaging with the right actors are essential in promoting inclusion.

\section{Individual, group approaches and clustering}

Information delivery can differ from one clinic to another and from one situation to another. When circumstances allow, farmers' queries can be answered individually. However, when too many farmers arrive at the same time, the plant doctors have found alternative ways of answering their queries. In some cases, when many farmers come with similar problems or the same crops, they can be attended to in small groups - clustered by crops and/or pest/disease. In other cases, queries can be answered in plenary sessions and farmers attending have the opportunity to learn about other crops and plant health issues beyond those that they brought themselves.
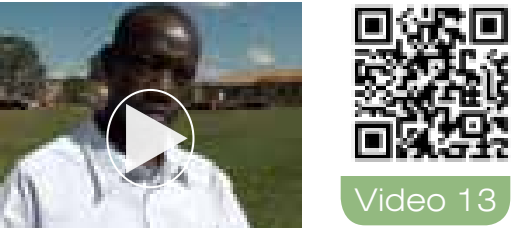

Video 13

"The information here is specific, in the sense that, first of all, before the day the clinic is scheduled to operate, we are informed about it on community radio and loudspeakers. The local leaders write to us in the villages informing us that there will be a plant clinic and that we should bring our problems to be diagnosed and be given information. The difference between this and other information is that we come with specific problems to get specific answers. Whereas the other information on radios and TVs is general information. Sometimes the other information does not concern me directly, but it is still information."

\section{Kato John Ssemawere Tremmsa}

farmer, Nkonkonjeru

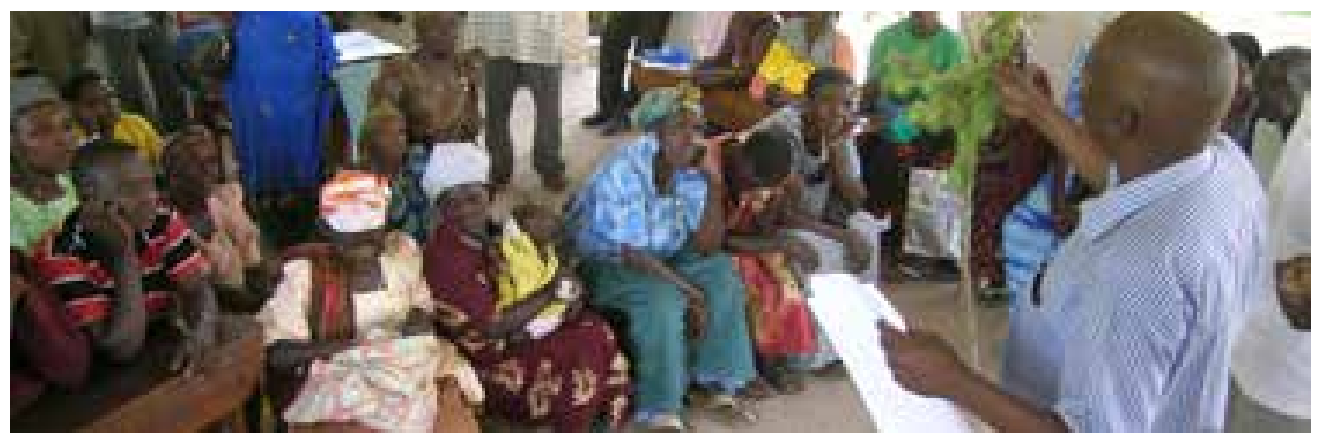




\section{ICT and mass media: new strategies}

The use of information gathered from the plant clinics for a wider audience of farmers is important. RIC-NET has been working on a number of strategies to share meaningful information with a wider audience. They have been using local information points: these are group managed locations at village level where information is disseminated through movies, brochures and leaflets. The information points are usually located at community centres or farmer group venues. The information on and from the plant clinic can be shared at those points. RIC-NET also uses SMS text messages to disseminate extension messages to farmers. RIC-NET and Self Help Africa also sponsor talk shows on the radio where outcomes of the plant clinic sessions are shared. During the talk shows farmers can call in to inquire about certain diseases. To make sure plant doctors can access information when needed, RIC-NET has started to use smartphones and to develop an online electronic library where useful resources for plant doctors are aggregated.
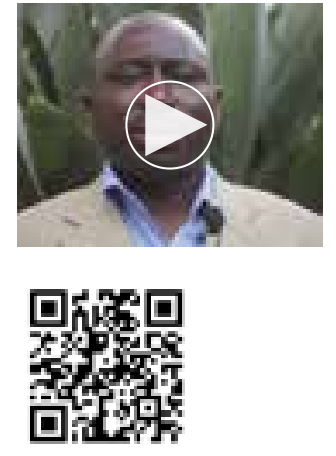

Video 14
"At the moment, my last year, in one year we were able to attend to 837 farmers from those plant clinics and we run five plant clinics weekly. Our plant doctors are also supported by RIC-NET with smart phones so they can access content online. RIC-NET developed an electronic library called elibrary.ric-net.co.ug, where the plant doctors can link to many resources that they need in their plant clinics. We're also connecting the plant clinics to the information centres that we have in the region. So far we have 50 information centres that are supporting the rural farmers and these information centres are owned by the farmers themselves. So the information centres, together with the plant doctors, they run all the extension, firstly in the markets and also through farmer-to-farmer information sharing."

Murugahara John Silko - executive director RIC-NET 


\title{
Holistic services to improve agricultural livelihoods
}

Most plant doctors are trained extension agents - they are knowledgeable on more than just plant health. Although the Plantwise theory of change assumes that plant clinics address any crop and any problem and plant doctor training emphasizes the importance of distinguishing between abiotic and biotic problems during diagnosis, there tends to be a focus on pests and diseases at most clinics. Some have started to provide more holistic services to their clients during plant clinic sessions, including advice on good agricultural practices, soil advice and testing, as well as advice on animal health. This may result in more costly and manpower intensive clinics, but could also be more responsive to clients' needs and foster cross-pollination between different extension services. But eventually, it could be more efficient, as experiences from Hoima suggest:

\begin{abstract}
Plant clinics are viewed as a very effective extension delivery mechanism by extension workers in Hoima. During plant clinic sessions, plant doctors learn a lot about current pest problems and outbreaks in the area, as well as other prevailing problems caused by e.g. poor soil health. Realizing the value of the information they are gathering at the plant clinic, the plant doctors use it to develop extension messages and complementary training sessions as part of their general extension work. They develop tailored training sessions for farmer groups or women's groups to help the farmers cope with the problems they are facing. For the extension workers, the plant clinics provide a huge bonus in that the problems farmers are facing in the area are quickly brought to their attention. Plant doctors consider the plant clinics to be highly complementary to other extension methods.
\end{abstract}

\section{How local adaptation improves service delivery}

Local adaptation is a prerequisite for plant clinics to be sustainable. In the end, adaptations are a response to local challenges and are an attempt to improve service delivery to farmers. Improved service delivery includes outreach (number of farmers), exposure (diversity of information), inclusion, proximity to the service, relevancy of the information and quality of the advice provided. It also means the integration of the services into the wider agricultural extension context. Not all adaptations have the same potential to influence the different components of improved service delivery positively. At this stage, a number of adaptations have emerged, but there is no evidence of impact yet (Table 11). 


\begin{tabular}{|c|c|c|c|c|c|c|c|}
\hline Adaptation & 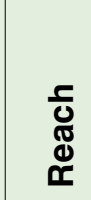 & 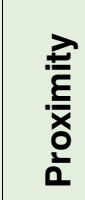 & 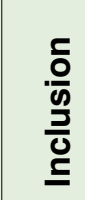 & $\begin{array}{l}\underset{Z}{\mathbb{0}} \\
\underset{0}{0}\end{array}$ & 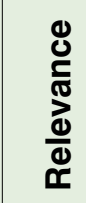 & $\begin{array}{l}0 \\
\frac{0}{5} \\
0 \\
\frac{0}{8} \\
\frac{0}{x}\end{array}$ & 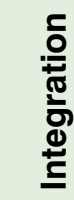 \\
\hline Nurses & + & & & + & & + & \\
\hline Change agents & ++ & ++ & ++ & & + & + & \\
\hline Mobile clinic & ++ & ++ & + & + & + & & \\
\hline $\begin{array}{l}\text { Farmer groups and } \\
\text { clusters }\end{array}$ & + & & & + & + & ++ & \\
\hline ICT and mass media & ++ & ++ & + & + & + & ++ & + \\
\hline Holistic clinics & & & & + & ++ & & ++ \\
\hline Rallies & ++ & + & & + & + & + & + \\
\hline
\end{tabular}

\section{Table 11}

Most of the adaptations have addressed reach. The engagement of plant nurses and change agents are good ways to mobilize farmers at community level and increase awareness of the services offered - while also providing closer proximity to the farmers. Mobile clinics and use of ICT also address reach and proximity of the services to the clients. Not all adaptations have the capacity to foster inclusion, however. To date little adaptation has been recorded in relation to gender - but there is potential. Mobile plant clinics, for example: by being closer to the clients make it easier, presumably, for women to attend in spite of their busy schedules. In addition, ICT allows information messages to be specifically targeted at women and excluded groups. Change agents, when well-selected, have the same potential.

Reach and inclusion are essential, but the relevance and the quality of the advice are also key to the system. Advice invariably needs to be adapted to the context and to the user. The local adaptations made by plant clinics mostly address the reach of advice. But potentially they can also contribute to the relevance and quality of the advice and the system's responsiveness to farmers' needs. The plant nurses, for example, are now helping the plant doctor to process the clients, leaving more time to the doctor for diagnosis. Exposure relates specifically to the diversity of information to which clients, 
and the wider community, are exposed. Groups and clusters allow farmers to sit in and hear about various problems and crops, hence improving their general agricultural knowledge. ICT and mass media can be used in a similar way to reach more users and non-users of plant clinics.

Finally, integration of plant clinic services into the wider plant health (services) systems is about sharing and absorbing the knowledge generated and information gathered within and outside the boundaries of the plant clinics to foster a more responsive plant health system, for example by including the outputs of plant clinics in wider extension messages and services. It also requires building effective linkages with other service providers, such as research and input suppliers. ICT and mass media are useful tools for this, but the plant doctor cluster meetings, and rallies, even if they are not considered adaptations, also have the potential to help foster a more responsive system. They provide the necessary opportunity for plant doctors to interact and discuss practices and adaptations. Many plant doctors have indicated that they are using the information and knowledge generated at the plant clinics in their other extension activities.

\section{References}

CABI (2014) Plantwise, a country-based approach to improve farmer livelihoods project progress report for IFAD. February 2014. CABI, Wallingford, UK. 
5

Gender responsiveness

in plant clinic delivery

By Richard Miiro, Frances Williams and Titus Kizauzi 


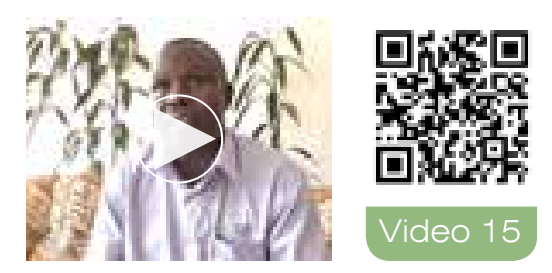

"When we look at our monitoring data we realize that few women and youth are attending plant clinic sessions. We are designing a strategy where we are looking at how do we move away from the current stations because we are operating the plant clinics to follow the groups that are excluded at the moment from accessing the service."

\section{Misaki Okotel}

Self Help Africa

This chapter shares what the implementing organizations have faced while implementing the plant clinics, what gender patterns and issues have arisen and how they have innovated and made adaptations so as to address the gender issues.

\section{Attending the plant clinic. Or not?}

Plant clinics are open to anyone, men and women, young and elderly. There is an assumption that both men and women will attend plant clinics and that there are no major barriers for women attending. Men and women will equally benefit. In addition, it is assumed that women will attend clinics more often with food crop-related issues and men with cash crop-related issues. The reality proves more complex. Different approaches to establishing and publicizing plant clinics have been used across regions and by the various plant clinic operators. The different strategies have affected the attendance of women and men.

In Hoima, farming is the main business for many families. These families work together on the farm with both men and women sharing roles. There is collective responsibility. Farming is their only source of income and they invest in making the farm a success. Both women and men may visit plant clinics depending on who has the time available when the clinic is running. A plant doctor in the area, Sulayiman Mulindwa, remembers the husband of one family visited a plant clinic one day, and then the next day, his wife visited a different plant clinic in the area with a different crop problem. According to Sulayiman this was not because of a lack of trust between husband and wife over obtaining advice for each other's crops, but rather that they both had equal responsibility and interest in making sure their farm was successful. 
Different sources (e.g. MAAIF data, the Plantwise Monitoring and Evaluation Stakeholder Workshop, Kampala, August 2013) suggest that female attendance at plant clinics (and use of other extension services) is significantly lower than male attendance. The lower female attendance indicates that even though women are actively involved in farming, especially in the production of food crops, there are factors that limit their access to advice. An exception seems to be the plant clinics run by RIC-NET in the Rwenzori area in Western region. There, women constitute 63\% of the clinic attendants. One possible explanation is that, in Rwenzori, women are generally the family members selling agricultural produce at the local market where the clinic is situated.

The question to ask here is what are the factors influencing the farmers' attendance at the plant clinics? These factors are many and different for men and women.

\section{Being in the know: awareness}

Farmers will not attend plant clinics if they do not know about them. It is as simple as that. The 2013 survey showed that, in Central and Eastern Uganda, the awareness of the existence of plant clinics among men and women (non-users) does not differ greatly. On the other hand, in Western Uganda more women than men appear to know about the clinics (Table 12). Implementing organizations invest in raising awareness in different ways, deploying different strategies to inform people about the existence of the clinics and on the timing/site of clinic sessions (see Part II). Nevertheless, implementation strategies disregard gender-specific disparities. The clinics are supposed to reach both men and women equally, but in practice this is not the case.

To increase attendance, it is useful to identify the most effective mechanisms for raising awareness among men and women about plant clinic services and which ones are the most effective in reaching either men or women.

How many farmers know about the plant clinic?

\begin{tabular}{lrr}
\hline & Fixed & Mobile \\
Central & 32 & 10 \\
Eastern & 44 & 1 \\
Western & 42 & 8
\end{tabular}

Table 12 
The 2013 survey showed that informal sources and social networks, such as family, friends and neighbours and lead farmers, are as important as formal sources of information about plant clinics for raising awareness with farmers: they are easily accessible and available in the communities. Some farmers are better connected to formal sources such as government extension services and NGO programmes. The conclusions of the report of the Plantwise Monitoring and Evaluation Workshop (Plantwise, 2013) suggest that, compared with men, women rely more on informal sources, and women's information sources are closer to home (friends, women's groups, other farmers, husbands). According to the survey, however, the disparities between men's and women's information sources are small. Other farmers, both men and women, rely on private actors such as the agro-input dealers.
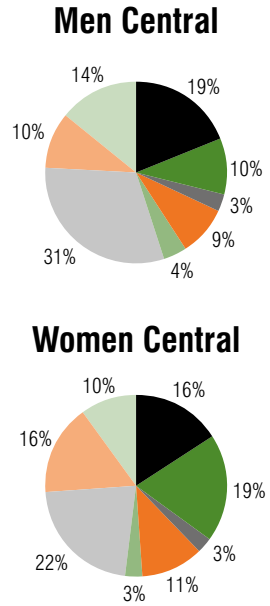

Men Eastern
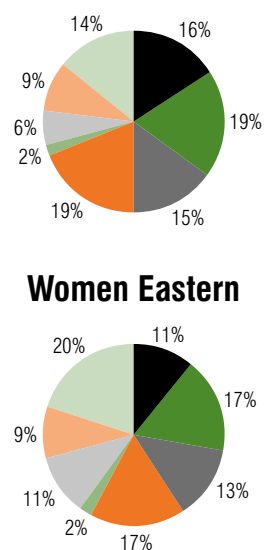

Men Western
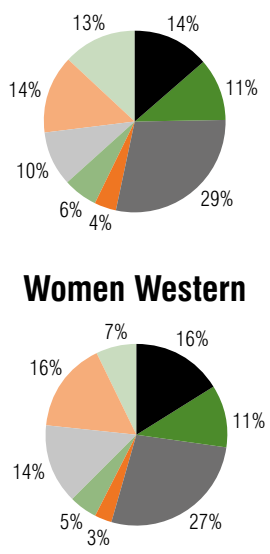

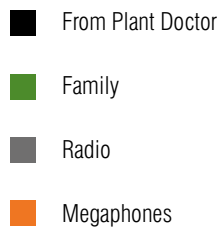

Churches/mosques and social functions Local leaders and farm leaders Sensitization meetings Other

Fig. 15. How did the farmer hear about the plant clinic? (\% of total men and women per region)

There are clear regional differences: the 2013 survey showed that women in Western Uganda tend to receive information from formal sources (radio, plant doctors and sensitization meetings) more than women in Central and Eastern regions do (Fig. 15). Of course it all depends on the strategy used by the local implementing organization: if they use radio and not megaphones, it is clear that farmers will learn about plant clinics more via the radio. In Central region, local leaders appear to communicate with men rather than with women, though women are better connected to lead farmers than local leaders. In Eastern Uganda, megaphone announcements reach more men than women; in addition, more men are told about plant clinics directly by plant doctors. 
In both Eastern and Western Uganda radio information is important. In Central region, radio does not play an important role, which might be because there are a large number of radio stations there; if information on plant clinics is broadcast on one or two stations, it reaches only a small number of farmers.

In Eastern and Western Uganda, radio in particular is a preferred medium for announcing times and locations of mobile clinics (Fig. 16). In Central Uganda, megaphone announcements are considered more effective. Some farmers in this region are better connected to formal sources such as government extension services and NGO programmes. Both male and female farmers in Central region expressed a preference for megaphone announcements. Nevertheless, few farmers ( $9 \%$ men, $11 \%$ women in Central; $4 \%$ men, 3\% women in Western) currently seem to hear about plant clinics through megaphone announcements. Increasing the use of megaphones and promoting plant clinic activities through local leaders could increase knowledge and attendance of the clinics.
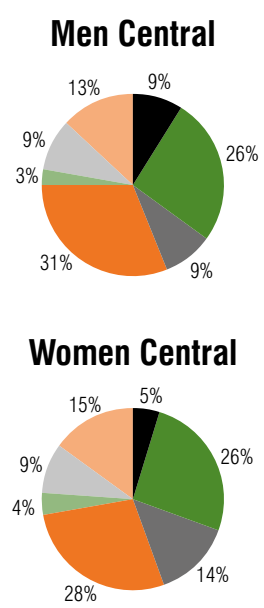
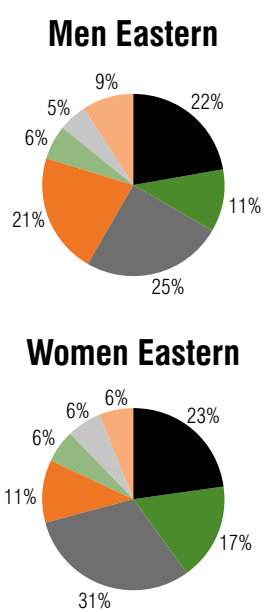

\section{Men Western}
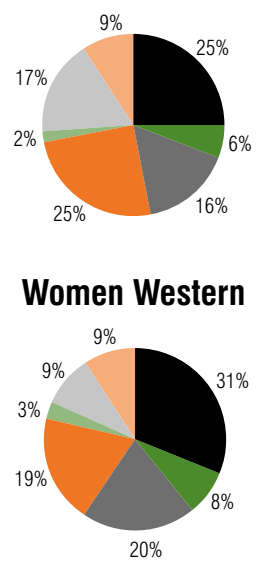

Radio

Megaphones

Churches/mosques and social functions Local leaders and farm leaders

Word of mouth

Sensitization meetings

Others

Fig. 16. Farmer's preferred awareness raising method (\% of total men and women per region)

Each implementing organization is using different communication channels to inform farmers about plant clinics. Nevertheless, it is worth noting that there are regional preferences and some differences between men and women. A mix of different channels, adapted to local preferences and differentiated according to gender (which is also district-specific), is regarded as most effective. However, using several different channels has cost implications. 


\section{Where to pitch a tent: market, trading centre or elsewhere?}

The nature of the location, the distance to the clinic and, consequently, the time required to reach it are important factors influencing the ability of farmers to attend sessions. Most plant clinics are based in market places, some are located at trading centres, while mobile plant clinics have no fixed location. Markets are assumed to be easily accessible to both men and women farmers. The assumption is that people will combine their visit to the market with a visit to the plant clinic. In reality the majority of the interviewed farmers attending the plant clinics said they came specifically for the clinic.

In certain locations, e.g. in the Rwenzori area in Western Uganda where RIC-NET runs fixed plant clinics at market places, RIC-NET's data show that this works very well, in particular for women. Markets in the Rwenzori area are dominated by women selling their produce. In Eastern and Central regions there are well-established markets where farmers sell their produce. Men often take the high quality produce to the markets in Kampala, while some women take the smaller, less valuable produce (food crops and vegetables) to the local markets. When questioned, women in Central and Eastern regions expressed an equal or stronger preference for plant clinics to be located in trading centres rather than in market places (Fig. 17). Trading places are easily accessible, permanent locations of shops and businesses. Women in Central and Eastern Uganda are more likely to visit a trading centre close to their homes than a

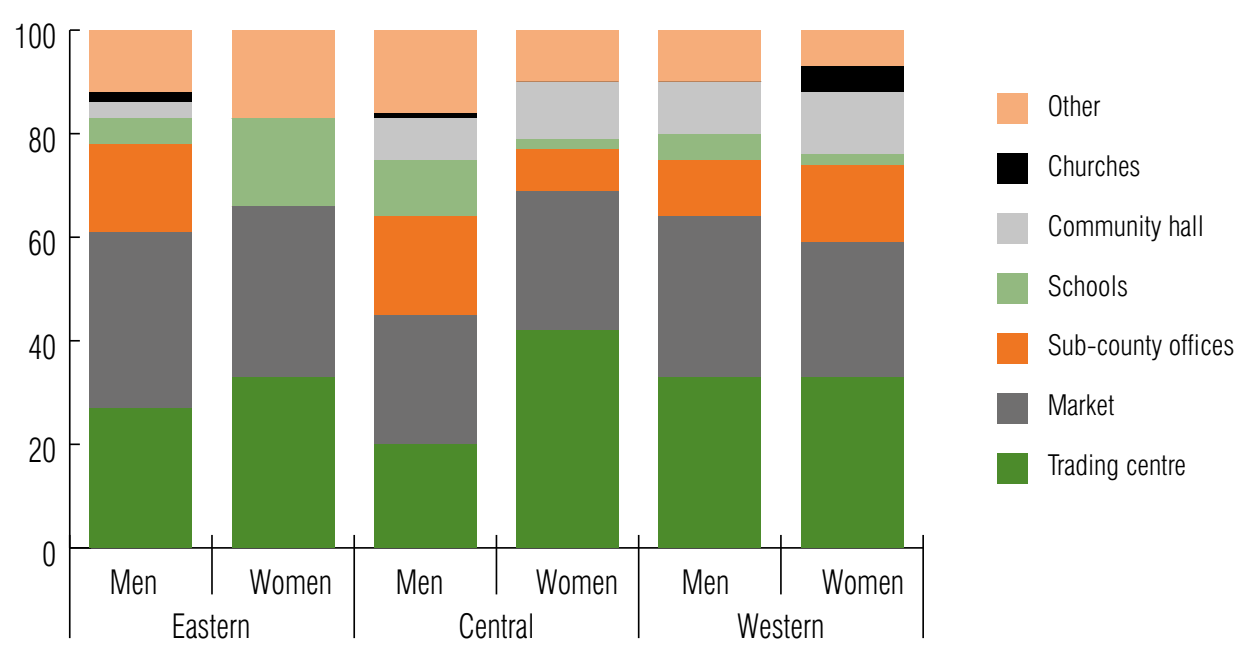

Fig. 17. Preferred locations of plant clinics by men and women in each region 
temporary market place, which is only operational once a week on market days and for a few hours (mostly in the morning). Men in these regions indicated a preference for plant clinics to be held in market places.

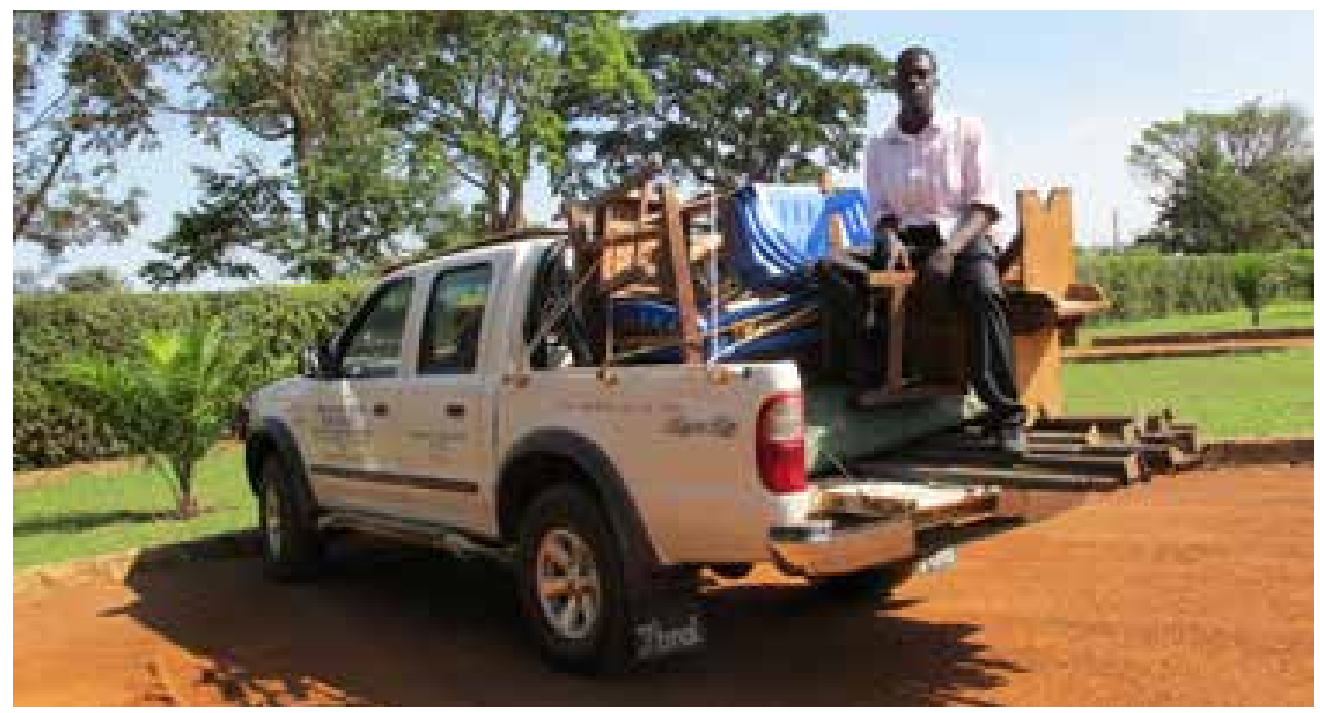

The longer the distance to travel - sometimes as much as $5-10 \mathrm{~km}$ - the less easy it is for people to attend the plant clinics (Fig. 18). Interestingly, in Eastern Uganda women visiting the plant clinics travel longer distances than men.

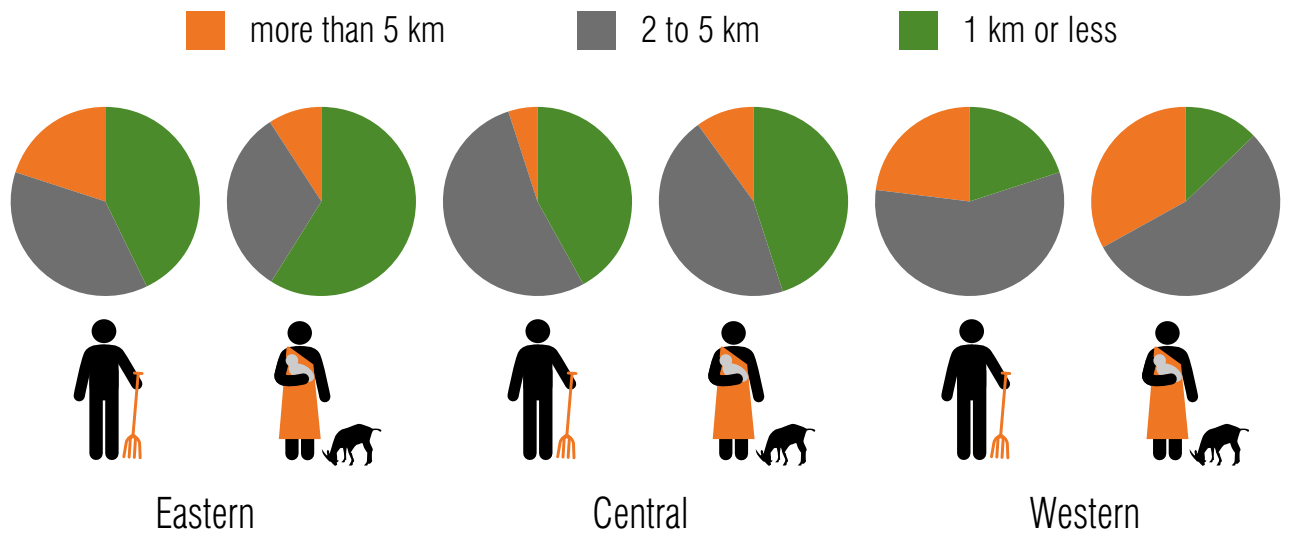

Fig. 18. Distance travelled to the plant clinic (\% of total men and women per region) 
Mobile plant clinics are one of the adaptations aiming to reduce the time taken to reach the plant clinic (see Chapter 4). Mobile clinics are located closer to the farmers' homes, often operating at the village level rather than in a market place. While this adaptation was not specifically designed to increase access for women, it has the potential to achieve exactly that. Because it is closer, it is easier for women farmers to find the time to visit a mobile plant clinic in between their other household and farm work. The proximity of plant clinics also contributes to their visibility and increases awareness among women about the existence and benefits of the clinics. It is assumed that this will lead to more women attending the plant clinics. However, more time is required to see if this happens.

In addition to the time required to reach the plant clinic, the time spent at the clinic also influences attendance. Women are normally more time-constrained owing to multiple responsibilities. During focus group discussions, women farmers indicated that long waiting times at plant clinics make them less likely to attend. However, those men and women who do attend clinics are generally satisfied with the time spent at the clinic to see a plant doctor and to receive advice.

\section{When the time is ripe}

Ideally, the plant clinic implementing organization should set the times for plant clinic sessions through a consultative process with farmer groups including women, market leaders and farmer leaders. However, most of the plant clinics in Eastern region simply follow market hours and run during the morning and end in the early afternoon, allowing farmers to visit the clinic after they have been to the market, which starts at $9.00 \mathrm{am}$. This allows both female and male farmers sufficient time to carry out their market business and then obtain the plant health advice that they need, before returning to the home and farm to carry out their other activities. Sixty percent of the farmers were happy with these hours with no apparent difference between men and women.

At Hoima in Western region, the timings of local government fixed plant clinics are set through a participatory process. When a new plant clinic is being established, one of the first steps is to hold a farmers' meeting to discuss the most appropriate time for the clinic sessions. Existing farmers' and women's groups are invited to this discussion and women's voices can influence the decision as they articulate their tight time restrictions and livelihood objectives. The majority of these fixed plant clinics run from $10.00 \mathrm{am}$ to $2.00 \mathrm{pm}$ allowing women sufficient time to complete their household and farming 
activities in the morning, including food preparation, before visiting the plant clinic. However, the participatory process does not necessarily lead to the most convenient session hours: over $60 \%$ of women and over $50 \%$ of men interviewed in Western region expressed the view that the best time for a plant clinic to be held was $2.00 \mathrm{pm}-4.00 \mathrm{pm}$. Women in particular arrive at the plant clinics very late in the day, often when the clinics are about to close, because they are busy on the farm and in the house in the morning and need to prepare the midday meal. Plant doctors do not turn people away from a clinic session and generally work beyond $2.00 \mathrm{pm}$.

\begin{abstract}
RIC-NET plant clinics in the Rwenzori area run from 9.00 am to $2.00 \mathrm{pm}$ at market places. Based on the experiences in other areas, this seems to be quite early for women to visit the clinic. But these clinics have over $60 \%$ female clients. Unlike other districts, in the Rwenzori area it is mostly women who go to the markets to sell agricultural produce. After they finish their business, they do not rush home. They often wait to buy fish, which only reaches the market about midday. In the hours in between they can easily visit the plant clinic and have time to discuss issues with the plant doctors and listen to the issues that other clients raise. The men in this area are much more focused in their attendance: they will come in with a specific problem, seek a solution and then leave.
\end{abstract}

Mobile plant clinics run by Self Help Africa in Central Uganda operate between noon and $5.00 \mathrm{pm}$. The times are set by Self Help Africa on the basis of its experience of working with its project farmers. Experience showed that women farmers are better able to reach the plant clinic between $2.00 \mathrm{pm}$ and $5.00 \mathrm{pm}$ when they are finished with the midday meal, but before having to prepare the evening meal. The men tend to come slightly earlier as their time is not so constrained; they are able to attend at any time during the afternoon. However, when asked about their time preferences for plant clinic sessions, $50 \%$ of men preferred the morning hours, with the rest evenly split between an afternoon session and an all-day session. Women from across the country showed little preference on timings, with $37 \%$ preferring the afternoon as opposed to the mornings $(36 \%)$ and $28 \%$ wanting the clinics to run all day.

Discussions with those involved in running plant clinics, including government extension workers, highlighted that individual plant clinics need to be better adapted to local needs than they are at present, meaning that the local cultural and societal norms, economic situation, local political scenery and current agricultural practices in the area should be considered. Before establishing a new plant clinic it is essential to discuss its purpose, timing 
and location with farmer groups, women's groups and local leaders who can mobilize other farmers. This will not only lead to local buy-in, but also ensure that the timing and location of the plant clinic is suitable for both women and men, as well as ensuring that all these farmers know that the plant clinic is available to them, and not to just a limited group of farmers. The way that the farmers are informed about activities in their area also needs to be considered. Adapting plant clinic operations to the local community is essential to increase levels of male and female farmer participation.

\section{Encouraging women's involvement}

Visiting the plant clinic and carrying out the recommendation often implies an investment. It might be small, but time and costs of transport can be a barrier to farmers, and especially to women. In all three regions, women are predominantly responsible for food crops and men for cash crops. Traditionally, there is little investment in food crops or expenditure on controlling pests in them. This means there is less motivation for women to visit plant clinics - or perhaps the motivation is there, but women are not given the opportunity to attend the clinics or to invest in plant health services or inputs. In many cases, men are in control of cash.

Lyazi Daniel, one of Uganda's most experienced plant doctors, takes a unique approach to encouraging not only female farmers, but also the whole family to be involved in farming. Realizing that in many households the wife undertakes most of the farming work, but has little decision making power, Lyazi Daniel now often refers to the wife as the farm manager. When he passes by a house and meets the husband, he is likely to comment "I stopped by yesterday but you weren't here - instead I spoke to the farm manager." Through this, he manages to convey the fact that women, even though they have little decision making power, are still in charge of what really happens on a farm as they provide most of the labour. To take things a little further, and understanding that the whole family can become involved in farming, when visiting a farm, Lyazi Daniel asks the whole family to join him to discuss the problems they are facing, and the advice he is providing. He thus speaks not only to the husband, but also the wife and children who may actually be the ones to put his advice into practice. Through this he engages the younger generation in farming and is able to discuss the problems with any member of the family when he next visits the household. 
Self Help Africa is encouraging women to become more engaged in farming as a business through making use of village savings and loans associations to provide the start-up capital for the business. As the female farmers have started to invest in agriculture, they have developed a stronger interest in preventing crop losses, investing both more time, by coming to plant clinics, and more money, by buying pesticides and fertilizers, in preventative measures. These female-focused interventions, while not directly addressing female attendance at plant clinics, seem to have increased it, though this is yet to be confirmed.

Another example of increasing usage of plant clinic services by women, seen by those on the ground, occurs where there are increases in female headed households, typically through death or divorce. These women are forced to take on all responsibility for ensuring the family income, and often farming can be the best option to bring in extra cash. Women in this position have explained that they are seeking the plant doctors' advice to improve their yields and therefore their incomes.

"Due to worsening economic condition in the area, Alice's husband opted to go away to look for employment. When he returned he was sick with HIVIAIDS and she also contracted the disease. She had to battle with stress, looking after her husband, and her own illness which almost broke her. She became the sole bread winner and head of the household and was left to take care of her five children, providing them with food, clothing, medical care and whatever assistance they needed. The only resource she had was land and agriculture was the only work she could engage in for the survival of the family. On her small piece of land she grows cassava, groundnuts and sunflower and keeps some livestock to earn money to support the family needs. In 2013 Alice thought that her whole groundnut crop would be destroyed by aphids and that she would have no food to eat that year. Then she heard about the plant clinic being advertised at the market place. She visited the plant clinic and after discussing the problem with the plant doctor she was advised which chemical to buy. She sprayed her groundnuts and was able to save the crop and harvest her groundnuts. She used the money to pay school fees for her children. The existence of plant clinics has helped her to reduce her crop losses and therefore be able to feed, clothe and take care of her family." 
In Buikwe (Central region) there has been a focus on encouraging women to become involved in the leadership of farmer groups and higher-level farmers' organizations. This has been successful and resulted in more women seeking extension advice, both through farmer groups but also through plant clinics. The resulting higher status in society that they then achieve has also meant that they are in a position to share the advice they have received with more women.

"In Mukono, Central Uganda, there are some efforts in the local government extension system where women are being encouraged into leadership. Daniel, the area plant doctor, indicated that he purposely encourages women to get into leadership of farmer groups as well as higher-level farmers' organizations. He particularly encourages them by pointing out women's strengths as leaders, and that women are good custodians of resources; they are the ones in charge of food security in homes and community. He also points out to the women that there are benefits of getting into leadership, for example that their networks enlarge and they get more opportunities in life. This has pushed many women into leadership, and he has seen them become bolder when expressing demands for services and technologies within the farmer groups. Additionally, these leaders are helping in mobilizing more women to attend plant clinics. These women farmer leaders become examples to the rest when it comes to implementing plant clinic advice. There are cases where advice given to an individual farmer at the plant clinic is later shared among many in the farmer groups. As an extra benefit to the women leaders their level of respect at home also grows, with their husbands trusting them more and increasingly seeking their opinions, especially as women apply what they are learning and the results of their learning leads to higher yields and income."

Lyazi Daniel - district local government agricultural extension worker and plant doctor, Mukono district 


\section{Is the advice suitable?}

The advice the plant doctor is able to give depends on a number of factors, including whether a sample is brought to the clinic to help diagnosis, how advanced the infestation or disease is (it can be too late to save some crops if the disease/infestation is very advanced), and the plant doctor's understanding of the farmer's situation (the recommendation can be tailored to be suitable for that farmer). It is worth noting, though, that in general plant doctors do not tailor their recommendations depending on whether the client is a man or a woman, but give the best advice available, i.e. the advice that is expected to be most effective from the perspective of plant health, without considering the socioeconomic status of the client.

In some situations the advice can be impractical for the farmer, whether male or female, to implement. For example, there are situations where the plant doctor has to recommend a chemical as there are no alternatives, but this is unaffordable to many farmers. If a farmer then says that she cannot cope with the high cost, the plant doctor might suggest sharing costs among farmers.

In Western Uganda (e.g. in Hoima district), plant doctors generally recommend cultural measures rather than chemicals to women, because the former have no or minimum cost implications. When plant doctors in Hoima recommend a chemical

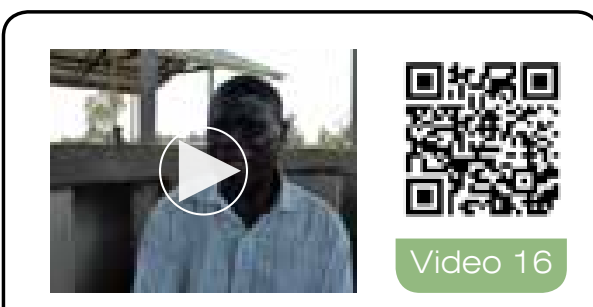

"I came and I had to explain to the agricultural officer, and he gave me advice to purchase some of the chemicals, the medicine. The medicine is very expensive. But he has advised me to collect some villagers whose problems are the same as mine, so we contribute and buy the litre."

\section{Kavuma Fred Kintu}

farmer, Mukono district solution, the immediate response from women farmers is to ask how much it will cost. Men are less likely to not apply a recommended chemical for financial reasons, while women, who are very preoccupied with the cost of applying it, have to deal with many more constraints, notably a lack of money for buying chemicals and a reluctance to invest cash in pesticides for food crops.

In Central and Eastern regions, cultural methods are also often recommended to women, especially when the pest problem is not too severe, but chemical recommendations are more likely to be given as the severity increases. In Rwenzori 

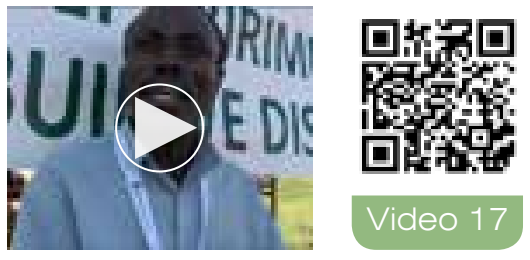

"You can imagine an elderly person, less energetic, the enterprises they will get involved in may not be the same as those for an energetic person. Elderly people will be talking about small plots of vegetables, how to manage those. While younger men mostly deal with cash crops. (...)Women are mostly to do with feeding the family, the food crops. So bananas are ladies' responsibility. Also sweet potatoes, cassava, maize on a small scale, this is predominantly the issues bought about by ladies. We try to answer them. When it comes to the recommendations, the advice we give, definitely for the elderly person who is weak, there are some pieces of advice you wouldn't give because they would not be applicable to them. We try to make the advice as specific as we can. Definitely there are challenges, but we try to find ways."

Luswata Kanakulya - district

agricultural officer and coordinator for plant clinics, Buikwe district
(Western region), regardless of whether the client is male or female, RIC-NET primarily recommends cultural solutions. Their plant doctors find, though, that women are more likely to implement these solutions while men appear to want a 'quick fix' chemical solution to the problem.

In some situations a cultural recommendation may be the best solution. However, this can also have implications for the applicability of the advice as many cultural measures take longer to implement than chemical spraying. Cultural measures tend to be the women's responsibility and they may struggle to find the time in their very busy days to implement such recommendations.

Plant doctors should take their recommendations one step further and help the farmer to think of the best way to apply the advice. Some plant doctors help women to find creative solutions. A recommendation might not differ from the one given to men, but its application can be adapted to the special needs and constraints that women face.

Many women come to the plant clinic in Nakifuma to seek advice about their crops. Lyazi Daniel, the area plant doctor, listens and explores the problem and will provide the same advice whether the farmer is a man or a woman as this is the best advice that he is able to give. He may, for example, advise that banana cuttings are planted in holes or that a whole bean crop is sprayed. However, sometimes the female farmer will comment that she is not able to do as he suggests because she does not have the time or because 
the work is too hard. In these situations Lyazi Daniel takes on a counselling approach, pointing out to the woman that she can slowly and in small portions accomplish some tasks that appear to be men's work, such as spraying crops, or digging holes one metre wide and one metre deep for bananas. He will discuss these options with the female farmer, including the implications on her time and may advise that, instead of digging ten holes for bananas all at once, she could dig one in the morning and one in the evening. This takes less time each day, and by the time a week has passed all the bananas would have been planted. In this sense, although the overall advice to the farmers is the same for men and women, discussing with the women how to achieve the same result through an incremental process makes a difference to whether women farmers are able to make use of the advice or not. This approach enables the female farmer to fit the work involved around all her other work and time commitments. This is an innovative, gender-sensitive approach to advising clients.

Suggestions like this can make the best possible advice recommended by the plant doctor much more suitable to the farmer and increase the likelihood of both female and male farmers making use of it fully and gaining a positive result.

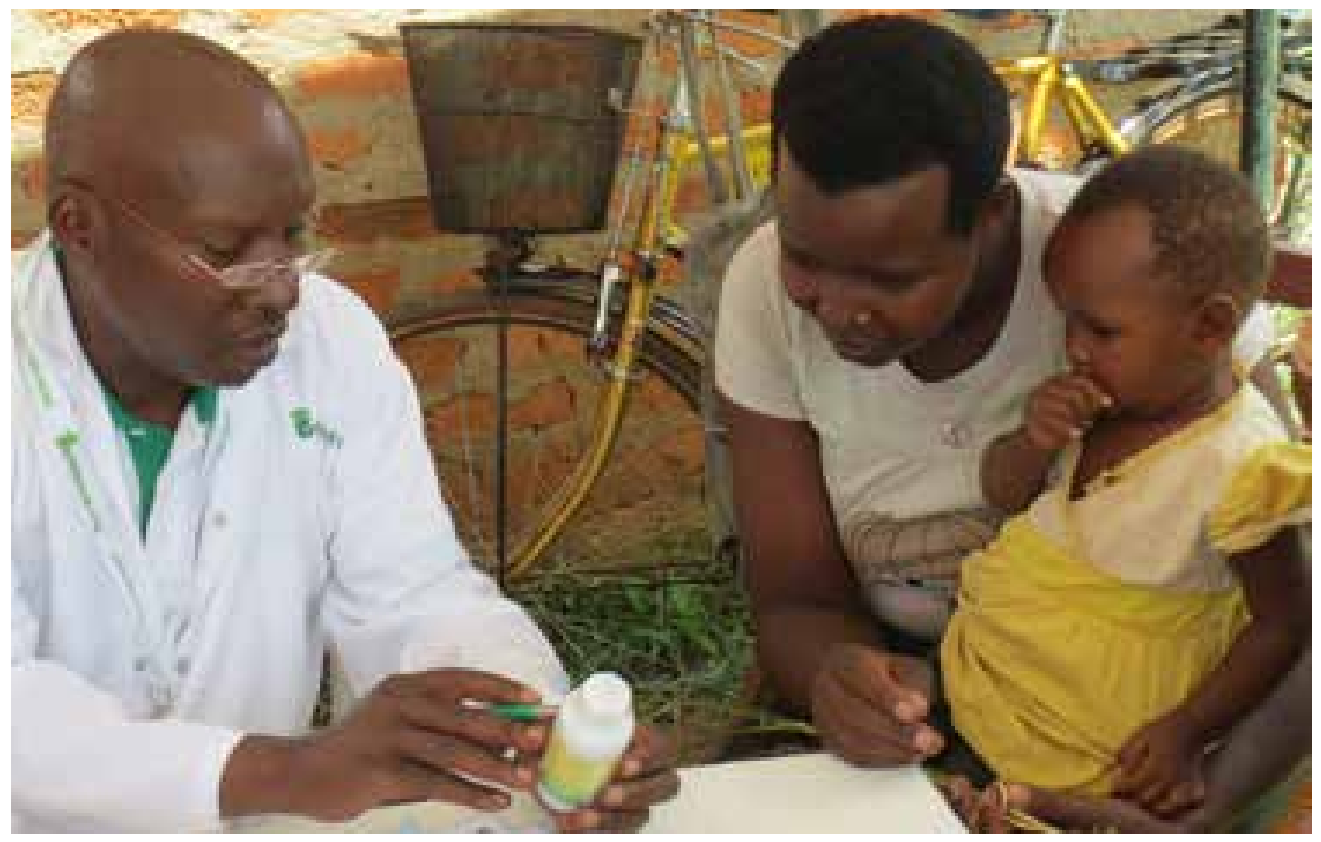




\section{The language}

The way the advice is communicated to female and male farmers also needs to be considered. Many of the issues relating to gender-sensitive advice delivery relate to language. To address the language issues, many plant doctors do not only provide advice in English, but also give a translation into local languages on the back of the form for the benefit of those farmers who do not speak English.

However, this does not help men and women farmers with low literacy levels. Only 62\% of rural women in Uganda are literate compared with 77\% of rural men (UBOS, 2010); illiteracy levels are also high among elderly farmers. Plant doctors indicated that they not only provide the advice in written form but also take additional time to explain it verbally in non-technical terms to make sure farmers understand the prescription properly. The use of simple language such as "Fill a jerry can with water and add two capfuls of the chemical" or "Use the lid from the chemical bottle to measure: two capfuls is the right amount" is more understandable to many farmers than litres and millilitres. As incorrect application of the advice can reduce its effectiveness, the use of such non-technical language may reduce errors, and the full effect of the management practice is more likely to be obtained. Twentyeight percent of women and $18 \%$ of men found the information on the prescription form unclear, partly because of the detailed technical language, but also because the information was provided in English.

In some cases, especially in low literacy areas such as Kayunga, the farmers were not taking the prescription form copies away with them as they thought they served no subsequent purpose. In other areas, such as Rwenzori, the main reason that farmers who were advised to buy a chemical took away their copy of the prescription form was to show to the agro-dealers so they could buy the right chemical. Otherwise their main interest was in what the plant doctors had to say. The copy of the form can also be shown to an extension worker, or to one of the farmer's children who can read English, so that it can be read as a reminder.

This implies that the verbal explanations given by the plant doctors are more useful for some farmers than the information written on the prescription forms. It is essential to ensure that plant doctors can speak the local language so that at least the verbal advice is understandable. Furthermore it benefits the farmers if the written recommendations are also provided in local languages. This will also allow farmers to share the recommendations with others as it is easier to share information if the farmer can refer to an understandable written reminder. 
In addition, the factsheets shared with or given to farmers need to be adapted to local conditions. This relates to both the language and the content of the message. A more visual format that still conveys the correct extension message would be understandable to many more farmers.

\section{What happens to the advice?}

The majority of both men and women stated that they follow the advice provided by the plant doctors. Of those who do not follow the advice, $57 \%$ of men and $43 \%$ of women said it was because the recommendation was too costly - referring to chemical methods. There are strong regional variations in this, though, with no women in Eastern region saying the recommendation was too costly, but half of them saying they did not know where to get the recommended product. In Western Uganda, 43\% of men and $29 \%$ of women who did not follow the plant doctor's recommendation thought that there were better ways to solve the problem (Fig. 19).

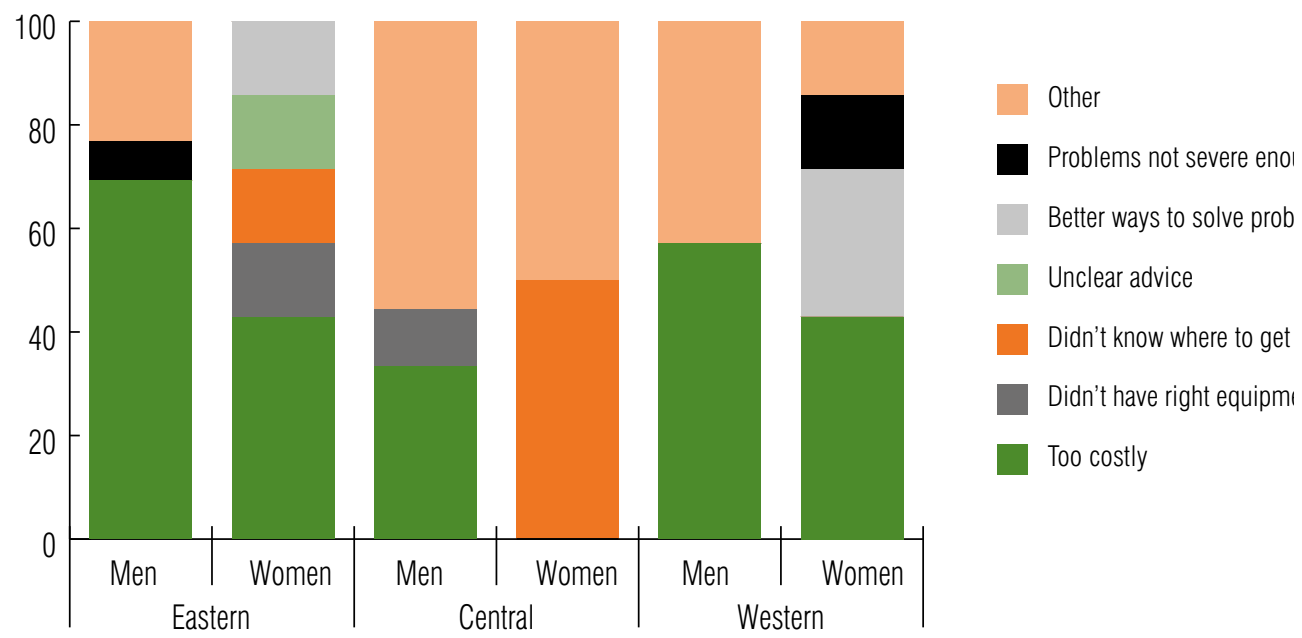

Fig. 19. Reasons for not following advice from plant doctors (\% of total men and women per region) 
According to the plant doctors in Central region, there are situations where the husband will bring both affected cash crops and food crops to the plant clinic. The husband generally has more time and linking to the extension worker is considered to be his responsibility, even if there is a problem with a food crop. However, this may not be very effective as the advice received by the man may not be passed on to his wife. In addition, if the husband has cash and food crop problems to take to the plant clinic, he might place less emphasis on the food crop problem when he is speaking to the plant doctor.

The effectiveness of plant clinics depends not only on how many farmers are actually attending the clinics, but also on how the information is further disseminated. The vast majority of plant clinic users share the advice received (see Chapter 3), in particular with other family members and neighbours. More men than women tend to share the information provided by the plant doctors with family members (Fig. 20). In contrast, more women than men share the information with neighbours and friends. Sharing information with farmer groups seems particularly uncommon in Eastern Uganda.

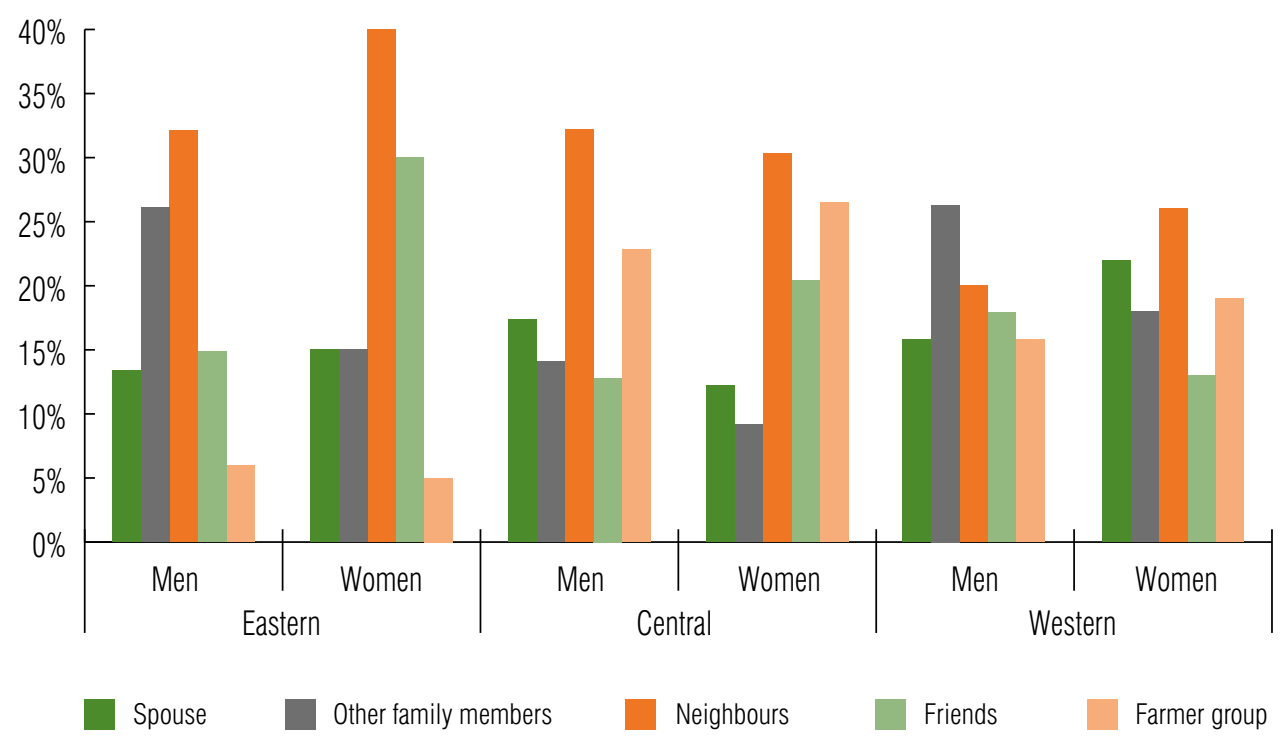

Fig. 20. Who advice is shared with, by gender and region 
Several of the plant clinic adaptations are geared towards reaching more farmers. None of these deliberately targeted women but some of the adaptations have the potential to reach out to women, for example by making use of women's networks and groups. In Hoima (Western Uganda), some of the change agents are linked to women's groups and pass on the information to them:

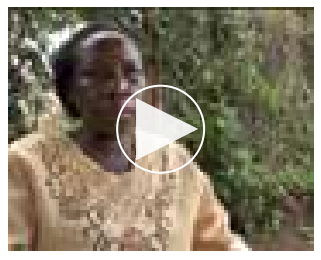

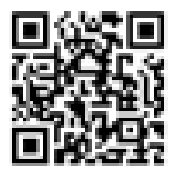

Video 18

"My name is Mugisa Juliet from Bugambe sub-county, Bugambe parish, from a group called Mwijutukorehamu Women Saving and Credit Association. I am chairperson of that group and we are farmers. In our association we are 30 members, three men

and 27 women. Our aim is to save and give credits to the group, to work together as farmers, and to take our children to school. I am here to learn about the diseases which attack our crops like beans, maize and cassava, bananas, onions and the other crops. I have learned the clinic is here from 2012. They come and train us. The problems we have are diseases on our crops, the diseases attack our crops. That is the problem we have. The clinic has helped us, we come here and we have the training at this clinic and we go and train other members in the group. The clinic is very good. The first time our crops were not growing well, but at this time at least the crops are coming, giving us crops. I have benefits, like paying school fees, building houses, doing produce and earning more profits, buying bicycles and motorcycles. I'm earning. When I come at the clinic I learn other methods of growing crops and preventing diseases."

Mugisa Juliet - change agent, Muhwiju village, Bugamba sub-county

As well as change agents, the use of mobile clinics and mass media, especially radio, are considered as promising adaptations to reach women in their locations. 


\section{Gender-responsive delivery from implementing organizations}

Although plant clinics and their implementers have sought a number of adaptations to improve service delivery, there have been few specific gender-responsive interventions. Some plant clinic organizations are more aware than others of the need to address women's and men's needs differently. This seems to have arisen either through the extensive experience of the plant doctors in delivering extension to all groups of farmers, or through the policy environment in which they are working. The following testimony by Sulayiman Mulindwa, a plant doctor and sub-county agricultural extension officer in Hoima district, Western Uganda shows how important the support from the local implementing organization and other stakeholders in the plant health system is to address gender:

Making plant clinic services gender sensitive requires not only the knowhow but also the support of government policy and local leadership. For Sulayiman Mulindwa, a plant doctor and sub-county agricultural extension officer in Hoima district, Western Uganda, gender responsiveness while conducting plant clinics would not have been possible if there had been no complementarity with government extension, no supportive government policy and no district local leadership supportive of women. Since his local government extension work requires that he promotes technologies that are demanded by the farmers in the groups, it turns out that most of these technologies benefit the women since they are the majority in the groups. Besides, when it comes to submitting his action plans for the season, none of his budgets and plans will be passed unless there is a minimum number of women among the beneficiaries. When it comes to accounting for what he has done at the end of the season, government auditors will be keen to find out how many women he reached. On the local government political side, he observed that local leaders will always be very supportive if his plans include reaching substantial numbers of women. All this has been possible because of the supportive government policy which in its affirmative action helps plant doctors and extension agents like Sulayiman become gender-responsive. 
From Chapter 4 we know that some delivery adaptations have inadvertently led to increases in women's access or use of plant clinics, and these provide indications of how services can become more gender-responsive. As further adaptations are developed on the ground, these can be supported by providing the plant clinic staff with the necessary gender skills to ensure the adaptations are designed with all gender groups in mind. An in-depth gender capacity building trajectory based on action learning and grounded in practice to provide guidance to staff over a period of time will be very useful.

\section{Reflections and implications for plant clinic service provision}

There are different pathways to enhance the gender responsiveness of plant clinics. One includes adaptations around the mobilization of male and female farmers; another concerns gendered advice and support related to the application of recommendations. These pathways require gender-specific competency in the stakeholders involved and mechanisms to allow plant clinics to identify the specific gender problems and needs, and then to provide appropriate solutions for both men and women - as well as for youth and the elderly, and other marginalized groups. Gender is context-specific. Hence, addressing gender requires competency at district level and an adaptive capacity of the stakeholders involved to enhance the plant health system for both women and men.

\section{References}

Plantwise (2013) Monitoring and Evaluation Stakeholder Workshop, Kampala, August 2013. Report. CABI, Wallingford, UK.

UBOS (2010) Uganda Census of Agriculture 2008/2009. Volume 1, Summary Report. Uganda Bureau of Statistics in collaboration with the Ministry of Agriculture, Animal, Industry and Fisheries, Kampala. 

6

\title{
Institutionalization
}

\author{
By Solveig Danielsen, Gabriel Karubanga and Joseph Mulema
}

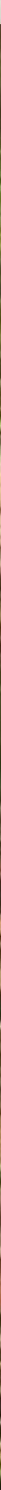


In Chapter 4, we presented a number of examples of how plant clinic services are adapted to the local context; one of the preconditions for sustainability. However, we need to consider whether that is enough for the plant clinics to keep running after the project ends. Plantwise is a project, implying that it has a limited duration and that plant clinics must continue without its support sometime in the future. Or, as an agricultural inspector in the plant quarantine section in the Ministry explained:

\section{"Plantwise is coming on board as a partner that is giving support, but after it is gone the government will take it on." \\ Benius Tukahirwa - Agricultural Inspector, MAAIF}

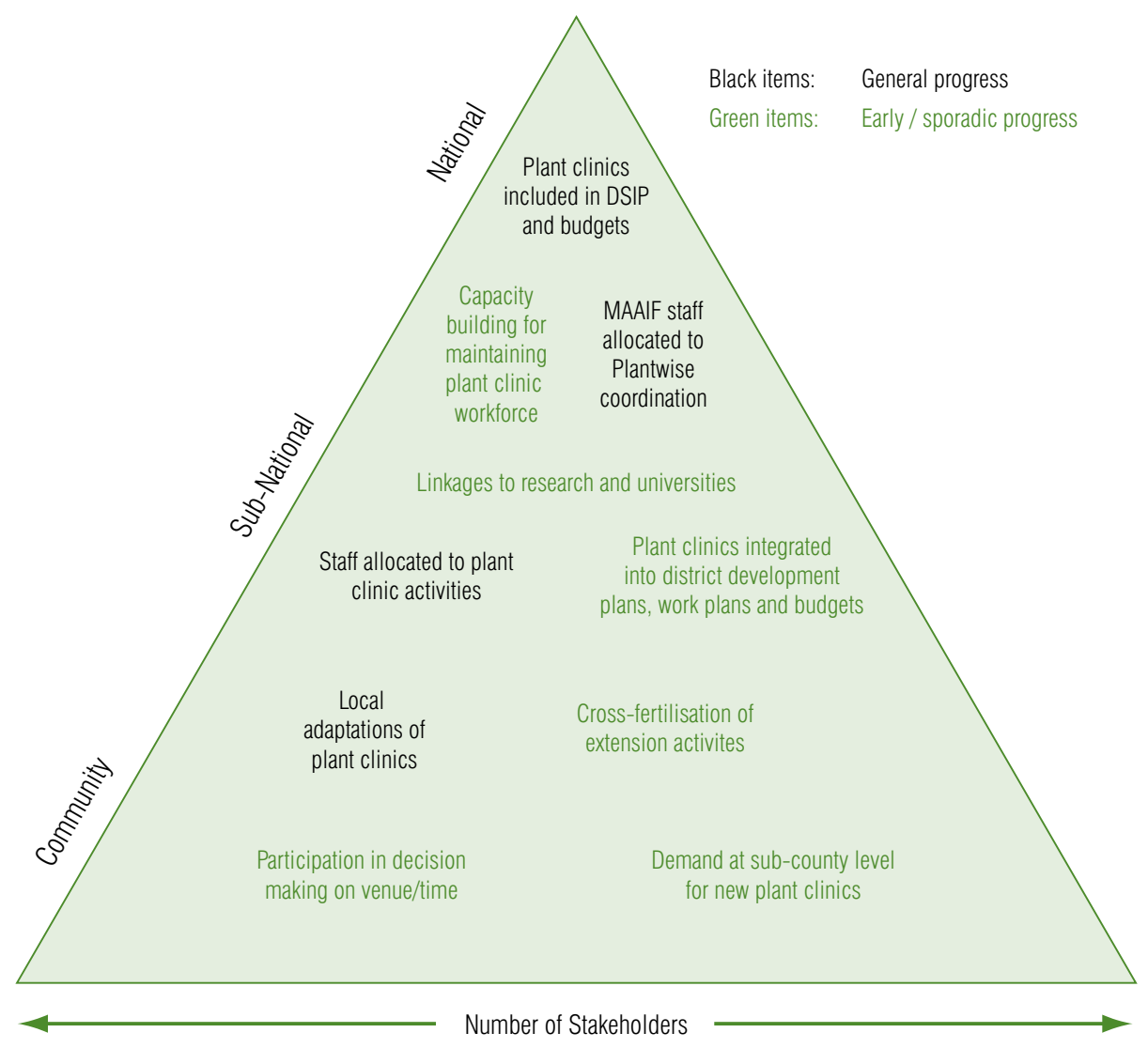

Fig. 21. Progress with plant clinic institutionalization in Uganda 
In this chapter we focus on the institutionalization of plant clinics. The sustainability of plant clinic services in Uganda is determined by the extent to which they become integrated into the prevailing policies, procedures, practices and, yes, cultures of the organizations involved and of the plant health system as a whole. But to what extent has government taken them on to date?

To provide a quick answer to the question: we have seen initial signs that plant clinics are being embedded into the national system. In order to clarify how this is taking place, we distinguish three strongly interrelated levels of the plant health system: the national, the sub-national (or district) and the community levels. We look at the institutional capacity that has been established that will help plant clinics be sustainable over time. Fig. 21 illustrates the progress made with plant clinic institutionalization at the three levels: the items marked in black are definite changes observed throughout; the green items represent incipient or sporadic developments.

Despite growing evidence of plant clinics becoming part of the Ugandan service landscape, there are a number of issues making institutionalization a steep challenge. Some relate to the context (policy, funding and workforce) and are therefore difficult to influence, while others relate to the way Plantwise is perceived and implemented.

\section{Policy support}

The government endorsement of plant clinics has been mentioned by many as a fundamental condition for the expansion of plant clinics in Uganda. Their inclusion in the DSIP in 2010 legitimizes staff and budget allocations by district local governments (MAAIF, 2010a).

The MAAIF Department of Crop Protection was one of the Global Plant Clinic's first partner organizations when it started piloting plant clinics in Uganda in 2005. Strengthening farmer services for crop protection was a key interest of the department. The plant clinics were seen as a unique way to target pest and disease control at local level and at the same time access information about plant health problems affecting farmers' fields that could be used to track epidemics and update the national pest list. The plant clinics help the government fulfil its functions as stated by MAAIF's Commissioner Crop Protection: 

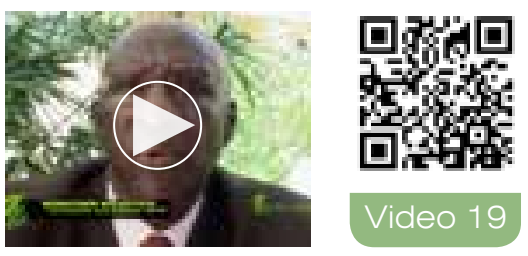

"It [the plant clinic] serves to belp us to provide technical back-up to staff in local governments. It's an extension tool we use to extend knowledge to the farmer through the plant clinics and generally it supports us in mapping out and generating information on pests and disease occurrences within Uganda. You know, pests and diseases are one of the challenges faced in agriculture. We lose between 20-30\% before harvest and 10\%-20\% after harvest. So if we can get this initiative to help us in reducing crop losses then that initiative is a good initiative."

\section{Komayombi Bulegeya}

commissioner crop protection, MAAIF

The department has allocated staff to support and oversee the activities. The DSIP budget for 2013/14 included USD 28,000 for plant clinic activities, such as plant clinic starter-kits, technical backstopping, monitoring plant clinic performance and plant clinic data management. MAAIF has declared its commitment to sustain the plant clinic initiative as part of the plans for agricultural sector development after the Plantwise programme ends.

The expansion of plant clinics in recent years was indisputably made possible by the official approval given by the government. Yet the inclusion of plant clinics in the DSIP has not, unlike the establishment of NAADS, been followed up by policy and budget guidelines to assist districts with implementation. It is left to each district to determine how they can make the plant clinics a reality.

The turbulence surrounding extension policies in Uganda, described in Chapter 1, has added to the difficulties. Many stakeholders are asking themselves: "Where do plant clinics belong? Under extension or crop protection? How do they materialize at central and district level?" The institutional set-up in Uganda - with decentralized extension, two parallel extension systems and weak linkages between the districts and MAAIF - provides no clear answer (Danielsen et al., 2014).

The Commissioner Crop Protection is clear in his view:

\section{"The plant clinics belong to us. We started them and we put them into the Development Strategy and Investment Plan."}

MAAIF and district local governments do have the formal mandate to manage pests and diseases, yet minimal capacity to implement and enforce actions. NAADS has more staff and resources to operate in the field, yet its implementing guidelines decree 
advisory services to be delivered to farmer groups who prioritize three commodities of their choice on which to receive support. The plant clinic approach of 'any crop, any problem' does not easily match the NAADS design. The lack of clear policy guidance for plant clinic implementation makes it difficult for the districts to plan and budget. Whether the clinics are taken up and embedded into the district's core activities depends on local initiative and leadership.

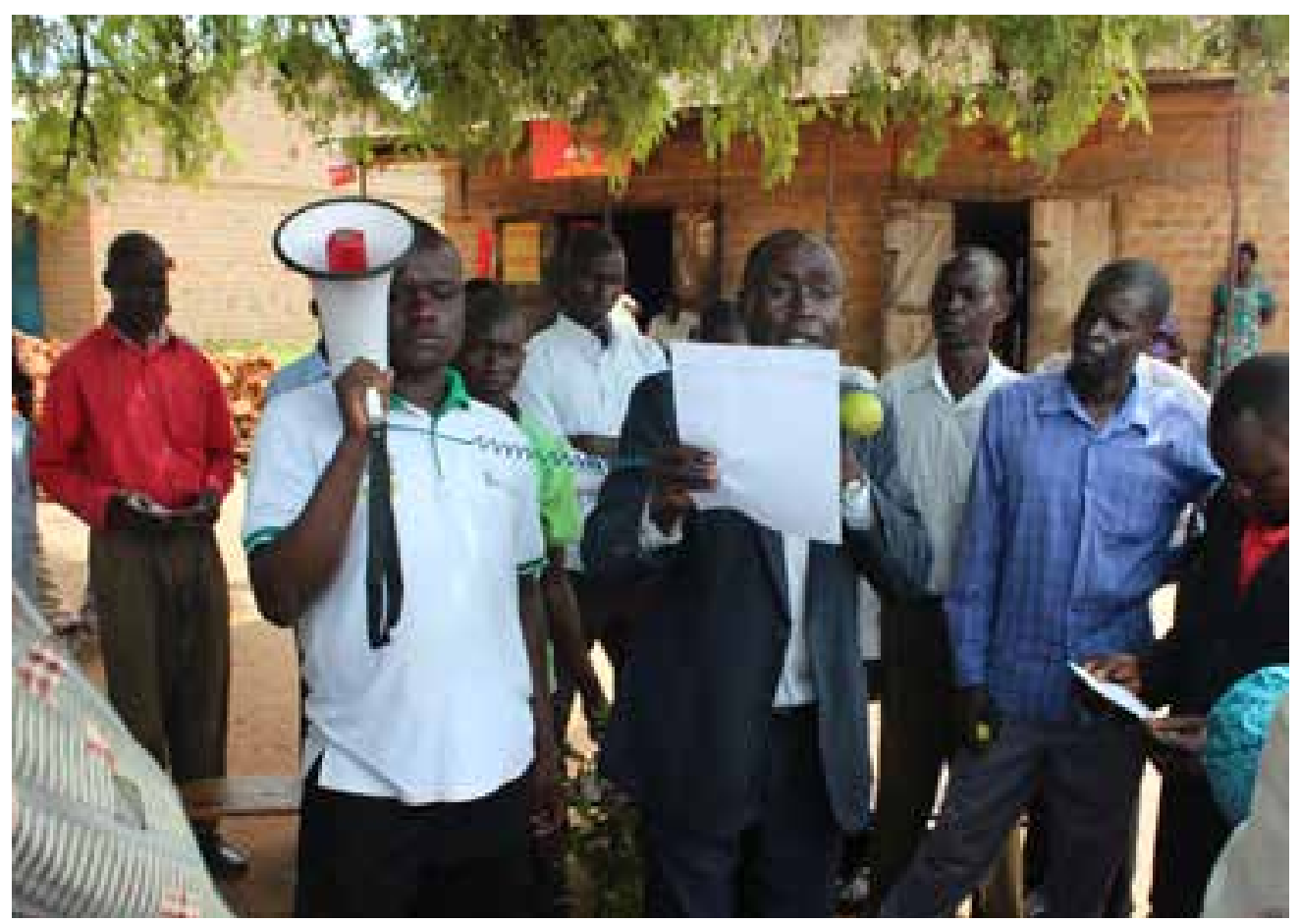

Direct involvement of and support from local leaders is key to success

\section{Financing}

The uncertain policy environment is also reflected in the budgets. The current level of DSIP funding is far from sufficient to cover the costs of basic activities that are supposed to be part of MAAIF's core functions (MAAIF, 2012). Data management, plant clinic monitoring, national coordination and oversight rely heavily on Plantwise funding. Given the current scale of plant clinic operations, the funds put aside in the DSIP to support plant clinics will not go far. Although agriculture is a high priority area for the Ugandan government, funding constraints to the national budget mean available funding for implementation at field level is limited. Many agricultural activities rely on donor-funded projects, which contributes to fragmented and uncoordinated interventions. 
Given the nature of funding of extension services, it is difficult for the district local governments to provide stable funding for plant clinics. The most frequently reported challenge was lack of operational funds for transport and allowances. This, together with workload and staff scarcity, are the main reasons for irregular plant clinic operations. The plant doctors sometimes subsidize their participation by using their own money to support the clinic activities.

In general, operational funds for district local government extension activities are minimal. NAADS provides some operational funds for field activities, though the amount is also restricted. Most of the available NAADS funds $(\sim 80 \%)$ are used to procure inputs for farmers. The district local governments' funding for social services comes mostly from conditional grants from line ministries and is meant to be supplemented by co-funding from internally generated resources. However, the mobilization of local revenue is a big challenge for most districts in Uganda, thus affecting the quality and scope of service delivery (Bashaasha et al., 2011).

District local governments expressed a lot of concern regarding sustainable funding of plant clinics. They argued that the five year DSIP is not enough to ensure the government's commitment to sustainable support of the plant clinics. The lack of guidelines for implementation and funding of the strategy creates doubt about who should be responsible for sustained funding of plant clinics.

\section{District budgets and work plans}

There are several signs that in some places plant clinics are being taken up by the districts and embedded into the existing structures and dynamics. One common feature is that all districts allocate staff time for plant clinic implementation. Commitment and appreciation of the plant clinic approach was expressed in different ways by district officials. One mentioned that the plant clinics have helped to strengthen the collaboration between NAADS and district local government extension staff.
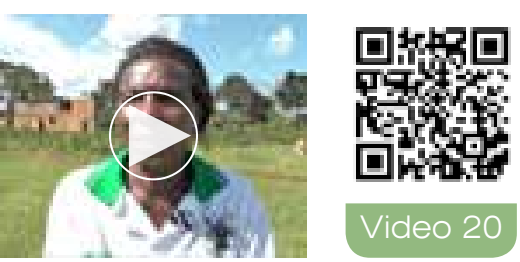

"Before we were very thin on the ground, it was not possible to see each person. When we're here, we don't see everybody, but when we announce there is a plant clinic many people come, we meet many people at the same time, using very few resources. One person can meet 20-25. When we go to the field we can meet about 5 , and the resources are very limited."

\section{Vicky Nyakatura}

plant doctor, Nkonkonjeru 
How the districts view and deal with the plant clinics varies from district to district. Policy guidelines are interpreted differently by different districts. Whereas some district local governments think of plant clinics as a separate project, others have moved further and started including plant clinics in their annual budgets and work plans. For example, Hoima district (Western Uganda) local government allocates about USD 3800 every financial year to cater for clinic staff logistics and purchasing simple materials. They are looking for ways to diversify funding sources. Currently the funds come from the district core budget, the Production and Marketing Grant and local revenue generated through a small tax charged on produce leaving the district, e.g. ten shillings (USD 0.004) per kilogram of rice and coffee.

The inclusion of the plant clinics in the district development plan in Hoima ensures the necessary political support to their institutionalization. The work plans are also shared with the district administrative leaders to nurture their collective buy-in.

In some districts (e.g. Buikwe in Central Uganda) the district agricultural officer allocates funds for plant clinics from the conditional MAAIF grants, such as the Production and Marketing Grant, without necessarily seeking political approval from the district council. Plant clinics are then included in the district local government work plans although they are not directly reflected in the terms of reference of the extension staff.
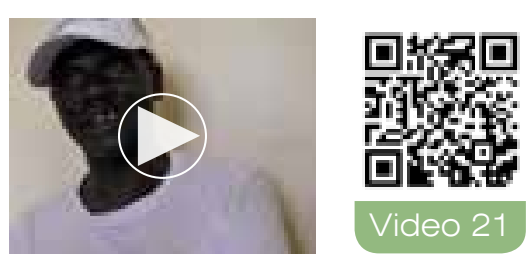

"If we generate money from the agricultural subsector, before we take the money to serve the whole district, to distribute it in various sectors, we first get 10\% of the money we have collected from the agriculture subsector as revenue sources. Then we say $10 \%$ will be ploughed back into the sectors for their own appropriation to facilitate the activities. This is how we have raised the money. So if we collected money form the fisheries sector for example ten million, automatically one million must go back to fisheries subsector. If we collected it from forestry produce, one million should go back to the forestry subsector. If we collected it from the agricultural production of rice, rice milling, if you have access to rice mills, maize mills, if they all paid that money we total it up and get $10 \%$ of the money that we have collected from the sources and then we plough it back to the budget of agriculture. So this is how we have taken that initiative and raised funds to finance some of the agricultural activity. This is why we're now working with Plantwise. They put in some small money and we also put in money that is being generated. If we let our crops die then we should have nothing to market tomorrow and the sector will die."

\section{Hon Mulindambura Mugenyi} chairperson district local government natural resource committee, Hoima 
Other districts are reluctant to use these grants for plant clinics since they are not explicitly mentioned in the guidelines. For example in Mukono (Central Uganda) the plant clinics are not regarded as part of the district's core functions. They are implemented as a 'surprise' activity and not mentioned in the work plans. A plant doctor from Mukono is trying to advocate for more district local government support to enable more frequent plant clinic sessions:

\section{"Instead of working twice a month here we can work every week, but in [a] different area so we can reach more people. I'm lobbying the local government to put funds here, or open up another tent. I don't think we need to go back to CABI to get this, because we have the tent."}

Lyazi Daniel - plant doctor, Mukono district

\section{Building a plant clinic workforce}

Human resources for agricultural extension are scarce in Uganda (Bashaasha et al., 2011; MAAIF, 2012). The projected level of staffing of the NAADS programme (two AASPs per sub-county) cannot be achieved with the current extension-worker-to-farmer ratio of 1:3189. The district reform in 2010, when some districts were split up, exacerbated the staff scarcity. It is difficult to run plant clinics as well as carry out all other duties as extension workers. Plant clinics are often an addition to existing extension functions rather than a replacement. Heavy workload and turnover of staff is a common challenge reported by district local government staff, and one of the factors affecting plant clinic regularity. In some districts, the plant clinic staff regard the clinics as extra work and the

\section{Roles of institutions in Plantwise}

Ministry of Agriculture, Animal Industries and Fisheries (MAAIF), Department of Crop Protection - technical backstopping of local governments in plant pest and disease control, equipping plant clinics, coordination and custody of data management

Makerere University - research and training, technical backstopping of plant clinics, including diagnostic support

National Agricultural Research Organisation (NARO) - research, technical backstopping of clinics, including diagnostic support 


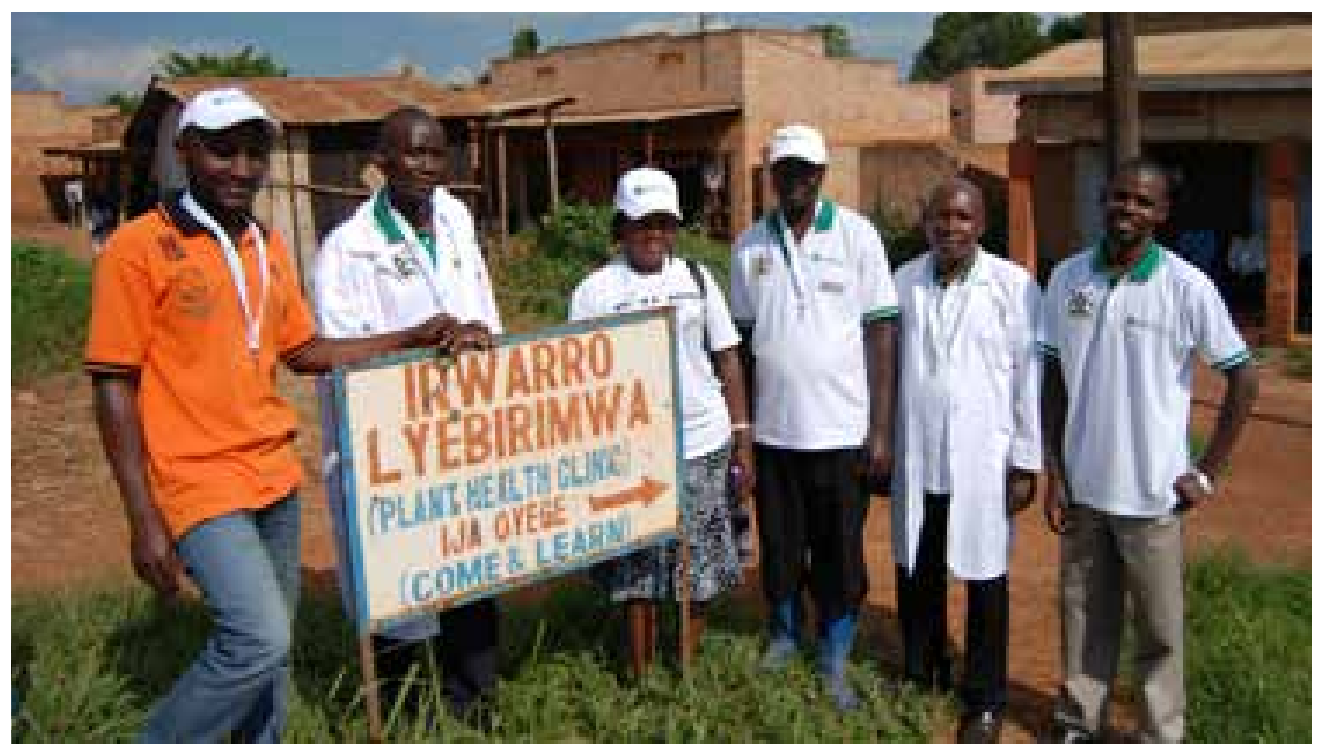

Plant clinic workforce

incentives to run them are limited. The plant clinics are not included in the contracts of the NAADS staff and are therefore not regarded as official duties in the same way as their other obligations. When the workload requires prioritization of tasks, the plant clinics are often sacrificed first owing to their more informal status.

MAAIF, Makerere University, NARO and district local governments have been involved in teaching recent courses. In the first two years of Plantwise the focus was on training plant doctors in field diagnostics and giving advice, while increasing emphasis has been given to data management and monitoring in 2014 .

In 2010, consultations started between CABI and Makerere University to discuss how Makerere and other universities and agricultural colleges could become involved in plant doctor training and eventually take over full responsibility. The School of Agricultural Sciences at Makerere University showed keen interest early on because it saw the plant clinic initiative as a means to support professional development of new and existing cadres of extension workers. It was also a way for it to apply its technical expertise more widely through the connection with plant clinics. A senior lecturer stated that, "Plantwise is helping us to do what we are supposed to do."

Little progress was made during the start-up phase of Plantwise, but from late 2012 renewed negotiations began. Different models are being developed for future plant doctor training, all under Makerere University's leadership (Fig. 22). The first model, described below, is being applied already. 


\section{Training of 1st year students as part of their practical year - being} implemented. Under this model the Plantwise Modules I and II are taught by Makerere University staff back-to-back over five days. The first cohort of 90 students from five African countries were trained in 2013. The course was well-received and Makerere University used the event to profile its role and commitment. ${ }^{6}$

The course will be repeated in 2014 with Plantwise funding, but from 2015 the costs will be included in the university budget. Ugandan Christian University has applied to conduct the training in 2015. Makerere University will carry out ToTs to enable such involvement by other universities.

2. In-service training - in planning. The first step in the process is to review the plant doctor course in its current form and assess whether there are clients willing to pay for it. Thereafter, the course will be modified to fit the needs of the clients: district local governments, NGOs (national and international), ministries and universities. The plan is to decentralize the course to other universities ${ }^{7}$ and keep accreditation and quality control with Makerere University. All who want to be trained will have to apply to Makerere University and cover their own costs. The same model is already being used for a one-week agro-dealer course offered by the university.

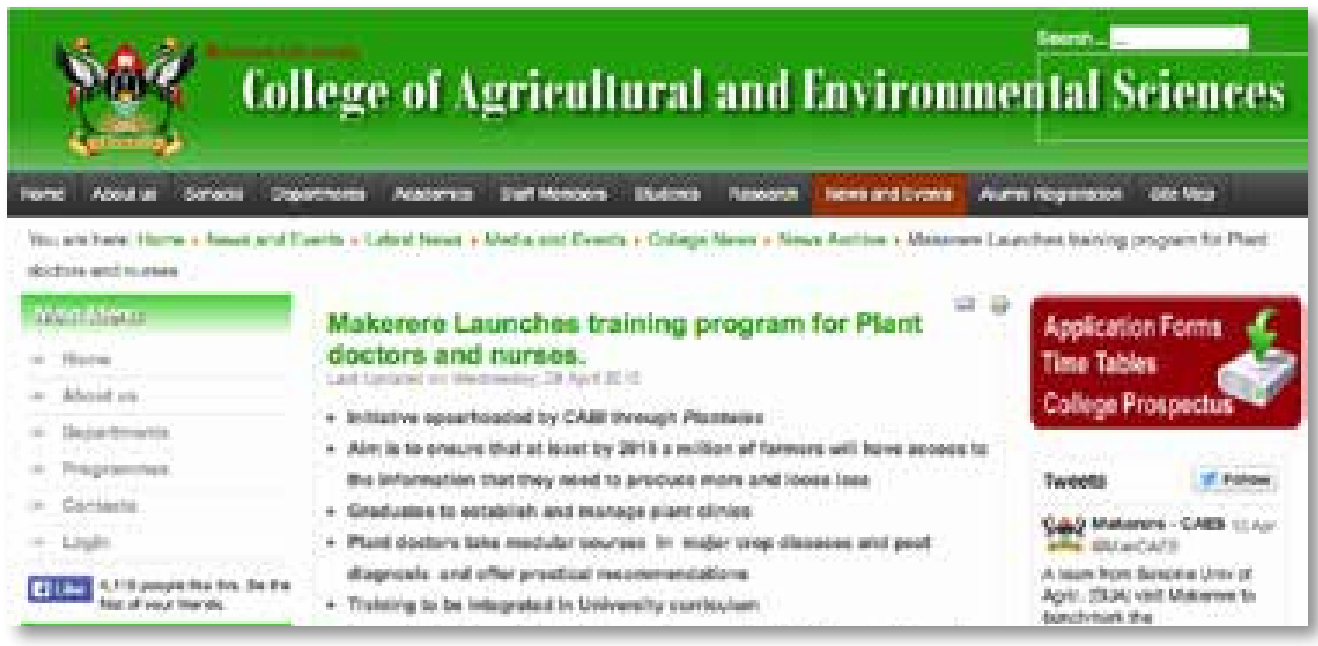

Fig. 22. Makerere University launches its training programme for plant doctors and nurses

6 http://caes.mak.ac.ug/news-a-events/latest-news/1415-makerere-launches-training-program-for-plant-doctorsand-nurses.html

7 e.g. Gulu University, Busitema University, Ugandan Christian University, Kyambogo University, Nkozi University and Bukalasa Agricultural College. 


\section{Integration of Plantwise modules into a university curriculum - in planning.} Changing a university curriculum is a long process that includes curriculum review, needs assessment, application to the university senate, curriculum development and several further rounds of review. Once such a course is in place, however, all agricultural students, most of whom end up in extension, will have the opportunity to be exposed to plant doctor training. This is part of formalizing the profession, akin to how it is in human health (doctors, nurses, etc.).

\section{Stakeholder engagement and networking}

Engagement with multiple plant health stakeholders is a key part of the Plantwise strategy. So far Plantwise's focus has been at the central level, where stakeholder engagement has taken place through Steering Committee meetings, national forums and individual meetings with MAAIF, Makerere University, NAADS and NARO. The Steering Committee aims to carry out advocacy and undertake strategic discussions about sustainability and stakeholder engagement. At the moment several Steering Committee members such as representatives of NARO, the Uganda National Agro-Input Dealers Association (UNADA), district local governments and UNFFE are not directly involved in specific activities, making their roles unclear. Apart from Makerere University's plans to establish a national system for plant doctor training, limited progress has been made to strengthen linkages with other plant health system actors.

The sole focus on the central level has restricted progress at district and community levels. For example, problems with farmers' limited access to quality inputs exist throughout the country. They are mentioned again and again by plant doctors and farmers. Currently no viable solution has been developed as to how plant clinics can help strengthen the links to reliable sources of inputs.

The introduction of plant clinics has in some cases led to strengthened linkages to diagnostic laboratories and other expert support from universities, research institutes and MAAIF. A plant doctor from Mukono reported that institutional arrangements between the districts, Mukono Zonal Agricultural Research and Development Institute (MUZARDI) and MAAIF existed already, but there was no tradition for extension workers to use these sources of technical backstopping. The plant clinics made the demand for expert support more explicit, so now samples are sometimes sent to either MUZARDI or MAAIF's laboratory in Namalere, although the numbers are still low. The logistics of the referral are challenging (packing, storing, transport). If a sample arrives in a decayed state at the laboratory there is not much that can be done about it. 

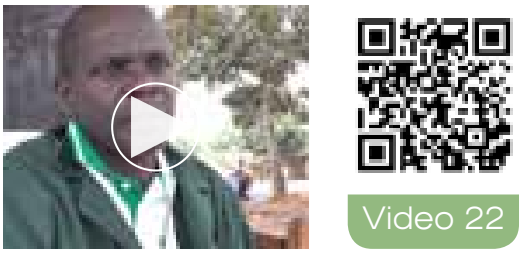

"T've come close to input dealers around the area whom I can send farmers to. They also tell me when there's something new on the market: seeds, fertilizer and pesticides. So we have the linkages. I can connect farmers to input dealers, to other pathologists as experts. In Mukono we have NARO, the research centre, that the first place you can refer to. I can call and move very fast. If they can't help they can send to higher authorities in Makerere and so on. We are getting more connections. I know how to refer and how to advise never to use uncertified seeds. So we are working with the market masters to get stalls for input dealers to come closer to farmers, to avoid some dubious inputs."

\section{Lyazi Daniel}

plant doctor, Nakifuma

\section{Local ownership and accountability}

For farmers to demand and use the plant clinics as a reliable source of information and advice, they need to trust them. There is still limited evidence of farmer communities 'owning' the plant clinics. The Plantwise interventions have so far not targeted this level directly by, for example, involving farmers in decisions about where, when and how the plant clinics should operate in their community. Some of the implementing organizations have made efforts to involve farmers in decisions on place and time, but most clinics are operated at a market, during market hours, on the assumption that this is most suitable for farmers, both men and women. Using plant nurses and or change agents from the target communities appears to create a conducive environment for the farmers to own and trust the plant clinic services.

Apart from the anecdotal evidence of the plant clinics being valued by the farmers, the survey conducted in 2013 in the three regions

showed that clinic users, both men and women, appreciate the services of the plant clinics. The number of clinics and plant doctors is inadequate. However, the interactions with plant doctors and the quality of the services in particular are perceived as adequate. Clinic users from Lugazi and Nkokonjeru said that they appreciate the open and friendly interaction with the plant doctors. For some clients the nature of the interaction helps relieve some of their stress, fears and worries and is seen as a form of 'counselling'. A farmer in Mairirwe plant clinic said: 
Such a favourable environment contributes to farmers gaining trust in the clinics and the plant doctors. A farmer from Nakifuma expressed his hopes that the plant clinic will stay:

\section{"I hope that they sustain these clinics because of the many advantages it has brought to the community. The farmers are appreciating it, they are using it, so it will be sustainable."}

There are also examples of sub-counties demanding new plant clinics. These examples point towards communities seeing the plant clinics as a valuable service they may want to keep and 'own'.
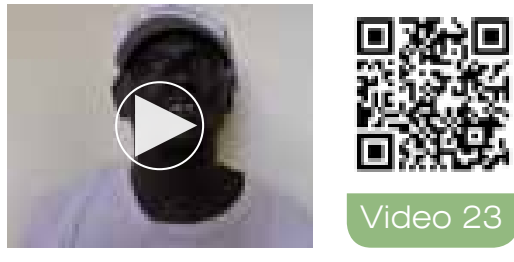

Video 23
"The idea of having plant clinics in our subcounties came up when we started experiencing strange diseases that could affect our crops, and consequently affecting the yields. So we looked at it through the agricultural budget component. We found it very paramount and important to have a budget line for funding local research on

these plant diseases. It came up along the way, organizing farmer groups that could work on the ground to establish the affected plants and bring them to the sub-county and then using the extension workers and the district agricultural offcer as the focal person, to pick up the plant materials that had been infected and study them critically, liaising with the Bulindi Zonal Agricultural Research Institute to establish the nature of the diseases. And also to disseminate the best farming practices that can wipe out some of the diseases, aware of the fact that some of the diseases come up because of climatic change, some from poor soil management during cultivation and agriculture, some arising out of transmission by vectors like during the process of pollination."

Mulindambura Mugenyi - chairperson district local government natural resource committee, Hoima

Engaging farmers and local leaders in decision making and establishing accountability mechanisms with the communities is not explicitly considered in the Plantwise strategy. Mechanisms to collect farmer feedback on a regular basis still need to be put in place. Asking farmers to come back and tell the plant doctors how the advice worked may not be the most obvious way.

\section{"I could not go back to the plant clinic because my problem was solved after applying cypermethrin against groundnut aphids as prescribed by the plant doctor. If a human being is cured after getting the treatment from the human doctor, does he/she go back and tell him/her 'I have been cured'?"}


The assumption is that if the plant clinics provide a regular service, offering effective, feasible and safe advice, then farmers will sustain the demand for plant clinics and embrace it as theirs. The plant clinic will become a 'social magnet'. There are several reasons why these assumptions may not fully reflect the reality in Uganda.

Farmers' demand and trust are influenced by the quality of services and the way they are delivered and perceived. Interviews with farmers quoted in other chapters revealed that the choice of location, day and hour for plant clinic operations do not always match farmers' routines, thereby limiting their accessibility. Plant clinics are part of a complex and sometimes messy service landscape with many actors and sudden changes. It takes time and compliance to gain the trust of communities. Government agencies are vulnerable to policy changes and political interference and often farmers are used to non-compliance of government service providers. A study by Sseguya et al. (2012) from Kamuli district showed that government agencies were less trusted by farmers compared with some of the NGOs. Some NGOs are stable and well-rooted in the communities, while others have a short-term project horizon that may change with changes in donor priorities. All this influences people's trust and willingness to embrace a specific service. The funding and staffing situation of the Ugandan plant clinics is precarious and for many of the staff it is challenging to comply with the established schedule. A previous study from Mukono and Buikwe reported cases of farmer complaints because plant doctors arrived late or failed to turn up for clinic sessions despite telling the farmers that they should come and attend (Karubanga et al., forthcoming). This lowers the farmers' motivation to attend subsequent clinic sessions. If it happens too often that a planned plant clinic session does not materialize, or that a plant doctor fails to provide promised prompt feedback after sending a sample to a laboratory, farmers' confidence will quickly be lost.

\section{Basic procedures}

Planning, coordination and communication of Plantwise activities are to a large extent driven from the top and rely heavily on Plantwise funding. Not all roles and mechanisms of coordination and communication are clear among CABI, MAAIF, NAADS and the districts. The interactions with the districts revolve around Plantwise activities planned and funded by CABI, such as training, review meetings, stakeholder meetings and monitoring visits. Beyond this there are no formal coordination and communication mechanisms between the Ugandan stakeholders. The Plantwise Steering Committee mainly oversees Plantwise implementation, and the National Stakeholder Forum functions primarily as a consultative group. Both entities are driven and funded by Plantwise. 
The lack of clear policy guidelines for plant clinic implementation by the Ugandan government leaves everybody in a stalemate where roles, responsibilities and procedures are unclear. Implementation is largely ad hoc, preventing both central- and district-level organizations from fully embedding the plant clinics into their core functions.

Monitoring plant clinic performance is also managed from the central level and funded by Plantwise. It is organized by the Plantwise national coordinator and carried out in two ways.

1. Regional review ('cluster') meetings with plant doctors and their supervisors. The meetings are supposed to be quarterly but this has turned out not to be realistic. The meetings are hugely popular, since they are one of the few occasions that the plant doctors can meet and interact with their peers and feel connected.

2. Monitoring visits to plant clinics by the Plantwise coordination team. The visits are used to assess the appropriateness of the clinic venue, check procedures and progress, talk to the plant doctors and identify challenges. With plant clinics in so many districts it is only possible to visit a fraction of them.

The district agricultural officers and NGO coordinators have the formal responsibility for monitoring their technical staff. Although some of them have received training in monitoring, clinic-relevant performance monitoring is done individually and randomly, if at all.

The reporting procedures vary between districts. Hoima district local government produces specific plant clinic reports, while others do not. The reports from Hoima indicate the progress of plant clinics in terms of number of clients who attended the plant clinics, the problems presented and the villages where the clients came from. The district agricultural officer reports to the district production and marketing officer who later reports to MAAIF. However, it is not clearly defined overall who should report to whom, and how and when. The Ntunda sub-county NAADS coordinator recommends that plant clinics should not be treated as a separate entity in reporting to decision makers but as a component in the district reports. However, some district local governments consider plant clinic reporting as a separate activity carried out for the funders, with or without reporting to the district officials. Parallel reporting systems impede institutionalization.

Plant clinic data management. The plant clinic data are regarded as key for strengthening plant clinics and the links between actors in plant health. The Plantwise data manager 


\section{Examples of potential uses of plant clinic data}

- Document farmer attendance

- Identify farmers' plant health problems in time and space

- Support surveillance by tracking epidemics and new diseases

- Identify topics for plant health rallies

- Assess quality of diagnostics and advice

- Identify plant doctor training needs

- Identify researchable topics calls them an 'engine' of the whole plant health system that can support decision making at different levels. Plantwise gives high priority to putting in place a functional data management system that can fulfil the multiple potential uses of the clinic data (Box 6). However, making the system work has been a big challenge. After 2.5 years the system is still not working as intended and the data are largely inaccessible. Despite several attempts during the course of the studies documented in this working paper, it was not possible to gather the most basic information about clinic operations (dates, attendance) in Uganda.

The data management system is based on Plantwise-designed formats and procedures. During recent data management training, a process for recording, entering, transferring, harmonizing, validating, analysing and sharing information was designed for Uganda to ensure effective management and use of data (Fig. 23). However, the way the data management system is set up creates many bottlenecks and dependencies. The process has turned out to be tedious, costly and unworkable.

Data recording. The prescription form developed centrally by the CABI Plantwise team is regarded as too long and complicated by many plant doctors. Plant doctors in the focus group discussions explained that it is time-consuming to fill and captures a lot of information that is never used. The Plantwise format leaves no room for local adaptations.

The prescription form attempts to serve several purposes. Parts of the form provide a type of aide-memoire to guide the plant doctors in the diagnostic process. Other parts target information intended for research. Use of a form that tries to collect information serving too many different purposes may cause confusion about the purpose and lead to unnecessary delays in the diagnostic and prescription process.

Data entry. MAAIF is supposed to be the national 'data hub' for plant clinic data for the whole country. The national data manager (a MAAIF member of staff) receives prescription forms from the respective district agricultural officers for data entry and harmonization, 


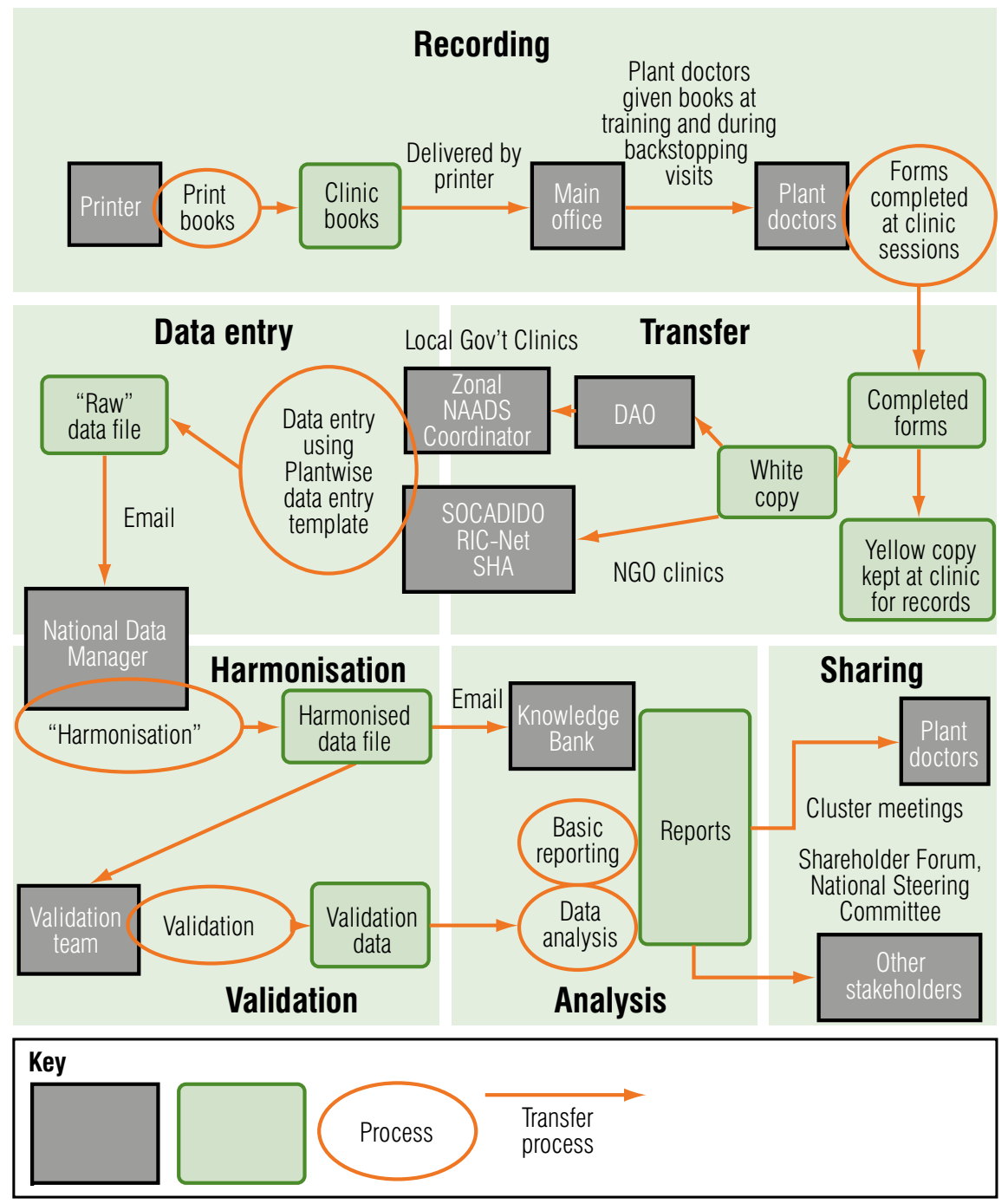

Fig. 23. Plant clinic data management system for Uganda developed at a Plantwise data management course (Masaka district, March 2014)

and later validation by a team of technical experts from Makerere University, NARO and MAAIF. The process of getting the prescription books to Kampala is a challenge in itself, as is keeping up to date with data entry. It quickly became clear that the workload would be too high for the MAAIF staff as the number of plant clinics increased. Prescription books collected at review meetings and monitoring visits quickly create a backlog of data to be entered, so at times MAAIF mobilize additional staff to help enter them. The national data manager finds the process complex and difficult to operationalize. So far only data from Self Help Africa and Mukono and Buikwe district local governments have been entered on the system. The data management structure (Fig. 23) suggests the involvement 
of the zonal NAADS coordinators in the data entry process. However, they still have not been recruited and it is also unclear what the incentives would be for them to carry out this task. The Plantwise Excel ${ }^{\circledR}$-based data entry template transforms the data into a spreadsheet with approximately 120 columns that national users find impractical and difficult to use.

Data harmonization (data cleaning and standardization to aid reporting, e.g. orange, oranges, orange trees) is perceived as a straightforward process, according to the national data manager. The data validation carried out by in-country experts with specialist knowledge (checking the diagnosis and recommendations given by the plant doctor, i.e. does the diagnosis match the symptoms, is it plausible, and are recommendations effective, safe, and practical?) is, on the other hand, resource-demanding. At a recent data validation workshop, ten experts from MAAIF, Makerere University and NARO spent 1.5 days validating 351 plant clinic queries. Assignment of this task to MAAIF, Makerere University and NARO implies that they have a formal mandate to assess the quality of the work of local government and NGO extension workers, which is debatable. Thus there are unanswered questions about the purpose of the data validation and who should pay for it in the future.

Data analysis is planned to take place within the access-controlled POMS using the different tools Plantwise has developed and continues to develop (including offline tools). At the moment, all data analysis responsibility rests with MAAIF and Plantwise. The Department of Crop Protection decides who can have access to the data. With the current system, the districts are unable to use the data for their own purposes. There are no functional procedures for reporting and data sharing. The data appear to become 'lost' as soon as they leave the district, which is a serious disincentive to comply with the data management system requirements. As the district does not retain copies of the prescription forms, it would not be possible for staff to enter and analyse the data locally even if they wanted to.

Self Help Africa has consistently sent prescription forms to MAAIF for data entry. So far the data have not been returned to them so there is uncertainty as to what the data are being used for. 


\begin{abstract}
Now that they send the prescription forms to MAAIF, they are left with notbing. "For us it is a big setback. We don't have the data as we had before. We only have the rough manual summaries that the community-based facilitators make every month. I think we need to go back to the old system with a simple format we could manage ourselves. The plant doctors complain that the new prescription form is too long, but then I say that we have to comply with the new standards that are required."
\end{abstract}

\title{
Dorothy Naikesa - Self Help Africa
}

Apart from the challenges of making the data processing work, the cost of implementing the proposed data management system is high. A rough cost estimate of the key steps (Table 13) shows that processing one query costs between USD 1.16 and USD 9.41 depending on whether the estimate is based on internal or external costs. Costs of transporting the prescription books to and from the districts are not included in this calculation.

This and previous studies on plant clinics in Uganda demonstrate how big a challenge information management is in general, at both central and district level. Information about plant clinics, their activities and farmer attendance remains largely inaccessible. It has required a huge effort by research teams to process

\section{Estimated costs of plant clinic data processing}

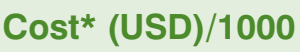

queries

\begin{tabular}{|c|c|c|c|c|}
\hline $\begin{array}{l}\text { Data processing } \\
\text { step }\end{array}$ & $\begin{array}{l}\text { No. queries/ } \\
\text { day/ person }\end{array}$ & $\begin{array}{l}\text { Staff } \\
\text { required }\end{array}$ & Internal & External \\
\hline $\begin{array}{l}\text { Prescription forms, } \\
\text { print cost }\end{array}$ & - & - & 440 & 440 \\
\hline Entry & 100 & Data clerk & 200 & 120 \\
\hline Harmonization & 1000 & Data clerk & 20 & 100 \\
\hline Validation & 40 & Expert & 500 & 8750 \\
\hline Total & & & 1160 & 9410 \\
\hline
\end{tabular}


the collected data to reveal what is happening on the ground. In 2010 MAAIF's Statistical Abstract (MAAIF, 2010b) included data summaries about plant clinic activity that had been published in a research working paper (Danielsen and Mutebi, 2010). In 2011 there were no plant clinic data in MAAIF's Statistical Abstract (MAAIF, 2011) because there were no means of getting hold of them. Poor data and information management affects accountability, planning and decision making at all levels. To date, the data management system introduced by Plantwise has not helped solve the fundamental problems.

\section{Project identity}

Despite signs of institutionalization of plant clinics, ownership is still hindered by their project identity. Many government interventions are carried out as projects with a myriad of partner organizations and donors. The agricultural sector in particular has been affected by years of fragmented and uncoordinated activities, thus undermining lasting organizational change (MAAIF, 2010a). Many agencies are used to the timelimited project dynamics and interventions are often seen as 'belonging' to the partner organization and/or donor.

This is the case with plant clinics. Owing to the way they were introduced, plant clinics are still by and large seen as a Plantwise/CABI project, which limits the scope for local adaptations and appropriation. The features listed in Box 7 signal Plantwise ownership. The lack of policy and budgeting guidelines for plant clinic implementation has left the districts with many unanswered questions that prevent them from 'owning' the plant clinics fully. The project identity raises expectations of funding and reliance on external guidance thus limiting local initiative to seek solutions to emerging challenges. Farmers are also used to projects, sometimes even to the extent that they are characterized by the organization they 'belong' to,

\section{Plantwise aspects that give} plant clinics a 'project identity'

- Dependency on Plantwise funds for key activities

- Centralized Plantwise coordination

- Limited participation in decision making re strategy, prioritization and procedures

- Introduction of pre-established procedures for e.g. clinic data management

- Plantwise branding of all materials (banners, uniforms, printed materials) 
e.g. 'NAADS farmers', 'Self Help Africa farmers', 'Caritas farmers', etc. The habit of labelling projects with logos of the implementers and donors add to the 'projectification' of farmers. This has at least two unfortunate consequences.

Firstly, the presence of different, at times competing, projects in the same area may cause farmers to over-estimate what a plant clinic can do for them. The previous study in Mukono and Buikwe showed that many farmers expected to find free agro-inputs and improved planting materials at the plant clinic as well as the advice provided by the plant doctor. A plant clinic user from Nkokonjeru compared the plant clinics to human health clinics:

\section{"When one visits a human clinic, and is diagnosed of malaria, helshe is provided with medicine after being given advice. But at the plant clinics only information/advice is provided to the clients. Will our crops cure just by the information given at the clinic without chemicals or drugs?" (Karubanga, 2012)}

Secondly, farmers may exclude themselves from attending the plant clinics if they do not see themselves as belonging to the organization or to a farmer group facilitated by the organization depicted on the banner or tent. Such a project mentality affects demand and ownership by farmers for plant clinic services.

\section{What is required to create a coherent plant health system?}

To ensure that plant clinics are sustained and institutionalized into the existing structures, the system in which they operate needs to be more coherent. The interventions must be better directed towards creating the necessary conditions. Fig. 24 summarizes the key recommendations drawn from the evaluation study.

\section{Develop adaptive plant health systems}

Central to the sustainability of plant clinics is the establishment of adaptive capacity in the plant health system and strengthening the linkages between the actors in the plant health system from bottom to top. Adaptive capacity in the plant health system requires space for joint reflection, experimentation, adaptation to the local context and collective action. It requires the involvement of representatives of relevant stakeholders, including farmers (men and women), plant doctors, district local government staff, researchers, agro-input dealers, NGO staff, local leaders and AASPs among others. Plant clinics are 
regarded as the vehicle for building the adaptive capacity of the system, but the ultimate objective should be the improvement of plant health services and not the implementation of the plant clinic model itself.

\section{Develop policy and funding guidelines}

Clear policy and funding guidelines are required to ensure effective policy implementation at both central and district level. Such guidelines should be developed jointly by MAAIF and the implementing agencies to make sure that the roles and responsibilities at district and central levels are clearly defined and match the existing human and financial resources, as well as the institutional mandates and structures. This will give the plant clinics a clear home and enable district local governments to allocate funds and staff to sustain the operations. Only then can plant clinics become part of the normal routine extension work. It also makes plant clinics less vulnerable to the unstable policy environment and political interference.

Diversified and proactive funding strategies are needed to counterbalance the unstable and insufficient funding from central government. Plant clinics should be mentioned explicitly in the guidelines of all relevant government grants (e.g. the Production and Marketing Grant) to enable resource mobilization. District local governments have several avenues for raising local revenue including the model used in Hoima, where middlemen are taxed a small amount per kilogram of produce that leaves the district. Alternative, as yet unexplored sources of funding include using the government's District Local Government Development Programme to strengthen local service delivery. 


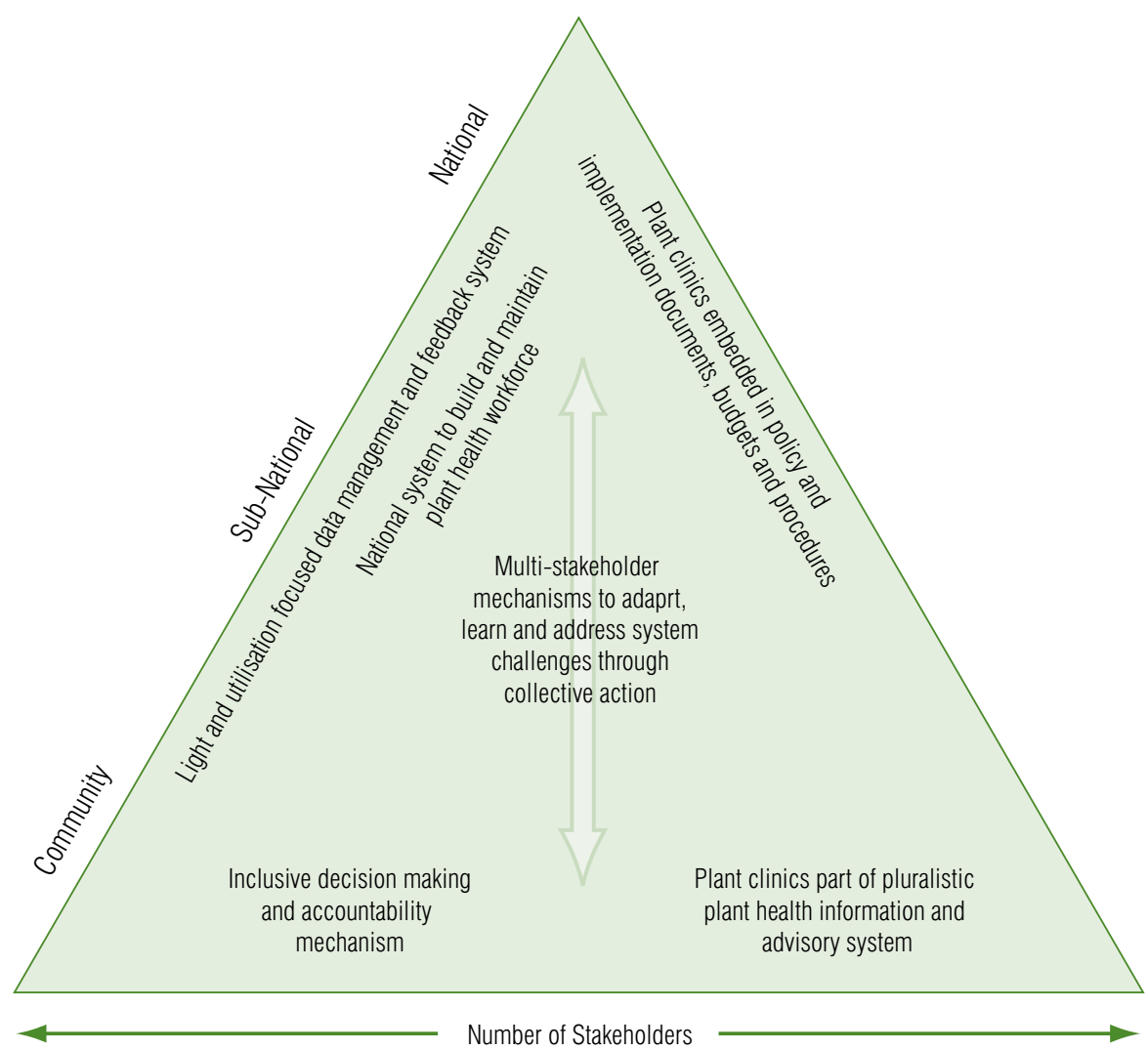

Fig. 24. Creating an enabling environment for plant clinics and their institutionalization at different levels

\section{Build and maintain plant health workforce}

The establishment of a national system to provide and maintain the necessary plant health workforce countrywide is a key part of institutionalization of plant clinics. A formalized system for plant doctor training embedded in the national educational system is seen as an important condition for the professionalization of the plant doctor function. The plan to decentralize the course to universities other than Makerere enhances the possibilities for training plant doctors locally, reducing costs significantly. The involvement of local universities and training institutes also provides opportunities to adapt the training modules to the local context and needs. Staff and resource scarcity can be a major constraint. It is worthwhile experimenting with engaging and strengthening alternative service providers, including agro-input dealers, as well as lead farmers. 


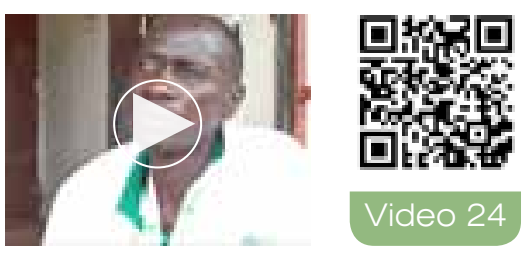

"In fact this kind of arrangement will be sustained. It needs the active involvement of the district officials, the people themselves to own it, not just separate people from outside. It needs a budgetary component, they should allocate a budget for this kind of plant clinic so it can be sustained. It is very important. The farmers themselves, they should continue demanding the services, that will allow the government to see the importance of this kind of arrangement and also allocate a budget for this kind of arrangement."

\section{Sulayiman Mulindwa}

plant doctor, Hoima district

\section{Establish simple and effective monitoring procedures}

A coherent plant health system relies on effective procedures for implementation, coordination, data management, monitoring and reporting. Implementing organizations must be guided by jointly agreed procedures and tools that can assist them in establishing plant clinics and make the necessary adaptations to make them fit the local conditions. The district should be self-reliant in all its operations. A model of driving events from the centre creates bottlenecks and blocks progress and creativity, especially in an uncertain policy environment like that in Uganda. It also undermines ownership. The districts must be in charge of their own monitoring and data to serve the specific needs of their districts. Only then can the plant clinics support decision making effectively and ensure accountability to farmers.

The data management system needs to be simple, 'light' and utilization-focused. Data should be made readily available and used to ensure good decision making at different levels and to support accountability, monitoring and learning. Therefore, the prescription form needs to be re-visited to make sure it fulfils its main purposes, e.g. (i) to provide a written recommendation to farmers, (ii) to provide basic information that can be used by clinic implementers for accountability, performance monitoring and follow-ups and (iii) to enable MAAIF to track pest patterns in the country. The higher up in the system, the less information is needed. For example, to be able to track epidemics, outbreaks and pest patterns, MAAIF only needs information about date, location and pest.

The current review meetings are fully funded by Plantwise and are unlikely to take place without it. Cheap, locally based alternatives are needed. One alternative could be to find avenues to add plant clinics to the agendas of existing follow-up and planning meetings in the districts and regions. 


\section{Involve farmer communities}

Strengthening grassroots would enhance farmer buy-in and accountability. There needs to be more attention on downwards accountability mechanisms, i.e. to farmer communities, and to find ways to engage these communities in decision making to enhance ownership, trust and farmer orientation. At the moment the focus is on upwards accountability. The support of local leaders is crucial to help embed the plant clinics in the community and create a sense of local ownership as well as sustaining farmers' trust in the service. For example, intensifying publicity through local leaders, politicians, farmer groups, schools and community meetings could be one way to create more awareness about and ownership of plant clinics.

\section{References}

Bashaasha, B., Mangheni, M.N. and Nkonya, E. (2011) Decentralization and Rural Service Delivery in Uganda. IFPRI Discussion Paper 01063. International Food Policy Research Institute, Washington, DC.

Danielsen, S. and Mutebi, E. (2010) The Introduction of Mobile Plant Clinics to Uganda: First Results and Lessons Learned 2005-2010. Working Paper 1. Centre for Health Research and Development (DBL), University of Copenhagen, Copenhagen.

Danielsen, S., Matsiko, F. and Kjær, A.M. (2014) Implementing plant clinics in the maelstrom of policy reform in Uganda. Food Security 6(6), 807-818

Karubanga, G. (2012) Performance assessment of plant health clinics in Buikwe and Mukono districts, Uganda. MSc thesis. Department of Extension and Innovation Studies, Makerere University, Uganda.

Karubanga, G., Matsiko, F. and Danielsen, S. (forthcoming) Performance assessment of plant health clinics from the perspective of clinic users in Buikwe and Mukono districts, Uganda. Journal of Agricultural Education and Extension.

MAAIF (2010a) Development Strategy and Investment Plan 2010/11-2015/16. Ministry of Agriculture Animal Industry and Fisheries, Entebbe, Uganda.

MAAIF (2010b) Statistical Abstract. Agricultural Planning Department. (www.agriculture. go.ug/userfiles/Statistical\%20Abstract\%202010.pdf, accessed 9 December 2014).

MAAIF (2011) Statistical Abstract. Agricultural Planning Department. (www.agriculture. go.ug/userfiles/Statistical\%20Abstract\%202011.pdf; accessed 9 December 2014).

MAAIF (2012) Proposed Plan to Operationalise the non-ATAAS Component of the Agricultural Sector Development Strategy and Investments Plan. Ministry of Agriculture Animal Industry and Fisheries, Entebbe, Uganda.

Sseguya, H., Mazur, R., Abbott, E. and Matsiko, F. (2012) Information and communication for rural innovation and development: context, quality and priorities in southeast Uganda. Journal of Agricultural Education and Extension 18(1), 55-70. 

7

\section{Conclusions}

By Remco Mur, Solveig Danielsen, Frances Williams and Joseph Mulema 
Let's start with what is not in this working paper: attendance figures. The effectiveness and impact of plant clinics in Uganda first and foremost depend on the number of farmers attending plant clinic sessions. Hence, it is a must to know how many farmers, men and women, are attending them. However, we are not able to provide clarity on this issue. The current data management system does not provide the required data. This leads to some important lessons, as we will see later in this chapter.

Nevertheless, there are plenty of interesting stories to tell and valuable lessons to draw. Through this working paper, we have made an effort to understand better how plant clinics can provide relevant, inclusive, demand-driven quality plant health services in a sustainable way, and how they can contribute to strengthening the plant health system of which they are part. The major aim of writing this working paper was to learn from practice. In this chapter we summarize the most important lessons from plant clinic experiences in Uganda. These lessons are valuable for people directly involved in and responsible for plant clinic operations, such as plant doctors and nurses, but also their managers, the operators of the plant clinics, and researchers. There are lessons that can benefit those involved in building the capacities of the plant clinic workforce, such as national universities and sub-national training institutions. National-level decision makers can benefit from the lessons learnt: how they can effectively contribute to the establishment of plant clinics and building resilient and adaptive plant health service systems in their country. In addition, there are a number of lessons and recommendations of particular interest for Plantwise and their funders, which deal with aspects of the question: how can Plantwise effectively facilitate national governments and sub-national-level actors in establishing and improving plant health services in sub-Saharan Africa and beyond? In addition, of course, the lessons can benefit anyone else with an interest in plant clinics, plant health services, or agricultural advisory services in general.

In this working paper we have zoomed in on three important practice areas.

- Plant clinic operations and local plant clinic adaptations that emerged to improve performance, reach, quality, effectiveness and impact.

- Inclusivity in plant clinic services, addressing the needs of diverse farmers in Uganda and more specifically, gender issues.

- Embedding and institutionalization of plant clinics in policies, procedures and practices of the organizations and institutions of which they are part. 
We do not claim to be exhaustive, as there might be many more interesting experiences out there that were not included in the reflections that formed the basis of this working paper.

\section{Local adaptation}

Plant clinics are based on an externally conceived model, now being implemented in 31 countries worldwide. In Uganda, the first clinics were established in 2005. At first sight, the plant clinic model seems a rather straightforward model for establishing demand-driven service delivery: you train plant doctors, you provide the necessary equipment and the clinics are ready to go. However, experiences presented in this working paper show otherwise: establishing and sustaining plant clinics, and contributing to better plant health systems, is far from easy. The model does not necessarily fit the local conditions of the area where it is implemented. There are many explicit and implicit underlying assumptions to the model that need to be tested. If they do not hold true, the model needs to be adapted. Often the best way to test the underlying assumptions is through experimentation. It requires the actors in the plant health system to experiment, reflect, learn and adapt. In fact, this is what has been happening in the local implementing organizations that have been operating in the districts in Uganda over recent years. In most cases, however, this has not been an explicit or deliberate process.

In this working paper, we have considered the establishment and operationalization of plant clinics as an institutional innovation process: the way plant clinics operate, are managed and integrated in the wider plant health system, and become part of policies, procedures and routine practices. How this materializes depends on many factors, including the agro-ecological features of the area (crops, diseases, soils, climate) and the policy, institutional and socio-economic environment the local implementing organizations operate in. These factors are different for each country, district and, yes, even for each plant clinic. We have seen many different plant clinic adaptations.

\footnotetext{
Plant clinic adaptations refer to the changes made to the plant clinic model to make it fit the local context. The adaptations are necessary for plant health services to remain relevant, inclusive and sustainable. These adaptations may be district-wide, particular to the local implementing organization, and also plant clinic-specific. Innovation is the process of bringing knowledge into use to achieve desired social or economic outcomes. It is
} 


\section{the ongoing and iterative process of reflection, trying out and adapting new ideas, knowledge or practices. The plant health system needs to continuously adapt to the changing context, including emerging new diseases, the ever changing needs of farmers, and policy changes. This requires adaptive capacity in the plant health system and its actors.}

Some of the major adaptations that we have described in this working paper include mobile clinics, the engagement of nurses and change agents, the use of ICT and mass media in information dissemination, and new combinations of plant clinic services with other services, e.g. soil testing and advice on agronomic practices. These adaptations are specific to the actors that are involved and the place where they occur. None of the plant clinic adaptations were planned for; they are not part of the 'official' plant clinic model. Nevertheless, they emerged, in a rather spontaneous manner, simply because there was a need for them: there were challenges to overcome or opportunities to be seized.

\section{'THE plant clinic' does not exist}

We have witnessed that plant clinic adaptations mainly take shape at the sub-national and local level, driven by the interactions between actors directly involved in plant clinic operations, including farmers, plant doctors, plant nurses, their managers, local leaders, farmers' associations and NGOs. The experiences presented in this working paper bring us to an interesting conclusion:

\section{In Uganda, there are many plant clinic adaptations. Adaptations are necessary because of the geographical disparities and the many different implementing organizations. Even at the different plant clinics within a district, adaptation has been taking place in different directions.}

\section{The need for a systems approach}

The major aim of the plant clinic adaptations that have taken place was to increase the reach of the clinics, either by enabling the clinics to handle more people at the clinic sessions, or ensure effective mechanisms to disseminate messages and knowledge generated at the plant clinic, for example, through farmer-to-farmer exchange, change agents, plant nurses, radio or text messages. Apart from widening the reach, some of the adaptations can enhance inclusion, for example of women farmers. Group approaches contribute to the exposure of farmers to a wider range of problems and consequent solutions. There are 
initiatives that integrate different types of services such as soil testing, general agricultural advisory services and animal health services. The Plantwise theory of change argues that plant clinics are an entry point to influence the bigger system, rather than an end in themselves. However, practice shows that so far the focus has been very much on the plant clinics as such, largely ignoring the wider system. This wider system includes different service providers deploying different extension approaches. Private, public and civil service providers each have their role to play.

The effectiveness of plant clinics lies not only in their direct encounters with farmers, but may lie even more in the ways the knowledge and messages generated at the plant clinic are disseminated through various indirect, formal and informal, channels. The effectiveness of these channels relies on many different actors and their mutual interactions; the plant health system. Future interventions need a more explicit focus on building the capacity of the plant health system and the actors that make up the system, rather than on promoting the plant clinic model as such. An actor-oriented and systems approach to plant clinics is considered most suitable. This will allow the emergence of synergies and complementarities of other extension approaches and other services, contributing to pluralistic and integrated service delivery systems.

\section{Plant health systems: redefining the boundaries}

What system, exactly, are we talking about? What are the boundaries, who are the actors and who is excluded? The way Plantwise addressed the plant health system in Uganda focused mainly on the formal actors, i.e. different government agencies at different levels, and research organizations and the NGOs that are directly involved. According to its theory of change, Plantwise aims to:

- Link farmers to extension

- Link different extension providers

- Link extension staff to technical expertise

- Link extension and input suppliers

- Link extension and regulatory bodies 
Although the theory of change suggests differently, in reality, the project has not explicitly targeted most of these linkages. It has mainly contributed to linking farmers to plant doctors, one of the many different types of extension workers operating in Uganda. There is some anecdotal evidence that other linkages have improved too, but these are exceptions, and opportunities may have been missed. For example, agroinput dealers have not been part of the project interventions whereas they appear to be a very important source of plant health information and technology for many farmers.

We argue that the boundaries of the plant health system need to be redefined. The different actors and their interactions that play a role in the development, exchange, adaptation and application of plant health information and technology are multiple. The system includes the actors identified in the theory of change. However, the local, informal plant health system actors have not been considered: farmers, and especially women farmers, depend on their informal networks of families, friends and neighbours for accessing plant health information. A less rigid way of looking at plant health services is required: private sector actors such as agro-input dealers and farmer leaders, among others, may play a role in advisory services. As we have seen, there are differences between the implementing organizations in the different districts. There is a need to redefine the boundaries of the system at the district level, taking into account the different stakeholders and local dynamics related to plant health information. This includes the development, dissemination, adaptation and application of knowledge and information, but also components related to access to seeds, fertilizers, botanical and chemical pesticides, agricultural tools and laboratory analysis.

\begin{abstract}
The boundaries of the plant health system go beyond the formal, government-based system. They include private and civil sector actors, local actors. First and foremost the system includes farmers themselves, in all their diversity, but also farmer groups and local leaders, among others. In each district the boundaries of the system will be different. Defining the actors that belong to the system is the responsibility of the actors themselves and is a first step in strengthening the plant health system.
\end{abstract}

\title{
A new focus: building adaptive capacity
}

The introduction of plant health clinics can serve as a vehicle to strengthen the plant health system, making plant health services available, accessible, more relevant and effective. So far, the emphasis of Plantwise in Uganda has been on the introduction 
of the plant clinic model and reaching scale rather than on strengthening the system, experimentation and local adaptation. There are reasons for that. Plant clinics are generally perceived as a promising model. District local governments have shown great interest. Currently there are 145 plant clinics in 70 districts, an impressive achievement in a short period of time. This large number implies that the attention CABI staff is able to pay to each of the districts is limited and that most plant clinic implementing organizations are pretty much 'on their own'. Apart from the plant doctor training, Plantwise interventions have mainly targeted actors at the national level. We recommend an approach that explicitly targets the actors and system at sub-national and local levels. This, however, does not imply that national stakeholders are excluded.

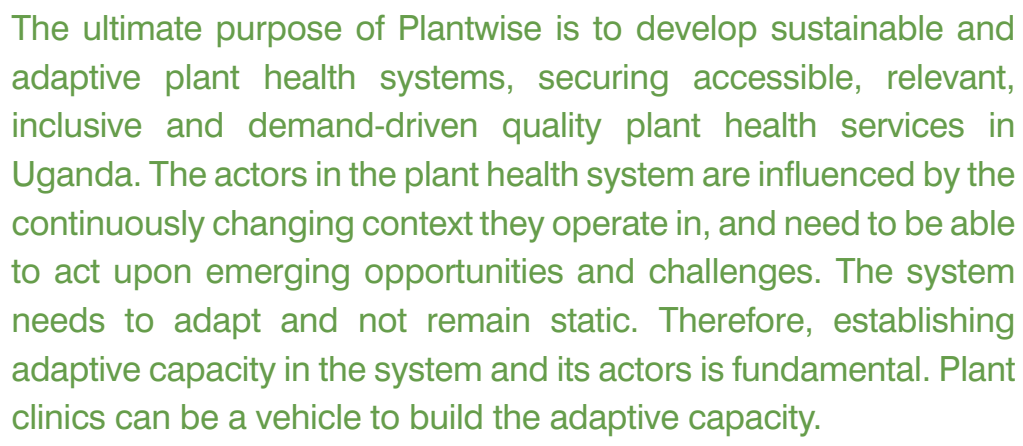

The need to strengthen the adaptive capacities of the system and the actors involved requires putting in place mechanisms through which the actors can jointly identify and address (contextual) challenges and opportunities, try out new ways of doing things, adapt and engage in collective action.

Plantwise has been rather rigid in promoting a particular plant clinic model, designed and implemented in a particular way (fixed market place, fixed day, standard prescription form, for example). In a more actor-oriented process, geared towards building adaptive plant health systems, stakeholders might even reject the plant clinic model in its current form and adopt other more suitable approaches, or combinations of approaches, to demanddriven plant health service delivery. This should not be regarded as a failure, but as the outcome of joint learning. 


\title{
Gender
}

The lack of attention to gender differences is a longstanding weakness in agricultural advisory services' discourse and practice. However in recent years it has started to get some much-needed attention. There are gender disparities in terms of access to and control over plant health services, the appropriateness of the way advice is provided, and the suitability and relevance of the provided advice. The constraints women face in accessing plant health services are related to their specific roles and responsibilities, including intra-household power relations and culture.

Although Plantwise has its Gender Strategy, the local implementing organizations do not explicitly address gender in any of the regions. Gender-disaggregated data collection on clinic attendance is the sole gender-related activity. However, as the data management system is not functioning properly, even this has been ineffective. It is high time to address the gender issue explicitly with rigour and broad experimentation.

Interestingly, many of the plant clinic adaptations can potentially address gender disparities: they bring services closer to farmers, including women, and they integrate plant clinics with other approaches to information dissemination that are more appropriate to women. Yet none of the adaptations are really focusing on the suitability and relevance of the advice for women.

In order to put gender on the agenda, there is a need for a Plantwise facilitated action learning approach, rooted in local realities, to support the implementing organizations and other local stakeholders in developing and implementing gendersensitive strategies.

\begin{abstract}
An explicit focus on strengthening the adaptive capacity of the plant health system at sub-national level can facilitate the inclusion of women in the plant health system. There is a need for experimentation with inclusive approaches to design, decision making, service provision, M\&E and accountability. Sound representation of women in multi-stakeholder mechanisms to adapt, learn and address system challenges through collective action, with an explicit focus on gender integration, is key.
\end{abstract}

The acknowledgement of the importance of informal sources of plant health information, often accessed by women, is important. The plant clinic adaptations that have emerged can provide interesting lessons in terms of inclusion. 


\section{Institutionalizing plant clinics: creating an enabling environment}

Innovation does not happen everywhere in the same way and at the same pace. Adapting the plant clinic model involves risks and uncertainty and the extent to which the actors are able to adapt differs from region to region. Two NGOs seem very innovative. Self Help Africa has initiated mobile plant clinics and RIC-NET has linked plant clinic services to new uses of ICT and local mass media. NGOs often have more autonomy and flexibility allowing them to be creative, think out of the box, and adapt. District local governments are often bound by formal policies and procedures, and consequent staff and resource constraints.

The inclusion of plant clinics in government policy for agricultural development and the commitment of the Department of Crop Protection have been a fundamental prerequisite for the expansion of plant clinics in Uganda. They have provided the necessary endorsement for district local governments to bring plant clinics on board. At the same time, the policy environment is unfavourable for institutional stability and effective delivery of government extension services. The future of extension in Uganda is uncertain, which makes long-term planning and prioritization a big challenge, for both MAAIF and the districts. The uncertainty surrounding extension policies in Uganda can undermine the sustainability of the plant clinics.

The plant clinic expansion has happened very fast. Plantwise's focus on the central level (with the exception of training efforts) currently limits the engagement of sub-national and local stakeholders. Now it is time to focus on consolidating and strengthening at the district and farmer community levels. However, Uganda's parallel extension systems with different extension approaches and uneven budgeting for NAADS versus district local government leave the plant clinics without a clear home, making planning and resource allocation for them a big challenge. Whether the districts take up the plant clinics and embed them in the existing work dynamics with their own budget line depends on the attitude of the individual district leaders.

\footnotetext{
After three years of rapid expansion, there is a need for consolidation: for strengthening the linkages between and building the adaptive capacity of the actors at sub-national and local level. The sustainability of plant clinics, the plant clinic adaptations and the consequent systemic changes depend heavily on the capacity of these actors and the extent to which they take ownership.
} 


\section{Towards local ownership}

Currently, the strong Plantwise brand and centrally driven intervention model are constraining local ownership, adaptation and innovation. Although external support and facilitation will remain critical in strengthening plant health systems in Uganda, the Plantwise branding and pre-established procedures signal that plant clinics are a CABI project. The project identity of plant clinics limits local and national ownership and buy-in. Also, the dependency on Plantwise funds for key activities is a risk to the sustainability of the initiative.

Creating adaptive plant health systems at district level requires support at central level. Responsibility and ownership at district level are fundamental to sustainability. There is a need to define roles and responsibilities clearly at central and district levels. This is particularly important in a Ugandan setting where the districts have a high degree of autonomy in policy implementation and decision making and MAAIF is constrained by its limited capacity and weak structures. The central level should facilitate, not impose or control, and constantly look for creative ways to make best use of its scare human and financial resources. Functions of central level could include:

- Establishing and maintaining a national plant health information system.

- Providing diagnostic backstopping.

- Developing effective and flexible mechanisms with the districts and sector institutions to respond promptly to disease outbreaks.

- Strengthening quality control and enforcing laws, rules and regulations (seeds, fertilizers, pesticides).

- Providing effective policy guidance.

The roles and responsibilities of the sub-national- and local-level stakeholders could include:

- Operating and managing plant clinics, including information dissemination.

- Making human and financial resources available.

- Ensuring downward accountability.

- Adapting plant clinics to the local context.

- Developing and managing simple and effective systems for plant clinic monitoring and data management. 


\section{Simplified, utilization-focused procedures}

The current data management system does not work. There are several bottlenecks in the data management chains which make the data inaccessible for decision making and monitoring, at both district and central level. Simple and effective procedures are needed; attention should be paid to the quality of the service, effective communication and feedback mechanisms. The larger the scale, the more difficult it is to follow developments and learn from them.

The establishment of procedures for coordination, reporting, data management and monitoring has so far focused on the central level, leaving the Plantwise coordination team with the main responsibility for this. It has turned out to be a challenging task because of the speed of plant clinic expansion, the lack of clear initial procedures, insufficient funding and capacity, and weak communication and coordination mechanisms between MAAIF and the decentralized districts. The emphasis must be redirected, with more effort put into helping strengthen the districts' capacity to deliver the best possible service under the given conditions.

\section{Final remarks}

Plantwise has achieved a lot in Uganda in three years. The number of plant doctors trained and the number of plant clinics established is impressive. Plant clinics are able to fill a gap in the extension system, as a NAADS coordinator rightly states:

\section{"The plant clinics could provide a strong contribution to extension. There is need to do something new about pests and diseases" (Danielsen et al., 2012, p.7)}

This working paper has uncovered a number of challenges that must be addressed in order to make plant clinics and the related changes in the plant health system more effective, responsive and sustainable (Table 14). In Chapter 2 we mentioned that systems change requires capacity at different levels. Plantwise has contributed a lot to establishing performance and personal capacity. However, if it is to take its objective of strengthening plant health systems in Uganda seriously, it is necessary to put building organizational and institutional capacity at the spearhead of its interventions. 


\section{Capacity achievements and challenges for Plantwise}

\begin{tabular}{|c|c|c|}
\hline & Achievements & Challenges \\
\hline $\begin{array}{l}\text { Performance } \\
\text { capacity }\end{array}$ & $\begin{array}{l}\text { Kits, tents, allowances } \\
\text { (partially) for plant } \\
\text { doctors and nurses are } \\
\text { available }\end{array}$ & $\begin{array}{l}\text { Financial resources are restricted and } \\
\text { deemed insufficient }\end{array}$ \\
\hline \multirow{2}{*}{$\begin{array}{l}\text { Personal } \\
\text { capacity }\end{array}$} & \multirow{2}{*}{$\begin{array}{l}\text { Plant doctors and plant } \\
\text { nurses have been } \\
\text { trained. } \\
\text { A plan to establish a } \\
\text { national work force has } \\
\text { been developed }\end{array}$} & $\begin{array}{l}\text { Scarcity of plant doctors } \\
\text { Improving data management }\end{array}$ \\
\hline & & $\begin{array}{l}\text { Improving gender awareness and } \\
\text { responsiveness }\end{array}$ \\
\hline \multirow{7}{*}{$\begin{array}{l}\text { Organizational } \\
\text { capacity }\end{array}$} & \multirow{6}{*}{$\begin{array}{l}\text { Local implementing } \\
\text { organizations have } \\
\text { allocated human } \\
\text { resources to plant clinic } \\
\text { operations } \\
\text { Plant clinics are } \\
\text { integrated in some } \\
\text { district development } \\
\text { plans and budgets }\end{array}$} & Plant clinics not part of job descriptions \\
\hline & & $\begin{array}{l}\text { Staff scarcity and insufficient funds for plant } \\
\text { clinic operations }\end{array}$ \\
\hline & & Irregular plant clinic operations. \\
\hline & & Uncertainty about future funding. \\
\hline & & $\begin{array}{l}\text { Data management systems unnecessarily } \\
\text { complicated and costly and not serving the } \\
\text { needs of the sub-national and local stakeholders }\end{array}$ \\
\hline & & $\begin{array}{l}\text { No effective financial incentives for the delivery } \\
\text { of quality services }\end{array}$ \\
\hline & & Dependency on project funds \\
\hline \multirow{7}{*}{$\begin{array}{l}\text { Institutional } \\
\text { capacity }\end{array}$} & & $\begin{array}{l}\text { Inadequate involvement of stakeholders in } \\
\text { decision making }\end{array}$ \\
\hline & & Downward accountability limited \\
\hline & & Uneven use of farmer feedback \\
\hline & $\begin{array}{l}\text { Endorsing national } \\
\text { policies are in place }\end{array}$ & $\begin{array}{l}\text { Limited opportunity for clinic implementers } \\
\text { to adjust operations to farmers' needs and }\end{array}$ \\
\hline & \multirow[t]{3}{*}{$\begin{array}{l}\text { Funding mechanisms } \\
\text { for plant clinics in place } \\
\text { in some districts }\end{array}$} & $\begin{array}{l}\text { Narrow boundaries of the system, not taking } \\
\text { into account private sector and informal } \\
\text { sources of plant health information. }\end{array}$ \\
\hline & & $\begin{array}{l}\text { Rigid focus on the plant clinic model and not } \\
\text { on the plant health system. }\end{array}$ \\
\hline & & $\begin{array}{l}\text { Unclear roles and responsibilities of key plant } \\
\text { health system actors }\end{array}$ \\
\hline
\end{tabular}


Systems change, rooted in local realities, requires reflexivity from the stakeholders involved, and a consciousness of their own practices, position and influence on the context they operate in and also an understanding of how the context influences them. Taking a step back, and reflecting, contextualizing, learning from experiences and adapting, is critical for development practitioners, managers and decision and policy makers. However, time and resources are often too scarce to allow such reflective processes to happen. Eventually the reflective process will pay off: if lacunas, challenges and threats are identified quickly and addressed by the stakeholders of the plant health system, and if assumptions are regularly tested, systems change can be achieved and become sustainable.

\section{References}

Danielsen, S., Masiko, F., Mutebi, E. and Karubanga, G. (2012) Second Generation Plant Health Clinics in Uganda: Measuring Clinic Performance from a Plant Health System Perspective 2010-2011. Working Paper 2. Centre for Health Research and Development (DBL), University of Copenhagen, Copenhagen. 

PART II

Case studies 
The second part of this working paper consists of five case studies (Fig. 25). One person involved in each of the clinic operations in the district was asked to write the story of the plant clinic as they know it, following certain guidelines so the cases present similar information. Case authors were asked to describe the farming system(s) in their district and how plant clinics were initiated. They then discuss plant clinics activities and describe a plant clinic day from mobilization to the end.

Case authors were asked to share what they feel is special about the plant clinics and what they think is interesting to share for others to learn from. This has provided good examples of how plant clinics have adapted the methodology to the local context in which they operate. The stories were collected during the writeshop held in Kampala in June 2014.

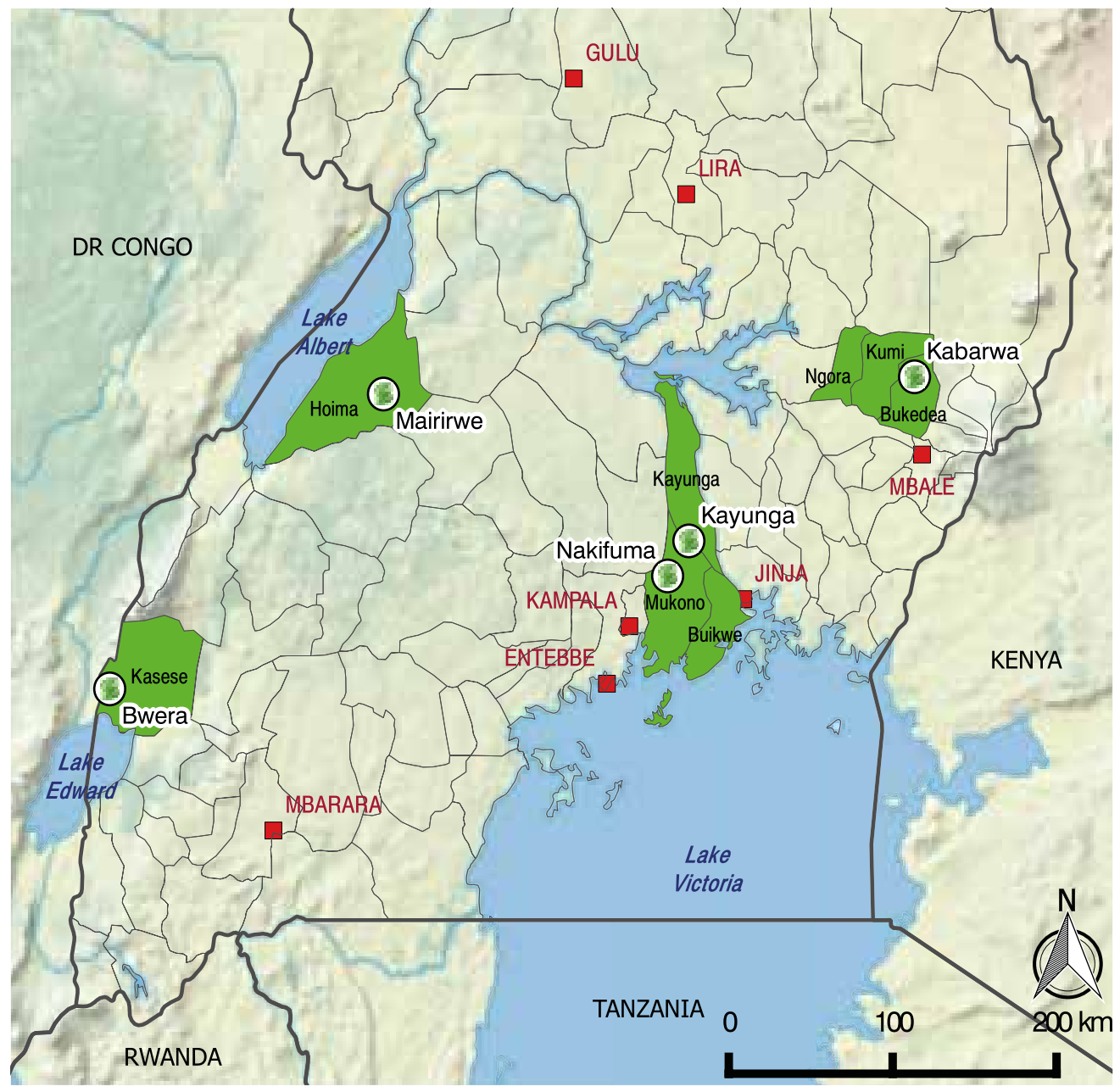

Fig. 25. Location of case studies 


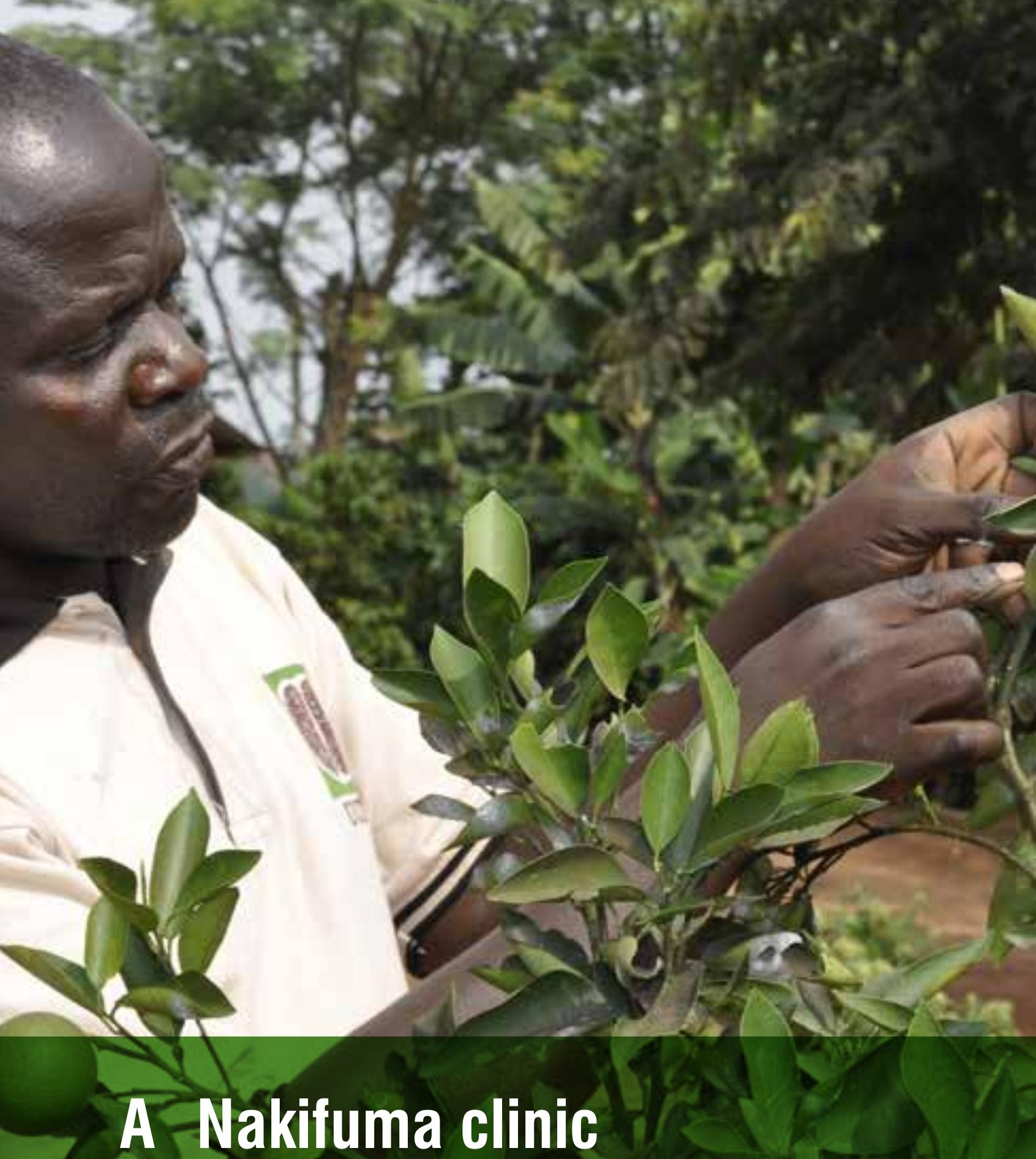

\section{By Lyazi Daniel and Remco Mur}




\section{Nakifuma plant clinic at a glance}

Local implementing organization: District local government

Nakifuma plant clinic location: Nakifuma market, Nakifuma sub-county, Mukono district, Central Uganda

Number of fixed clinics in the district: 5

Number of villages in the sub-county: 36

Number of plant doctors in district: 9 (2 female, 7 male), all district local government staff

\section{Training:}

9 doctors: Module I: Field diagnosis and running plant clinics

5 doctors: Module II: Plant healthcare

5 doctors: Production of extension materials

8 doctors: Monitoring plant clinic performance

Number of plant nurses in district: 7 ( 1 for each plant clinic; 1 female, 6 male)

\section{Number of plant doctors at Nakifuma plant clinic: 1}

Plant doctor: Lyazi Daniel, district local government agricultural extension worker. Agronomist with an agriculture diploma. Plant doctor since 2005.

Number of nurses at Nakifuma plant clinic: 1 (male)

Number of change agents in sub-county: 8 (5 female, 3 male)

Operations: twice a month

Start (year): 2005 
Lyazi Daniel became a plant doctor back in 2005. The Nakifuma plant clinic was among the first plant clinics in Uganda. At the time, it was operated by the NGO Caritas Uganda. Later, the district local government took over the plant clinics. His involvement in plant clinics was a great opportunity for Lyazi Daniel; he benefits from his contacts with farmers and the trust farmers put in him as a plant doctor. His routine extension services are more relevant now: he identifies urgent problems during plant clinic sessions and addresses these problems during other routine extension activities. In this way, he can expand the reach of his plant health advice.

\section{Farming in Nakifuma}

This working paper started with a quote from Frederick Mayambala, a farmer from Nakifuma sub-county. He expressed his dream for the next five years: expanding his farm, turning it into a profitable business. For this to happen, adequate plant health advice is a prerequisite. He is not an exception. Nakifuma sub-county indeed provides great opportunities for smallholder farmers to make farming into a business. Nakifuma town is situated only $50 \mathrm{~km}$ from Kampala, which provides opportunities for farmers to market their agricultural products. Healthy crops are key if you want to sell them at the Kampala markets. Nakifuma is a lively centre, attracting many traders from Kampala and many farmers from the sub-county and beyond come to sell their farm produce. Lyazi Daniel, who operates the plant clinic, is probably the longest serving plant doctor in the country. He has been involved in plant clinic services since they started in 2005 .

Farming is the main economic activity in Nakifuma sub-county. Other economic activities include boda-boda services (operated by young people) and minor trade in agricultural products, for example vegetables. The soils are moderately good. Land is owned mainly by men, but women can own land by inheriting from parents or husbands. And in some cases women acquire small plots of land. In addition, farmers, including women, can lease land owned by Buganda kingdom. An average farm is between 2 and 5 hectares.

The major cash crops are coffee, banana, vegetables such as tomato, cabbage, eggplant/ aubergine and water melon, and large-scale maize. Cash crops are the responsibility of men. On separate plots, women take care of food crops such as banana, small-scale maize, potato, cassava, vegetables (for home consumption) and beans. Intercropping is common, for example for coffee and banana, coffee and beans (as a cover crop), maize and beans (for consumption), just to mention a few. 
Most families raise some local chickens. Pigs and cattle are also common. Cattle are used for dairy products, both for home consumption and to generate household income. Cattle are also an important form of savings. They are not used for animal traction.

For farmers it is difficult to hire external labour. Most people that used to provide permanent casual labour in the past have started farming themselves or moved to the city. Temporary casual labour is available on a small scale. Hence, most labour is provided by family members.

Specific tasks conducted by men include bush clearing, digging holes for banana planting, carrying the harvest from the field to the home, marketing of cash crops and spraying. Women are responsible for weeding, and marketing of surpluses of food crops and some vegetables. Both men and women are involved in opening up land, harvesting and threshing. For harvesting purposes, casual labour is hired, if available, especially for horticulture. Casual labour is paid in cash or in kind with poor-quality harvested products that are not good enough to sell.

Farmers are generally not organized. There is hardly any collective marketing. Farmers sell individually at the Nakifuma market. Maize, beans and other commodities are sold at the farm gate to middlemen at harvesting time, when prices are low. Farmers generally do not store their harvested products as they are often in need of cash to pay back their debts or to purchase inputs for the next season. Men sell vegetables in Kampala where they fetch better prices. Women sell their vegetables locally and at Nakifuma market. Coffee is sold to processors.

Constraints in agriculture include the low capital base of farmers, especially women. Prices of inputs at the start of the growing season, are high, and prices of products at harvest, when cash needs are high, are low. The number of incidents of theft of livestock and agricultural products from the field has been increasing in recent years. Uncertain weather conditions threaten the crops. The prevalence of pests and diseases is a problem for many farmers, with both recurrence of known ones and new ones emerging. Because land is now under continuous cultivation, without a break, the pest and disease pressure has increased. The availability of genuine pesticides is limited and local stockists have a limited range of, often expensive, products (up to USD 60/ litre). 


\section{Back to the beginning: 2005}

In 2005 the first out-of-office plant clinics were initiated by MAAIF under a project to address farmers' problems with pests and diseases. In Mukono district, two subcounties, Nakifuma and Nkokonjeru, were selected as they had market days and were relatively accessible. Caritas, a Catholic NGO working in Lugazi diocese, supervised the first plant clinics in close collaboration with the district agricultural office. Caritas provided field staff to work with the agricultural extension staff of the respective areas. They provided furniture (chairs, tables), prescription books and allowances for lunch. The Caritas staff worked as plant clinic nurses, as most of them were not agriculturists by training, but were social workers.

Agricultural staff were given extra training by the MAAIF Department of Crop Protection and the Global Plant Clinic to help them become functioning plant doctors and run plant clinics effectively. They needed additional skills and more information on pest and disease occurrences in the area and on available solutions. Training was provided to all staff involved. Plant doctors approached the market officials about organizing a suitable and accessible clinic location.

At the start, the new approach of plant clinics was difficult to understand for both farmers and staff: how could it help farmers? Initially farmers did not bring samples and staff did not have photo sheets and factsheets, preventing delivery of appropriate advice and information. For a long time, researchers were not involved. Caritas was responsible for the plant clinic operations initially: the district local government did not have a sense of ownership so plant clinics were not integrated in annual district plans or budgets. When Caritas funding stopped the programme was forced to stop for a while, until the district local government took over responsibility.

Nowadays, the plant clinics are the full responsibility of the district production and extension services even though not all policy makers at district level are aware or convinced of the importance of the plant clinics. Plant clinics are now included in the plans and budgets of district local government, but some areas lack funding or do not receive the funds when needed, making work difficult. CABI is still supporting some clinics, but this needs to be handed over to local government to make the services sustainable. It is expected that the number of clinics will increase in the next financial year.

$\mathrm{M} \& \mathrm{E}$ of activities by district and ministry officials is still inadequate. They bear the responsibility for monitoring pest and disease occurrence and data collection and management. 


\section{Clinic operations}
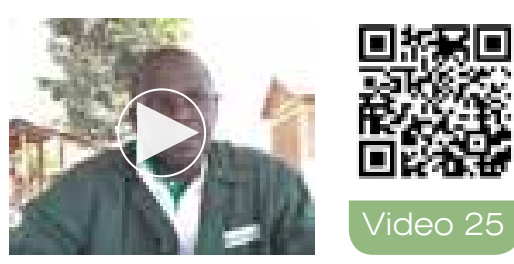

"Before Plantwise I was dealing with farmers in the field, dealing with them in meetings, training meetings. Giving them advice on diseases and soil. Before the plant clinic, we had a top-down flow of messages. During the meeting I could stage a topic to talk about, maybe we talked about bananas, maybe we talked about coffee, and maybe we talked about maize and potatoes. So farmers' challenges, problems like diseases and pests, were not addressed properly. Later, at the plant clinic now, it has changed and farmers' views are listened to. They come with a specific problem, but earlier before, you could give advice without real problems. Now they come with problems: 'I'm growing cabbages, my problem is this' or 'I'm growing pumpkin my problem is this in pumpkins'. And you give advice accordingly.”

Lyazi Daniel - plant doctor, Nakifuma plant clinic

Normally the Nakifuma plant clinic is operated by one plant doctor, Lyazi Daniel. He is assisted by a plant nurse. Plant clinics are run twice a month at Nakifuma market, which is generally known by many farmers and other stakeholders. It is an urban market in a rural area: many people attend the market; it is located in an agricultural area, near the main road, which allows farmers from Nakifuma as well as other subcounties such as Nabbale, Kasawo, Nama and Ntunda to attend the clinic. A wide variety of traders, buying a wide variety of products, attracts a wide variety of farmers, including women.

The day before the plant clinic session the plant doctor and plant nurse inform relevant stakeholders, including the Nakifuma market leaders, farmer group leaders and local leaders, by visiting or calling them. They in turn tell farmers about what is going to happen.. Local leaders use megaphones to inform the villagers. The plant nurse mobilizes farmers at Nakifuma market on the day of the clinic session. The plant doctor also tells farmers during his routine extension activities. Prior to the plant clinic session, the plant doctor and the plant nurse try to collect samples of cases of pests or diseases they have come across in the sub-county. They bring the samples to the clinic to show to farmers for reference. 


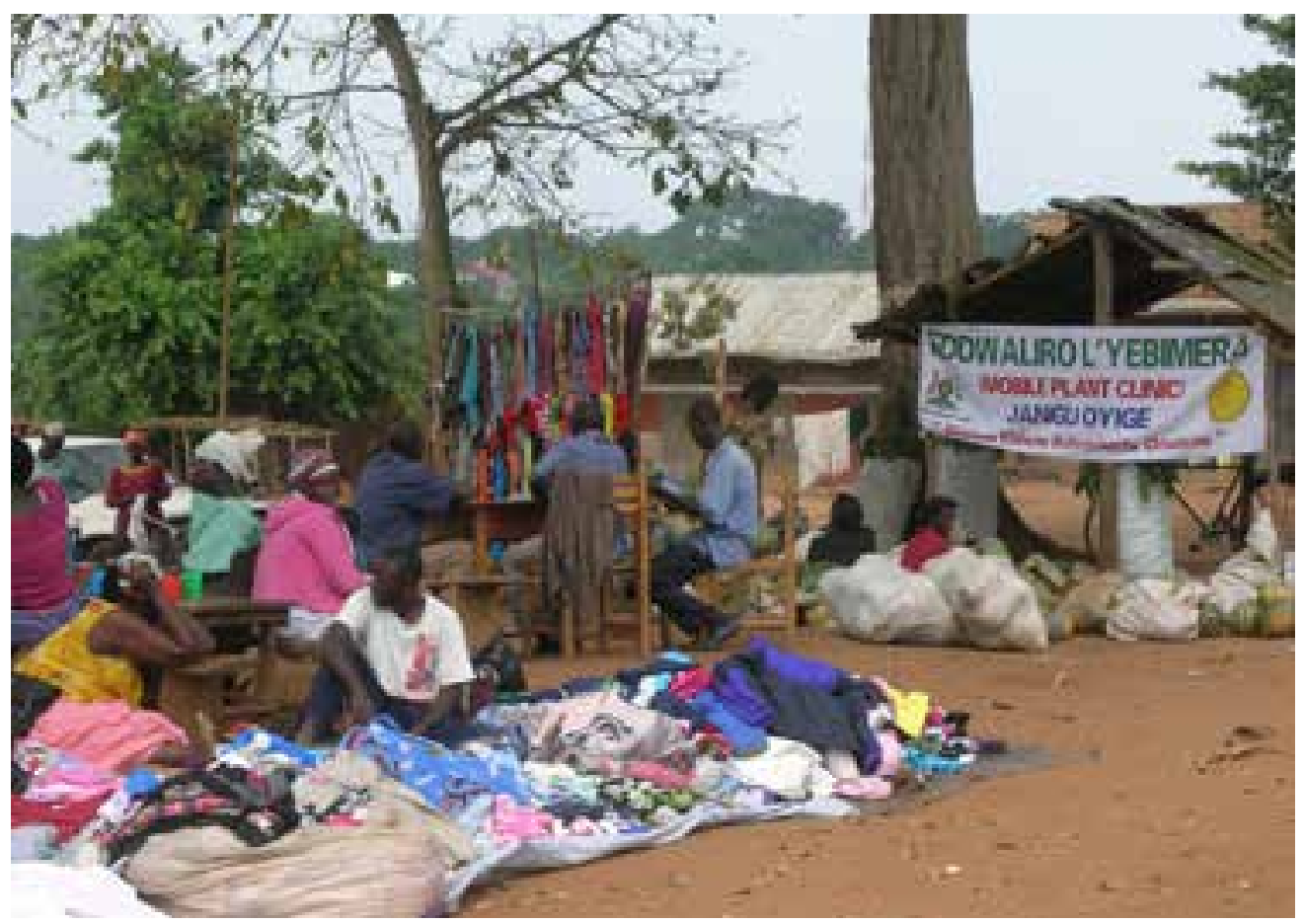

The plant clinic runs from 9.00 am to $1.00 \mathrm{pm}$. The major business at the market takes place before $9.00 \mathrm{am}$. After that, the buyers from urban centres leave and the farmers, who came to the market to sell their produce, have time to attend the plant clinic. Attending the plant clinic therefore does not impose any additional travel costs on these farmers. The location of the tent is very strategic: it is next to the main entrance to the market, meaning that all market visitors have to pass it, and it is also at the highest point in the market, making it difficult to miss. The tent is set up before $9.00 \mathrm{am}$, with the logo facing the market entrance. The banner faces the market, so visitors can easily identify the clinic. In addition, the plant doctor and the plant nurse are easily recognizable from their Plantwise overcoat or $\mathrm{t}$-shirt. The clinic is equipped with a kit that includes knives, lenses, photo sheets and factsheets.

Owing to its clear visibility, the plant clinic also attracts people that initially did not intend to visit the clinic session. Their curiosity attracts them to the clinic, to find out about its purpose and activities. They directly witness the plant doctor attending to farmers' problems. Some of the farmers who have never seen a plant clinic before have unrealistic expectations: some ask whether it is possible to have their blood tested, thinking that it is a general health clinic. Others expect to receive free inputs, such as fertilizers or pesticides. Normally, the plant nurse deals with these people. 
Farmers who come to the plant clinic on purpose generally bring a sample of the affected crop. They raise questions about pests and diseases, but also about soil problems and general plant agronomy. The plant doctor tries to address all these issues. As an experienced agricultural extension worker he is well-placed to do so. Some farmers come to the clinic simply to find out about other farmers' problems and solutions provided by the doctor. They will sit and listen and take notes.

A special challenge is the transport of samples of affected crops by farmers. There is a risk in bringing diseased samples to plant clinics as it can spread the disease. Farmers need training on how to carry the samples in a responsible way. Upon arrival, the farmers are received by the plant nurse. The nurse is responsible for registration of visitors in the plant clinic register book before they see the plant doctor. The plant nurse is given a small allowance to cover basic costs such as lunch and transport only if there is money available. Apart from the (uncertain) allowance, the major incentives for the plant nurse include items like a cap, $t$-shirt, ballpoint pens and, maybe more importantly, additional training and knowledge. The current plant nurse received basic training on plant health from the Global Plant Clinic in 2007. As he is a farmer himself, he can directly apply the derived knowledge on his own farm.
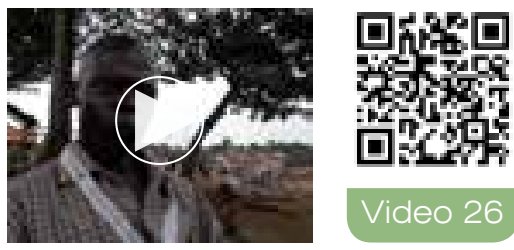

"My name is Ntege. I'm 46 years. I am farmer and also I help to advise farmers. I have worked for seven years at the plant clinic. A team came from Kampala and they told Video 26 me about the plant clinic and I brought my sick plants to the clinic and I got very good advice. I went back and started mobilizing other farmers. The farmers who came to the clinic, after telling them that I got very good advice, when the other farmers went to the clinic, they got very good advice and they were very happy about it. When I came back I was invited to do some training in Mbale district Eastern Uganda (...)

"The world has changed, we are observing so many more pests and diseases than we had in the past. The plant clinics have given me this opportunity to fight these pest and diseases. As we move forward pests and diseases are going to become less of a problem because we are more aware."

Ntege Henry - plant nurse, Nakifuma plant clinic 
The plant doctor attends to the problems brought by the farmers. If the attendance numbers allow he will attend to farmers individually. If there are many farmers, he deals with them in clusters according to crop and problem. While attending to the farmer, he works through and fills in the prescription form. Complicated samples are referred to the subject matter specialists at district level (twice in the last year), or to NARO Mukono which is $20 \mathrm{~km}$ from Nakifuma market. In most cases the plant doctor is able to diagnose and provide a solution. Approximately once a year he refers a sample to NARO, where he goes to follow up in person. Other samples are disposed of by burning after being examined to prevent the spread of the pest or disease.

At the end of the session, the plant doctor and the plant nurse store the materials at the nurse's house. Transport and storage of the materials at the market is not facilitated and markets have no free, secure stores.

"Before plant clinic activities started in 2005, I used to go to farmers with new technology which could improve their production. It was not addressing their problems. At the plant clinics, farmers can demand for services and technologies they need. He or she has crops which have problem and need solutions. This makes work easier and convenient to both farmer and agriculture offccer as you follow up for targeted problem. In addition, there is scheduled programme with fixed place to bandle farmers' problem. Since I am a plant doctor, there is more trust by farmers because the pest and disease affecting their plant become healthy. Now, farmers come and call to demand for services, they deliberately look for me. Whoever has a problem will come to the clinic. Also my bosses trust me now and one of them had a presentation of my plant clinic at Makerere University providing exposure and help making friends from there.

"The training I received has enabled me to learn more about constraints, ranging from soil nutrition problems to pest and diseases. I have received tools like glasses, knives, tent, helping to perform, where other programmes are set without giving tools to use. The involvement with other work was easy as it was in line with usual duties of giving advice to farmers. It is very good as farmers' problems are dealt with, and solutions given in short time. In addition, if we are exposed to new pests and diseases in the area in a short time, we immediately seek for solutions from the district subject matter specialists, fellow plant doctors 


\begin{abstract}
or researchers. Hence, we are learning more on pests and diseases and have improved our access to information. As it's centred in the market, some farmers from other areas where a plant clinic does not exist, have demanded for it. For example Kyampisi sub-county, Busukuma subcounty have now requested for plant clinics and they are included in district government plans for 2014/15."
\end{abstract}

Lyazi Daniel - plant doctor

\title{
Interactions and information flows in Hoima
}

Farmers get their information from many sources. Those involved in NAADS-targeted farmer groups maintain strong connections with the NAADS extension agent, NGOs and the plant doctor. In Nakifuma, farmers are well-connected to agro-input dealers.

The location of the plant clinic at the market means there is also easy access to agroinput dealers; thus the plant doctor can make a recommendation to a farmer, and the farmer can go to the agro-input dealer to buy the recommended product. Agro-input dealers are an important source of information for many famers and their proximity to

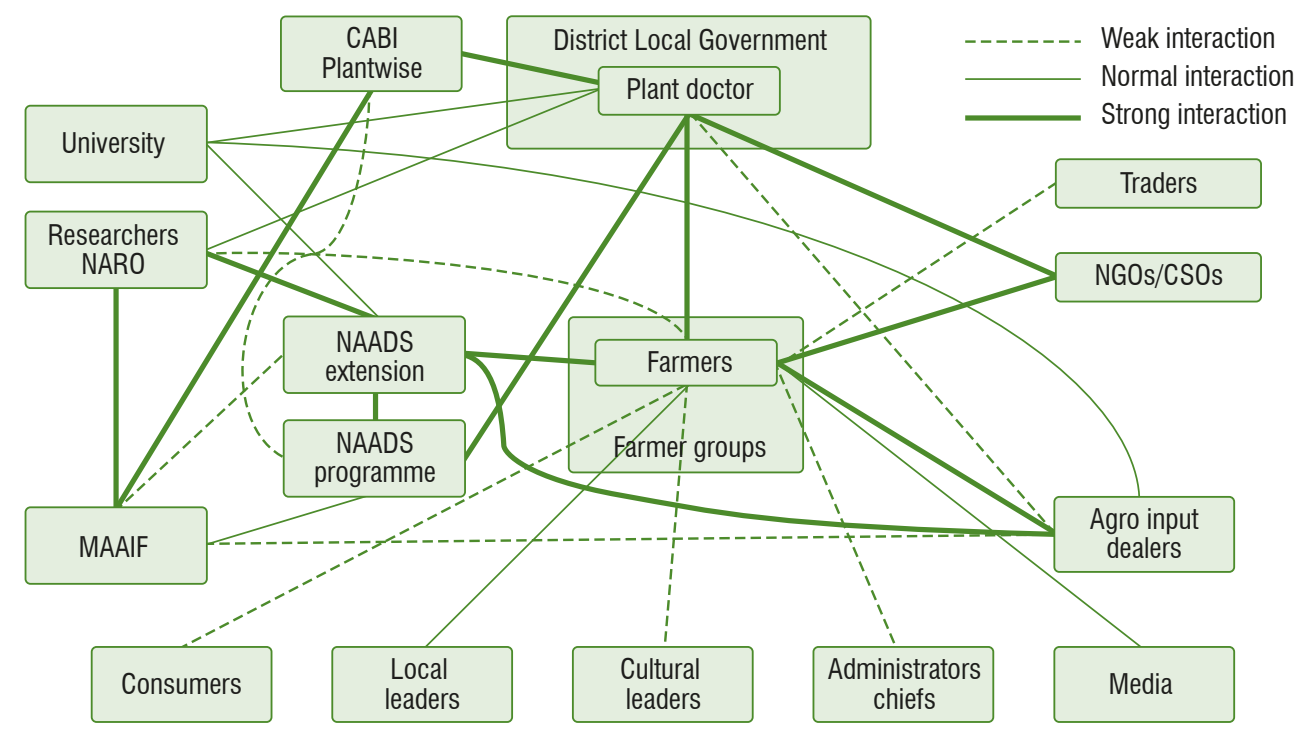

Fig. 26. Information exchange between different actors in the plant health system in Hoima district 
the clinic is highly appreciated. However, farmers may sometimes doubt the quality of the products sold by the agro-input dealers. They may suspect dealers of selling lowquality and even fake products. Also, for many farmers the high prices of the inputs are a problem.

The district local government offices are near the plant clinic venue which makes it easy for the plant doctor to contact subject matter specialists if required. Plant clinics are not well-connected to researchers, who are yet to become involved in plant clinic activities. They are regarded as key in providing up-to-date information on agricultural practices, including plant health to plant doctors. There is a need to establish better linkages to be able to access information and deal with specific cases. Researchers should occasionally attend plant clinics (Fig. 26). Plant doctors have strong connections with Plantwise, NGOs and the NAADS programme. There is a relationship between plant clinics and NARO, but it needs to be strengthened to improve information flow in the plant health system. 



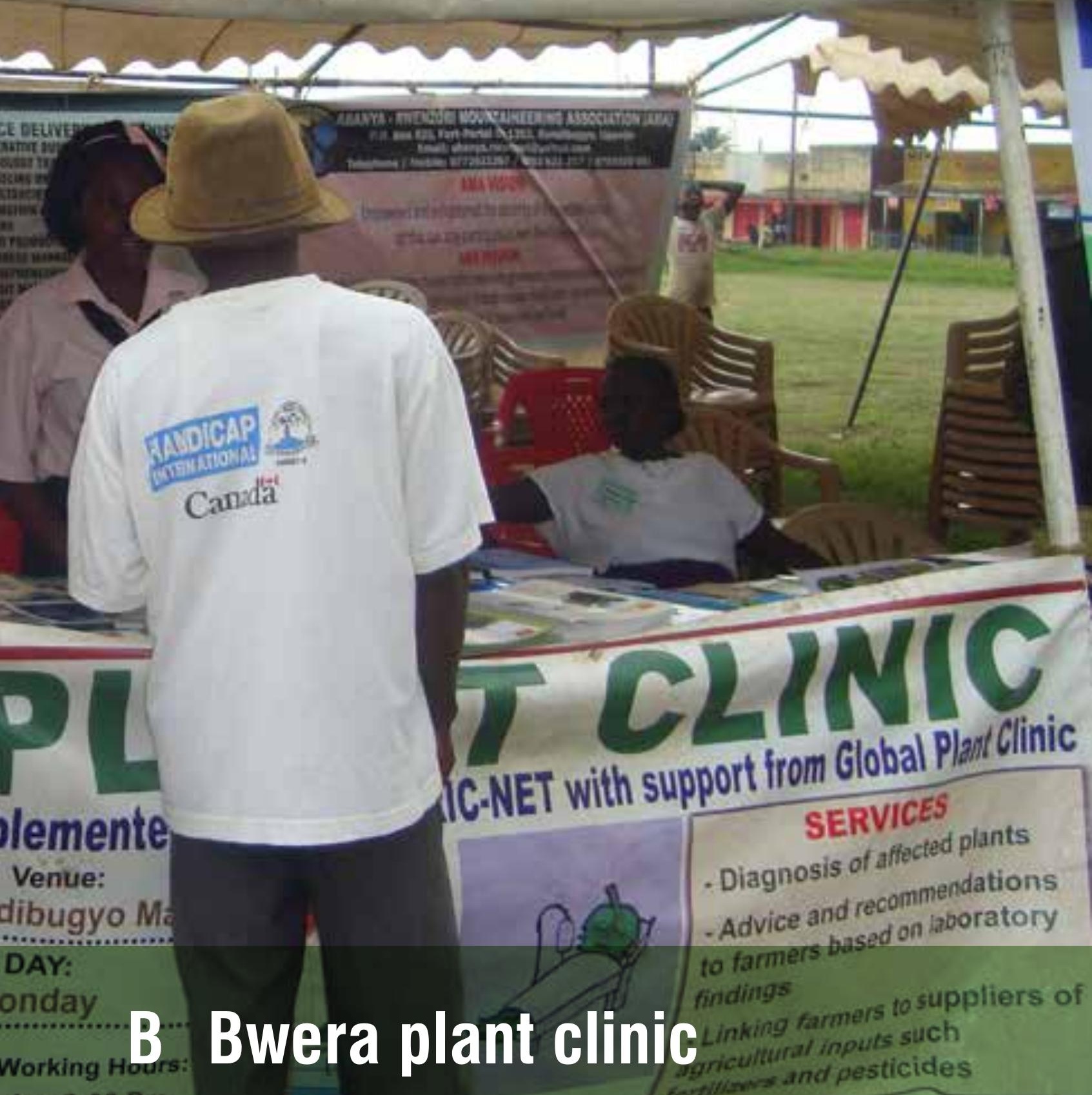

\section{Am-2:00. By John Silco and Remco Mur}

lact us on:

il: Trienetayah

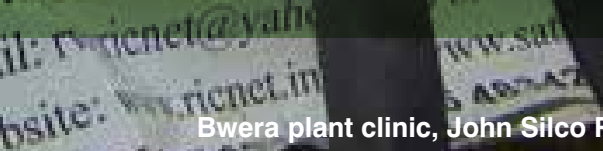

Bwera plant clinic, John Silco RIC-NET

8

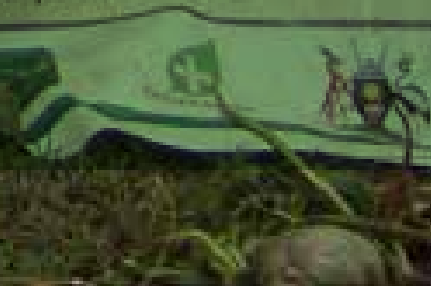




\section{Bwera plant clinic at a glance}

Local implementing organization: Rwenzori Information Centres Network (RIC-NET)

Bwera plant clinic location: Mpondwe-Lhubiriha market, Mpondwe-Lhubiriha town council (formally Bwera sub-county), Kasese district, Western Uganda

Number of RIC-NET operated clinics in the district: 6 fixed, 1 mobile

Number of government operated plant clinics in the district: 1 mixed operation, 1 operated by district local government only

Number of villages in the sub-county: 28

Number of plant doctors in district: 3 (1 female, 2 male)

\section{Training:}

6 doctors: Module I: Field diagnosis and running plant clinics

4 doctors: Module II: Plant healthcare

1 doctor: Production of extension materials

2 doctors: Green and Yellow Lists

Number of RIC-NET plant nurses in the district: 6 (3 female, 3 male)

Number of plant doctors at Bwera plant clinic: 1

\section{Number of change agents in sub-county:}

Bundibugyo: 2 female and 4 male community information facilitators (CIFs), and 10 (5 female, 5 male) community process facilitators (CPFs) or change agents

Kasese: 6 CIFs (3 female, 3 male) and 48 CPFs (24 female, 24 male)

Operations: weekly

Start: 2009 
RIC-NET joined the plant clinic initiative because it saw it as a means to expand and strengthen local services through existing information networks. RIC-NET's strength is information dissemination through the use of various channels, including local information centres, radio, video, mobile technology and farmer groups. As an operator of plant clinics, RIC-NET builds on its existing networks and approaches to reach out to as many farmers as possible in the Bwera area. Although the organization is not specialized in agricultural development or service provision, its approach seems a welcome addition to the plant health system.

\section{Farming in Bwera}

Farmers in the Bwera area practice mixed farming, growing food crops and some cash crops. Most farmers rear some animals. The major food crops are beans, bananas, cassava, maize, yams, and potatoes. The most important cash crops are cotton, coffee and maize. Cash crops are the responsibility of men, the food crops of women. Farm sizes are small, about $1 \mathrm{ha}$, in the undulating hills where most of the food crops are grown. In the savannah grassland area, where cotton and maize are grown, farm sizes are on average 5 ha per household. Apart from farming, other income generating activities include cutting wood, charcoal making and fishing.

The Bwera region has three clear distinctive agricultural areas based on relief and soils: a mountainous area, an area of gently undulating hills and lower dry savannah grasslands. The mountainous area is forested, with much of it forming the Mt Rwenzori National Park. Here, passion fruit and other fruits, 'climbing bean', yam, tomato and cabbage are grown in river valleys. The undulating hills are characterized by lateritic sandy soils as is the lower savannah region, which constitutes a major part of the Queen Elizabeth National Park and is bordered by lakes Albert and George. The hills are suitable for Arabica coffee intercropped with cassava, beans, banana and maize. The savannah grassland is used for cattle and goat rearing, cotton, groundnuts, pineapple and maize.

Land is owned mainly by men. Women can buy or inherit land. Land titles are customary: there are no formal land certificates or land registration procedures in place. The arable area devoted to agriculture activities is less than half of the total potential arable land. Farmers face problems in accessing the uncultivated areas suitable for arable farming as they are occupied by the national parks and government institutions such as prisons and (non-operational) irrigation schemes. Owing to the increasing population, land is becoming scarce. 
Tractors are used for primary tillage in the cotton and maize areas. Animal traction is not common, so most of the land preparation for food crops is done manually. Women play an important role in agriculture. They are responsible for the food crops for which they provide most of the labour. Coffee and cotton are very labour intensive crops. Men, women and children are involved in planting and weeding, with serious implications for school attendance in the area. For cotton and maize, casual labour is required.

Marketing is done individually. However, farmer groups or cooperative societies facilitate group marketing of cotton, coffee, maize and passion fruit. Farmers generate extra income from cross-border trade with the Democratic Republic of the Congo (DR Congo).

Famers are challenged by drought. Land issues between cattle keepers and arable farmers are not uncommon, and animals, mainly elephants, from the national parks destroy crops. Price fluctuations and low prices at harvest time affect the farmers' incomes. In addition, farmers have limited access to information about prices of inputs and products. Access to finance for pesticides and primary tillage, especially for cotton cultivation, is a major challenge in addition to unfavourable land tenure systems for cotton and maize in the lower-lying savannah. Pests and diseases such as banana wilt, pineapple wilt, cassava brown streak disease and cassava mosaic disease are a serious challenge to agricultural production, food security and livelihoods.

\section{How it started and was sustained}

Extension services in Bwera were traditionally provided by government extension officers at sub-county level. They would travel around to educate farmers. The extension system was very top-down, imposing certain crops on farmers. In the 1990s, after public funding was significantly reduced, services essentially stopped. Extension officers had no resources for transport and equipment, were no longer motivated and did not reach farmers. NAADS was supposed to fill the gap, but the focus shifted away from advisory services to input supply. In the coffee and cotton sector, commodity-based cooperatives provided extension services in combination with input supply, spraying services and marketing. Nowadays, the cooperatives have limited their services to marketing.

It was obvious that there was a need for new approaches to service provision. So when RIC-NET staff met with representatives from the Global Plant Clinic in 2008 they were immediately interested. (See Box 8 for a more information on RIC-NET.) After 
a follow-up meeting, RIC-NET, together with an NGO, the Sustainable Agricultural Trainers Network (SATNET) developed a joint project proposal. The Global Plant Clinic provided training and funded the required materials such as the tent, banners, kits, reference books and information and factsheets for the plant doctors.

\section{Rwenzori Information Centres Network (RIC-NET) community- owned information sharing network established in 2005}

Vision: Informed and active citizens in a democratic society.

Mission: Empowering citizens' access and use of information for civic engagement and wealth creation.

Started with plant clinic in: 2009

Operating in: Kasese, Kabarole, Bundibugyo, Kyegegwa, Kyenjojo, Kamwenge and Ntoroko districts.

Partners: SATNET (Sustainable Agricultural Trainers Network), district local government and development initiatives.

"RIC-NET is a network of information centres situated in the Rwenzori region. RIC-NET has a holistic approach to development geared towards the transformation of social-economic spheres within the Rwenzori region" (Danielsen et al., 2012, p.6). RIC-NET joined the plant clinic initiative because it saw it as a means to expand and strengthen local services through existing information networks. RIC-NET does not specialize in agriculture, but in information and knowledge. Plant clinics are complementary to its mandate. RIC-NET runs its own clinics without support from the local government, but has one jointly operated clinic.

Box 8

In 2009, RIC-NET and SATNET started operating plant clinics in Kasese district. RIC-NET and SATNET funded the operating costs of the clinics through existing projects. In 2010, SATNET withdrew from the initiative because of funding problems. The RIC-NET contributions came partly from the Hivos ${ }^{6}$-funded Information Sharing to Farmers' project which ended at the end of 2012. Since 2013, RIC-NET has been funding the clinic operations from its own resources, mobilized through the income generating activities of the information centres, and through the 'Information for Poverty Eradication' project, funded by the Development Initiative (UK). 
RIC-NET is collaborating with district local government, but the RIC-NET operated plant clinics are not integrated in government plans or budgets. Nevertheless, over the years, district local government has developed an interest in plant clinics and in 2013 it opened its first plant clinic. RIC-NET informs government of all its activities, and agricultural extension officers, facilitated by RIC-NET, are involved in certain RIC-NET activities such as learning visits to a demonstration farmer's field.

RIC-NET has established information centres in the towns (administrative centres) across the district. The plant clinics are operated from these information centres. The Bwera Information Centre (BIC) networks with other organizations with access to agricultural information, such as Caritas Kasese with its kitchen gardens project, the Netherlands Development Organisation (SNV), which is promoting schools gardens, the Uganda Community Library, SATNET and various research institutions.

\section{How it works}

The Bwera plant clinic is situated at Mpondwe-Lhubiriha market in what is now Mpondwe-Lhubiriha town. Formerly, this was part of Bwera sub-county, which was split up into separate sub-counties and a town council. In the former Bwera area there were three plant clinics. The location of the Bwera clinic is considered very strategic, as the Mpondwe-Lhubiriha market attracts farmers from many sub-counties across the district and beyond. Kasese is on the border with DR Congo and many farmers from across the border visit the market and benefit from the plant clinic. When it first started operating, permission was sought from the market authorities for a permanent site. The market authorities do not charge any fees.

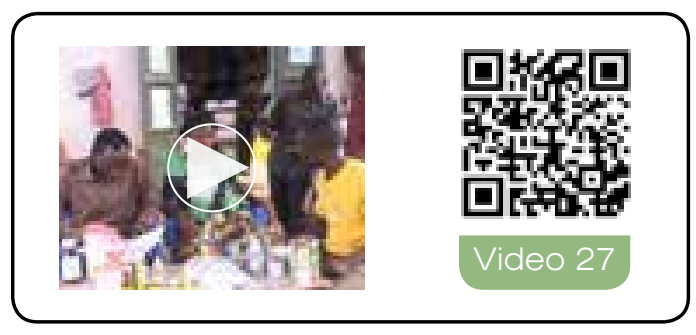

SMS clinic announcements used by RIC-NET to inform farmers

"Farmers, come with your diseased crop or fruit every market day at Mawa, Mpondwe-Lubiriha Markets for advice at plant clinic"

"Do you have a diseased crop of fruits, bring a sample at the plant clinic on the market day"

"RIC-NET informs farmers that plant doctors who advise farmers on crop pests and diseases will be in Mpondwe market on Fridays"

Box 9 
The Bwera plant clinic is managed by BIC and situated near the Mpondwe-Lhubiriha market gate, contributing to its visibility as many people pass by.

A plant clinic session starts with the mobilization of farmers prior to the plant clinic day through radio jingles, text messages in local languages (Box 9) (using the RICNET phone number database for 870 farmers in the Bwera area, out of a total of 3500 in the Rwenzori region), and announcements on public notice boards and at farmer group meetings. In addition, RIC-NET community process facilitators (CPFs) and community information facilitators (CIFs) mobilize farmers in the villages. On the clinic day the mobilization of famers continues through the use of loudspeaker announcements and banners and leaflets distributed in the market. Plant doctors set up the tent with the plant clinic banner at its regular spot, with chairs for farmers and the plant doctor, plant nurse and volunteers. The plant doctors brings charts, factsheets, empty containers of some sample pesticides, a smartphone or camera and other equipment for use in diagnosis.

"Did you know that plants have a clinic? Now listen to this, RICNET, Plantwise Uganda and CABI-UK, have started a programme of 'Healthy plants for healthy people'. This programme plans to fight plant pests and diseases so as to bring increase in food production, boost food security and eliminate poverty in Rwenzori region. This programme known as 'plant clinic' serves all people, operates on market days in the markets Kisinga, Mpondwe-lhubiriha, Kyondo-Kinyabisiki; and even Mpanga market in Bundibugyo town council and Harughale. What you can do is to bring a sample of a diseased crop or fruit so that they can guide you with best control and treatment."

(RIC-NET, http://ricnet.co.ug/?wpfb_dl=66)

Volunteers (interns, CIFs or CPFs) receive the farmers and register them in the attendance book. The clinic day starts with a general session on plant disease and pest control, addressing all farmers that are present at the time. After this session, farmers' problems are attended to. If there are a lot of clients, the plant nurse will try and attend to the farmers' problems first and, if possible, suggest a solution. The plant doctor fills in the prescription form. If the nurse is not capable of diagnosing the problem, he/she refers the farmer to the plant doctor who then deals with him or her. When there are many farmers with a similar crop and problem, the plant nurse organizes them into clusters and the problems are dealt with on a crop/problem basis. If, as is normally the case, attendance numbers are not too high, the plant doctor and nurse attend to individual farmers' problems together. 
Not all cases are registered; this depends on the number of visitors and problems and whether visitors are clustered or not. When prescription forms are filled out, the farmers each receive their copy; another copy is held at the clinic (or information centre) and a third copy is held by RIC-NET. RIC-NET's information officer summarizes the information from the prescription forms and the attendance book. The information is not fed into the POMS.

Plant doctors or nurses train progressive farmers, who then advise individual famers in their locality on plant pest and disease control and other agricultural skills (Table 15). Plant doctors remain in close contact with these farmers to update them with the most recent information and knowledge.

As first-line solutions RIC-NET plant doctors propose organic remedies, which are often less costly than pesticides and are widely available. In addition, organically grown products can provide a niche market for farmers. RIC-NET plant doctors are experts on local concoctions for pest and disease control (see Box 10 for examples) - it is part of the indigenous knowledge in the area. RIC-NET is closely collaborating with Mountain Moon University and Caritas Kasese to collect and document the indigenous remedies and carry out scientific research. 
Capacity achievements and challenges for Plantwise

\begin{tabular}{|c|c|c|c|c|}
\hline Actor & Number & $\begin{array}{l}\text { Role in } \\
\text { plant clinics }\end{array}$ & Status & $\begin{array}{l}\text { Training } \\
\text { received }\end{array}$ \\
\hline \multirow{4}{*}{$\begin{array}{l}\text { Community } \\
\text { process } \\
\text { facilitator } \\
\text { (CPF) }\end{array}$} & \multirow{4}{*}{$\begin{array}{l}1 \text { per sub- } \\
\text { county }\end{array}$} & \multirow{4}{*}{$\begin{array}{l}\text { Awareness } \\
\text { raising } \\
\text { Mobilization }\end{array}$} & \multirow{2}{*}{$\begin{array}{l}\text { Volunteer, selected } \\
\text { through community } \\
\text { participation }\end{array}$} & \multirow{2}{*}{$\begin{array}{l}\text { Communication } \\
\text { Data collection }\end{array}$} \\
\hline & & & & \\
\hline & & & $\begin{array}{l}\text { CPF for RWECO } \\
\text { consortium } \\
\text { (comprising } 4 \\
\text { NGOs) }\end{array}$ & \multirow[t]{2}{*}{$\begin{array}{l}\text { Facilitation of } \\
\text { community } \\
\text { meetings }\end{array}$} \\
\hline & & & Often a farmer. & \\
\hline \multirow{5}{*}{$\begin{array}{l}\text { Community } \\
\text { information } \\
\text { facilitator } \\
\text { (CIF) }\end{array}$} & \multirow{5}{*}{$\begin{array}{l}15 \text { in } 8 \\
\text { county } \\
\text { information } \\
\text { centres; } \\
2 \text { in BIC }\end{array}$} & \multirow{5}{*}{$\begin{array}{l}\text { Mobilization in } \\
\text { villages } \\
\text { Volunteers at } \\
\text { clinic session: } \\
\text { receives and } \\
\text { registers } \\
\text { farmers }\end{array}$} & \multirow{2}{*}{$\begin{array}{l}\text { Fully attached to } \\
\text { RIC-NET information } \\
\text { centres }\end{array}$} & $\begin{array}{l}\text { Information } \\
\text { documentation }\end{array}$ \\
\hline & & & & ICT \\
\hline & & & \multirow{3}{*}{$\begin{array}{l}\text { Information } \\
\text { gate keeper: } \\
\text { communicates } \\
\text { special web-based } \\
\text { information from } \\
\text { the internet to the } \\
\text { community }\end{array}$} & Advocacy \\
\hline & & & & Facilitation \\
\hline & & & & $\begin{array}{l}\text { Community } \\
\text { mobilization }\end{array}$ \\
\hline \multirow[t]{2}{*}{ Plant nurse } & & Mobilization & \multirow[t]{2}{*}{ Farmer } & \multirow{2}{*}{$\begin{array}{l}\text { Plant health } \\
\text { issues (by CABI } \\
\text { or on-the-job by } \\
\text { plant doctors) }\end{array}$} \\
\hline & & $\begin{array}{l}\text { Receives and } \\
\text { registers plant } \\
\text { clinic visitors }\end{array}$ & & \\
\hline \multirow[t]{5}{*}{ Plant doctor } & & Mobilization & Involved in & \multirow{3}{*}{$\begin{array}{l}\text { Agriculture } \\
\text { diploma } \\
\text { certificate (from } \\
\text { government } \\
\text { agricultural } \\
\text { institution) }\end{array}$} \\
\hline & & \multirow{4}{*}{$\begin{array}{l}\text { Runs plant } \\
\text { clinics }\end{array}$} & $\begin{array}{l}\text { community outreach } \\
\text { activities }\end{array}$ & \\
\hline & & & \multirow{2}{*}{$\begin{array}{l}\text { Runs farmer-to- } \\
\text { farmer information } \\
\text { sharing during field } \\
\text { meetings }\end{array}$} & \\
\hline & & & & \multirow{2}{*}{$\begin{array}{l}\text { Plantwise } \\
\text { training }\end{array}$} \\
\hline & & & $\begin{array}{l}\text { Facilitates learning } \\
\text { on pest and } \\
\text { diseases, and on } \\
\text { other agronomic } \\
\text { practices }\end{array}$ & \\
\hline
\end{tabular}




\section{Examples of RIC-NET's natural pest/disease control solutions}

Tobacco: poisons bugs when they ingest it or when they simply come into contact with it.

Urine: from any source; make sure your choice has a powerful and frightening smell that will send banana weevil and several pests away.

Ashes: Suffocate most storage and garden pests, prevent egg laying/ hatching of storage pests hence reducing fungal infection in most stored seed/grains.

Compost tea: You may use this as a light fertilizer to give your plants a little boost. It can also be used as a foliar feeding medium. Tea contains tannic acid, which helps plants to digest their food faster and more easily hence resilient to pests and diseases.

Oil: Nontoxic smothering agent for insects.

Sugar, molasses and corn syrup: Stimulate chlorophyll formation in plants and help feed the good soil bacteria.

Insecticide soap spray: Put one tablespoon of dish detergent per gallon of water into a sprayer. Apply liberally on top and bottom of leaves. Reapply after rain or one to two weeks.

Tomato leaf spray: Is effective in killing aphids and mites. It works because the alkaloids in the tomato leaves (and the leaves of all nightshades, actually) are fatal to many insects. Intercropping tomato with cabbage has a significant effect in controlling most cabbage pests.

Garlic oil spray: This mixture works because the compounds in garlic (namely, diallyl disulfide and diallyl trisulfide) are irritating or deadly to many insects. The oil and soap help the mixture stick to plant leaves. What insects does garlic oil repel? Whiteflies, aphids and most beetles will avoid plants sprayed with garlic oil. Caution: don't apply this spray on a sunny day, because the oils can cause foliage to burn.

Hot pepper spray: Hot pepper spray works because the compound capsaicin, which causes the 'heat' in hot peppers, is just as irritating to insects as it is to us. This mixture also helps repel whiteflies, but it may have to be re-applied if you start to see the mites or whiteflies returning.

Simple soap spray: Is useful in taking out a wide variety of garden pests, including aphids, scales, mites, and thrips. 


\section{Summary of cases reported to the RIC-NET-operated plant clinic} per crop in $2013(n=3077)$

\begin{tabular}{|c|c|c|c|}
\hline Crop & Problems reported & $\begin{array}{l}\text { Reported } \\
\text { by men } \\
(\%)\end{array}$ & $\begin{array}{l}\text { Reported } \\
\text { by women } \\
(\%)\end{array}$ \\
\hline Coffee & $\begin{array}{l}\text { Bacteria and pests lead to leaf spots, } \\
\text { holes in branches, drying of leaves, } \\
\text { brown patches on leaves }\end{array}$ & 41 & 59 \\
\hline Maize & Striga, stunted growth, yellowing & 35 & 65 \\
\hline Beans & Stunted growth, yellowing & 25 & 75 \\
\hline Mango & Rush, premature dropping & 88 & 12 \\
\hline Orange & $\begin{array}{l}\text { Yellowing and drying of fruits before } \\
\text { ripening period, black spots }\end{array}$ & 72 & 28 \\
\hline Cocoa & Premature fruits, pest attacks & 40 & 60 \\
\hline Cotton & Stunted growth, yellowing of leaves & 65 & 35 \\
\hline Banana & $\begin{array}{l}\text { Banana xanthomonas wilt leads to } \\
\text { yellowing }\end{array}$ & 45 & 55 \\
\hline Groundnut & Stunted growth, yellowing & 23 & 77 \\
\hline $\begin{array}{l}\text { Eggplant/ } \\
\text { aubergine }\end{array}$ & Pest attacks on plants, leaf yellowing & 29 & 71 \\
\hline Potato & Attack by worms & 10 & 90 \\
\hline Cassava & Cassava mosaic disease, yellowing & 12 & 88 \\
\hline Cabbage & Attack by worms, stunted growth & 28 & 98 \\
\hline Tomato & $\begin{array}{l}\text { Bacterial wilt leading to yellowing and } \\
\text { fruit fall, rush }\end{array}$ & 56 & 44 \\
\hline Onion & Wilting of leaves from the top & 57 & 43 \\
\hline
\end{tabular}


Interestingly, more women than men attend plant clinic sessions. A major reason might be that women normally visit markets to sell products and visit the plant clinics at the same time. Women also bring problems with crops that are traditionally men's crops, such as cotton and coffee (Table 16).

\section{Beyond the plant clinic: building on RIC-NET's information and communication systems}

Plant clinics are just one of the various channels used to inform farmers about plant pests and diseases. RIC-NET deploys various strategies to reach out to farmers on plant health and other agriculturerelated issues. RIC-NET's strength is in communication and information sharing, which also includes the use of mass media such as the internet, mobile phone applications and radio. RIC-NET publishes quarterly

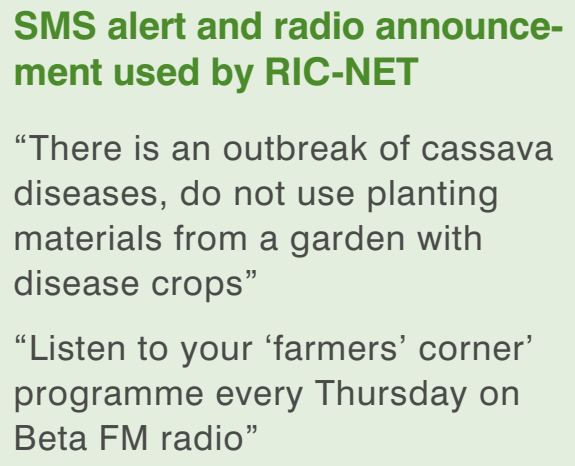

SMS alert and radio announcement used by RIC-NET

"There is an outbreak of cassava diseases, do not use planting materials from a garden with disease crops"

"Listen to your 'farmers' corner' programme every Thursday on Beta FM radio"

Box 11 magazines, brochures and leaflets. It also operates online e-libraries (http://library.ricnet.co.ug/) and an agricultural disease database (http://diseaseinfo.wordpress.com), facilitates radio programmes and sends out SMS alerts. Many of the strategies are linked to other RIC-NET projects and activities.

Plant doctors and nurses combine plant clinic activities with learning visits for farmers to a demonstration farmer's field to strengthen practical hands-on skills. Occasionally they invite district extension staff, university staff and other resource persons, for example from NARO. BIC participates in agricultural shows in Rwenzori region and in other regions in the country where farmers can access plant clinic services.

Knowledge is also shared regularly through radio programmes. 'Farmers Corner' is broadcast on a weekly basis, providing general information on agriculture-related issues, including plant health, but also topics such as organic farming and marketing. 'Radio Plant Clinic' (ricnet_co_ug.mp3) broadcasts on a monthly basis. During a radio session, a plant doctor provides information on specific pests and diseases, describing symptoms and providing possible solutions. Farmers can call in to ask 
questions related to the specific problem or to other pests or diseases. Each session lasts 45 minutes and is broadcast live on two local radio stations in Kasese: Life FM and Radio Guide. Both have a wide reach.

RIC-NET's BIC has established 12 rural information points in the area to facilitate sharing and use of information and resource materials in local languages in the form of locally made videos, books, pamphlets and brochures. The information shared at these information points covers plant health-related issues as well as other agricultural best practices. When pests are detected during plant clinic sessions, the rural information points can be used to share information specifically on these pests. The rural information points are managed by one or more farmer groups but are accessible to any farmer. Farmer groups have between 20 and 50 members. 



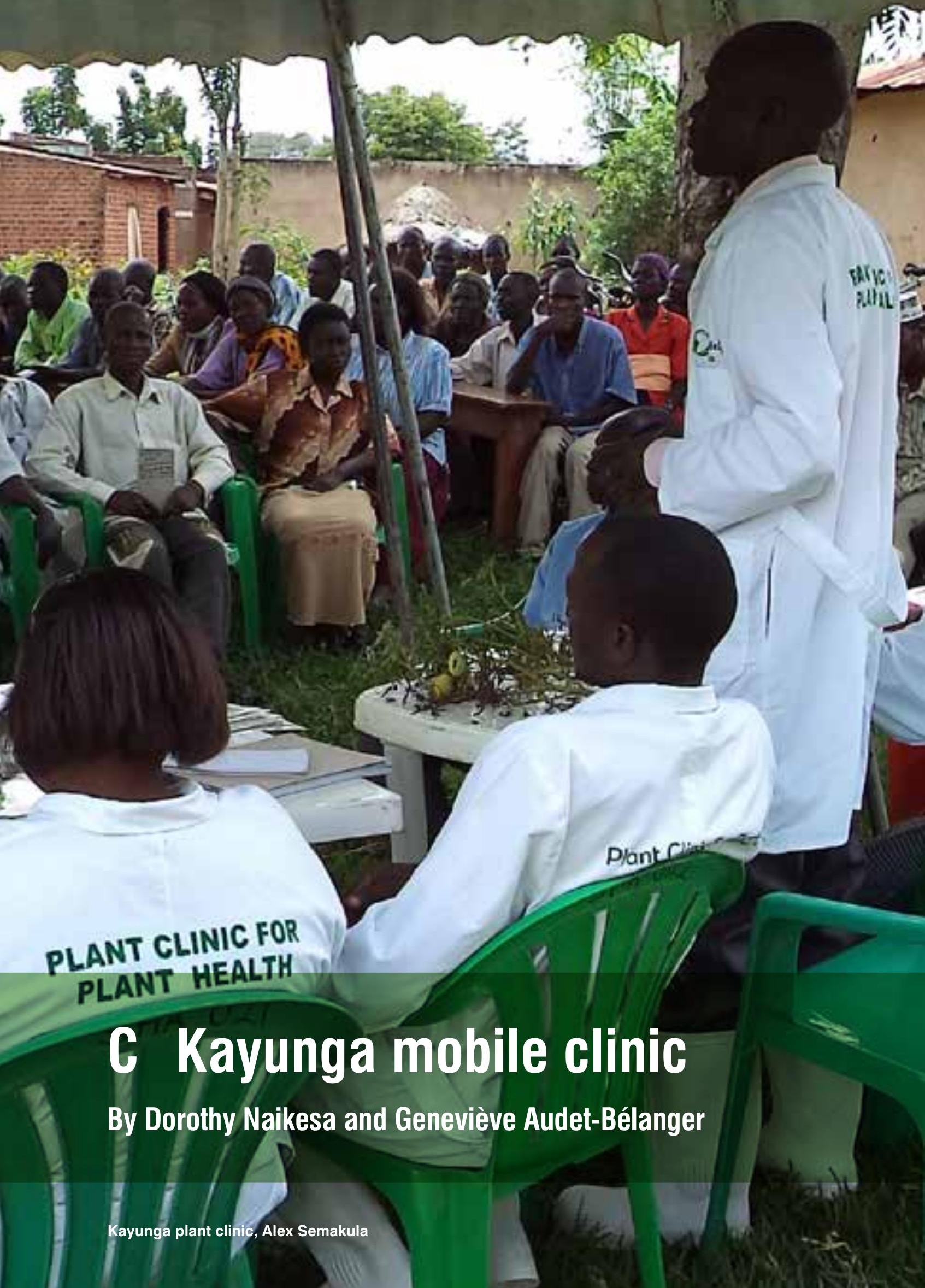




\section{Kayunga district mobile plant clinic at a glance}

Local implementing organization: Self Help Africa

Other organizations involved: Kayunga District Farmers Association (April 2013), district local government

Clinic location: Mobile clinic, Kayunga district, Central Uganda

Number of clinics in the district: 1 mobile clinic

Number sub-counties covered: 8 sub-counties and 1 city council

Number of plant doctors in district: 13 (4 female, 9 male), all Plantwise/ MAAIF trained; 11 from district local government, 2 from Kayunga District Farmers Association

\section{Training:}

13 doctors: Module I: Field diagnosis and running plant clinics

13 doctors: Module II: Plant healthcare

2 doctors (men): Production of extension materials

2 doctors (men): Monitoring plant clinic performance

Number of plant doctors at plant clinic session: 1 supervisor (trained plant doctor), 2 plant doctors operate a clinic event together with 1 plant nurse (sometimes a plant doctor acts as a nurse)

Number of plant nurses: 2 trained nurses from 2 different associations:

Busaana Farmer Producer and Marketing Association

Gakuwebwamuno Farmer Producer and Marketing Association

Operations: $8-10$ clinic events per month. Plans are made on a monthly basis

Start: November 2010 (3 fixed clinics)

May 2011 (fixed clinics became mobile clinic) 
Six months after Self Help Africa started the operation of its first fixed plant clinics in 2010, the organization decided to go mobile. The major reason was that it wanted to reach more farmers. Since 2012, the mobile clinics have been run by district local government plant doctors. In April 2013, two plant doctors from the Kayunga District Farmers Association became involved and are gradually taking over the supervision of the plant clinic activity. The 1 district agricultural officer is contributing 11 trained plant doctors, a car and a driver to transport equipment.

\section{Farming systems}

Kayunga can be divided in two when it comes to farming systems. Southern Kayunga farmers have small plots of about $0.5-1.5 \mathrm{ha}$, but one family can have more than one plot. The land is over-used and farmers face issues of declining soil fertility. Farmers own few animals, making access to manure and animal traction difficult. A tractor owned by Self Help Africa can be hired at the Katikanyonyi Farmers' Association by members and non-members for a fee. However, because plots are small, much of the labour is done manually. There are two good farming seasons in southern Kayunga. The northern Kayunga farming system is the opposite of that in the south. Bigger plots of 1-3 ha are common. The land is quite fertile as it was previously forest land. Northern Kayunga is a cattle corridor and farmers own cattle. They rely on one growing season from March to June, as the second rains are often not so good. Farmers use animal traction in their fields because of the availability of cattle and large landholding size.

The main food crops include cassava, sweet potato, maize, banana and beans. These crops are grown mostly by women. Perennial crops such as cassava and banana are available throughout the year for home consumption. The periods from February to June and August to January are the best for sweet potato, but some farmers plant it in June as it requires little rain. Maize is an emerging cash crop in the area, and both men and women grow it. Men sell the crops after harvest or process the maize into flour and sell it. Women are in charge of processing food products for family consumption.

The main cash crops include coffee, maize and pineapple. Coffee and pineapple are crops reserved for men. The main markets for cash crops are Nakasero, Kalerwe and Nakawa markets in Kampala. Products are also exported to Juba, South Sudan and to Kenya.

Men and women share roles in the field. Together they do the weeding and harvesting, while women are in charge of post-harvest activities associated with food crops. The more marketable the crop, the more men are involved in the different steps of 
production and marketing. Opening up virgin land is a man's job, and so is transporting products from the land to the home and from the home to the market.

Major challenges faced by famers in Kayunga include pests and diseases, unreliable weather conditions, especially as most farmers rely on rain-fed agriculture, and the deteriorating soil fertility. Some initiatives are promoting soil conservation practices, others encourage the diversification of livelihoods through the promotion of livestock rearing, beekeeping and fruit growing.

\section{Self Help Africa}

Vision: Self Help Africa seeks to strengthen agricultural systems, improve access to services and inputs, and provide rural African communities with the opportunities to market and sell their produce.

Mission: Its mission is to empower rural Africa to achieve economic independence - and on a continent where up to $75 \%$ of people rely on small-scale agriculture for their survival, it believes that it is only by tackling the challenges faced by rural farming communities that real and sustained economic progress can be made across sub-Saharan Africa (www.selfhelpafrica.org).

\section{Started plant clinics in: 2010}

Self Help Africa supports plant clinics through implementing partners in the districts where it has its projects. It provides funds for training of plant doctors but channels the funds for plant clinic operations through its partners:

Eastern Uganda (Kumi Ngora and Bukedea) Transform Uganda

Central Uganda (Kayunga)

Kayunga District Farmers

Association

Northern Uganda (Nwoya)

Forum for Social

Transformation

Self Help Africa has been using a number of different approaches to deliver plant clinics including mobile clinics in areas where there is an active demand from farmers' and women's groups. 


\section{How were services provided prior to plant clinics?}

Before the introduction of plant clinics in the area, agricultural advisory services were provided through group leaders, i.e. knowledgeable and well-connected farmers, and the regular extension services from the government, which are a combination of the district local government and mainstream NAADS services. In addition to these sources of information there was a community-based organization (CBO): Kayunga District Farmers Association; and the NGO Caritas. Constraints were similar to those found in other parts in the country: the extension services had little capacity to offer services and especially to address the needs of individual farmers.

\section{How did it start?}

In 2009 and 2010 Self Help Africa became involved in supporting farmers in Kayunga who were heavily hit by cassava brown streak disease. The epidemic was a good reason for Self Help Africa Uganda to discuss the potential for collaboration with the Global Plant Clinic, building on previous discussions at Self Help Africa headquarters. In July 2010, three agricultural staff from Self Help Africa and two district local government staff were trained by the Global Plant Clinic in Module I: Field diagnosis and running plant clinics. Two community firstline extension officers from Busaana and Gakuwebwamuno Farmer Producer and Marketing Association were selected and trained as plant nurses.

November 2010 marked the start of operations of the plant clinics in Kayunga. Self Help Africa plant doctors received equipment and clinic kits from the Global Plant Clinic to conduct their activities as there was no budget yet allocated from Self Help Africa. Three clinics started their operations in the Kayunga markets of Busaana, Nazigo and Bbaale, which were the only markets with an agricultural component.
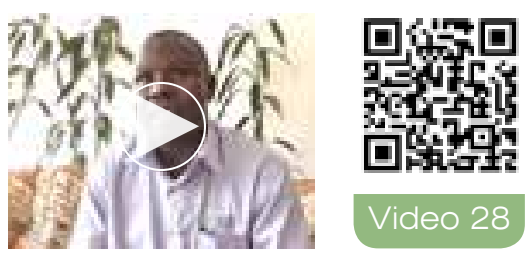

"Kayunga district is unique because when we tried to fix the clinic, the attendance was not very good. So we went on a mobile basis where we pitch a camp where farmers need a service, and we keep on rotating in terms of where to host the plant clinic. In Kumi, Bukedea, Ngora, Noya districts those ones are all permanent bases where the markets are operating from. So those ones have eight plant clinics operational. One of the main benefits is, especially if you look at the eastern part of the country is the fruit growing area, the plant clinics belp to bring out the challenges farmers are going through."

Misaki Okotel - Self Help Africa 
After six months Self Help Africa, in consultation with district local government, decided to stop the fixed clinics and to go 'mobile'. The major reason was the limited reach of the fixed clinics. Thus, the organization established mobile clinics. Initially they were run by Self Help Africa plant doctors.

In 2012, Self Help Africa established a partnership with the district local government with the idea that the clinics would be more sustainable if they were included in the Kayunga District Farmers Association budget and activity plans. The main drivers behind this partnership are sustainability, efficient use of resources and complementarity.

\section{"We have learned from previous projects. When there is no or limited involvement of local institutions and organizations, when you leave nothing continues, and all falls apart."}

\section{Dorothy Naikesa - Self Help Africa}

Kayunga District Farmers Association and the district local government are better positioned to offer sustainable services and community-driven development as they can continue to run the plant clinics after Self Help Africa is gone. However, the current government budgets for plant clinics are not sufficient to support the operations and frequency of the plant clinic sessions. The plant clinics are complementary to other programmes operated by Kayunga District Farmers Association, like village savings and loans activities. Overall, the complementarity of initiatives strengthens local farmer organizations and services offered to the producers.
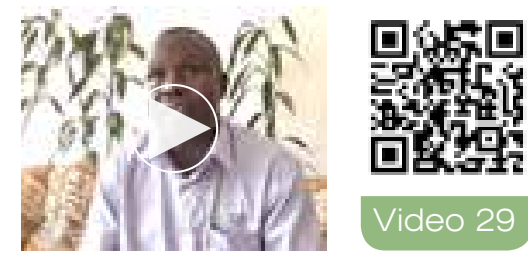

Video 29
"As Self Help Africa together with CABI we don't use our own staff, we work with district extension staff. So the skill and knowledge is developed and it is left there. What is now the only challenge is in terms of logistics, the districts are beginning to put into place, for instance they are putting them into their

budgets that is a step towards sustaining the plant clinics, with or without CABI and Self Help Africa in Uganda. For us in the long run, we want to pull out from providing equipment and we want to be engaged more at the policy level and really encourage the districts to take up plant clinics as an extension system, that's what we are looking at. Because ours is right now at the institutional level and saying, it works, how does it work. Need a table, you need a chair, you need a trained person you need this kind of small equipment to enable that person to move to the field and do the work."

Misaki Okotel - Self Help Africa 
This partnership led to the training of nine district local government extension staff as plant doctors and the follow-up training of the two previously trained government staff members. The Self Help Africa plant doctors were repositioned within the organization. The plant clinics were then run with nine Plantwise trained plant doctors. The district local government has a supervisory function as a partner and is allocating staff. Together with Self Help Africa, district local government performs collaborative monitoring of the clinics and Self Help Africa reports to the local government on clinic activities. Self Help Africa is responsible for managing the activities of the clinics.

Since April 2013, two plant doctors (one woman, one man) from the Kayunga District Farmers Association have become part of the plant clinic team in the district. They play the role of plant clinic supervisor. They were engaged as Self Help Africa wanted to improve the accountability and the sustainability of the clinics. Supervisors are responsible for monitoring clinic operations, while Self Help Africa is now moving away from the direct implementation of clinics. Self Help Africa believes that local organizations need to be involved in hosting and steering plant clinics as they know the local context best, and are in the best position to drive development. Kayunga District Farmers Association ranked as the best agricultural CBO in the area, has good capacity and is covering the whole district. It has a membership of 10,800 producers (35\% male, $65 \%$ female).

\section{Plant clinic operations}

The mobile plant clinics change locations for each event. Usually, there is one clinic session per sub-county per month, based on the locations of farmer associations working with Self Help Africa projects. In each sub-county there are three to four, geographically spread locations where the plant clinic operates. This means that normally the clinic will return to the same location after three to four months. When there is an outbreak in a specific village or sub-county the planning can be altered and the clinic will run in the affected location(s).

Initially, the decisions about time and location of the mobile clinics were made by Self Help Africa in collaboration with farmers' associations involved in its projects. The locations were identified on a demand basis. Later, farmers or farmer groups started to ask government extension services for clinic services in their areas. While the district local government and Self Help Africa try to accommodate all requests for plant clinics, it is sometimes difficult to address new needs owing to budgetary and planning constraints. Priority is given to areas where new pests/diseases or major events are recorded; it is then worthwhile going to those areas rapidly to avoid the spread of 
the problem. More recently, monthly planning meetings with all the stakeholders (Kayunga District Farmers Association, Self Help Africa, district local government and local farmers' associations) have been held to schedule the plant clinic venues and the selection of villages according to both demand and availability of plant doctors and transport.

Self Help Africa, the district local government and Kayunga District Farmers Association try to run the plant clinics according to the schedule, as they are well aware that if a planned clinic session does not take place, they will lose the trust of the farmers. Sometimes when the Kayunga District Farmers Association transport is not available Self Help Africa hires transport to make sure the clinic session takes place.

\section{Roles and responsibilities}

The clinics in Kayunga now operate with 13 plant doctors: four women and nine men. They share responsibilities for the sessions. Usually, four people run a clinic session: one Kayunga District Farmers Association supervisor, two plant doctors and

\section{Roles and responsibilities of plant clinic staff in Kayunga}

\begin{tabular}{ll}
\hline Function & Roles \\
\hline Supervisor & Oversight role, does not answer queries \\
& Records general data \\
& M\&E interactions with clients \\
& Stands in for Self Help Africa in plant clinic activities \\
& for accountability \\
& On-site analysis of trends and needs \\
Plant doctor & Answers queries \\
& Fills in prescription forms \\
& Takes records \\
& Makes sure clients are comfortable \\
& Disposes of diseased samples \\
& In charge of on-the-day mobilization
\end{tabular}


a plant nurse. Sometimes a plant doctor acts as a nurse (Table 17). This means that each of the non-Kayunga District Farmers Association staff will attend about two to three sessions per month, while the two Kayunga District Farmers Association staffsupervisors will take part in a least four or five clinic sessions each per month.

\section{Resources}

Self Help Africa prepares clinic sessions in partnership with Kayunga District Farmers Association supervisors and government extension workers. The district local government provides its extension workers, vehicles for transportation and drivers. Self Help Africa through Kayunga District Farmers Association provides supervising staff and equipment and organizes the logistics (Table 18).

\section{Resources used for plant clinic operations in Kayunga}

\begin{tabular}{|c|c|}
\hline Organization & Resources \\
\hline $\begin{array}{l}\text { District local } \\
\text { government }\end{array}$ & Manpower: 11 plant doctors \\
\hline \multirow{2}{*}{$\begin{array}{l}\text { Kayunga } \\
\text { District Farmers } \\
\text { Association }\end{array}$} & Salary of 1 Kayunga District Farmers Association supervisor \\
\hline & Man-power: 2 plant doctors \\
\hline \multirow[t]{5}{*}{ Self Help Africa } & Material and equipment \\
\hline & Mobilization \\
\hline & Fuel \\
\hline & $\begin{array}{l}\text { Percentage of the salary of the Kayunga District Farmers } \\
\text { Association accountant }\end{array}$ \\
\hline & $\begin{array}{l}\text { Percentage of the salary of the coordinator of the CBO } \\
\text { activities and funding for other Self Help Africa activities }\end{array}$ \\
\hline
\end{tabular}

\section{Table 18}

\section{A plant clinic day: from mobilization to the end}

A stationary megaphone is used to make announcements before the clinics. Although megaphones have a limited reach, in only the village in which the announcement is made, it acts just like local radio in this limited locality. The cost is affordable at USD 1.60 per announcement. Local sensitization announcements are also made in local 
churches and during other ongoing project activities, and given to farmer group leaders for dissemination in advance of the plant clinic day. The group leaders are usually a good way to share information. They are a well-respected source of information in their communities and have an extended network. Radio announcements are also being used, but are not always effective at reaching the targeted clientele because of the number of different stations available. Information dissemination and mobilization are also carried out during radio talk shows on a monthly basis when the next plant clinic sessions are advertised.

Public parish-level meeting places, schools and trading centres are all appropriate locations to host the plant clinic. The venue is suggested by the hosting farmers' associations. Clinics run from midday to $5.00 \mathrm{pm}$. The registration of visiting farmers at the clinics is done by a plant nurse. The nurses are trained in handling farmers, agronomic practices and basic plant health and they usually have strong relations to the farmer groups.

The plant doctor's role is to attend to farmers on an individual basis. They diagnose and provide recommendations on a wide range of agronomic practices, soil improvements, the use of chemicals, the right chemicals and the places where they can be purchased. The plant doctor is also responsible for completing the prescription form. A copy of the form should then be handed to the farmer for reference. Up to $40 \%$ of farmers do not receive a copy of the prescription form, although it has been completed. Low literacy is a constraint, and a prescription form in English is not very useful to a farmer if everything needs to the translated and described. For this reason forms are not always offered to the clients because plant doctors assume that farmers will not use them. A second copy of the form is kept by Self Help Africa and used for plant clinic planning purposes and as input for the monthly radio talk shows. Self Help Africa uses the forms to identify common problems and to package extension messages in its project activities. It takes a third copy to MAAIF for data entry. However, often the forms remain at Kayunga District Farmers Association; on the occasions that they reach MAAIF, SHA receive little feedback on the data use. Self Help Africa is looking for a quicker way to gather and register information during the plant clinic sessions since there is a high accumulation of hard copy data which is at risk of being lost during storage and transfer.

A supervisor attends all clinic sessions: he/she makes sure that the clinic is running as it is supposed to, and that farmers are attended to in the right way. He/she takes note of high risk areas for follow-up (where there are massive attacks of a pest/disease), takes and consolidates records, and prepares an activity report of the clinic session 
and shares the outcomes with the district local government and Self Help Africa. The reports can feed into other Self Help Africa and government extension activities and programmes.

\section{After the clinic operations}

Follow-up visits are sometimes offered by the supervisor to farmers with massive attacks in their fields. In an ideal world, Self Help Africa would like to offer 10\% of the farmers a follow-up visit, but this is often not possible because of limited budgets and staff. At this stage, there are no data available on the number of followup visits conducted by the plant doctors.

An important duty of the supervisors is repackaging of extension messages according to the realities on the ground. The messages are used in Self Help Africa projects and in subsequent clinic sessions. These extension
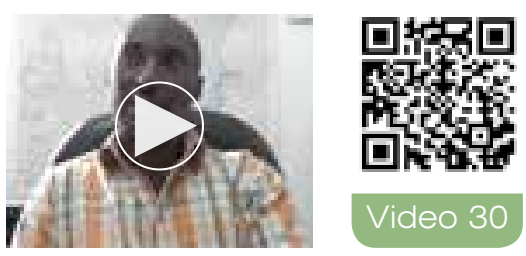

"We (Self Help Africa) work closely with the research institutions in the country and there is more connection. They are the ones training the plant doctors and plant nurses and when farmers find a pest or disease that cannot be dealt with at the local level, then we're connecting them with the labs for better tests within the ministry and research institutions, so that they can be helped out and that way we are forming a family of the researchers, the practitioners in the field and us that are the go between and giving them the technical support."

Tony Kisadha - Self Help Africa programmes also cover other villages and sub-counties. Messages are used in radio talk shows, crossing district boundaries, and during sensitization meetings with the Kayunga District Farmers Association staff. The radio programmes are presented by one plant doctor from the Kayunga District Farmers Association and a plant doctor from district local government. These monthly talk shows last one hour and have a number of functions. The radio station is in the next district: plant doctors are each provided with an allowance of USD 52 for making a radio programme and the driver receives USD 12. Self Help Africa also pays for the fuel for the car to take them there. The car and the driver's salary are the responsibility of the district local government. A summary of the last clinic sessions and other plant health-related issues are shared during the radio programme together with key learning points and extension advice. Farmers can also call in with inquiries and questions. The next plant clinic sessions are advertised. 


\section{Adaptations: what is special?}

The change from fixed clinics in markets to mobile clinics came about when Self Help Africa project beneficiaries reported that they did not have access to the clinics. Distances to the markets were long and farmers would not travel that far for the plant clinics. Clinics located in the markets were thus reaching buyers instead of producers, and not supporting the Self Help Africa farmers. More often than not, those that did attend a clinic would not bring a sample. When they brought samples, they often turned out not to be fresh and, because of long distances travelled to the market, there was a risk of them enhancing disease spread. Mobile plant clinics have the potential for reaching more beneficiaries as they are closer to the farmers. The simple fact that they are closer means more people can find the time to attend, both men and women. Mobile clinics aimed to improve access of beneficiaries of Self Help Africa projects to the clinic services.

\section{Self Help Africa clinics at a glance}

\begin{tabular}{ll}
\hline Total number of clinic sessions & 41 \\
Average number of sessions per month & 6 \\
Max. number of sessions per month & 12 (October) \\
Min. number of sessions per month & 0 (July) \\
Total number of visitors & 1009 \\
Average number of visitors per session & 25 \\
Percentage of female visitors & $40 \%$ \\
Max. number of visitors per session & 64 (29 August 2013, Nanjwenge, \\
Min. number of visitors per session & 11 (26 October 2013, Kiziika, Nazigo) \\
Max. number of sessions in one location & 3 (Katikanyonyi, Kiwangula) \\
\hline
\end{tabular}

(Based on Self Help Africa records, 29 May - 16 December 2013)

\section{Table 19}

Between 29 May and 17 December 2013, 42 plant clinic sessions were run in eight subcounties in Kayunga district, attracting 1009 farmers, or 25 per clinic session, of which $40 \%$ were women. Kayunga sub-county hosted most clinic sessions (eight) (Table 19). On average six clinics per month were run, although no clinic sessions took place in July. Regularity of plant clinics is an issue. 


\section{Sustaining the plant clinics}

The plant clinic operations covered by Self Help Africa are currently financed through funds from Irish Aid, but these funds are terminating in 2015. Currently Self Help Africa is looking into other funding possibilities. If funding was to stop now, it would not be possible to continue running the clinics. At present, the Kayunga District Farmers Association has only included eight clinics in its annual budget - a month's operations. With an average attendance of 25 farmers per clinic, the cost per farmer is USD 4.56 (Table 20).

\section{Self Help Africa clinics at a glance}

\begin{tabular}{ll}
\hline Item & Cost (USD) \\
\hline Transport & 40 \\
Staff allowances: plant nurse, 2 plant & 60 \\
doctors, supervisor, driver & \\
Radio announcement & 6 \\
Megaphones & 4 \\
Set-up and removal & 4 \\
Total & 114
\end{tabular}

\section{Table 20}

Annual costs of running mobile plant clinics in Kayunga with eight sessions per month are USD 12,624 including the salary of the supervisor at USD 140 per month. Self Help Africa is now working on an exit strategy and on strengthening the capacity of Kayunga District Farmers Association. This includes capacity building, both at the level of district local government and at the level of Kayunga District Farmers Association and the local farmers' associations. More needs to be done for the local actors to take ownership: during an internal assessment of Kayunga District Farmers Association's performance after the first year of the partnership the need for support was identified in the areas of accountability, governance and M\&E. Plant clinic operations were suspended for three months in early 2014 because of this assessment. 



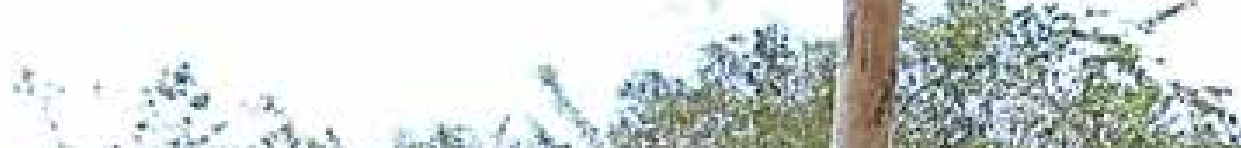

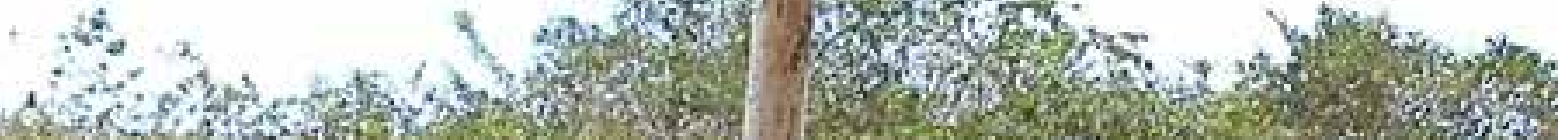
8.

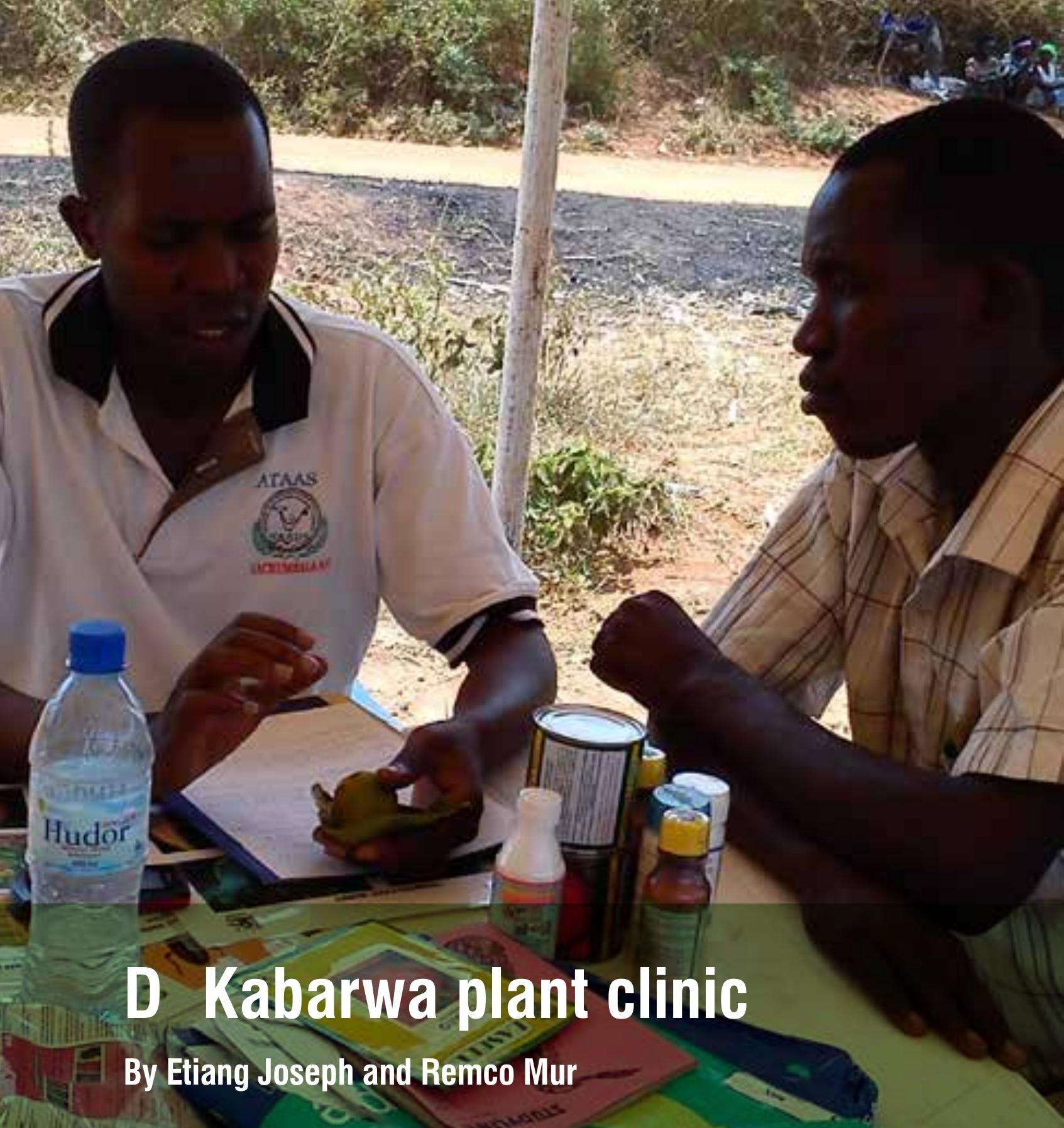

\section{By Etiang Joseph and Remco Mur}




\section{Kabarwa plant clinic at a glance}

Local implementing organization: district local government and NGO

Kabarwa plant clinic location: Kabarwa parish, Malera sub-county, Bukedea district, Eastern Uganda

Number of clinics in the district: 2 government-run ( 3 clinics as of July 2014), 3 NGO-run (TRANSFORM Uganda)

Number of villages in Malera sub-county: 28

Number of plant doctors in district: 10 (1 female, 9 male); 8 NAADS staff, 2 district local government officers

\section{Training:}

10 plant doctors: Module I: Field diagnosis and running plant clinics

6 plant doctors: Module II: Plant healthcare

1 plant doctor: Monitoring plant clinic performance

Number of plant doctors at Kabarwa plant clinic: 2 male (NAADS and district local government)

Plant doctors at Kabarwa plant clinic: Opolot Michael and Ejiet John William

Number of plant nurses in sub-county: 3 (1 female, 2 male)

Operations: weekly

Start: April 2013 
Malera sub-county has the highest prevalence of crop pests and diseases in the district. At times, the Kabarwa plant clinic receives overwhelming numbers of farmers that cannot not be attended to in a day. District local government has acknowledged the need for plant health services and has integrated plant clinics in its annual development plans and budgets. In order to ensure quality services, the plant clinic works hand-in-hand with TRANSFORM Uganda, a local NGO that now also operates plant clinics in the district. Currently, local government is operating two clinics and the NGO three clinics.

\section{Farming system}

Kabarwa plant clinic is located in Malera sub-county in Bukedea district. The population of the sub-county is estimated at 41,000 people. Malera sub-county falls under the Teso farming system with two rainy seasons. The main economic activity in the area is subsistence agriculture. Other income generating activities include beekeeping, small-scale businesses (services, brickmaking) and construction work. The farming system is highly diversified. Crops such as cassava, maize, sorghum, rice, groundnut, cowpea, sweet potato, sunflower, green gram, beans, millet, vegetables, citrus and mango are integrated with the following livestock: cattle, goats, sheep, local poultry (chicken, turkeys, ducks and guinea fowls), pigs and beekeeping. The major food crops are cassava, maize, sorghum, groundnut, beans and cowpea, while citrus, rice, sunflower and livestock products are farmed for cash.

Animal traction is widely adopted for opening up land, but when it comes to labour requirements for other operations the household resorts to sharing the work within the family and, if they can afford it, hired casual labour. Other activities are carried out solely by women, such as transport of produce from the field, threshing grain, domestic milling, collecting water and firewood, cooking and taking care of the children. Men tend to have more time to relax than the women.

Land is owned solely by men, and women therefore do not have full control of any resources, except where widows have become household heads. However, there are many cases where other members of such families have tended to grab land from widows and orphans. The average landholding in the district stands at 1.4 ha. Malera has higher than average landholdings of 4 ha but farmers actually cultivate on average $1.2-2$ ha of land in that sub-county. 
The main challenges affecting farmers are unpredictable weather conditions causing flooding and drought. Farmers have limited access to pest- and disease-resistant crop varieties, and the quality of inputs procured by the farmer is low as some dealers do not handle them in the correct manner. Farmers are not organized in marketing groups and this affects their ability to bargain for better prices. The area has experienced cattle rustling, and as a result the army was deployed there for some time and the prevalence of HIV/AIDS escalated, which probably explains why there are high numbers of widows, orphans and vulnerable children. Last but not least, the problems of crop pests and diseases are on the rise in the area, affecting production levels and threatening local livelihoods.

\section{The urge to provide quality services}

So, the need for plant health services was very clear to local government. In order to address these challenges affecting farmers, the district local government provided resources to plant clinics under the local government management and service delivery programme. Under this programme the district local government has so far allocated USD 8000 towards Kabarwa and Kolir plant clinics: USD 2000 in the financial year 2012/13, USD 3000 in 2013/14 and an additional USD 3000 in 2014/15.

TRANSFORM Uganda is currently operating three plant clinics in Bukedea, Kidongole and Kachumbala sub-counties. TRANSFORM Uganda does not have its own trained plant doctors, so the clinics are run by plant doctors from the district local government. The NGO facilitates the clinic, ensures the mobilization of farmers and raises funds to cover operations. Apart from operating these three plant clinics, TRANSFORM Uganda occasionally provides support to Kabarwa plant clinic, for example when the local government is not able to provide timely operational funds. TRANSFORM Uganda is funded by Self Help Africa and it is allowed to provide these additional funds as long as they match Self Help Africa budget lines.

In the financial year 2014/15, the district local government will take over responsibility and running of Kabarwa plant clinic from TRANSFORM Uganda and it has allocated additional resources for plant clinics from the Production and Marketing Grant. The funds will be used for clinic operations: allowances for the plant doctors, plant nurses and driver, fuel, and other related costs. 
The support of some key politicians in the district appears vital to getting the plant clinics integrated into the district development plans and budgets and in creating awareness among farmers and other stakeholders in the agricultural sector. Hon. Malinga Aloysius (Chairperson Production Committee) actively lobbies for resource allocation for plant clinic activities. He is also involved in mobilizing farmers, and occasionally participates in plant clinic activities hosted at Kabarwa plant clinic. Hon. Ilaborot Margret recently participated in a plant clinic rally at Kabarwa and mobilized farmers in the community to participate in plant clinic activities. The two political leaders participate in the review and approval of work plans and budgets for plant clinic activities. According to the plant doctors, the buy-in of politicians has a positive impact on the attendance and is providing a positive image for the clinic.

The district agricultural officer, who is a trained plant doctor, seconds staff for plant doctor training, and supervises plant health-related activities carried out by plant doctors. He lobbies for support from the district local government and develops work plans and budgets incorporating plant clinic activities.

\begin{abstract}
A short profile of the plant doctor supervisor
Etiang Joseph is the current district agricultural officer in Bukedea district. He knows the district very well as he was born there. As a farmer's son, he is well-informed about the farming systems in the area and the challenges related to agricultural production and development. He is in close contact with the farmers. Joseph was trained as a plant doctor at the Kabanyolo Agricultural Research Institute in 2012. Since then, he has been supervisor of the ten plant doctors operating the six plant clinics in the district. He makes plans and budgets, and lobbies for support at different levels. He also works as a plant doctor himself, operating plant clinic sessions, providing services to framers. Joseph has an MSc degree in Soil Science from Makerere University, Kampala. He considers plant health and soil science very much interrelated and his expertise on both topics is a good basis for providing quality advisory services to farmers. After his graduation in 2003, he was involved in several projects. In 2008 he returned to Bukedea district to become a district agricultural officer at the district local government. From 2011 to 2013 he was the district NAADS coordinator.
\end{abstract}




\begin{abstract}
To Joseph, a plant clinic provides an opportunity for farmers and service providers to meet. It is a space where they come together to share problems and solutions are provided. Clinics help to bridge the gap between extension officers and farmers, both men and women. The plant clinics are a great example of how needsbased services can be brought closer to the farmers.
\end{abstract}

\title{
This is how it works
}

Kabarwa plant clinic operates at Kabarwa market on Wednesday of every week except when resources are not available. It operates during market hours, from 9.00 am to 1.00 pm. The district has equipment provided by Plantwise (tent, chairs, tables, benches and information materials), which are transported to the site before $9.00 \mathrm{am}$. At the site, the mobilizer takes the megaphone to mobilize farmers who come to the market and inform them about the plant clinic. Megaphones allow farmers at and around the market place to be reached, but not farmers in their villages. There are currently two plant doctors assigned to Kabarwa plant clinic, i.e. Opolot Michael and Ejiet John William. Furthermore, each clinic session has one Plantwise trained nurse, but there is no nurse based specifically in Kabarwa parish.

The special plant clinic tent is set up and the seating arrangement is such that the plant nurse sits inside the tent, in a corner near the entrance.

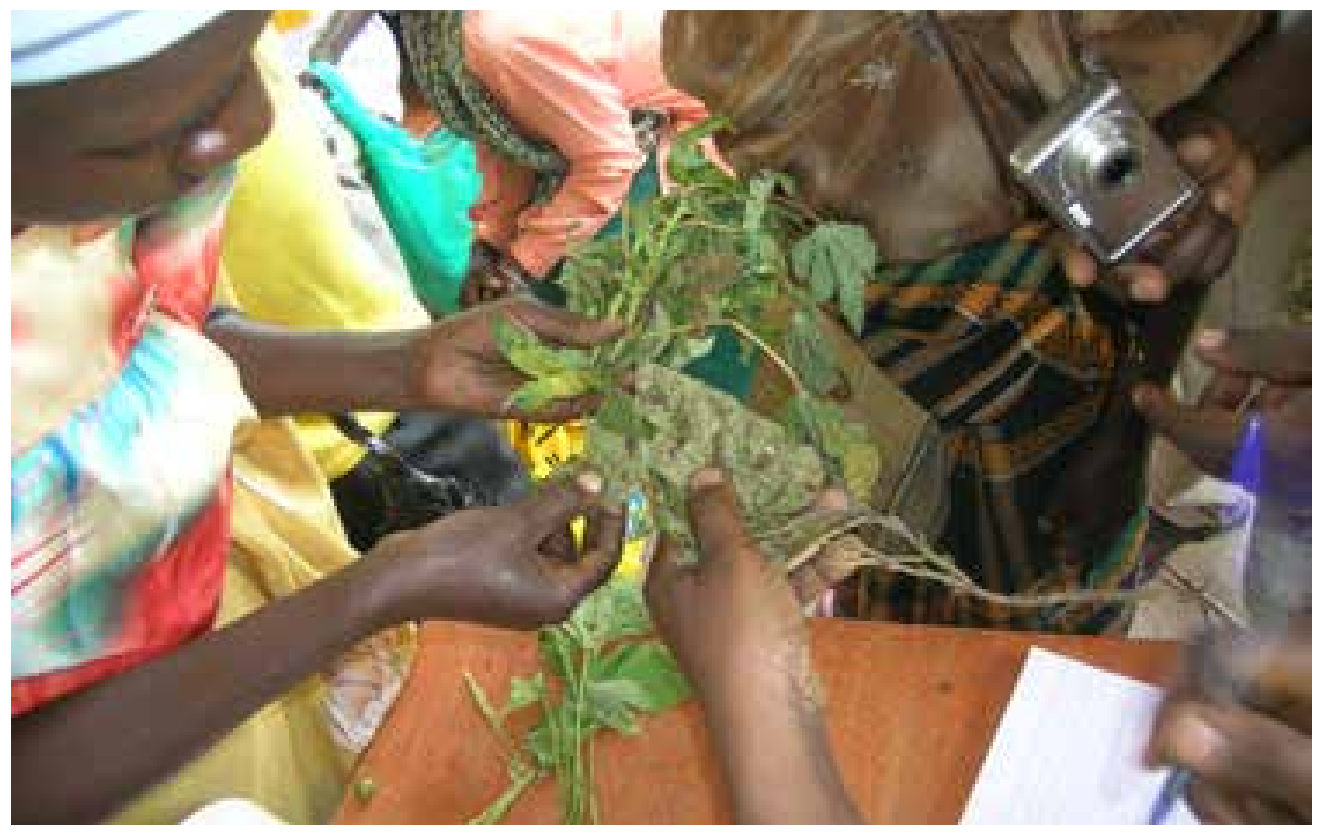


The plant doctor sits on another table with chairs and a dustbin nearby. There may be two or three plant doctor tables, depending on the number of farmers attending and the mobilization conducted. The TRANSFORM Uganda plant clinic register is on the nurse's table and there is a bench and some chairs for the waiting farmers. As farmers arrive the plant nurse takes some details: the name of the farmer, their location, and a description of the plant sample.

The plant nurses also cut and prepare the samples that farmers have brought to the plant clinic ready for the plant doctors to make their diagnosis. When farmers are directed to the plant doctor's table, the plant doctor attends to them one by one. The plant doctors diagnose the farmer's problems and provide recommendations for them. In some instances, a large number of farmers, up to 50, may attend a clinic session with only two plant doctors present. In order to address the needs of all visitors, the plant doctors ask them to come to the next clinic session when they will organize for an additional plant doctor from the district to join them. There is a high demand for plant doctor services in the sub-county. Farmers seek further advice after clinic hours and increasingly know that they can find the plant doctors in their offices. The plant doctors conduct follow-up visits to cases where it is deemed necessary, if financial resources allow. Financial resources are a constraint and for this reason very limited field visits actually take place.

Plant clinics use the TRANSFORM Uganda registration books and the prescription forms for record keeping. The registration book is a simple tool to keep track of the farmer's data. The prescription forms are filled out in English by the plant doctor. The farmer is given a copy of the form, which includes the recommendation. Once the advice has been given to a farmer, the plant clinic register is updated by the plant nurse with the recommendation from the prescription form. After each session, a second copy of the prescription form is handed over to the district agricultural officer, who submits the forms to MAAIF for data entry, while plant doctors provide reports to the district. A third copy is stored at the district office.

Currently neither the prescription forms nor the clinic register play an important role in monitoring plant health-related issues, for example in identifying potential outbreaks. These are rather identified through direct interactions between plant doctors and farmers.

It has been suggested that it might be better for data to be entered at the district level to enable a more practical and sustainable process. In this way, plant doctors would be able to undertake faster analysis and take quicker decisions if required, for example in the 
case of a disease outbreak. Additionally, plant doctors do not regularly meet to reflect on plant clinic operations, identified cases or related issues. They meet in other meetings at district level where they have many other issues to discuss.

\begin{abstract}
Rapid response to disease outbreaks
"On an early morning in 2012, a farmer woke up only to find their garden of cassava drying up. Little did he knows that his garden was affected by cassava bacterial blight. The entire garden was affected and was beginning to spread to neighbouring fields. The farmer reported to the Bukedea sub-county and the information reached the district agricultural officer who immediately asked two of his plant doctors to visit the field. He also reported to the district agricultural officer about the need to send a sample to the laboratory for verification. The plant doctors visited the affected field and collected and prepared the sample and submitted it to MAAIF's laboratory at Namalere. At Namalere, the report confirmed the disease to be cassava bacterial blight. The report advised the farmer to destroy all the cassava in that field and cautioned other farmers to be on the lookout for any field that may become infected to avoid spread of the disease. These actions were undertaken under the supervision of the plant doctor. This helped to control the spread of the disease and up to now such a case has not been reported in the area."
\end{abstract}

Etiang Joseph - District Agricultural Officer and plant doctor supervisor, Bukedea district).

The above story shows that disease or pest outbreaks require prompt and adequate reactions from the district local government and other actors in the plant health system. The plant clinics are supposed to play an important role in identifying and controlling outbreaks. In Bukedea, there have been several cases that required an immediate and effective response. Although plant doctors acted adequately, for many farmers the remedies arrived too late.

At the end of 2013, farmers were complaining about some major problems affecting their crops. They did not know the problems, nor the remedies. Across sessions, numerous samples were brought in showing the symptoms of maize lethal necrosis disease, groundnut rosette, and citrus cercospora leaf and fruit spot. The potentially devastating effects of these diseases required an immediate response. This triggered the decision by the district agricultural officer to hold a rally to raise awareness among farmers about these specific diseases. Plantwise supported the district local 
government in planning and running the rally. Unfortunately, lack of access to funds delayed the execution of the rally until the next cropping season, thus delaying the response process and limiting farmers' ability to cope with these challenges.

Eventually, the rally was conducted at Kabarwa trading centre, near the market, on 2 June 2014 and was attended by 36 farmers from various parishes. Three MAAIF officers also attended the rally. Mobilization of farmers was carried out using a megaphone. Through lectures by various facilitators, demonstrations, and question and answer approaches, farmers were informed about the three diseases and the existing remedies. In addition, the issue of declining soil fertility was discussed. The event was supported by the political leaders from the district including Hon. Ilaborot Margret (Secretary Production and Marketing). As with regular plant clinics, some farmers brought samples which were examined on the spot by the team and specific recommendations were provided to them. 




\section{Mairirwe plant clinic at a glance}

Local implementing organization: district local government

Mairirwe plant clinic location: Mairirwe trading centre, Bugambe parish, Bugambe sub-county, Hoima district, Western Uganda

Number of fixed clinics in the district: 4

Number of villages in the sub-county: 41

Number of plant doctors in district: 6 (all male district local government staff)

\section{Training:}

6 plant doctors: Module I: Field diagnosis and running plant clinics

5 plant doctors: Module II: Plant healthcare

1 plant doctor: Monitoring plant clinic performance

Number of plant doctors at Mairirwe plant clinic: 1 (with support from 2 others if required)

Plant doctor: Stephen Kibego, district local government extension worker

Number of plant nurses in sub-county: 3 ( 2 female, 1 male)

Number of change agents in sub-county: 8 ( 5 female, 3 male)

Operations: monthly

Start: 2010 
The initiative for plant clinics in Hoima district was born locally in 2009. Mairirwe plant clinic, one of the first clinics established in the district, is closely collaborating with local communities. It has established a partnership with the Mairirwe Cooperative Farmers' Organisation and works with other farmer groups. Members of the organization play an active role in the mobilization of farmers. One of their members is a plant nurse. The plant nurses and local change agents are key in the clinic's strategy for reaching out to farmers.

\section{Farming in Bugambe sub-county}

The Mairirwe Plant Clinic is located in Bugambe sub-county in Hoima district in the Western region. Some people are involved in minor trade, marketing or other income generating activities, but farming is the most important economic activity in the area. Farms in the area are relatively large, with an average size of $2 \mathrm{ha}$. Small-scale farmers cultivate approximately 0.8 ha, whereas some large-scale farmers have more than 8 ha. Due to large landholdings and shortages in casual labour, not all land is cultivated.

Soils in Bugambe are said to be rich, but soil fertility is declining owing to bad agricultural practices. The farming systems in Bugambe are highly diverse. Most farmers grow more than ten different crops in a season, both food and cash crops. The most important cash crops in the area are tea, tobacco and coffee. Tea and tobacco are grown with support from private companies. The out-growers receive extension services from the companies, but also access plant clinics for their cash crops as well as for food crops. The inaccessibility to company extension agents is a problem. Upland rice is another important crop, for both cash and food. The most important food crops include beans and millet. In addition, farmers cultivate cassava, groundnut, sweat potato, maize and banana. Intercropping is common practice, for example coffee with banana, cassava with maize or beans, and beans with maize. Most farmers own some cattle, goats, pigs and chickens.

A major problem faced by farmers is their low capital base. Together with the shortage of casual labour in the area, this is preventing them from bringing all their land under cultivation. In some cases, acute cash needs force farmers to sell their crops prior to the harvest to local middlemen, at very low prices. The farmer and middlemen agree on a price after which the middlemen pay the farmer, collecting the product at harvest time. The farmers' low capital base also prevents them from buying inputs, both fertilizers and pesticides. Fluctuations in market prices of agricultural products mean farmers are unable to secure sufficient income and 
resources to prepare for the next season. Crops are affected by pests and diseases. A common problem is rice blast, causing up to $40 \%$ crop losses. In addition, banana bacterial wilt can lead to total crop loss.

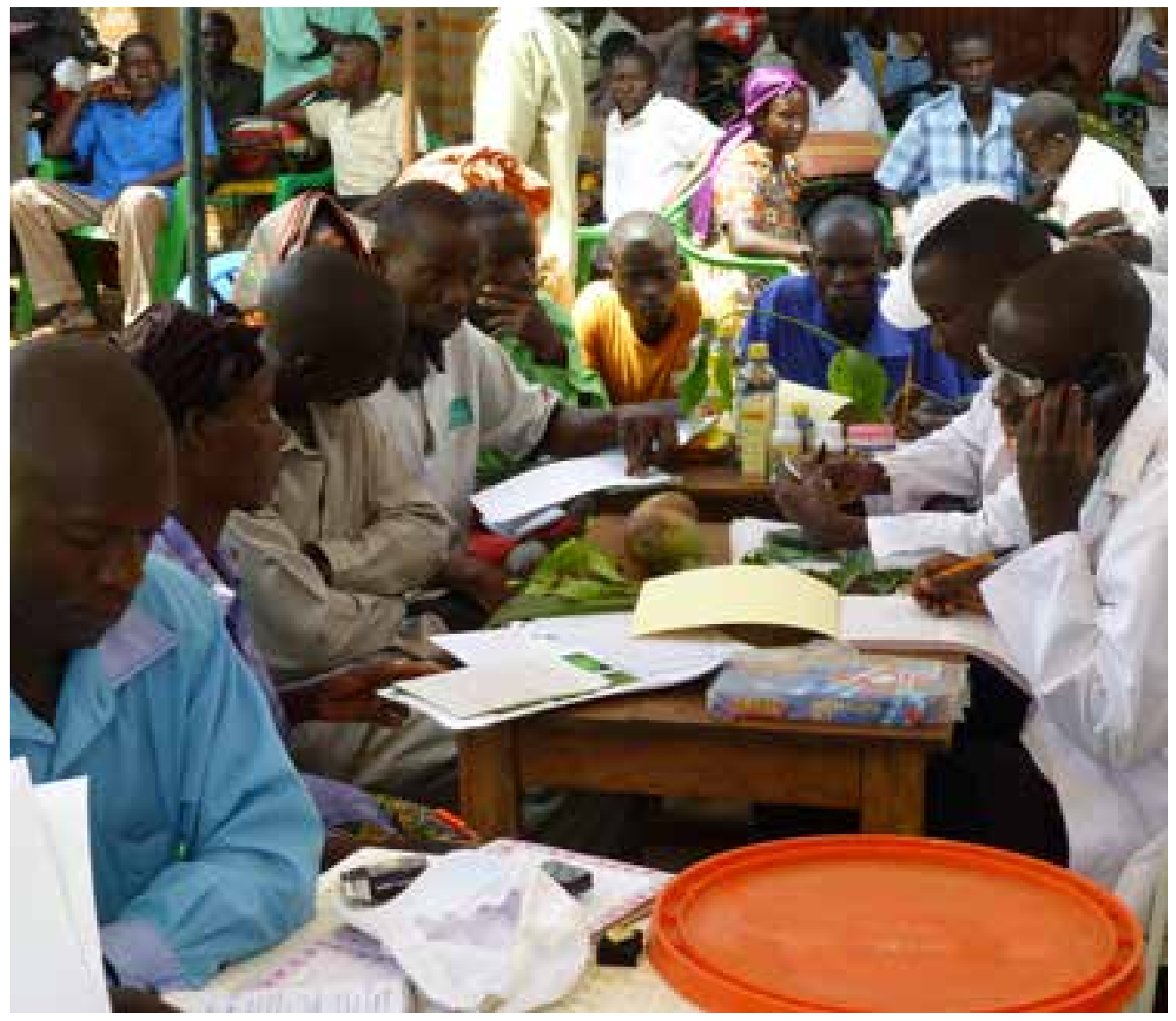

\section{From local initiative to routine operations}

Before the introduction of plant clinics in the district, farmers used to report cases to extension staff during agricultural training days held by the extension staff in their respective sub-counties or sometimes at the district agricultural office. However, this did not happen very often, and farmers reported mainly issues with major crops considered as potential for cash, for example vegetables, fruits, coffee or banana. Women did not attend the training days and so had very limited access to extension workers. 
Interestingly, the initiative to establish plant clinics in Hoima district was born in the district itself in 2009. The district production and marketing officer from Hoima district local government clarifies:

"The plant clinic idea came up in 2009 during a NAADS review workshop where pest and diseases turned out to be one of the biggest challenges of farmers. The NAADS projects focus on production, but there is no entity that takes care of pests and diseases in a systematic way. Facing the constant threats of epidemics such as banana bacterial wilt, cassava viruses and army worm, we felt that we needed to do something different.

"When the Plan for Modernisation guidelines for 2009/2010 came out, we saw that 'establishment of diagnostic plant clinics' was one of the priority areas. We started exploring and discussing how a mobile plant clinic scheme could be organized and got in contact with the Department of Crop Protection of MAAIF who gave us some general guidelines. We made a plan for mobile clinics for the financial year 2010/2011 and the first clinic was held on 11 August 2010. The clinics were approved by the district council and included in the District Development Plan." (Danielsen et al., 2012)

Since 2010, plant clinic operations have been included in the district local government plans and budgets. The clinics received funds through the Production and Marketing Grant from MAAIF. The funds provided by the district local government are very important, yet not sufficient to cover all costs as plant doctors need allowances for lunch and fuel and for mobilization, but also for follow-up visits. The mobile clinics that also operate in the district are especially expensive, basically because they are normally operated by more plant doctors (2-3 for mobile against $1-2$ for fixed clinics)

The district production and marketing officer is the head of the production department in Hoima district. Together with the district agricultural officer, he draws up plans and budgets for the plant clinics. He presents the plans to the district council for approval and, once approved, integrates the plant clinic budget in the overall district budget. He works with the district agricultural officer and, besides playing an important role in drawing up plans and budgets, he is a trained plant doctor, facilitating the plant clinics and monitoring plant clinic activities. He supervises the plant doctors and nominates staff for training. 

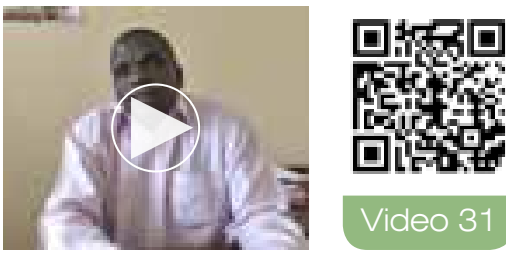

Video 31
"Because we have been sure that when pests and disease are there, productivity will be affected. So by implication, we have a feeling that productivity is increasing as well as these interventions. For us it is really a good investment area and if we removed it now, we would have an outcry in the community. If actually we say, next financial year we will not have this, I am sure these farmers will rise to demand for it. So it is nice and very important to have it continue and that's why in our budgets it is no longer a debate, it is known that this is a budget line now which we created. And it is now very clear in the split out budget lines of the district plant health clinics. And we even put it in development, it is not our current budget it is a development budget to emphasize the importance of the clinics."

Dr Kajura Charles - District Production and Marketing Officer, Hoima

MAAIF put the district local government in touch with Plantwise. Plantwise provided training to plant doctors and provided equipment, such as tents, chairs, tables and factsheets. Both MAAIF and Plantwise still provide some facilitation and a small amount of funds for the plant clinics in Hoima.

Plant clinics are not part of job descriptions yet, but are considered as part of the terms of reference of the extension officers. They now combine plant clinics with other routine activities. But, as a plant doctors stated:

\section{"You are not a plant doctor during the plant clinic sessions only. No! You are a plant doctors seven days a week, 24 hours a day!" \\ Sulayiman Mulindwa - plant doctor.}

In principle, whenever there is a need for advice, farmers can approach the plant doctor. In Mairirwe the plant doctor is based in the sub-county and is easily approachable. Farmers might also call him, but in reality this is rarely the case.

\section{How does it work?}

Mairirwe is an important trading centre and is strategically located: many farmers from the sub-county regularly visit the centre for various reasons. While they have been operating the Mairirwe plant clinic, the district local government has established 
a partnership with the Mairirwe Cooperative Farmers' Organisation, which was established under NAADS in 2005. The clinic is situated in a permanent structure which is owned by the farmers' organization. The building was constructed as a store for harvested products, but since the farmers' group has its own mill, they established a new store. The old store is now used as a meeting place for the organization and for community meetings and hosts the plant clinic. The farmers themselves manage the building. The clinic has had a permanent signpost at the trading centre for three years so it is visible and well-known by farmers that visit or pass the trading centre. The organization has more than 200 members but not all members attend the clinic sessions. Clinic sessions are open to non-members as well. Often the sessions are attended by a mix of members and non-members, both men and women. People from other sub-counties also attend the clinic sessions. Nevertheless, for many farmers the distance to the clinic is too far, especially for those that cannot afford the associated transport costs or do not have the time.

In total, there are six Plantwise trained plant doctors in Hoima district. They mobilize farmers prior to the sessions, which works best through radio as it can reach a good number of people and can be repeated several times on the day before the clinic day. Megaphones are also used, but only reach the people in the immediate surroundings of the plant clinic. Although Mairirwe is a busy centre, not all farmers are aware of the existence of the plant clinics, the services provided, or the benefits.

Steven Kibego, the plant doctor based in Mairirwe, is a district local government extension officer. At clinic sessions he often gets support from one or two colleague plant doctors from other sub-counties in the district, Sulayiman Mulindwa and Joseph Mercy Asaba. Sulayiman Mulindwa explains how a clinic session is conducted:

\section{"I start preparing the clinic session a day before by consulting Plantwise data on internet on actual information that could be relevant in my area. I need to be well-prepared and know about emerging problems. We also start mobilizing farmers in different ways. We use local radio stations to announce the sessions. There are two radio stations we use: Hoima Radio and Libert FM. In addition, the community-based facilitator uses megaphones to inform people in the villages. In fact we use our network and we involve ourselves in informing as many people as possible. And mobilization continues on the day of the clinic session.}


"On the day of the plant clinic session, I organize all the items I need to bring, including the factsheets. I also need to make arrangements at the location, for example the chairs, tables, banner, lenses. I also collect some samples of affected crops that I come across in the area myself. And sometimes I also take samples of problems that have different causes, for example a nutrient deficiency. I ask farmers what they think the problem is and show them the difference between the pests and diseases and the actual problem. Farmers also bring their samples. At the plant clinic I attend clients with different problems. If there are many people, we treat crop by crop. And for each crop, we try to group the problems. All attending people, even those bringing other problems, would listen to us, so we do reach quite good numbers of farmers. At the clinic, the plant doctor fills the prescription form of which the farmer gets a copy. If more farmers face the same problem, we often fill one form only.

"When there are complicated problems, I make follow-ups to the field as the sample alone is not sufficient to diagnose the problem. I need to understand the situation. In some cases, I need to consult my colleagues at the district. When the clinic ends at 2 pm, I take the clinic items back to the district headquarters."

\section{Sulayiman Mulindwa - plant doctor}

Not all farmers bring samples to the plant clinics. They expect other farmers with the same problem to bring in samples. If there are no samples, diagnosis is based on oral explanations, which is very difficult. Diagnosis is also complicated for badly managed samples. The plant doctor often refers farmers to an agro-input dealer for purchasing a product (a pesticide or other product), but farmers often expect products for free from the plant clinic. There is a need to lower these expectations and communicate clearly what the plant clinic's mandate is. Other government programmes do hand out free products, hence the inherited expectations.

An additional problem is that women and small-scale and subsistence farmers in particular, who are growing food crops, lack the resources needed for remedies or are not willing to invest in their crops. Farmers are more eager to invest in cash crops than in food crops and men who generally bring cash crops to the clinic are more eager to spend money on pesticides. The plant doctors are aware of the women's busy schedules at home and aim to attend to women's problems efficiently. Plant doctors often prioritize elderly people and women. 
Plant doctors fill out the prescription forms; one copy is given to the farmer, one copy is sent to MAAIF, and one copy remains with the plant doctor. The plant clinic also has a logbook in which the data from the prescription forms are summarized. According to the plant doctor, the prescription forms and the log book are especially important for ensuring a systematic process from diagnosis to recommendation and for follow-up visits to farmer fields. When different farmers come to the clinic with a similar problem, the plant doctors, with assistance from the plant nurses, try to cluster the visitors per crop and per problem. The plant doctor attends the problem in one go, using only one prescription form. Cases dealt with by nurses or change agents are recorded in their personal notebooks (black books), but are not registered through prescription forms. Therefore, the exact number of farmers receiving direct or indirect plant health services, the frequency of a certain problem and even certain problems are not registered or known. A major weakness of the monitoring system is that the records from the prescription forms are not processed and fed back to the district or to the Mairirwe plant doctors.

Plant clinics can potentially play an important role in identifying pest outbreaks. However, there is no systematic monitoring or tracking system in place. The prescription forms are an attempt to do this, but unfortunately there are still many challenges to overcome. Nevertheless, plant doctors are alerted when many farmers bring a similar problem, even without a functioning formal monitoring system in place. An example is the outbreak of giant looper caterpillar (Boarmia selenaria) in 2012. The outbreak was identified during a clinic session and required an immediate response. The plant doctors reported the problem to the district agricultural officer, who instantly contacted MAAIF's Commissioner Crop Protection, who responded with the necessary chemicals.

\section{Reaching out to the community level}

The clinic sessions in Mairirwe operate on a monthly basis. This is not very often. Farmers in Bugambe sub-county with plant health-related problems can always approach the plant doctor in between clinic sessions. He will provide advice and registers the case in the plant clinic record. Farmers can also ask one of the three plant nurses. Nurses also are important in mobilizing farmers for the plant clinic sessions. There are two female plant nurses and one male. They can be approached at any time during the month, so people do not need to wait for the next clinic session. The nurses are: 
- A male CBF (part of the NAADS structure)

- A female farmer (paid by the farmers' association)

- A female NAADS service provider

Their knowledge on plant health varies: the NAADS service provider and the CBF have a background in agriculture and can often assist farmers directly. The farmer has not received any formal training on agriculture, but she plays an important role in signalling diseases, and in linking farmers to other plant nurses or to the plant doctor. The nurses record the cases, which they share with the plant doctor.

Change agents, based at village level, attend plant clinic sessions and are key in bridging the gap between the plant clinic and the surrounding villages. Since 2014, change agents have been involved in clinic operations and outreach. Currently, eight change agents, five female and three male, have been identified, covering the subcounty. Change agents are farmers of either gender who are influential and wellknown in their communities. They are volunteers who attend the plant clinic sessions and pass on the acquired information to their fellow farmers. The change agents are potentially a powerful mechanism to reach out to communities. Through the change agents, farmers who do not attend clinic sessions are still exposed to the information shared during the clinic sessions. There is a need for more training of both plant nurses and change agents.

Interactions between change agents and farmers are deliberate way of achieving farmer-to-farmer plant clinic information sharing. Farmer-to-farmer information sharing is a mechanism that contributes to reaching impact at scale. As well as the deliberate information sharing between change agent and farmers, farmers also share information among one another, but also with individuals who inform farmer groups. Farmers who attend the plant clinics tend to share the information with others in their household as well as their neighbours.

\section{Interactions and information flows}

For those farmers that visit plant clinics in Bugambe sub-county, plant doctors, plant nurses and change agents are important sources of information. They are wellconnected (Fig. 27). Plant doctors get their plant health-related information from Plantwise; they have all been trained, but they also consult the Plantwise website for additional information. Farmers also have strong interactions with agro-input dealers and MAAIF extension officers; they are an important source of information. 
Other extension agents such as those from the tea and tobacco companies have weak relations with farmers, providing limited services. The agro-input dealers are not wellconnected to the formal, public extension system: they get their information mainly from UNADA and the agro-chemical companies (not shown in the Figure). The lack of a strong relationship with the formal system may cause a lack of authority and regulation in the agro-dealers' activities. This lack of inclusion within the system could be one of the causes of the mistrust that exists between agro-dealers and other actors. Plant doctors are currently not very well-connected to research or universities as the necessary links are still being established: when samples have been referred to NARO, feedback has taken some time. In some cases the sample condition has limited the ability of NARO to provide accurate feedback. The current relationship has meant difficulties in sharing information, diagnosing new cases of diseases and establishing an appropriate response strategy. Overall, there is currently limited interaction between research (NARO, universities) and field operations, which are needed to strengthen the system as a whole.

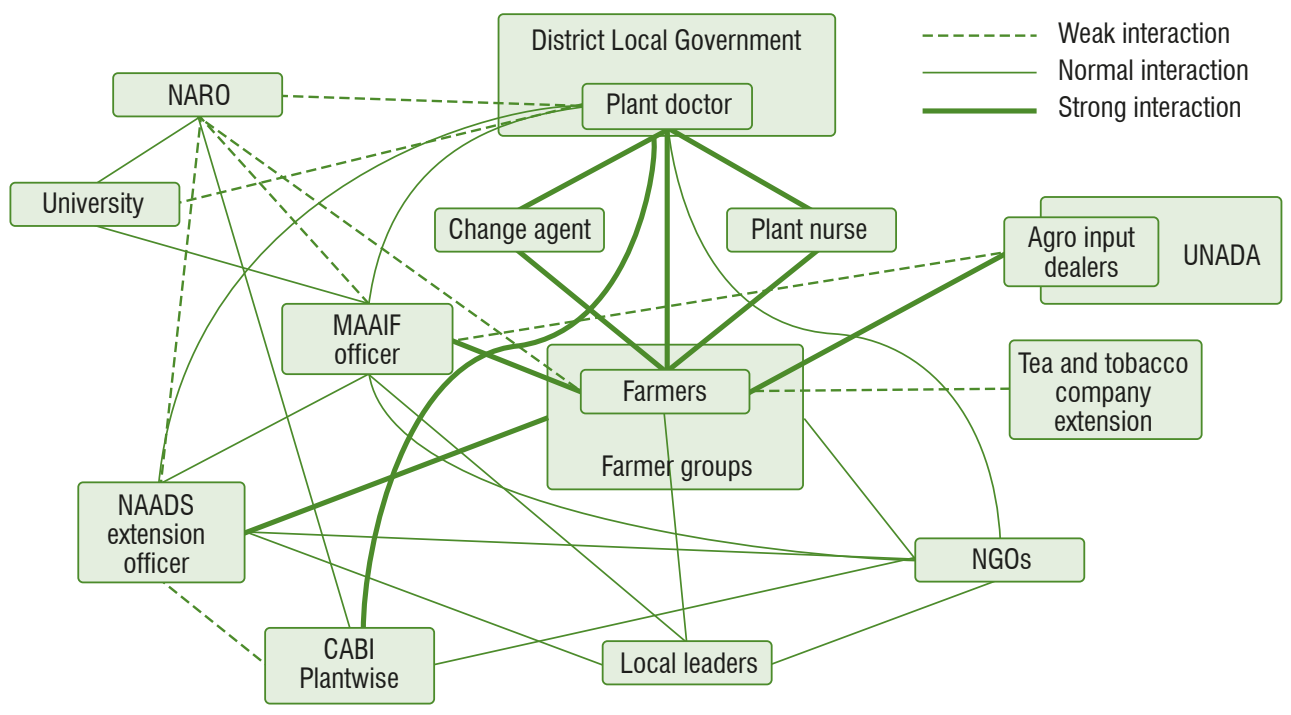

Fig. 27. Interactions between different actors in the plant health system in Hoima district 


\section{New ideas emerging: integrated crop and livestock health services}

After seeing the progress made by the plant clinics, the district production and marketing officer suggested a mixed approach that could address both animal and crop problems holistically. This was proposed because all farmers in the district rear livestock as well as growing crops. The approach would enable plant doctors and veterinarian doctors to attend to farmers' problems at an 'agric clinic'. However, there are many concerns about the transportation of livestock samples, especially with large animals. So it was suggested that small livestock, e.g. poultry, could be brought to the clinic, while farmers could describe the symptoms for large animals, and this would form the basis on which a vet could give advice or follow-up with the farmers. This approach is likely to start in the financial year 2014/15. 


\section{Annex 1. List of movies}

1.

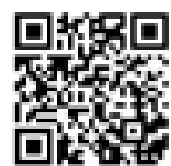

2.

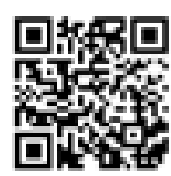

3.

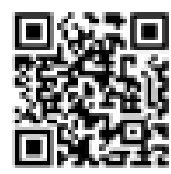

4.

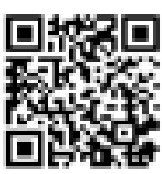

5.

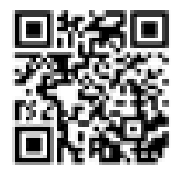

6.

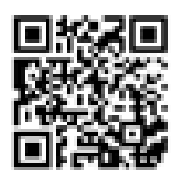

7.

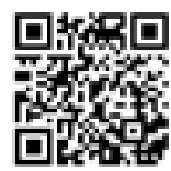

8.

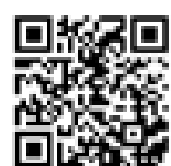

Nakifuma

Mayambala Frederik

Farmer

Nakifuma

Mayambala Frederik

Farmer

Hoima

Asaba Joseph Mercy

Plant Doctor

Buikwe

Luswata Kanakulya

District Agricultural

Officer and coordinator

for plant clinics

Kampala

Misaki Okotel

Self Help Africa,

Head of Programmes

Buikwe

Luswata Kanakulya

District Agricultural

Officer and coordinator

for plant clinics

Kampala

Oruka David

NAADS

Entebbe

Komayombi Bulegeya

Commissioner Crop

Protection, MAAIF
Based on the advice, I did observe improvement. It has increased my earnings, to help my family, but also to enlarge my garden.

Learning is a continuous experience, so every time, I come here to be advised. Farming is one of the enterprises that gives money, I want young farmers to know this.

The ministry is also embracing the idea of plant clinics. It is going to continue.

Plant clinics help us in surveillance of pests and diseases. When a farmer sees something not familiar to him, he brings it to the plant clinics.

Plantwise introduced us into plant clinics way back in 2010. We saw very big potential, and took it as a project, funded by Irish Aid.

We now are able to reach more farmers, and interact with farmers more.

We are benefiting more from very specialized training.

If the cases are complicated, we have a referral system where the samples are sent to the laboratory which gives feedback. 
9.

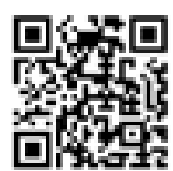

10.

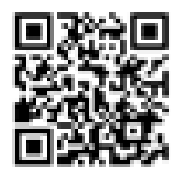

11.

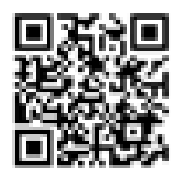

12.

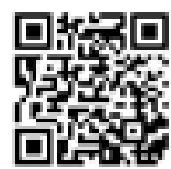

13.

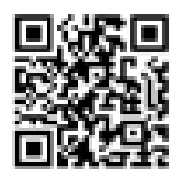

14.

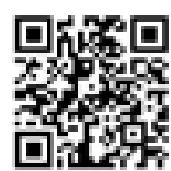

15.

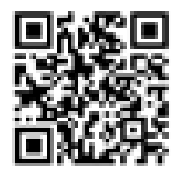

16.

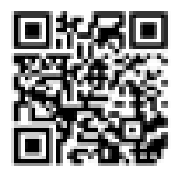

17.

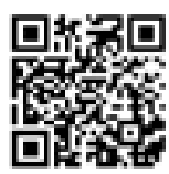

Hoima

Kyamanywa Livingstone Farmer

Hoima

Sulayimani Mulindwa

Stephen

Plant doctor

Hoima

Asaba Joseph Mercy

Plant Doctor

Kampala

Misaki Okotel

Self Help Africa,

Head of Programmes

Nkonkonjeru

Kato John Ssemawere

Tremmsa

Farmer

Kasese

Murugahara John Silko

Executive Director,

RIC-NET

Kampala

Misaki Okotel

Self Help Africa,

Head of Programmes

Mukono

Kavuma Fred Kintu

Farmer

Buikwe

Luswata Kanakulya

District Agricultural

Officer and coordinator

for plant clinics
Profits have increased, access to inputs has increased and we are living a better life. But we have the challenge of buying pesticides, herbicides and seed varieties.

When the farmers come with problems, we diagnose the problem and advise the farmers based on the history of the problem.

Change agents are volunteering. We have to get people that are in touch with farmers all the time for technical backstopping.

When we tried fixed clinics attendance was not very good. So we went on a mobile basis: we pitch a camp so farmers can have a service. We keep on rotating.

The day the clinic is supposed to operate, we are informed about it. We come with problems to get a specific answer.

Last year we were able to attend to 837 farmers. Our plant doctors are equipped with smart phones to access content online.

We realise that few women and youth are attending plant clinic sessions. We are designing a strategy to increase access from those excluded groups.

The agricultural officer gave advice to purchase expensive chemicals. He advised me to collect some villagers with the same problem, so we contribute and buy the product together.

Elderly people, men, women; we try to make the advice specific. There are challenges, but we try to find ways. 
27

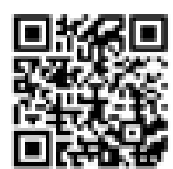

28.

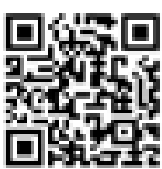

29

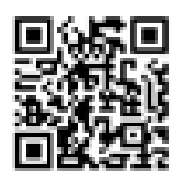

30.

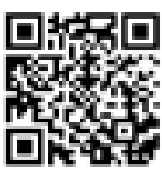

31.

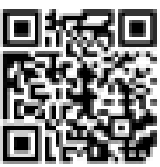

Bwera

RIC-NET

Lead Implementing

Organisation

Kampala

Misaki Okotel

Self Help Africa,

Head of Programmes

Kampala

Misaki Okotel

Self Help Africa,

Head of Programmes

Nakifuma

Tony Kisadha

Self Help Africa

Hoima

Kajura Charles

District Production and

Marketing Officer
Farmers come with your diseased crop or fruit every market day for advice at the plant clinic.

One of the main benefits is the plant clinics help to bring out the challenges farmers are going through.

At Self Help Africa we work with district extension staff. In the long run we encourage the districts to take up plant clinics as an extension system.

We work closely with the research institutions in the country. They're the ones training the plant doctors and plant nurses and we're connecting to them is there is an unknown problem. I want to call upon donors and all practitioners to put more effort on this.

It is really a good investment. Farmers demand for it. It is a development budget line, to emphasize the importance of the clinics. 


\section{Annex 2. Contributors}

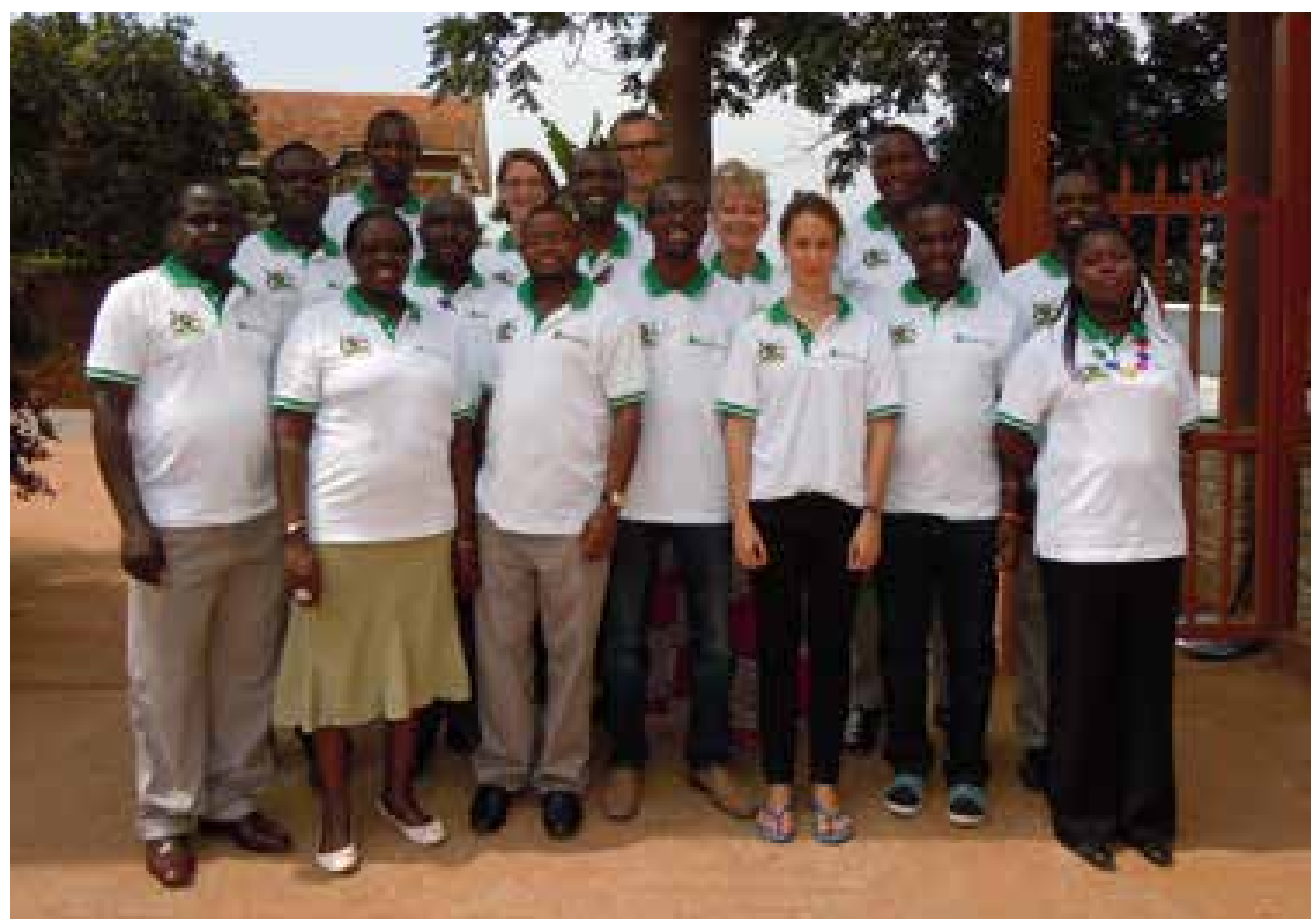

Participants in the writeshop in Kampala, Uganda, 10-20 June 2014

\section{Contributors}

\section{Lyazi Daniel}

Agricultural extension officer, and plant doctor

Mukono District Local Government, Nakifuma sub-county

PO Box 110, Mukono, Uganda

danilyazai@yahoo.com

+256(0) 779360836

He is a plant doctor and extension officer in Nakifuma sub-county, Mukono district, in Central Uganda. He has been a plant doctor since 2005. Nakifuma plant clinic was among the first plant clinics in Uganda. 


\section{Oruka David}

Plantwise National Coordinator

NAADS

Plot 5 Kyadondo Road, Legacy Towers, Block B, Nakasero, PO Box 25235, Kampala, Uganda

davoru02@yahoo.co.uk

He oversees and monitors all aspects of plant clinic operations. He helps in identifying opportunities for scaling up and out of plant clinics and other Plantwise activities; and publicizing objectives and successes of Plantwise to stakeholders and potential partners. He oversees the delivery of work by collaborating partners and extensionists; and supports the M\&E of plant clinic activities.

\section{Etiang Joseph}

District Agricultural Officer

Bukedea District Local Government

PO Box 5026, Bukedea, Uganda

joerets@gmail.com

He supervises plant doctors, plans for plant clinic activities in Bukedea district and advises farmers on management of plant health problems.

\section{Gabriel Karubanga}

Assistant Lecturer

Makerere University

PO Box. 7062, Kampala, Uganda

gkarubanga@caes.mak.ac.ug / amootigabs@gmail.com

In Plantwise, he has worked as a research fellow on various research studies conducted in Uganda. He has also assessed the institutionalization of plant clinics in Uganda to provide lessons and recommendations for other Plantwise countries.

\section{Titus Kisauzi}

Sub-County NAADS Coordinator

NAADS

Busukuma sub-county

tkisauzi@gmail.com

He carried out a research internship on the project, studying factors influencing the gendered patterns in plan clinic access and use in Uganda. 


\section{Richard Miiro}

\section{Senior Lecturer}

Department of Extension and Innovation Studies, School of Agricultural Sciences, College of Agricultural and Environmental Sciences, Makerere University PO Box 7062, Kampala, Uganda rfmiiro@gmail.com

$\mathrm{He}$ is a researcher on processes and factors that address gender needs in plant clinic access and use, including the suitability of the plant clinic extension approach. He is also a mentor of research interns, and a uses research results to facilitate farmers' discussions on strategies for improving plant clinic impact.

\section{Nassib Mugwanya}

Research Assistant

Makerere University

PO Box 7062, Makerere University

nmugwanya@gmail.com

He is a research assistant on a study assessing the performance of plant clinics in Eastern Uganda.

\section{Sulayiman Mulindwa}

Agriculture Officer/ Sub-County NAADS Coordinator

Hoima District Local Government

PO Box 2, Hoima, Uganda

sualmuli@yahoo.com

He is a plant doctor and advises farmers on management of plant health problems.

\section{John Silco Murugahara}

Executive Director

Rwenzori Information Centres Network (RIC-NET)

Plot 18, Mugurusi Road, Fort Portal, PO Box 916, Fort Portal, Uganda info@ricnet.co.ug / mjohnsilco@gmail.com

He manages the deployment and operations of plant doctors. He also monitors farmers' utilization of plant clinics services and information acquired. He is in charge of mobilizing resources to support plant doctors and clinic operations. RIC-NET uses the plant clinic information as a farmer-to-farmer extension service in rural areas of Rwenzori region. 


\section{Dorothy Naekesa}

Monitoring, Evaluation and Learning Coordinator

Self Help Africa

PO Box 34429, Plot 44 Ministers' Village, Ntinda, Kampala, Uganda

dorothy.naikesa@selfhelpafrica.net

She is responsible for M\&E for Self Help Africa in Uganda. She focuses particularly in the plant clinics that are run by Self Help Africa, monitoring their implementation and assessing and evaluating how effective they are at providing plant health advice to Self Help Africa farmers.

\section{Benius Tukahirwa}

Agricultural Inspector, Plant Quarantine

Department of Crop Protection, MAAIF

PO Box 102, Entebbe, Uganda

btukahirwa@gmail.com

+256773454318

He is the National Data Manager coordinating Plantwise data management from clinics, to the centre in the Department of Crop Protection. He is also a local Plantwise trainer participating in Module I, Module II and data management training of plant doctors. As part of the Plantwise team, Benius is the Plantwise desk officer at MAAIF.

\section{Editing team}

\section{Joseph Mulema}

Research Fellow

CABI

PO BOX 633-0621, Nairobi, Kenya

j.mulema@cabi.org

He is the CABI Country Coordinator for Plantwise in Uganda. He coordinates all Plantwise activities in the country on behalf of CABI, works with stakeholders to plan activities during the year, and raises awareness about Plantwise at any given opportunity. He is also a trainer for all Plantwise modules. 


\section{Geneviève Audet-Bélanger}

Advisor

KIT Sustainable Economic Development

PO Box 95001, 1090 HA Amsterdam, the Netherlands

g.audet.belanger@kit.nl

+31(0)20658 8713

She participated in the documentation of experiences of plant clinics in Uganda in themes such as adaptations, gender and institutionalization.

\section{Frances Williams}

Plantwise Regional Monitoring and Evaluation Support Officer

CABI

PO BOX 633-0621, Nairobi, Kenya

f.williams@cabi.org

She supports the M\&E activities of Plantwise throughout Africa with a focus on learning from the programme to improve the implementation of activities.

\section{Solveig Danielsen}

Plantwise Research Coordinator

CABI

Kastanjelaan 5, 3833 AN Leusden, the Netherlands

s.danielsen@cabi.org

As part of the Plantwise M\&E team, she helps develop and evaluate M\&E mechanisms for the programme, and contributes to in-country capacity development on M\&E. Being a plant health systems specialist with a wide in-country experience in implementation and research, she stimulates systems research and analysis within Plantwise.

\section{Remco Mur}

Senior Advisor

KIT Sustainable Economic Development

PO Box 95001, 1090 HA Amsterdam, the Netherlands

r.mur@kit.nl

+31(0) 205688507

As an advisor on agricultural services and innovation, he led a study of plant clinics in Nakuru North district in Kenya in 2013. In 2013 and 2014 he was involved in a study on plant clinics in Uganda, aiming to draw lessons from experiences related to plant clinic adaptations, gender and institutionalization. 


\section{Annex 3. The organizations}

\section{CABI}

$\mathrm{CAB}$ International (CABI) is a global, intergovernmental, not-for-profit organization, owned and run by its 47 member countries. CABI has its headquarters in the UK and operates through a network of centres in Africa (Kenya, Ghana), South Asia (Pakistan, India), South-east Asia (Malaysia), China, the Caribbean and Latin America (Trinidad and Tobago), Switzerland and the UK, and offices in Ethiopia, the Netherlands and the USA. From its inception, CABI has been concerned with enhancing the effectiveness of agriculture with its role in international development closely aligned to the Millennium Development Goals and international treaties and agreements (e.g. Convention on Biological Diversity, World Trade Organization). CABI works to improve livelihoods, natural resource management and sustainable agriculture throughout the world while conducting research into commodity crops, good agricultural practices and integrated pest and crop management (IPM/ICM). In addition, CABI's publishing operations provide print and electronic training and information products that can be used to support this capacity building in farmer and extension communities.

Plantwise, a global CABI-led programme, aims to increase food security and improve rural livelihoods by reducing crop losses. Working in close partnership with relevant actors, Plantwise strengthens national plant health systems from within, enabling countries to provide farmers with the knowledge they need to lose less and feed more. This is achieved by establishing sustainable networks of local plant clinics, run by trained plant doctors, where farmers can find practical plant health advice. Plant clinics are reinforced by the Plantwise Knowledge Bank, a gateway to online and offline actionable plant health information, including diagnostic resources, pest management advice and frontline pest data for effective global vigilance.

\section{KIT Sustainable Economic Development}

KIT Sustainable Economic Development (Amsterdam, the Netherlands) is an independent centre of knowledge and expertise that generates and shares applied knowledge, derived from practice, to improve the performance of companies and organizations that pursue sustainable and inclusive agricultural development. Our professional advisors work with public- and private-sector partners internationally to find sustainable solutions to the development challenges they face related to inclusive 
value chains, sustainable agribusiness development, rural innovation, land tenure, food and nutrition security, gender and inclusion. We work in the global South where we operate in extensive networks of partners and clients. KIT Sustainable Economic Development acts as a bridge between different kinds of knowledge-holders situated in academia, policy and practice. We work with partners to co-create knowledge and generate new insights that improve efficiency and the effectiveness of organizations, enhancing their impact. KIT brings key competencies including contemporary and relevant global knowledge and thinking, access to international networks and innovations, applied research capacity, ability to translate insights for client use, analytical skills to review organization and programme performance, capacity to engage clients in learning, and experience to translate and communicate outcomes into policy. 


\section{LISTENING TO \\ THE SILENT PATIENT}

\section{UGANDA'S JOURNEY TOWARDS INSTITUTIONALIZING INCLUSIVE PLANT HEALTH SERVICES}

CABI WORKING PAPER 7

\section{Edited by Remco Mur, Frances Williams, Solveig Danielsen, Geneviève Audet-Bélanger and Joseph Mulema}

Every day extension workers are bombarded by questions from farmers on how to overcome problems with their crops. The huge variety of crops grown and tremendous variety of pests means that it is not possible for an agricultural advisor to have the encyclopaedic knowledge required to identify all pests and make good recommendations to the farmers for pest control.

The Diagnostic Field Guide provides the essentials of pest identification, covering all the main problems that crops encounter (nine groups of pests and two abiotic conditions) to group level. It includes summary sheets that cross-reference symptoms with causes, line drawings of the major insect pests, and photos of the symptoms of the major pest groups and symptoms associated with mineral deficiencies.

The Guide has a full colour glossary to allow for accurate symptom description and a section that specifically hones in on causes that can produce similar symptoms and provides detailed information allowing the reader to differentiate between them.

Following a successful diagnosis, the farmer still requires a means of controlling the pest. The principles of pest management are provided with an emphasis on integrated pest management but with an acknowledgement that chemical intervention is also often required. Use of the most environmentally damaging and toxic chemicals is not encouraged and information is provided on the resistance groupings of various chemicals to prevent pesticide resistance.

For further information on these titles and other publications, see our website at www.cabi.org

\section{CABI}

Nosworthy Way

Wallingford

Oxfordshire

OX10 8DE

UK
CABI

38 Chauncy Street

Suite 1002

Boston, MA 02111

USA

Front cover image: Sorghum stalk borer (Chilo partellus), Rob Reeder, CABI 